\title{
THE USE OF LITHIUM SALTS AND SUPPLEMENTARY CEMENTING MATERIALS TO CONTROL REACTIVITY OF RECYCLED CONCRETE AGGREGATE
}

\author{
By: \\ Waleed Mikhaiel \\ B.Sc. Civil Engineering \\ El Minia University, Egypt, 1994
}

\begin{abstract}
A Thesis
Presented to Ryerson University
\end{abstract}

In partial fulfillment of the

Requirements for the degree of

Master of Applied Science

In the Program of

Civil Engineering

Toronto, Ontario, Canada, 2009

Waleed Mikhaiel (C) 2009 


\section{Author's Declaration}

I hereby declare that I am the sole author of this thesis.

I authorize Ryerson University to lend this thesis to other institutions or individuals for the purpose of scholarly research.

Waleed Mikhaiel

I further authorize Ryerson University to reproduce this thesis or dissertation by photocopying or by other means, in total or in part, at the request of other institutions or individuals for the purpose of scholarly research.

Waleed Mikhaiel 


\section{Borrowers Page}

Ryerson University requires the signatures of all persons using or photocopying this thesis. Please sign below, and give address and date.

Name

Address

Date 


\section{ABSTRACT \\ The Use of Lithium Salts and Supplementary Cementing Materials to Control Reactivity of Recycled Concrete Aggregate}

Waleed Mikhaiel, Master of Applied Science, 2009, Civil Engineering Department Ryerson University

This thesis covered the second phase of a study that focused on the reactivity of recycled concrete aggregate (RCA) produced from concrete affected by alkali-silica reaction (ASR). The first phase investigated the reactivity of ASR-affected RCA and the use of Supplementary Cementing Materials (SCM) as a preventive measure. The second phase was carried out to study the efficacy of lithium nitrate, when used individually and in combination with SCM, in suppressing the reactivity of RCA. The use of different dosages of lithium nitrate combined with SCMs reduced expansion due to ASR. However, the expansion results showed that increasing the dosage of lithium beyond a certain level does not help in suppressing the expansion. The high reactivity of the tested RCA was attributable to its relatively high alkalis and calcium hydroxide contents that fuel further ASR. The alkalis consumed or contributed from RCA were evaluated through leaching the aggregate particles in distilled water and alkaline solutions at different molarities with and without lithium nitrate. Alkalis consumption was found to decrease when lithium was presented in the leaching solutions. Examining RCA samples under scanning electron microscope (SEM) showed that the crushing process of the RCA exposes fresh surfaces of the reactive virgin aggregate and creates cracks within the particles that provide an easy path of alkalis to reactive sites within the RCA. Examination of the composition of the ASR gel showed that exposing the RCA to lithium solution decreased the calcium content and $\mathrm{Ca} / \mathrm{Si}$ of the gel. This could add to the suggested mechanisms by which the lithium mitigates ASR. 


\section{Table of Contents}

Chapter 1

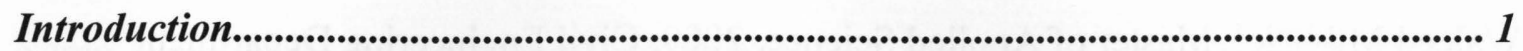

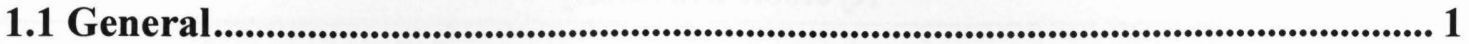

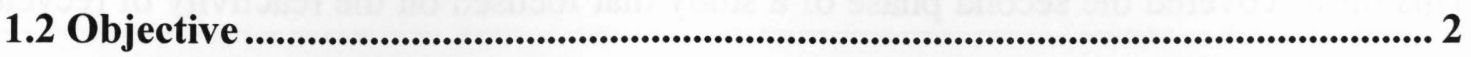

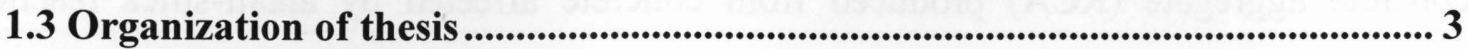

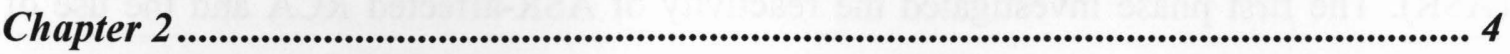

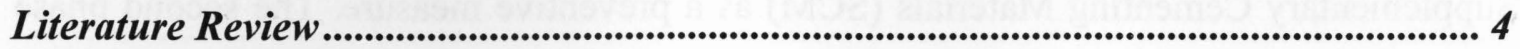

2.1 Recycled Concrete Aggregate (RCA) ............................................................... 4

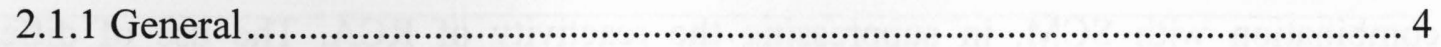

2.1.2 Recycled concrete Properties........................................................................... 6

2.1.3 Recycled concrete Applications........................................................................ 8

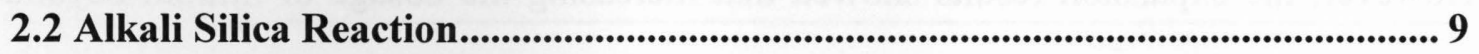

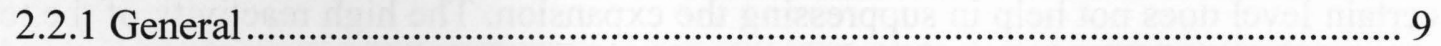

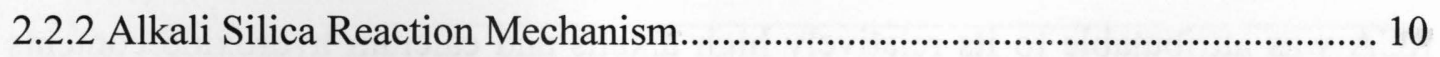

2.2.3 Factors affecting alkali silica reaction .............................................................. 12

2.2.3.1 Presence of reactive aggregate................................................................. 12

2.2.3.2 Available soluble alkalis in concrete pore solution .................................. 13

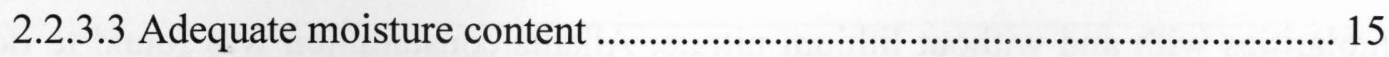

2.2.3.4 Other Factors affecting ASR ..................................................................... 15

2.2.4 Test methods to evaluate expansion due ASR .............................................. 15

2.2.4.1 Petrographic examination (ASTM 295).................................................. 16

2.2.4.2 Accelerated Mortar Bar Test (CSA A23.2-25A, ASTM C 1260) ............. 16

2.2.4.3 Concrete Prism Test (CSA A23.2-14A, ASTM C 1293)......................... 17

2.2.4.4 Accelerated Concrete Prism Test method................................................... 18

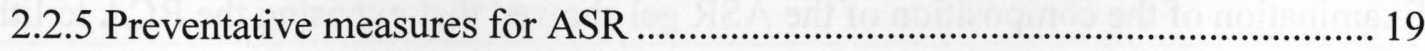

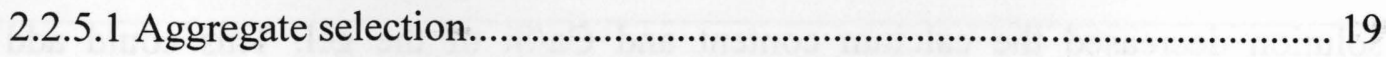

2.2.5.2 Limiting the alkali content in concrete ..................................................... 19 
2.2.5.3 Use of Supplementary Cementing Material (SCMs).............................. 20

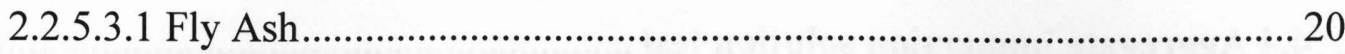

2.2.5.3.2 Granulated Ground Blast Furnace Slag (GGBFS) .............................. 23

2.2.5.3.3 Silica Fume ……………….............................................................. 25

2.2.5.3.4 Ternary Blends................................................................................ 26

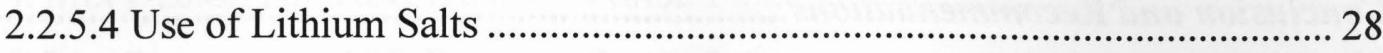

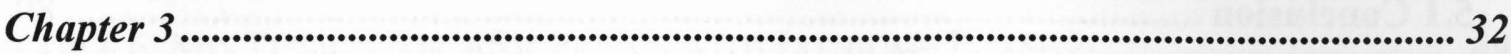

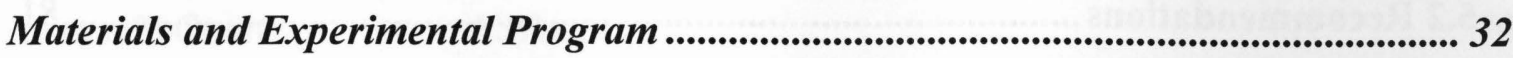

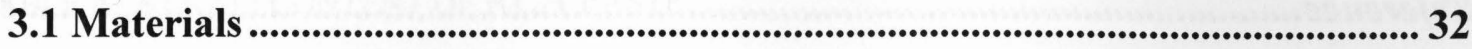

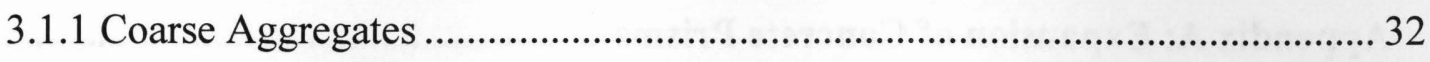

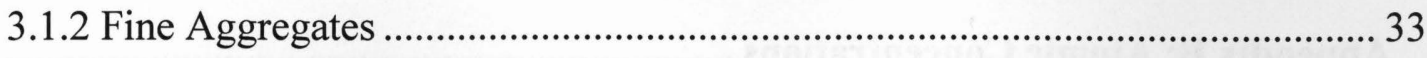

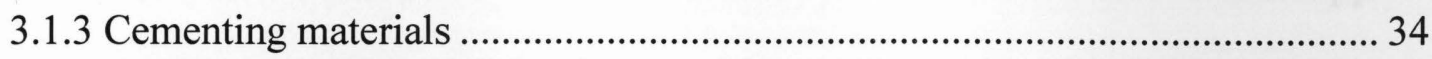

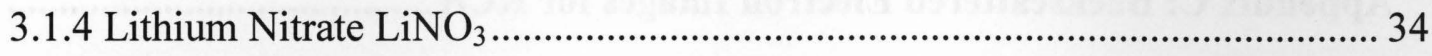

3.2 ASR concrete prisms (CSA A23.2-14A, ASTM C 1293) .................................... 38

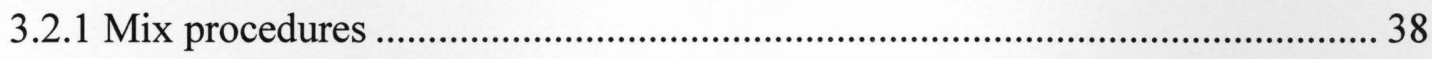

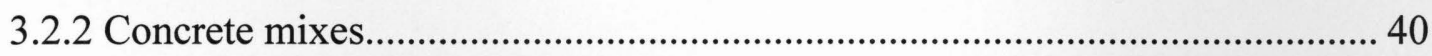

3.3 Scanning Electron Microscopy (SEM) ......................................................................... 45

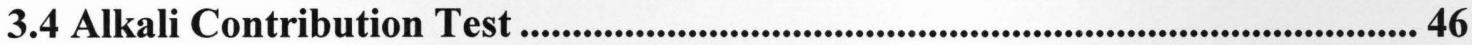

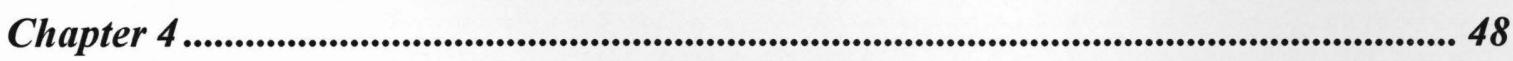

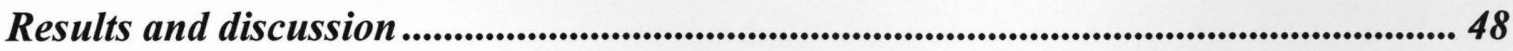

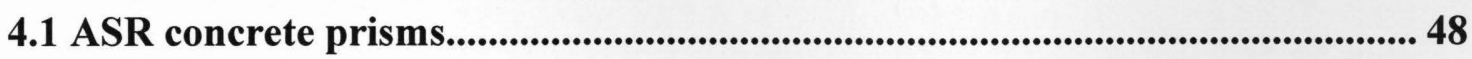

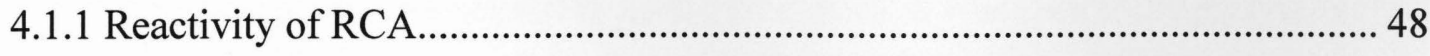

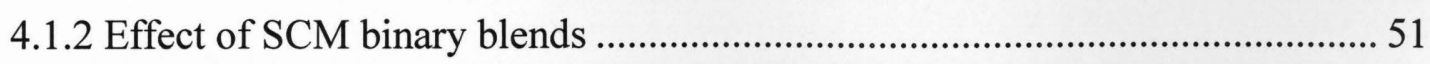

4.1.2 Effects of SCM ternary blends........................................................................ 56

4.2 ASR concrete prisms test for blends containing lithium nitrate .........................60

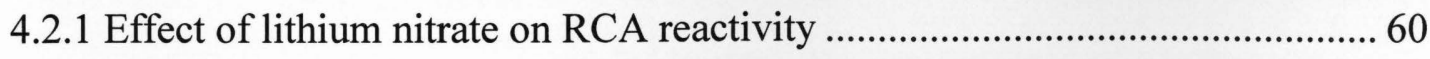

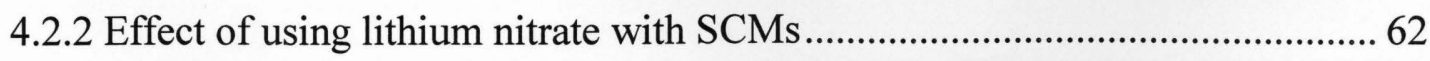

4.2.3 Dilution effect of the reactive aggregate........................................................... 67 


\section{List of Figures}

FIGURE 1. GENERALIZED FLOW DIAGRAM FOR AN AGGREGATES RECYCLING OPERATION.... 5

FIGURE 2: CHANGES IN COMPRESSIVE STRENGTH DUE TO VARYING REPLACEMENT

QUANTITIES OF RECYCLED AGGREGATE (TOPCU, 1997)............................................. 6

FIGURE 3: ILLUSTRATION OF EXPANSION FORCES INDUCED BY EXPANDING ALKALI-SILICA REACTIVE SILICEOUS LIMESTONE PARTICLES CAUSING CRACKING OF THE PARTICLES AND THE SURROUNDING CEMENT PASTE (FOURNIER \& BÉRUBÉ, 2000).

FIGURE 4: EFFECT OF ALKALI CONTENT OF CONCRETE ON THE 2-YEAR EXPANSION OF CONCRETE PRISMS CONTAINING SPRAT AGGREGATE (SHEHATA \& THOMAS, 2000)... 14

FIGURE 5. EFFECT OF CAO CONTENT OF FLY ASH ON EXPANSION OF CONCRETE CONTAINING $25 \%$ FLY ASH (SHEHATA \& THOMAS 2000). 22

FIGURE 6. EFFECT OF ASH CHEMICAL COMPOSITION ON THE EXPANSION OF CONCRETE PRISMS CONTAINING 25\% FLY ASH (SHEHATA \& THOMAS 2000).

FigURE 7: EXPANSION OF CONCRETE WITH SPRATT AGGREGATE ALKALIS $=1.25 \% \mathrm{NA}_{2} \mathrm{O}_{\mathrm{E}}$ (BY MASS OF CEMENT) (THOMAS \& INNIS, 1998).

FiguRE 8: EFFECT OF SiLICA FUME ON THE ALKALINITY OF PORE SOLUTION OF PASTES, REPRESENTED BY THE SUM OF ALKALI CATIONS IN THE PORE SOLUTION (SHEHATA \& THOMAS, 2002)

Figure 9: EFFECT OF SilicA FUME (SF) \& Fly Ash (OK) AND COMBINATION OF SK/OK ON PORE SOLUTION ALKALINITY (SHEHATA \& THOMAS, 2002).

FiguRE 10: AGgREGATE MICROSTRUCTURE BY SEM, NB: RESPOND, NS: DID NOT RESPOND TO LITHIUM NiTRATE ON ASR SUPPRESSION EFFECT, (X.FENG ET AL, 2005). 30

FiguRE 11: AGgREgate IMMERSION TEST FOR TWO REACTIVE AGgREGATES, NB:

RESPOND, NS: DOES NOT RESPOND TO LITHIUM NITRATE ON ASR SUPPRESSION EFFECT, (FENG ET AL, 2005).

FigURE 12: SCANNING ELECTRON MiCROSCOPE - SEM ….................................................... 46

FIGURE 12: RCA AND SPRATT AGGREGATE CONCRETE PRISMS EXPANSIONS.

FIGURE 13: COMPARISON OF THE ASR CONCRETE PRISMS EXPANSIONS BETWEEN THE ASR AFFECTED RCA AND TWO NON REACTIVE RCAS 50

FIGURE 14: RCA MECHANICAL CRACKS. 50 
FIGURE 15: ASR CONCRETE PRISMS EXPANSIONS COMPARING RCA AND SPRATT

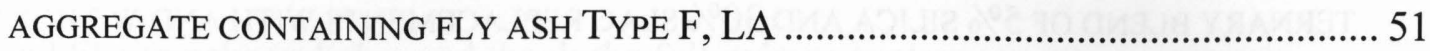

FIGURE 16: ASR CONCRETE PRISMS EXPANSIONS COMPARING RCA AND SPRATT AGGREGATE CONTAINING FLY ASH TYPE F, HA _.................................................... 52

FIGURE 17: ASR CONCRETE PRISMS EXPANSIONS COMPARING RCA AND SPRATT AGGREGATE CONTAINING 5\% SILICA FUME.

FIGURE 18: ASR CONCRETE PRISMS EXPANSIONS COMPARING DIFFERENT SCMS AT DIFFERENT REPLACEMENT LEVELS IN RCA CONCRETE

FIGURE 19: ASR CONCRETE PRISMS EXPANSIONS COMPARING DIFFERENT FLY ASH AT DIFFERENT REPLACEMENT LEVELS IN RCA CONCRETE

FIGURE 20: ASR CONCRETE PRISMS EXPANSIONS COMPARING DIFFERENT FLY ASH AT

DIFFERENT TERNARY BLENDS REPLACEMENT LEVELS IN RCA CONCRETE.

FIGURE 21: ASR CONCRETE PRISMS EXPANSIONS COMPARING TERNARY BLENDS VERSUS

BINARY BLENDS IN RCA CONCRETE.

FIGURE 22: ASR CONCRETE PRISMS EXPANSIONS COMPARING TERNARY BLENDS VERSUS

BINARY BLENDS IN RCA CONCRETE.

FIGURE 23: ASR CONCRETE PRISMS EXPANSIONS COMPARING TERNARY BLENDS VERSUS

BINARY BLENDS IN RCA CONCRETE. 60

FIGURE 24: ASR CONCRETE PRISMS EXPANSIONS OF RCA WITH DIFFERENT MOLAR RATIO

OF $[\mathrm{LI}]:[\mathrm{NA}+\mathrm{K}]$

FIGURE 25: COMPARISON OF CONCRETE PRISMS EXPANSION OF RCA CONCRETE WITH AND WITHOUT LITHIUM AT MOLAR RATIO OF [LI]: [NA+K] 1:1 62

FIGURE 26: COMPARISON OF CONCRETE PRISMS EXPANSION OF RCA CONCRETE WITH 20\% FLY ASH TYPE F LA WITH AND WITHOUT LITHIUM AT MOLAR RATIO OF [LI]: [NA+K] $1: 1.5$ 63

FIGURE 27: COMPARISON OF CONCRETE PRISMS EXPANSION OF RCA CONCRETE WITH 25\% FLY ASH TYPE HC LA WITH AND WITHOUT LITHIUM AT MOLAR RATIO OF [LI]: [NA+K] $1: 1.5$ 64

FIGURE 28: COMPARISON OF CONCRETE PRISMS EXPANSION OF RCA CONCRETE WITH SLAG REPLACEMENTS WITH AND WITHOUT LITHIUM 
FIGURE 29: COMPARISON OF CONCRETE PRISMS EXPANSION OF RCA CONCRETE WITH TERNARY BLEND OF 5\% SILICA AND 30\% SLAG REPLACEMENTS WITH AND WITHOUT LITHIUM 66

FIGURE 30: COMPARISON OF CONCRETE PRISMS EXPANSION OF RCA WITH FLY ASHES AND

SLAG BINARY AND TERNARY BLENDS AT DIFFERENT MOLAR RATIO OF [LI]: [NA+K]. 67 FIGURE 31: COMPARISON OF CONCRETE PRISMS EXPANSION OF RCA AND SPRATT WHEN COARSE AGGREGATE REPLACEMENT WITH NON REACTIVE AGGREGATE IS USED FOR DILUTION 68

FIGURE 32: COMPARISON OF CONCRETE PRISMS EXPANSION OF RCA DILUTION WITH SCMS

FIGURE 32: ATOMIC CONCENTRATIONS IN RCA ASR GEL .................................................. 72

FigURE 33: ATOMIC CONCENTRATIONS IN RCA PASTE …………………………............ 72

FiguRE 35: EFFECT OF LITHIUM ON THE CA/Si RATIO IN THE ASR GEL .............................. 73

FIGURE 36: COMPARISON OF ALKALI CONSUMPTION WHEN RCA WAS IMMERSED FOR 6 MONTH IN ALKALI SOLUTION WITH LITHIUM OF LI: NA+K OF 1:1 AND WHEN IMMERSED IN ALKALI SOLUTION WITHOUT LITHIUM 76

FIGURE 37: COMPARISON OF ALKALIS CONSUMPTION BY THE PASTE AND SPRATT AGGREGATE WHEN IMMERSED FOR 4 WEEKS IN ALKALI SOLUTION WITH LITHIUM OF LI: NA+K OF 1:1 AND WHEN IMMERSED IN ALKALI SOLUTION WITHOUT LITHIUM 77

FiguRE 38: COMPARISON OF THE LITHIUM CONSUMPTION BY PASTE SAMPLES AND SPRATT AGGREGATE WHEN IMMERSED IN SOLUTION WITH LI: NA+K OF 1:1 FOR 4 WEEKS ..... 78 Figure 39: EFFECT OF Li :(NA+K) Molar Ratio on the Alkali CONTRIBUtion oR CONSUMPTION FROM RCA IN 0.7 MOLARITY SOLUTION. 78 


\section{Acknowledgments}

I would like to acknowledge and thank the following people:

Dr. Medhat Shehata - It has been an honor and privilege to study under your supervision. Thanks for your guidance and inspiration during the time I worked with you, Thank you for the knowledge, support, friendship, encouragement and your indescribable efforts you always provided.

\section{Ontario Ministry of Transportation and Natural Science and Engineering Research}

Council of Canada - The financial support of both organizations is highly appreciated.

Faculty and Staff at Ryerson University - I would like to thank Nidal Jalouk, Domenic Valle and Roger Smith for their rapid and reliable assistance, which enabled me to complete my thesis.

Classmates and colleagues - I would like to acknowledge the continued assistance from my colleague Giri Raj's who helped me a lot during the experimental program that would have been very difficult to carry on with out his help.

Family and Friends - Lastly, but most importantly, I would like to thank my spouse, family and friends for their continued support, love, and motivation. 
Dedication:

To the sole of my Father 


\section{List of Abbreviations}

$\begin{array}{ll}\text { AAR } & \text { Alkali Aggregate Reaction } \\ \text { ACR } & \text { Alkali Carbonate Reaction } \\ \text { ASR } & \text { Alkali Silica Reaction } \\ \text { ASSHTO } & \text { American Association of State Highway and Transportation Officials } \\ \text { ASTM } & \text { American Society for Testing Materials } \\ \text { CH } & \text { High Calcium } \\ \text { CI } & \text { Intermediate Calcium } \\ \text { CSA } & \text { Canadian Standards Association } \\ \text { C-S-H } & \text { Calcium Silica Hydrate } \\ \text { F } & \text { Low Calcium } \\ \text { FA } & \text { Fly Ash } \\ \text { GU } & \text { General Use } \\ \text { HA } & \text { High Alkali } \\ \text { LA } & \text { Low Alkali } \\ \text { MTO } & \text { Ontario Ministry of Transportation } \\ \text { PC } & \text { Portland Cement } \\ \text { RCA } & \text { Recycled Concrete Aggregate } \\ \text { RH } & \text { Relative Humidity } \\ \text { SCM } & \text { Supplementary Cementing Materials } \\ \text { SEM } & \text { Scanning Electron Microscope } \\ \text { SF } & \text { Silica Fume } \\ \text { SSD } & \text { Saturated Surface Dry } \\ \text { w/c } & \text { Water to Cementing Materials Ratio } \\ \text { Ca/Si } & \text { Calcium to Silica ratio } \\ & \end{array}$




\section{Chapter 1}

\section{Introduction}

\subsection{General}

Conventional concrete aggregates usually contain natural fine and coarse aggregates. However, there is a growing interest in finding alternative aggregate materials due the major environmental concerns resulting from disposal of construction waste and depletion of natural aggregate sources. Many major infrastructures are due for replacement as a result of aging, lack of serviceability or other structural concerns. This increases the demand of recycling the debris produced from demolishing these structures. Each year 200 million tons of construction waste is continuously discarded in landfills (Gomez-Soberon, 2002).

Deteriorations take place in concrete due to sever environmental conditions and chemical attack such as the repeated cycles of freezing and thawing and the use of de-icer salts. Sometimes, deteriorations are caused by concrete constituents as a result of damaging reactions even without severe environmental conditions or exposure to external chemicals attack. For instance, alkalis inside the concrete react with some forms of reactive silica inside the aggregates producing expansive gel that causes damage of concrete structures. In many cases repairs are more difficult and more expensive to implement, and removal may be the best solution.

Hence, the debris resulting from demolishing these structures is of a concern if recycled as aggregate for new concrete structures. The quality of concrete with recycled concrete aggregate (RCA) is very dependent on the quality of the recycled material properties. Unfortunately most of the RCA with history of ASR is used as a landfill or as a sub-base, 
which are not the best use of it if the demolished structure is in a remote area with scarce natural aggregate sources. This necessitates the need of finding preventive measures to counteract ASR in new concrete containing RCA.

\subsection{Objective}

The purpose of this study is to determine if deterioration continues in new concrete containing RCA affected by ASR, the extent of the deterioration, and whether or not the deterioration can be controlled. This was carried out in two phases.

\section{Phase 1:}

This phase focused on evaluating the reactivity of RCA produced from ASR-affected concrete. This was accomplished by testing aggregates without preventive measures. In addition, preventative measures in the form of binary and ternary blends of supplementary cementing materials (SCM) were investigated. The investigated blends included various levels of silica fume, fly ash, slag, ternary blends of silica fume and fly ash or silica fume and slag, low alkali cement, and pre-washing aggregates to remove excess alkalis.

\section{Phase 2:}

Phase 2 presented in this thesis covers the following:

1- Investigate the effects of SCMs; at higher replacement levels than those used in Phase 1; to reduce expansion in new concrete with ASR-affected RCA.

2- Evaluate the reactivity of the ASR-affected RCA when used as partial replacement of coarse aggregate. 
3- Investigate the effect of using the lithium nitrate at different molar ratios to mitigate the expansion of concrete containing ASR-affected RCA

4- Investigate the synergy effect of using the lithium nitrate in combination of SCMs with different molar ratios.

5- Evaluate the amount of alkalis contributed from the ASR-affected RCA when immersed in solutions of alkalis concentrations representing those likely to be encountered in concrete pore solution.

6- Studying the composition of ASR gel found in the original RCA, gel in the concrete prisms and gel in the RCA after exposed to alkaline solutions with and without lithium. The objective is to find out if the lithium has an effect on the gel composition.

\subsection{Organization of thesis}

In this thesis:

- Chapter 2 provides a literature review of the ASR and its common preventative measures.

- Chapter 3 presents the materials and experimental program.

- Chapter 4 discusses the results obtained and possible reasons for the obtained trends.

- Chapter 5 covers the conclusions and recommendations for possible further studies. 


\section{Chapter 2 \\ Literature Review}

A review of literature is presented pertaining to alkali silica reaction and the role of SCMs and lithium salts as preventative measures against ASR expansion.

\subsection{Recycled Concrete Aggregate (RCA)}

\subsubsection{General}

Recycling of concrete is a relatively simple process. It involves demolishing old concrete structures, removing non-concrete materials and crushing existing concrete into a material with a specified size. The quality of concrete with recycled concrete aggregates is very dependent on the quality of the recycled material used. If the demolished concrete was exposed to de-icer salts, the RCA produced will contain salt ions (Prieur \& Nikitine 2006). Similarly, if the demolished concrete had history of ASR, the produced RCA will contain portions of the reactive aggregate including ASR gel.

Removal of reinforcements and other contaminating materials is essential to obtain quality aggregate to be used as aggregate for new concrete. Figure 1 illustrates the typical steps required to process recycled material. Technology primarily involves crushing, sizing, and blending to provide aggregates suitable for a variety of applications. Concrete and asphalt recycling plants can be used to process natural sand and gravel, but sand and gravel plants usually won’t process recycled material (David \& Thomas, 1998).

Another advancement in the use of Recycled Concrete Aggregate is the advantage of using a mobile crusher to recycle concrete in place of demolition to be used as a sub-base or in new concrete, if applicable. 
Material to be recycled

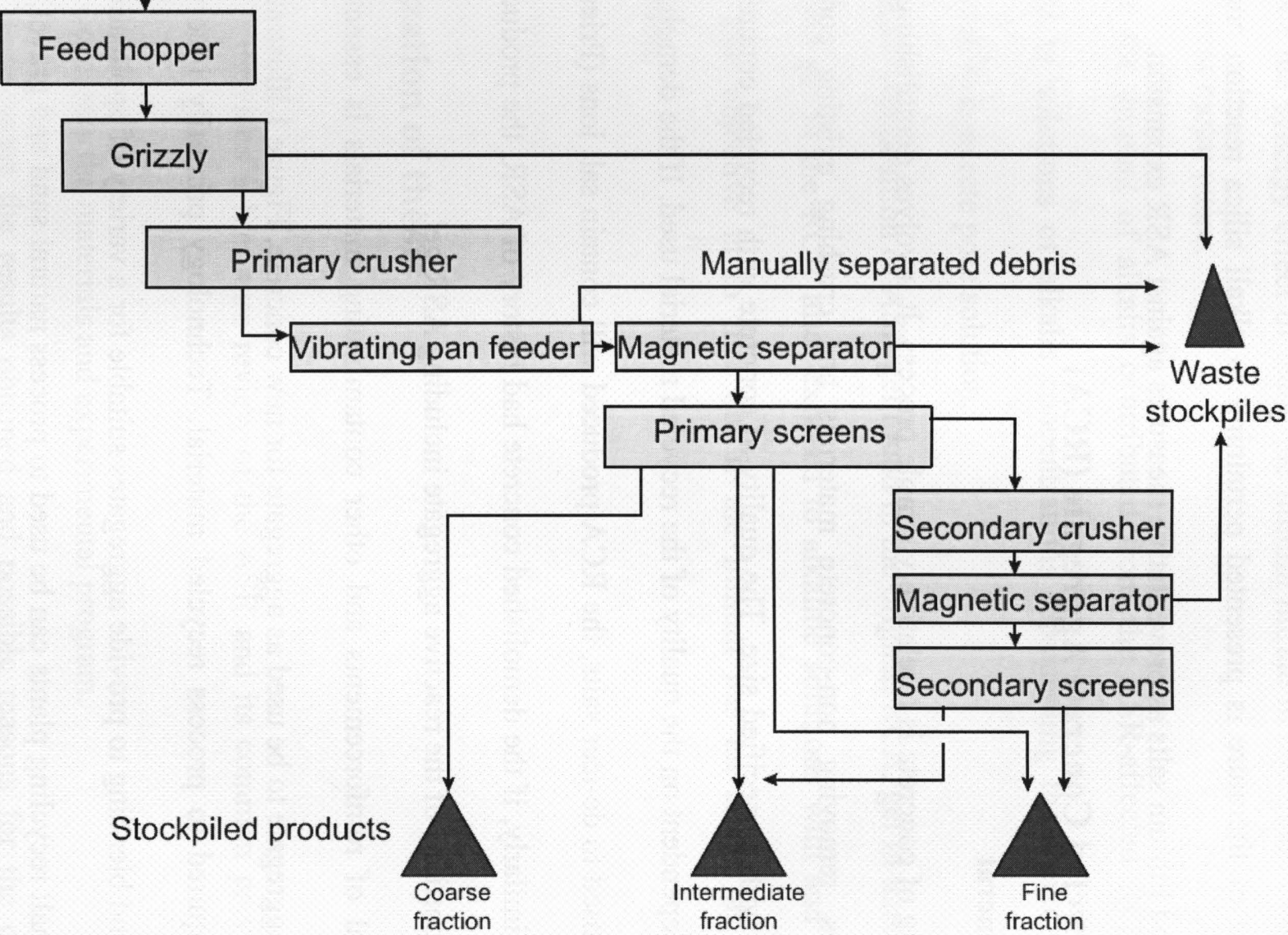




\subsubsection{Recycled concrete Properties}

RCA consists of part of original aggregate attached to residues of the old concrete mortar. The mortar attached to the aggregate particles affects the performance of the new concrete as it alters the aggregate absorption and density and affects the mechanical characteristics of the new concrete. Recycled coarse aggregate was found to have absorptions of $5 \%$ to $6 \%$; whereas recycled fine aggregate absorptions was $9 \%$ to $10 \%$ (McGovern, 2002). Compressive strength of concrete decreases as the percentage of RCA increases as seen in Figure 2.

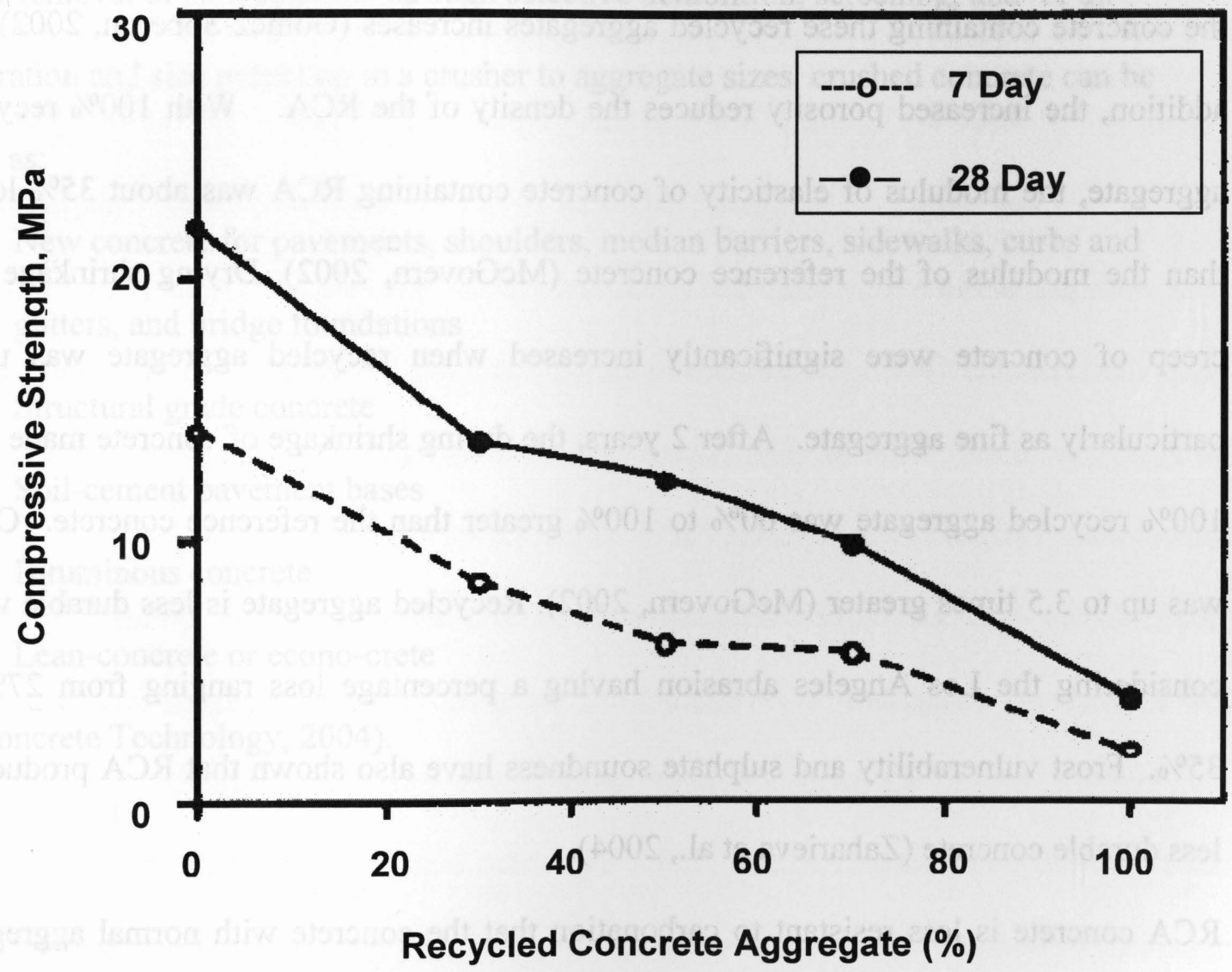

Figure 2: Changes in compressive strength due to varying replacement quantities of recycled aggregate (Topcu, 1997). 
When RCA is used as $100 \%$ of the coarse and fine aggregates in concrete the reduction in strength could be as much as $80 \%$ compared to concrete without RCA (Topcu, 1997). Although concrete containing RCA has been demonstrated to have a lower compressive strength, it is possible to produce concrete containing RCA with equal to or greater compressive strength than the original recycled concrete (Ajdukiewicz \& Kliszczewicz, 2002). Tensile strength is approximately $10 \%$ lower in concrete containing RCA than in concrete containing limestone aggregate (Ajdukiewicz \& Kliszczewicz, 2002). According to Gomez-Soberon (2002), recycled aggregates have a lower density and higher porosity than natural aggregates. As the replacement level of the RCA increases, the porosity in the concrete containing these recycled aggregates increases (Gomez-Soberon, 2002). In addition, the increased porosity reduces the density of the RCA. With $100 \%$ recycled aggregate, the modulus of elasticity of concrete containing RCA was about $35 \%$ lower than the modulus of the reference concrete (McGovern, 2002). Drying shrinkage and creep of concrete were significantly increased when recycled aggregate was used, particularly as fine aggregate. After 2 years, the drying shrinkage of concrete made with $100 \%$ recycled aggregate was $60 \%$ to $100 \%$ greater than the reference concrete. Creep was up to 3.5 times greater (McGovern, 2002). Recycled aggregate is less durable when considering the Los Angeles abrasion having a percentage loss ranging from $27 \%$ to $35 \%$. Frost vulnerability and sulphate soundness have also shown that RCA produces a less durable concrete (Zaharieva et al., 2004).

RCA concrete is less resistant to carbonation that the concrete with normal aggregates (Otsuki et al., 2003). 


\subsubsection{Recycled concrete Applications}

In general, applications without any processing include:

- Many types of general bulk fills

- Bank protection

- Base or fill for drainage structures

- Road construction

- Noise barriers and embankments

After removal of contaminants through selective demolition, screening, and /or air separation and size reduction in a crusher to aggregate sizes, crushed concrete can be used as:

- New concrete for pavements, shoulders, median barriers, sidewalks, curbs and gutters, and bridge foundations

- Structural grade concrete

- Soil-cement pavement bases

- Bituminous concrete

- Lean-concrete or econo-crete

(Concrete Technology, 2004). 


\subsection{Alkali Silica Reaction}

\subsubsection{General}

Alkali-Silica Reaction (ASR) is the reaction between the soluble alkalis in the pore solution and some types of aggregates that contain poorly crystallized silica. The reaction results in the ASR gel formation that is not stable, and upon absorption of water expands causing rupture of the aggregate fragments. Hence, these cracks propagate into the concrete structure. Aggregates that contain opaline silica as a mineral, as primary or secondary materials, are highly reactive; aggregates that contain chalcedony as a mineral are moderately reactive such as cherts and flints; and aggregates that contain volcanic glass are reactive in some cases such as basalt and rhyolites (Swamy, 2003).

Alkali-Silica Reaction (ASR) was first identified by Stanton from investigation of cracking in concrete pavements and bridges in 1940 (Stanton 1940). Since then, ASR has been recognized in more than 50 countries around the world. It is likely that the problems associated with ASR exist in a larger number of countries, but the deterioration of the concrete may have been attributed to other causes (Fournier \& Bérubé, 2000). ASR can cause extreme deterioration problems when combined with other forms of deterioration, such as chloride attack (Neville, 1996). When recycled concrete aggregate (RCA) that was affected by ASR is used as partial or full replacement for coarse aggregate, some of the alkalis contained in the aggregate contributes to raise the available alkalis in the pore solution, and the ASR expansion obtained from that type of RCA was found to be similar to the one obtained from the original natural aggregate. It was found that the early expansion was even higher with RCA due to early age moisture swelling of the past portion of the RCA (Scott \& Gress, 2004). 


\subsubsection{Alkali Silica Reaction Mechanism}

It is generally recognized that the alkali silica reaction is a multi stage process, with the first step being the dissolution of silica on the surface of aggregate particles (Diamond, 1997). The Polar water molecules react with $\mathrm{SiO}_{2}$ creating silanol moieties (-Si-OH) in their place, which can be expressed by the following equation:

$$
\mathrm{H}_{2} \mathrm{O}+\mathrm{Si}-\mathrm{O}-\mathrm{Si} \rightarrow \mathrm{Si}-\mathrm{OH} \ldots \mathrm{OH}-\mathrm{Si}
$$

In highly alkaline environment, such as concrete pore solution, hydroxyl ions will attack the silanol bonds created in equation (1), which will yield some free $\mathrm{Si}-\mathrm{OH}$ molecules that are no longer bound to the larger mineral structure, the free Si-OH groups react with free alkali ions, creating alkali silica molecules as shown in equation (2). These molecules cluster at the surface of the aggregate, creating the ASR gel

$$
\mathrm{Si}-\mathrm{OH}+\mathrm{NaOH} \rightarrow \mathrm{Si}-\mathrm{O}-\mathrm{Na}+\mathrm{H}_{2} \mathrm{O}
$$

Silica is an amphoteric material, which means that it dissolves at extreme $\mathrm{pH}$ in strongly acidic or strongly alkaline conditions, but not at natural $\mathrm{pH}$. In the alkali-silica reaction, there are three forms of silicon; the undissolved silica contained in the aggregate; the dissolved silica in the alkaline solution and the undisclosed ASR gel. Only the solute silicon is present in the solution and is measured as dissolved silica (Feng et al, 2005).

At first the ASR gel is restrained from expanding into the cement paste. However, cracking occurs when the tensile stresses that are developed exceed the tensile strength of the cement paste as shown in Figure 3. As soon as adequate micro cracking has occurred, the gel spreads out freely through the cracks in the cement paste. It continues spreading, but gradually loses its expansive properties with the absorption of calcium. 
The calcium enters the system through an ion-exchange process with the hydrates of the paste (Fournier \& Bérubé, 2000).

The Role of Calcium in ASR is controversial. Some researchers stated that the presence of calcium is essential for the formation of ASR gel and thus the expansion due to ASR. They suggested that without calcium ions the residual solution is merely an alkali-silica solution. Thus calcium ions initiate the condensation of silicate ions and link the silicates species in order to form a solid (Nieto \& Zanni, 1997).

Two categories of ASR reactive rocks were recognized in Canada according to the silica form involved:

1) Rock types incorporating poorly crystalline or meta-stable silica minerals. Concrete structures that incorporate even as little as 1 to $2 \%$ of these silica minerals have shown to greatly expand in ASR conditions.

2) Rocks that contain very fine quartz grains or some variety of macro-granular quartz. This category is common in Eastern Canada. It is characterized by an initial delay of expansion, followed by deterioration cracks that can take 10 to even 25 years to become apparent in field conditions (Fournier \& Bérubé, 2000). 


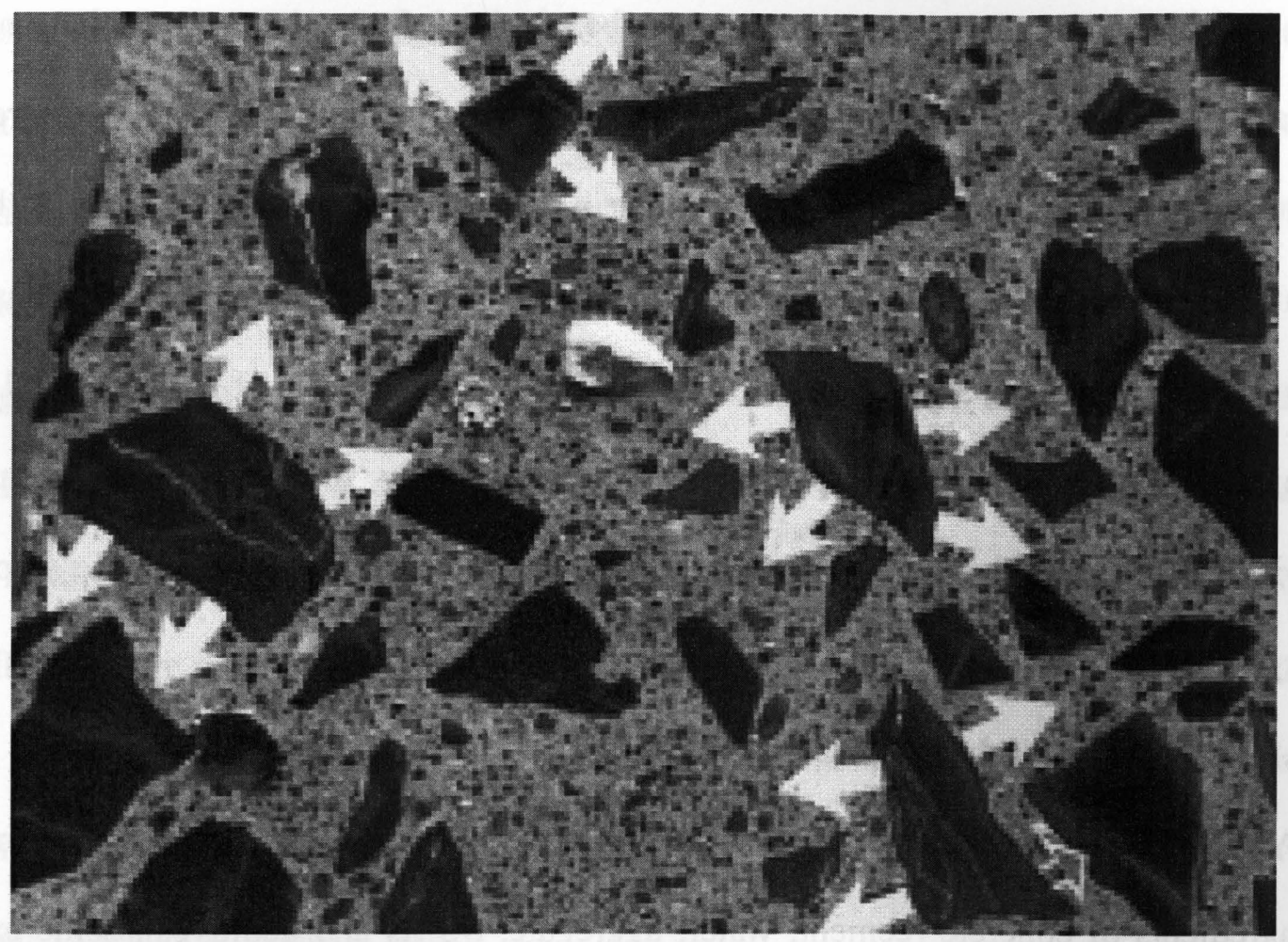

Figure 3: Illustration of expansion forces induced by expanding alkali-silica reactive siliceous limestone particles causing cracking of the particles and the surrounding cement paste (Fournier \& Bérubé, 2000).

\subsubsection{Factors affecting alkali silica reaction}

Three derivative conditions mainly control the ASR formation in concrete; presence of reactive aggregate, available soluble alkalis in concrete pore solution and the presence of adequate moisture (Neville, 1996).

\subsubsection{Presence of reactive aggregate}

With the mixture proportions being constant, the reactivity level will generally increase with an increased amount of reactive particles in the aggregate. The reactivity level will also increase as the aggregate particle size decreases, or in other words increasing the surface area of the aggregate (Fournier \& Bérubé, 2000). 
It is said that a maximum expansion can be obtained for a given proportion and size fraction of such reactive particles. It should be noted also that all natural rocks react to some extent with the alkaline pore solution in concrete (Rogers et al., 2000). Although, introducing fresh faces of aggregate that still have un-reacted reactive silica; and introducing the poor structure with many cracks such as in case of ASR-affected RCA; this would drive more ASR expansion to take place in new concrete with RCA exactly as with virgin natural aggregate. Hence, the ASR reaction is proportional to the amount of replacement of RCA in concrete.

\subsubsection{Available soluble alkalis in concrete pore solution}

Available soluble alkalis in the pore solution are usually introduced by the internal ingredients of concrete (cement, water, aggregate, SCMs and additives), some external quantities may become available in concrete due the excess exposure to De-icer salts. Aggregates generally expand in the concrete with an increased amount of total alkali content in the form of sodium hydroxides, as seen in Figure 4 (Shehata \& Thomas, 2000). However, the amount of alkali content needed to initiate and sustain ASR varies from one aggregate to another (Fournier \& Bérubé, 2000).

Alkalis contained in the aggregate can be expelled into the pore solution. This is particularly true with feldspar-rich aggregates (Bérubé et al., 2002). RCA with history of ASR contains considerable amount of alkalis in the ASR gel and from the de-icing salts contained with the RCA that have determinate effect on ASR of the new concrete.

The alkalis from Portland cement and RCA in concrete creates very high initial $\mathrm{pH}$ levels that are more aggressive than those seen in concrete where cement is the only alkali source (Scott \& Gress 2004). 
Unwashed sea dredged sands can contribute to the increase of the available alkalis due to the salt content of these aggregates. Chemical admixtures such as superplasticizers have been known to contain alkalis. Hard water also can contain moderate levels of alkalis (Neville, 1996).

The high alkali content of the SCMs such as fly ashes (Shehata, \& Thomas 2000), silica fume (Boddy et al., 2003), and slag (Hooton, 2000) contributes in the gel formation due ASR. Total alkalis available to various testing solutions for samples containing highalkali fly ash were much higher than those contributed by fly ash of lower alkali contents. These fly ashes may be expected to provide considerable sources of alkalis if the alkalinity of the pore solution drops due to alkali being consumed by the reactive aggregate (Shehata \& Thomas 2006).

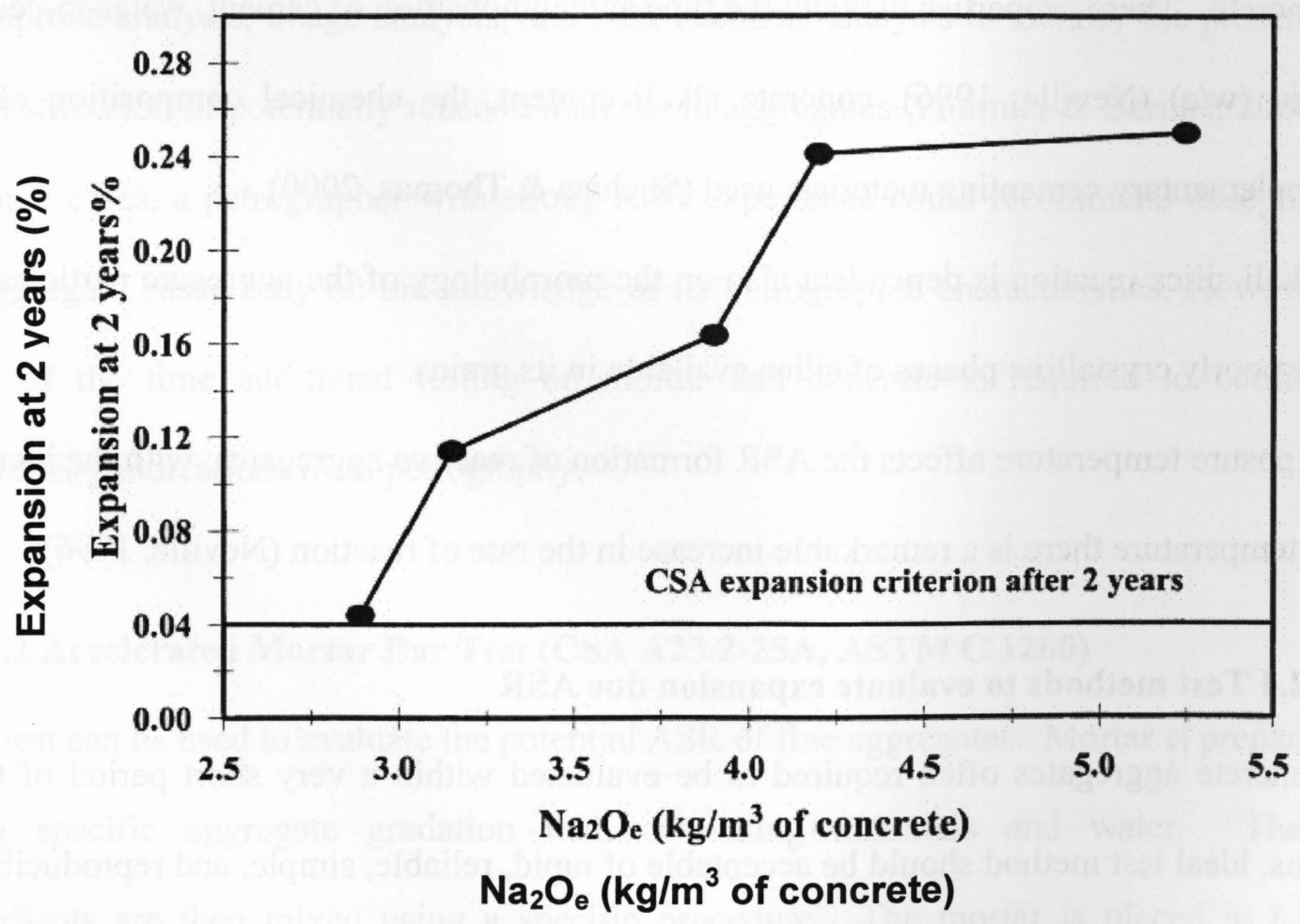

Figure 4: Effect of alkali content of concrete on the 2-year expansion of concrete prisms containing Sprat aggregate (Shehata \& Thomas, 2000). 


\subsubsection{Adequate moisture content}

The alkali-silica gel needs water to swell, which causes expansive pressure on the concrete. Alkali-aggregate reactivity typically occurs in concretes that are exposed to internal relative humidity of approximately 80 to $85 \%$ (Neville, 1996). Investigations have shown that partially dehydrated gel due to drying of the specimen can be rehydrated and expand if additional water is supplied to the specimen (Fournier \& Bérubé, 2000). However, dried and carbonated gels are unlikely to regain their expansive properties (Neville, 1996).

\subsubsection{Other Factors affecting ASR}

The chemical properties of the components added to the concrete mix affect the ASR in concrete. These properties include: the type and composition of cement, water-to-cement ratio (w/c) (Neville, 1996), concrete alkali content, the chemical composition of the supplementary cementing materials used (Shehata \& Thomas, 2000).

Alkali silica reaction is dependent also on the morphology of the aggregate particles and the poorly crystalline phases of silica available in its grains.

Exposure temperature affects the ASR formation of reactive aggregates; with the increase in temperature there is a remarkable increase in the rate of reaction (Neville, 1996).

\subsubsection{Test methods to evaluate expansion due ASR}

Concrete aggregates often required to be evaluated within a very short period of time, thus, ideal test method should be acceptable of rapid, reliable, simple, and reproducible to evaluate the potential for ASR expansion for particular combination of materials. 


\subsubsection{Petrographic examination (ASTM 295)}

ASTM C295-03 Standard outlines procedures for the petrographic examination of samples representative of materials proposed for use as aggregates in cementitious mixtures or as raw materials for use in the production of such aggregates. Essentially this is the first step in testing aggregates for ASR. Petrographic analysis uses microscopic techniques described in ASTM 295. Some of the items that can be reviewed by petrographic examination include paste, aggregate, supplementary cementing materials and air content. Also, distress effects due to frost, sulphate attack, and alkali aggregate reactivity can be reviewed by this method (Kosmatka et al, 2002).

However, a standard petrographic analysis is sometimes accompanied by other methods such as X-ray diffraction, infrared spectroscopy, Scanning Electron Microscope (SEM), microprobe analysis, image analysis, and bulk chemical analysis to identify the presence and distribution of potentially reactive material in aggregates (Fournier \& Bérubé, 2000). In some cases, a petrographer with strong ASR experience could recommend accepting an aggregate based only on the knowledge of its petrographic characteristics. However, most of the time additional testing on mortar and concrete is required to confirm preliminary indications from petrography.

\subsubsection{Accelerated Mortar Bar Test (CSA A23.2-25A, ASTM C 1260)}

This test can be used to evaluate the potential ASR of fine aggregates. Mortar is prepared using specific aggregate gradation with cementing materials and water. These ingredients are then mixed using a specific procedure. The mortar is placed in bars approximately $25 \times 25 \times 285 \mathrm{~mm}$ in size. After 24 hours of moist curing in their 
moulds, the bars are placed in a sealed plastic container filled with water at $23^{\circ} \mathrm{C}$, and the container is stored in an oven at $80^{\circ} \mathrm{C}$. The next day, an initial length measurement is taken, and the bars are transferred to a $1 \mathrm{~N} \mathrm{NaOH}$ solution at $80^{\circ} \mathrm{C}$. Measurements occur several times over a 2-week time period. Reactive aggregates are determined based on a 14-day expansion of approximately $0.10 \%$. This test is typically an effective method to determine the ASR reactivity of aggregates within 2 weeks. However, it was found to be misleading for several aggregates with good field performance, but greatly expansive mortar bars (Fournier \& Bérubé, 2000). Therefore, the Accelerated Mortar Bar Test should not be used for rejecting aggregates. Further testing using the concrete prism test as per CSA A23.2-14A, ASTM C 1293 is required.

\subsubsection{Concrete Prism Test (CSA A23.2-14A, ASTM C 1293)}

This test is used to evaluate the potential alkali-reactivity of coarse aggregates. Prisms are prepared using a specific quantity of cement, coarse-to-fine aggregate ratio, and water. The water cement ratio (w/c) should be 0.42 to 0.45 , except when supplementary cementing materials are used. In the case of using SCMs, the CSA 2004 limits the w/c to 0.35 to 0.40 . The prisms are kept in their molds for $24 \mathrm{~h}$ at $23^{\circ} \mathrm{C}$, and then stored above water in a sealed plastic container lined with a damp material. After the one-day curing, the prisms are placed in a room controlled at $38^{\circ} \mathrm{C}$. Length change measurements are made periodically up to 1 year with concrete containing no SCM and 2 years with concrete containing SCM. Aggregates can show different expansion rates in the Concrete Prism Test. Generally, the more rapid the onset of expansion and the development of micro-cracking due to ASR, the faster the leaching of alkalis out of the 
test prisms and the levelling off of the expansion curve (Rogers et al., 2000). Reactive aggregates are determined based on an expansion of approximately $0.04 \%$. There are a number of disadvantages to this test. One disadvantage is that the testing period is too long for most construction projects. Another disadvantage is that depending on the storage conditions, some alkali leaching from the prisms is evident which would slow down or stop the expansion (Rogers et al., 2000).

\subsubsection{Accelerated Concrete Prism Test method}

In 1992, Rance and Debray proposed accelerating the rate of expansion in the concrete prism test, hence, shortening its duration by increasing the exposure temperature to $60 \mathrm{C}^{\circ}$. Since then, there have been a number of studies on the accelerated test (Fournier et al, 2004) although the test method has yet to be standardized. Some research work showed reasonable correlation between the 3-month expansion of prisms at $60 \mathrm{C}^{\circ}$ and the 12 month expansion at $38 \mathrm{C}^{\circ}$ for concrete with and without preventive measures (Airentrainment, SCMs and lithium nitrate) (Touma et al, 2001). Other researchers have not been able to reproduce the good correlation that was reported by Touma. It has been observed that the higher temperature in the accelerated concrete prisms test increases the rate of alkali leaching during test, and reduces the pore solution $\mathrm{pH}$ due to sulfate ions replacing some of the hydroxyl ions in the solution. Acceptance of this Test method is not yet approved due the uncertainty of its correlation. 


\subsubsection{Preventative measures for ASR}

\subsubsection{Aggregate selection}

The most effective measure against ASR is the use of non-reactive aggregates. This solution may not be practical or economical because non-reactive aggregates may not be locally available or must be transported over long distances to a construction site. On the other hand, in some cases such as in demolishing deteriorated structures to produce RCA with history of ASR, it could be the best option available as source of aggregate in place of construction.

\subsubsection{Limiting the alkali content in concrete}

Portland cement contains some alkalis (from within $\mathrm{Na}_{2} \mathrm{O}$ and $\mathrm{K}_{2} \mathrm{O}$ ) that cannot be eliminated completely from the cement produced. In modern cement plants, the hot gases leaving the upper end of kiln preheat raw materials. These gases contain a significant proportion of the volatile alkalis, which ultimately contributes in raising alkalinity in the cement. However, by bleeding off a part of the gases, the alkali content can be controlled (Neville 2006). ASR can be considerably reduced or even prevented by the use of lowalkali cement or by limiting the total alkali content of concrete under a limiting value. Low alkali cement with upper limit of 0.60 percent of sodium oxide equivalent $\left(\mathrm{Na}_{2} \mathrm{O}+\right.$ $0.658 \mathrm{~K}_{2} \mathrm{O}$ ) has been standardized and used in the USA for nearly 50 years in the cement to minimize the risk of ASR (Neville 2006). 


\subsubsection{Use of Supplementary Cementing Material (SCMs).}

SCMs are found to be effective in controlling ASR. The use of any SCM reduces the permeability of the concrete, which reduces the ability of the gel to absorb water and expand (Neville, 1996). Alkali dilution and consumption of $\mathrm{Ca}(\mathrm{OH})_{2}$ through pozzolanic reaction are also thought to play a role in the beneficial effect of SCMs against ASR (Fournier \& Bérubé, 2000). The efficacy of SCMs in mitigating ASR is attributed, mainly, to their ability to reduce the alkalinity of pore solution (Shehata \& Thomas, 1999). It was stated that due to chemical and mineralogical composition variation and the distinct alkali release characteristics, each SCM imparts specific role in controlling ASR. Fly ash contributes $17 \%$, GGBFS $50 \%$, and silica fume $100 \%$ of its total $\mathrm{Na}_{2} \mathrm{Oe}$ to the pore solution (Hobbs, 1988). This nearly in good agreement with the proposed revision of Appendix B of the Canadian CSA A23.1 and A 23.2 standards as $15 \%$ of total $\mathrm{Na}_{2} \mathrm{O}_{e}$ for fly ash, $50 \%$ for both GGBFS and silica fume (Duchense \& Bérubé, 1994). Experimental results of studies showed that some fly ashes were found to release more alkali in the pore solution than the suggested level (Shehata and Thomas 2006). The role of each SCM in controlling ASR is covered in the following subsections.

\subsection{Fly Ash}

Fly ash has proven to be an effective SCM in reducing ASR expansion. The amount of alkalis and calcium content in the fly ash were important factors in the amount of reduction that occurred. Of course, an increased amount of alkalis in the fly ash increases the expansion that occurs. In addition, high calcium fly ash is not effective in mitigating ASR, specially, at lower replacement levels. The reason for the lower efficiency of a 
class C fly ash is likely due to the greater portion of the silica in the fly ash that is tied up by lime, lowering the amount of silica available to control the alkali-silica reaction (Mindess et al, 2003). Experimental results elsewhere showed that low calcium fly ash is effective in suppressing ASR. The main reason behind the effectiveness of such fly ash is due its higher alkali binding capacity (Shehata \& Thomas 2006). The Reduction of alkalinity in the pore solution is due to the incorporation of more alkalis in the secondary C-S-H (Duchense and Bérubé 1994). It was also noted that the increase in total silica content of the fly ash increased the effectiveness of the fly ash to reduce expansion.

In a study by Shehata and Thomas (2000) on concrete made using reactive siliceous limestone (Spratt) a relationship was developed between expansion and $\mathrm{CaO}$ of the ash as shown in Figure 5.There is a slight increase in the expansion as the $\mathrm{CaO}$ content increases ranging from $5 \%$ to $20 \%$ with a sudden and remarkable increase above $20 \pm 22 \% \mathrm{CaO}$. In nearly all cases, fly ashes (with low to moderate alkali) that meet the CSA specification for Type F or Type CI were effective in limiting the 2-year expansion of concrete prism to $\leq 0.04 \%$ when used at replacement level of $25 \%$.

The relation in Figure 6 was established from the same experimental results in an attempt to correlate the fly ash composition and replacement levels with the expansion of the concrete prisms. Multiple regression analyses were performed between expansion as the dependent variable and the $\mathrm{CaO}, \mathrm{Na}_{2} \mathrm{Oe}$, and $\mathrm{SiO}_{2}$ contents of the fly ash as the independent variables. The best fit was achieved when the $\mathrm{Na}_{2} \mathrm{Oe}$ and $\mathrm{CaO}$ were normalized to the $\mathrm{SiO}_{2}$ content. The graph shows a general trend of increasing expansion as the $\mathrm{Na}_{2} \mathrm{Oe}$ and $\mathrm{CaO}$ contents of the fly ash increase and as its silica content decreases. The graph also indicates that fly ash with chemical composition that satisfies the 
condition $\left[\left(10 \mathrm{Na}_{2} \mathrm{Oe}+4.45 \mathrm{CaO}\right) / \mathrm{SiO}_{2} \leq 2\right]$ will likely meet the $0.04 \%$ expansion criterion of the concrete prism test after 2 years when used at a replacement level of $25 \%$ (Shehata \& Thomas 2000).

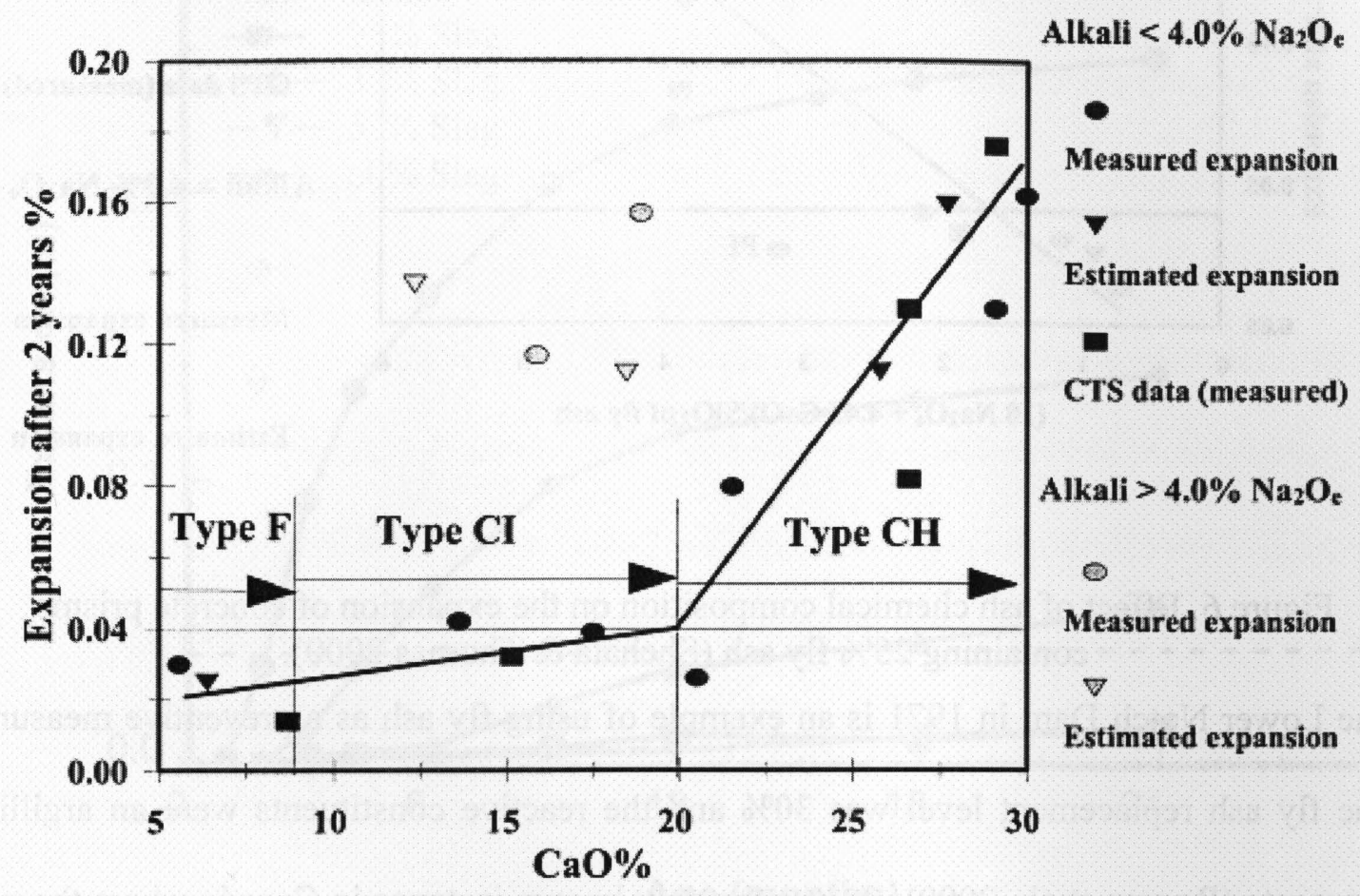

Figure 5. Effect of $\mathrm{CaO}$ content of fly ash on expansion of concrete containing $25 \%$ fly ash (Shehata \& Thomas 2000). 


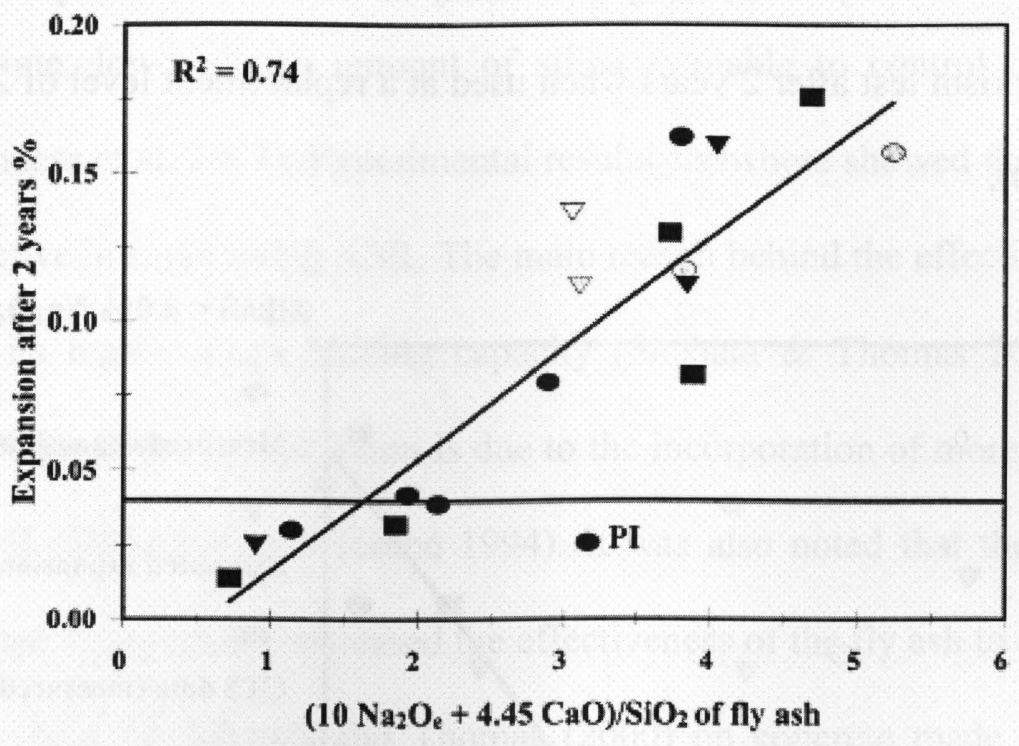

Alkali $<4.0 \% \mathrm{Na}_{2} \mathrm{O}_{e}$

Measured expansion

Estimated expansion

CTS data (measured)

Alkali $>4.0 \% \quad \mathrm{Na}_{2} \mathrm{O}_{\mathrm{e}}$

-

Measured expansion

$\nabla$

Estimated expansion

Figure 6. Effect of ash chemical composition on the expansion of concrete prisms containing $25 \%$ fly ash (Shehata \& Thomas 2000 ).

The Lower Notch Dam in 1971 is an example of using fly ash as a preventive measure. The fly ash replacement level was $30 \%$ and the reactive constituents were an argillite aggregate (Rogers et al., 2000). It was the only known instance in Canada where the use of a known alkali reactive aggregate was permitted with high alkali cement combined with fly ash (Rogers et al., 2000).

\subsection{Granulated Ground Blast Furnace Slag (GGBFS)}

Thomas \& Innis (1998) reported that high proportions of slag are necessary to reduce expansion as shown in Figure 7. In their study on four alkali-silica reactive aggregates (siliceous limestone, sandstone, greywake and granite) they found that the minimum replacement level of slag required to control expansion to an acceptable level $(0.04 \%$ in 2 
years) varied depending on the nature of aggregate and the amount of alkali present in the concrete.

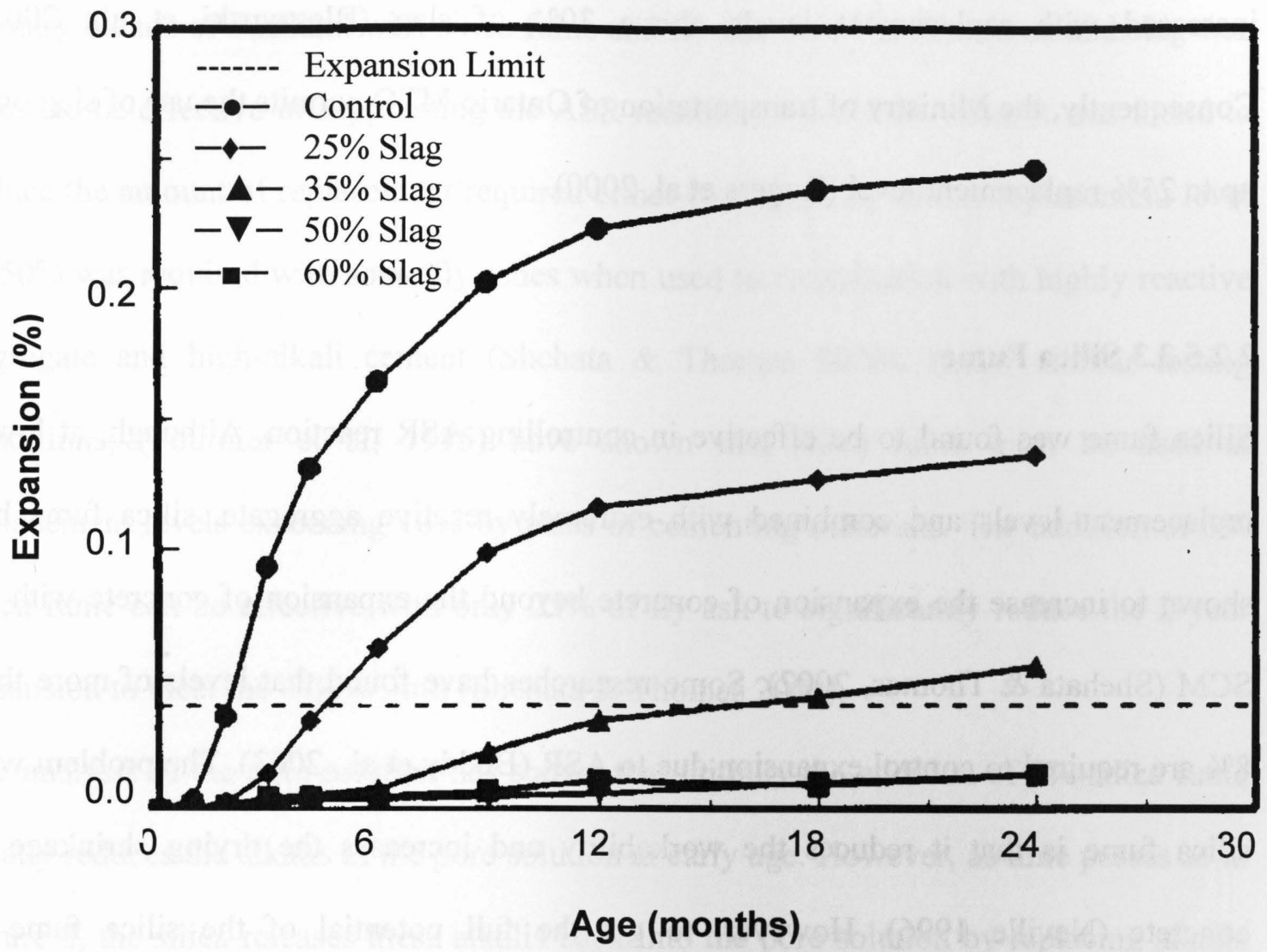

Figure 7: Expansion of concrete with Spratt aggregate alkalis $=1.25 \% \mathrm{Na}_{2} \mathrm{O}_{\mathrm{e}}$ (by mass of cement) (Thomas \& Innis, 1998).

Slag replacement level ranging from $25 \%$ to $65 \%$ was found to be effective in retarding the rate of expansion. However, the effectiveness of slag was found to be decreasing with the increase in the alkali content of cement. Thomas \& Innis (1998) believed that slag helps to reduce the hydroxyl ion content of the pore solution; this is achieved by incorporating higher levels of alkalis into the C-S-H matrix compared to the C-S-H that is produced when Portland cement is used alone. The efficacy of slag was attributed to the dilution effect as well as the stabilization and immobilization of alkalis. 
A disadvantage with the use of slag as a preventative measure is the amount required which may lead to other deleterious problems such as salt scaling that shown to be increased with replacement levels above $30 \%$ of slag (Bleszynski et al., 2002). Consequently, the Ministry of transportation of Ontario MTO permits the use of slag only up to $25 \%$ replacement level (Rogers et al, 2000).

\subsection{Silica Fume}

Silica fume was found to be effective in controlling ASR reaction. Although, at lower replacement levels and combined with extremely reactive aggregate, silica fume has shown to increase the expansion of concrete beyond the expansion of concrete with no SCM (Shehata \& Thomas, 2002). Some researches have found that levels of more than $8 \%$ are required to control expansion due to ASR (Boddy et al., 2003). The problem with silica fume is that it reduces the workability and increases the drying shrinkage of concrete (Neville 1996). However, to get the full potential of the silica fume in controlling ASR, its quantity should be sufficient in the concrete mix. The efficacy of silica fume is due to its effect in reducing the calcium hydroxide contents of cement paste and pore solution due the pozzolanic reaction forming secondary C-S-H. Those reaction products decrease the porosity and cause retardation of transportation of $\mathrm{Na}^{+}$and $\mathrm{K}^{+}$ion towards aggregate (Hooton, 1993). But, Silica fume doesn't have a high capacity to retain alkalis in its hydration products; however, ternary blends containing silica fume and fly ash have excellent capacity to bind and retain Alkalis (Shehata \& Thomas, 2002 and 2006). 


\subsection{Ternary Blends}

Ternary blends of Portland with silica fume and fly ash or with silica fume and slag was found to be effective in suppressing the ASR reaction in concrete. Also, it was found to reduce the amount of replacement required either by slag or fly ash. A replacement level of $50 \%$ was required with some fly ashes when used in combination with highly reactive aggregate and high-alkali cement (Shehata \& Thomas 2000). Under similar testing conditions, (Fournier et al, 1995) have shown that silica fume must be used at replacement levels exceeding $10 \%$ by mass of cementing materials. The addition of $5 \%$ silica fume can be effective with only $25 \%$ of fly ash to significantly reduce the 2-year expansion to meet the $0.04 \%$ limit (Shehata \& Thomas 2002).

The analysis of the pore solution has shown that initially the addition of $5 \%$ silica fume greatly reduces the alkalis in the pore solution at early age. However, as time passes as in Figure 8 , the silica releases these alkalis back into the pore solution by replacing alkalis for calcium. The presence of both SF and FA results in a low pore solution alkalinity at both early and late ages. Hence, the synergy that exists between SF and FA can be explained on the basis of their different effects over time. SF is very effective in reducing the alkalinity at early age whereas FA becomes increasingly effective at later ages. The combination of the two materials produces a pore solution that is initially low in alkalis and remains that way as seen in Figure 9 (Shehata \& Thomas, 2002).

The very low range of the permeability of the ternary blended concrete can reduce the permeation of moisture, which is essential for ASR expansion into the concrete. Also the 
low range of permeability can reduce the ease of ionic diffusion of the soluble Alkalis in the pore solution.

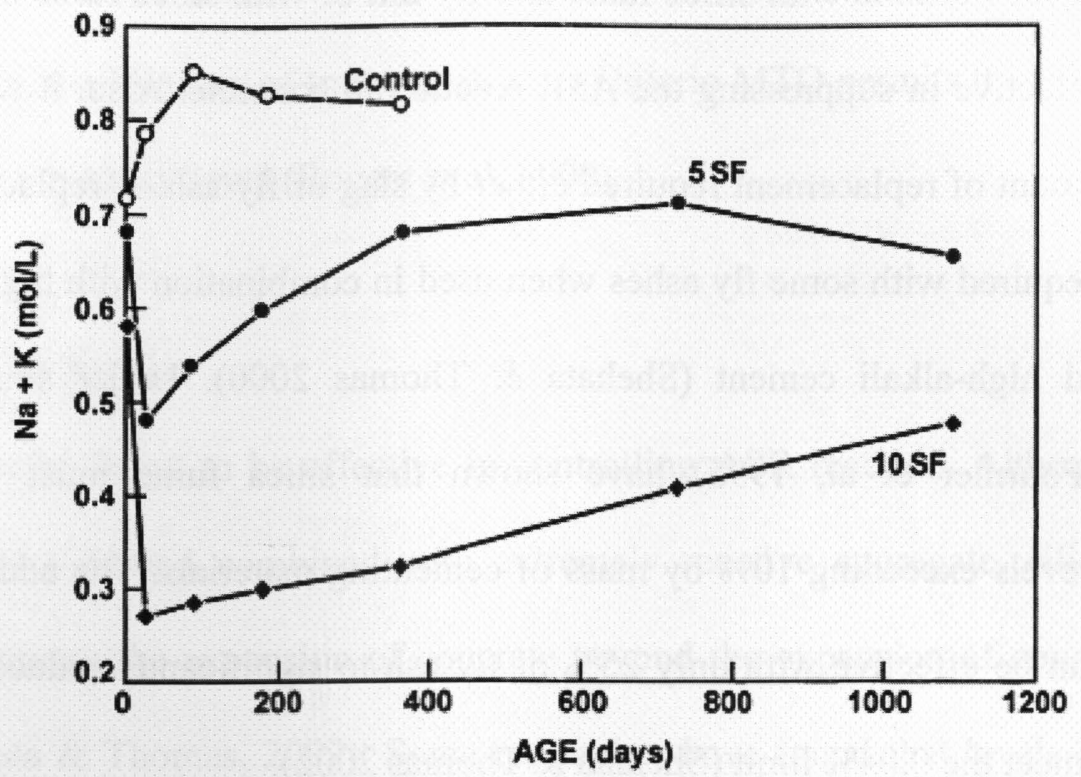

Figure 8: Effect of Silica Fume on the alkalinity of pore solution of pastes, represented by the sum of alkali cations in the pore solution (Shehata \& Thomas, 2002).

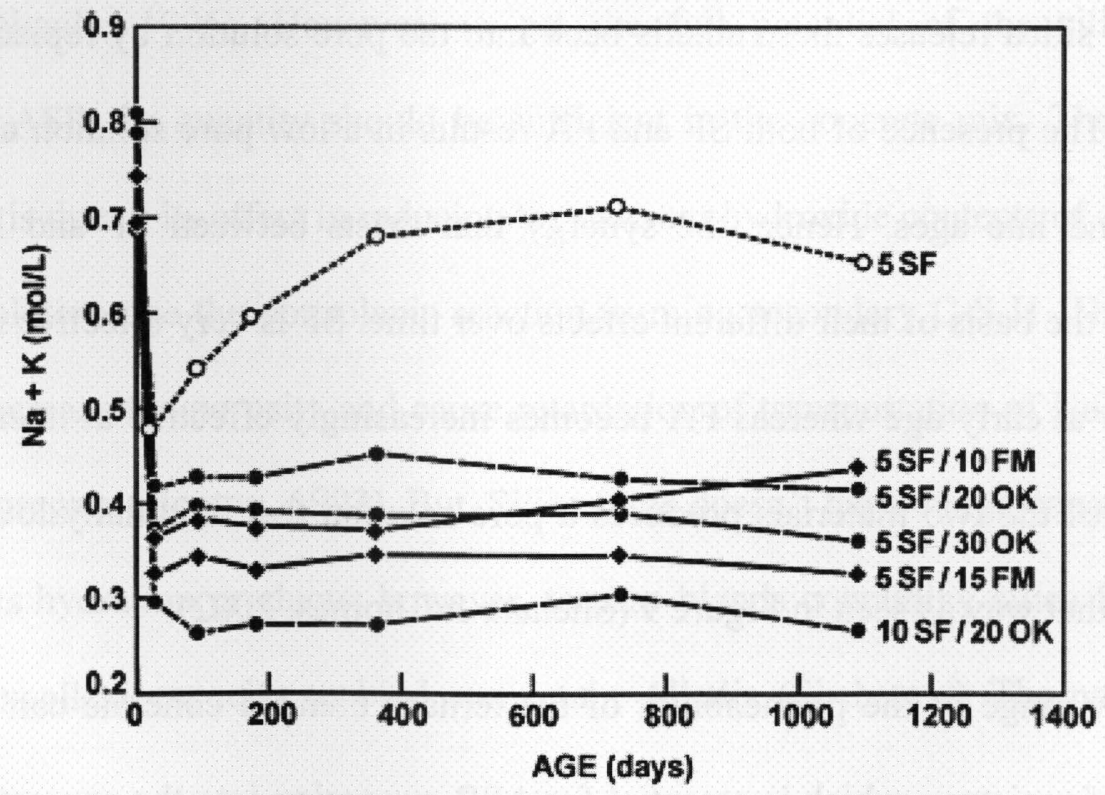

Figure 9: Effect of Silica fume (SF) \& Fly Ash (OK) and combination of SK/OK on pore solution alkalinity (Shehata \& Thomas, 2002). 


\subsubsection{Use of Lithium Salts}

Since McCoy and Caldwell in 1951 found that Lithium-based compounds were probably among the most effective chemical compounds against ASR, many researchers have investigated the effects of lithium hydroxide and several lithium salts on the ASR. It is known that some $\mathrm{Li}$-bearing compounds including, $\mathrm{LiOH}, \mathrm{LiNO}_{3}, \mathrm{LiF}, \mathrm{LiCl}$ and $\mathrm{Li}_{2} \mathrm{CO}_{3}$ are able to suppress the expansion caused by the ASR when used at an adequate dosage (Stark et al, 1994). However, the mechanism of the lithium behaviour is not yet well understood (Ramyar et al, 2004).

Lithium nitrate has shown high efficacy in mitigating expansion due to ASR in both new and in service concrete. The efficacy of $\mathrm{LiNO}_{3}$ was recognized as it appears not to be susceptible to pessimum effects and does not increase the $\mathrm{pH}$ of the pore solution contrarily to $\mathrm{LiOH}$ and some other Lithium salts (Stokes et al, 1997). A significant increase in the pore solution $\mathrm{OH}^{-}$ion concentration (and $\mathrm{pH}$ ) by lithium hydroxide and inadequate dosages are known to result in increased, rather than decreased expansion (Diamond, 1999). Generally, $\mathrm{LiNO}_{3}$ was found to be more effective against ASR than $\mathrm{LiOH}$ at Similar $\mathrm{Li} /(\mathrm{Na}+\mathrm{K})$ molar ratios ( Fournier and Bérubé, 2001). Although the $\mathrm{Li}^{+}$ is still adsorbed into the hydration products, the release of $\mathrm{NO}_{3}$ does not seem to have a negative effect in the concrete and also does not increase the amount of alkalis in the pore solution.

It has been reported by Diamond et al (1992) that when $\mathrm{NaOH}$ is added into cement paste for accelerating the alkali silica reaction, about $25 \%$ of the added $\mathrm{Na}$ ions will be bound by the cement hydration products. Only the remaining $75 \%$ would be available for driving the ASR. Similarly, when lithium containing compound is added to the system, 
the fate of the $\mathrm{Li}$ ions is similar to that of the $\mathrm{Na}$ ions. Only, about $60 \%$ of the $\mathrm{Li}^{+}$ions will be available for suppressing the ASR expansion and $40 \%$ will be bound by the cement hydration products (Diamond et al 1992).

Some researchers believe that the lithium ion $\mathrm{Li}^{+}$has both a smaller ionic radius and higher surface charge density than $\mathrm{Na}^{+}$or $\mathrm{K}^{+}$(Mo et al., 2003). This allows the $\mathrm{Li}^{+}$to enter the ASR product more readily than $\mathrm{Na}^{+}$or $\mathrm{K}^{+}$. As the Lithium ions enter the ASR product, this produces a crystalline and non-expansive gel (Mo et al., 2003). Another mechanism was suggested by Kurtis et al (2000), is that some of the Lithium salts may prevent re-polymerization of the gel.

Others believe that lithium decreases the rate of silica dissolution (Shomglin et al., 2003). Feng et al (2005) conducted a study on two reactive aggregates that were ground to the size between $150 \mu \mathrm{m}$ and $300 \mu \mathrm{m}$ and placed in plastic containers at $1 \mathrm{~N} \mathrm{NaOH}$ solution with and without $\mathrm{LiNO}_{3}$ at 0.74 Molar ratio in presence and absence of calcium. Solution filtrates were then separated from aggregate residues and were analyzed by induction coupled plasma emission spectrometry (ICP-ES) to determine the silicon concentration, and by flame atomic emission to determine the $\mathrm{Li}^{+}$and $\mathrm{Na}^{+}$ion concentrations in the immersing solution. In presence of calcium, silica dissolution was much less; this was attributed to the formation of C-S-H. But the trend in $\mathrm{Na}$ and $\mathrm{Li}$ ion concentrations reduction were similar compared to the trend in the absence of calcium. Feng et al (2005) believed that the reduction of both $\mathrm{Na}^{+}$and $\mathrm{Li}^{+}$ions from the solution may indicate there are insoluble reaction products such as sodium-silicate, and lithium-sodium-silicate forming in the system. There was no significant difference between the aggregates that respond to the lithium effect to mitigate ASR expansion in concrete prism test and the 
other that did not in terms of the amount of reduction of silica dissolution, or lithium and alkalis consumed as seen in Figure 11. Thus, the different response to Lithium exhibited by the aggregates may be due to textural differences rather than mineralogical differences. The Lithium Nitrate was effective to suppress the ASR expansion in case of NB aggregate (rhyolite), but not for the NS aggregate (greywacke). The NB is coarse grained, and almost all quartz likely coexists with albite while NS is fine grained with preferred orientation, and quartz likely exist alone Fig 10 (Feng et al, 2005).
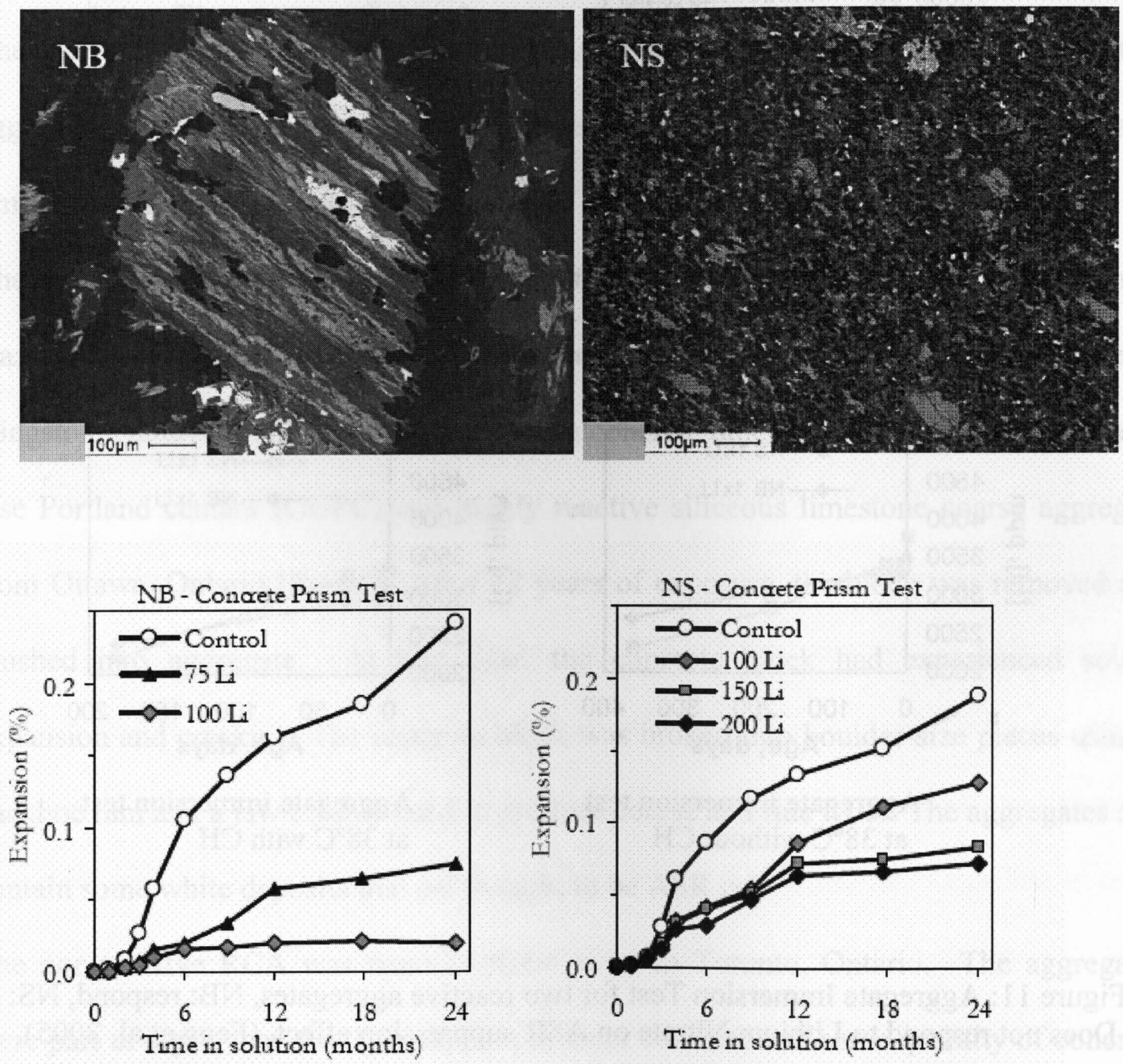

Figure 10: Aggregate microstructure by SEM, NB: respond, NS: Did not respond to Lithium Nitrate on ASR suppression effect, (X.Feng et al, 2005). 

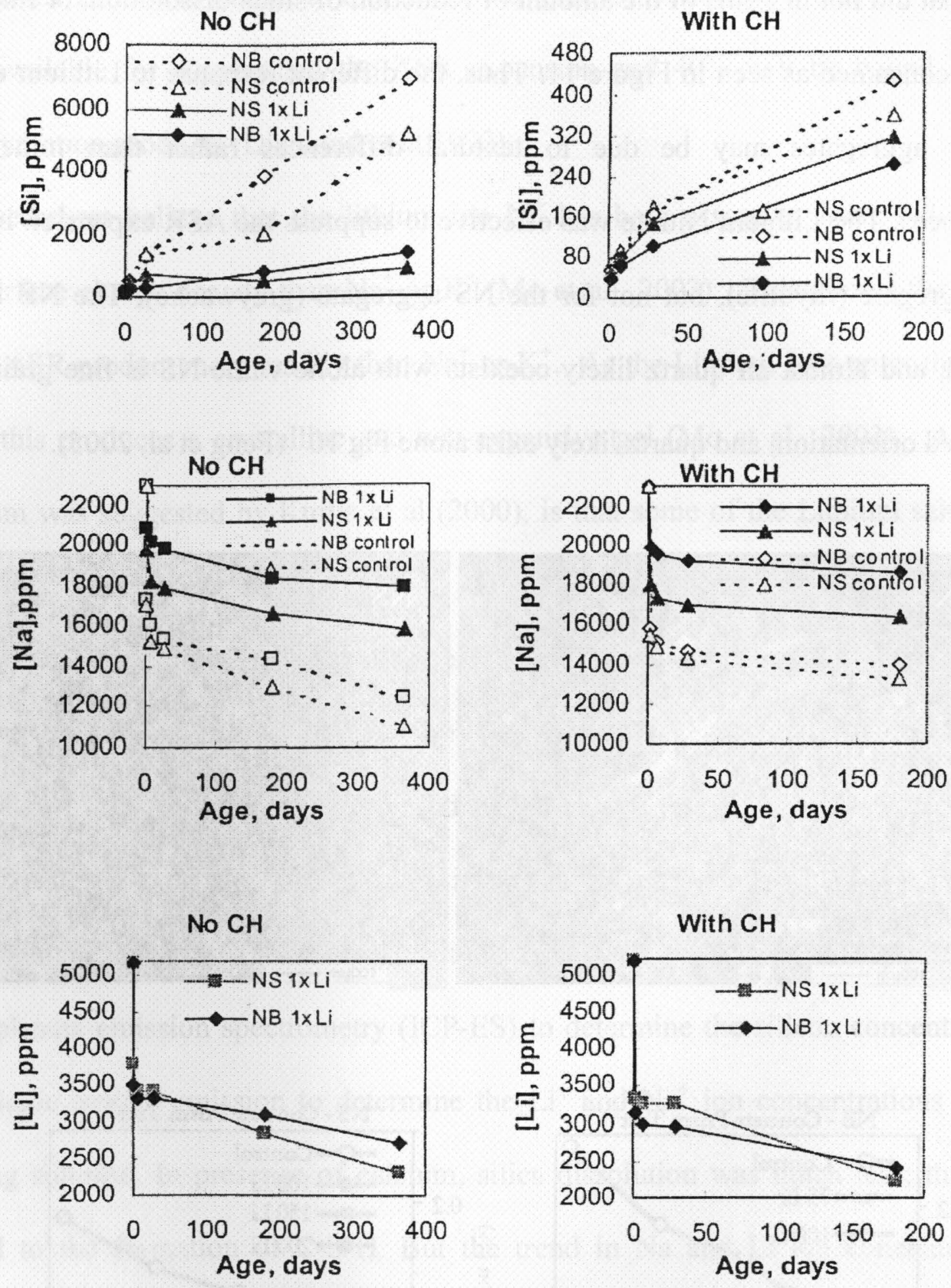

Aggregate immersion test at $38^{\circ} \mathrm{C}$ without $\mathrm{CH}$

Aggregate immersion test at $38^{\circ} \mathrm{C}$ with $\mathrm{CH}$

Figure 11: Aggregate Immersion Test for two reactive aggregates, NB: respond, NS: Does not respond to Lithium Nitrate on ASR suppression effect, (Feng et al, 2005). 


\section{Chapter 3}

\section{Materials and Experimental Program}

\subsection{Materials}

\subsubsection{Coarse Aggregates}

The properties of all the aggregates used in the first phase of this study were covered by Christidis (2006) and are reported here in Table 1. Four different types of coarse aggregates were tested; two reactive and two non-reactive.

The reactive aggregates were Spratt and ASR-affected RCA. The two non-reactive aggregates were limestone and Non-ASR recycled concrete aggregate. The 3/4" coarse limestone was received from Acton, Ontario.

The Spratt aggregates were obtained from Ottawa, Ontario. The RCA used in this study was obtained from the Ontario Ministry of Transportation outdoor exposure site in Kingston, Ontario. The concrete was part of a concrete block placed in 1991 with General Use Portland cement (GUPC) and highly reactive siliceous limestone coarse aggregate from Ottawa, Ontario (Spratt). After 12 years of exposure, the block was removed and crushed into aggregate. At that time, the concrete block had experienced severe expansion and cracking. The concrete block was broken into boulder-size pieces using a backhoe ram and a jaw crusher used to produce coarse and fine RCA. The aggregates still contain some white deposits that are thought to be ASR gel.

The non-reactive RCA was from Dufferin plant in Toronto, Ontario. The aggregates were part of a pile that mostly contained leftover concrete and some quantity of concrete 
collected from the demolition of old concrete structures. Most of the non-concrete debris was removed.

The RCA was separated in 3 sizes for testing of coarse material conforming to ASTM C1293. The coarse ASR-affected RCA was not washed to avoid removing the pre-existing alkalis. Heating the aggregates was avoided because it was assumed that the heat would destroy some of the ASR gel.

In the second phase of the program which is covered in this thesis, the coarse aggregates used were:

- $\quad$ Two reactive aggregates: The same ASR-affected RCA used in phase 1 and Spratt aggregate obtained from Ottawa, Ontario.

- Two non-reactive aggregates: Non-reactive limestone from Ontario, and non-ASR recycled concrete aggregates obtained from Dufferin plant (demolished RCA)

\subsubsection{Fine Aggregates}

The fine aggregates used in the first phase :

There were four different types of fine aggregate tested; three reactive and one nonreactive. The reactive aggregates were natural sand, Jobe, and ASR recycled concrete aggregate that was primary crushed and secondary crushed. The one non-reactive was Ottawa sand. The natural fine aggregate was from Orangeville Ontario. This sand was found to correspond with the gradation limits in ASTM C136. Jobe was from New Mexico and has been proven to be very reactive with respect to alkali silica reaction. ASR fine recycled concrete aggregate that was primary crushed was obtained from the original crushing of the deteriorated out door-exposure of the concrete block and contain the white deposits similar to the coarse aggregate. The secondary re-crushed fine RCA 
was acquired from re-crushing the ASR coarse aggregates, mentioned above, into the appropriate gradations.

Second phase only used the non-reactive natural sand from Sunderland, Ontario which is similar to the natural sand from Orangeville Ontario used in phase 1.

Fine aggregates were separated in 5 sizes for testing conforming to ASTM standard C1260.

\subsubsection{Cementing materials}

The cement and supplementary cementing materials used in this study were received by various suppliers. The chemical analysis for cement, slag, and silica fume are shown in Table 2. The chemical analysis for the fly ash can be seen in Table 3. Carbon content was measured with Leco SC444DR Carbon/Sulfur Analyzer. The chemical analysis was performed on a dry, ignited basis for the fly ash and on a dry basis for the slag, silica fume and cement using a Bruker S4 X-ray fluorescene spectrometer according to ASTM D4326. Cement used for Phase 2 of this study was of 0.97 Alkali content.

\subsubsection{Lithium Nitrate $\mathrm{LiNO}_{3}$}

The lithium compound used in this study was in the form of a $30 \%$ lithium nitrate solution. This was used to evaluate the dosage used based on molar ratio of $\mathrm{Li} / \mathrm{Na}+\mathrm{K}$ where the $\mathrm{Na}+\mathrm{K}$ are obtained form the Portland cement alkali content in the concrete $\operatorname{mix}$. 
Table 1: Aggregate Properties using ASTM Standards

\begin{tabular}{|c|c|c|c|c|c|}
\hline Aggregate Type & $\begin{array}{c}\text { Bulk Relative } \\
\text { Density (Dry) } \\
\left(\mathrm{Kg} / \mathrm{m}^{3}\right)\end{array}$ & $\begin{array}{l}\text { SSD Bulk Relative Density } \\
\qquad\left(\mathrm{Kg} / \mathrm{m}^{3}\right)\end{array}$ & $\begin{array}{l}\text { Apparent Relative Density } \\
\qquad\left(\mathrm{Kg} / \mathrm{m}^{3}\right)\end{array}$ & $\begin{array}{c}\text { Dry Rodded } \\
\text { Density } \\
\left(\mathrm{Kg} / \mathrm{m}^{3}\right)\end{array}$ & Absorption \\
\hline \multicolumn{6}{|c|}{ Coarse Aggregate } \\
\hline Limestone & 2680 & 2694 & 2718 & - & 0.51 \\
\hline Spratt & 2665 & 2680 & 2706 & - & 0.58 \\
\hline $\begin{array}{l}\text { ASR Recycled } \\
\text { Concrete }\end{array}$ & 2333 & 2441 & 2615 & 1385 & 5.07 \\
\hline $\begin{array}{l}\text { Non-ASR Recycled } \\
\text { Concrete }\end{array}$ & 2249 & 2400 & 2647 & - & 6.69 \\
\hline \multicolumn{6}{|c|}{ Fine Aggregate } \\
\hline Ottawa Sand & 2417 & 2418 & 2419 & - & 0.00 \\
\hline Natural & 2648 & 2660 & 2691 & - & 0.60 \\
\hline Jobe & 2515 & 2534 & 2564 & - & 0.77 \\
\hline $\begin{array}{l}\text { Primary ASR } \\
\text { Recycled Concrete }\end{array}$ & 2023 & 2203 & 2469 & - & 8.94 \\
\hline $\begin{array}{l}\text { Secondary ASR } \\
\text { Recycled Concrete }\end{array}$ & 2107 & 2217 & 2367 & - & 5.21 \\
\hline
\end{tabular}


Table 2: Chemical analysis of cement, slag, and silica fume

\begin{tabular}{|c|c|c|c|c|c|c|c|}
\hline Sample Material & $\begin{array}{c}\text { 1.06 Alkali } \\
\text { Cement }\end{array}$ & $\begin{array}{l}0.97 \text { Alkali } \\
\text { Cement * }\end{array}$ & $\begin{array}{c}0.96 \text { Alkali } \\
\text { Cement }\end{array}$ & $\begin{array}{c}0.89 \text { Alkali } \\
\text { Cement }\end{array}$ & $\begin{array}{c}0.55 \text { Alkali } \\
\text { Cement }\end{array}$ & Slag & Silica Fume \\
\hline Carbon Content & 0.48 & - & - & - & - & 0.21 & - \\
\hline Silicon Dioxide, $\mathrm{SiO}_{2}$ & 19.51 & 19.55 & 19.58 & 19.92 & 20.12 & 34.40 & 96.19 \\
\hline Aluminum Oxide, $\mathrm{Al}_{2} \mathrm{O}_{3}$ & 4.94 & 5.51 & 5.35 & 5.57 & 4.43 & 7.40 & 0.35 \\
\hline Iron Oxide, $\mathrm{Fe}_{2} \mathrm{O}_{3}$ & 2.65 & 2.39 & 2.29 & 2.10 & 2.80 & 0.94 & 0.10 \\
\hline Sulfur Trioxide, $\mathrm{SO}_{3}$ & 4.24 & 4.39 & 4.10 & 3.86 & 3.60 & 0.83 & - \\
\hline Calcium Oxide, $\mathrm{CaO}$ & 62.65 & 62.63 & 62.84 & 63.02 & 62.41 & 43.20 & 0.27 \\
\hline Sodium Oxide, $\mathrm{Na}_{2} \mathrm{O}$ & 0.31 & - & 0.21 & 0.20 & 0.27 & 0.57 & 0.11 \\
\hline Magnesium Oxide, $\mathrm{MgO}$ & 2.56 & 2.48 & 2.43 & 2.55 & 3.01 & 9.30 & 0.23 \\
\hline Potassium Oxide, $\mathrm{K}_{2} \mathrm{O}$ & 1.13 & - & 1.13 & 1.05 & 0.44 & 0.58 & 0.51 \\
\hline Phosphorus Pentoxide, $\mathrm{P}_{2} \mathrm{O}_{5}$ & 0.16 & - & 0.11 & 0.12 & 0.13 & $175 \mathrm{ppm}$ & - \\
\hline Titanium Dioxide, $\mathrm{TiO}_{2}$ & 0.28 & - & 0.31 & 0.31 & 0.23 & 0.44 & - \\
\hline Chloride, $\mathrm{Cl}$ & $786 \mathrm{ppm}$ & - & - & 0.01 & - & - & - \\
\hline Manganese Oxide, $\mathrm{Mn}_{2} \mathrm{O}_{3}$ & 0.07 & - & 0.07 & 0.05 & 0.13 & - & - \\
\hline Strontium Oxide, $\mathrm{SrO}$ & 0.11 & - & 0.08 & 0.09 & - & - & - \\
\hline $\mathrm{Na}_{2} \mathrm{O}_{\mathrm{e}}$ & 1.05 & 0.97 & 0.95 & 0.89 & 0.56 & 0.95 & 0.44 \\
\hline
\end{tabular}

Note: All cements in study were Type 10 Portland cements

Silica Fume was not palletized

A dash (-) represents that no data was available

* St Lawrence cement used in phase 2 of this study 
Table 3: Chemical analysis of fly ash

\begin{tabular}{|l|l|l|l|l|l|l|}
\hline Sample Material & $\begin{array}{l}\text { Fly ash } \\
\text { F, LA }\end{array}$ & $\begin{array}{l}\text { Fly ash } \\
\text { F, HA }\end{array}$ & $\begin{array}{l}\text { Fly ash } \\
\text { CI, LA }\end{array}$ & $\begin{array}{l}\text { Fly ash } \\
\text { CH, LA \#1 }\end{array}$ & $\begin{array}{l}\text { Fly ash } \\
\text { CH, LA \#2 }\end{array}$ & $\begin{array}{l}\text { Fly ash } \\
\text { CH, LA \#3 }\end{array}$ \\
\hline Carbon Content & 1.58 & - & 1.29 & - & - & - \\
\hline Silicon Dioxide, $\mathrm{SiO}_{2}$ & 55.74 & 61.29 & 40.15 & 33.26 & 35.92 & 31.39 \\
\hline Aluminum Oxide, $\mathrm{Al}_{2} \mathrm{O}_{3}$ & 27.35 & 16.81 & 21.37 & 18.24 & 21.18 & 18.54 \\
\hline Iron Oxide, $\mathrm{Fe}_{2} \mathrm{O}_{3}$ & 5.59 & 4.62 & 9.92 & 6.45 & 5.85 & 5.22 \\
\hline Sulfur Trioxide, $\mathrm{SO}_{3}$ & 0.26 & 1.12 & 2.46 & 2.59 & 1.29 & 2.62 \\
\hline Calcium Oxide, $\mathrm{CaO}$ & 4.43 & 6.42 & 16.97 & 28.73 & 24.48 & 29.83 \\
\hline Sodium Oxide, $\mathrm{Na}_{2} \mathrm{O}$ & 0.44 & 3.68 & 1.36 & 1.94 & 1.70 & 2.10 \\
\hline Magnesium Oxide, $\mathrm{MgO}$ & 1.56 & 2.15 & 4.23 & 5.32 & 4.46 & 5.22 \\
\hline Potassium Oxide, $\mathrm{K}_{2} \mathrm{O}$ & 2.29 & 0.98 & 1.04 & 0.33 & 0.48 & 0.31 \\
\hline Phosphorus Pentoxide, $\mathrm{P}_{2} \mathrm{O}_{5}$ & 0.31 & 0.54 & 1.10 & 0.88 & 1.36 & 1.20 \\
\hline Titanium Dioxide, $\mathrm{TiO}_{2}$ & 0.67 & 0.95 & 1.39 & 1.45 & 1.68 & 1.60 \\
\hline Chloride, $\mathrm{Cl}$ & - & - & - & - & - & - \\
\hline $\mathrm{Manganese} \mathrm{Oxide}, \mathrm{Mn}_{2} \mathrm{O}_{3}$ & - & - & - & - & 0.03 & 0.11 \\
\hline Strontium Oxide, $\mathrm{SrO}$ & - & - & - & - & 0.44 & 0.55 \\
\hline $\mathrm{Na}_{2} \mathrm{O}_{\mathrm{e}}$ & 1.95 & 4.33 & 2.04 & 2.16 & 2.02 & 2.30 \\
\hline
\end{tabular}

Note: $\mathrm{F}=$ Low Calcium $<8 \% \mathrm{CaO}, \mathrm{CI}=$ Intermediate Calcium $8-20 \% \mathrm{CaO}, \mathrm{CH}=$ High Calcium $>20 \% \mathrm{CaO}$

LA $=$ Low Alkali, HA = High Alkali

A dash (-) represents that no data was available. 


\subsection{ASR concrete prisms (CSA A23.2-14A, ASTM C 1293)}

\subsubsection{Mix procedures}

The concrete prism test (CPT) [CSA A23.2-14A] was used to evaluate the reactivity of the RCA and the efficacy of preventive measures. Water/cement ratio was kept between 0.42 and 0.45 as per ASTM C1293. Whenever binary blends used w/c was kept as of 0.4 except when used ternary blends where a w/c of 0.43 was required to achieve a relatively workable mix. When superplasticizers EUCON was used (2.7-3.1 1/m3) a w/c ratio of 0.40 was workable enough for the concrete prisms of the ternary blends. Since the RCA has a relatively low relative density, a volume of dry-rodded coarse aggregate of $0.69 \%$ of unit volume of concrete was found to produce workable and homogeneous mixtures. This ratio, which lies within the limit of CSA A23.2-14A, was then used in all the tested samples. The RCA was not washed so as to eliminate any leaching of alkalis from the residual mortar.

In Phase 1: In order to increase the total alkalinity of the concrete to $1.25 \%$ by mass of the cement, $\mathrm{NaOH}$ was dissolved in the total mixing water in accordance with ASTM C1293. However, $\mathrm{NaOH}$ was dissolved in half of the total mixing water and the other half of clean mixing water was mixed for one minute with the coarse RCA prior to adding the cement and the non-reactive fine aggregates. The remaining water (with the $\mathrm{NaOH}$ ) was then added to the mixer. This was done to prevent the $\mathrm{NaOH}$ that was dissolved in the water from being rapidly absorbed by the high porosity RCA.

The mix sequence involved one minute of mixing the coarse RCA with half the total clean mixing water, then the mixer was stopped and the cement was added on top the RCA and the fine aggregate was added on top the cement. The mixing time was: three 
minutes mix, two minutes rest, two minutes mix, two minutes rest, and 1 minute mix. The $\mathrm{NaOH}$ dissolved in half of the mixing water was slowly added in the first 30 seconds, after the PC and SCMs were introduced.

In phase 2: For all the samples prepared with lithium nitrate solution, no alkalis were added to achieve the $1.25 \%$ by mass of cement assuming that the alkalis contributed from the RCA would be more than enough to reach that ratio of alkali content of the concrete $\operatorname{mix}\left(5.25 \mathrm{Kg} / \mathrm{m}^{3}\right)$. Also, the lithium nitrate was added with the $2^{\text {nd }}$ half of the mixing water instead of the sodium hydroxide.

The molds were filled in two layers with concrete. Each layer was tamped with a standard metal tamper 20 times and the ends, where the studs were, were spaded 10 times to insure that the studs were covered with concrete. Each layer was also consolidated by lifting and dropping the ends of the mould for one time. Care was taken to avoid bleeding. The top surface of the material was finished with a metal spade. The samples were cured for one day by covering the molds using damped burlap at room temperature. After de-molding, a reading of the initial length was taken and recorded. The samples were then placed in 20 litre buckets with wicking cloth from the inside as per test standard to maintain a relative humidity of approximately $100 \%$. Samples were placed in a heat room at a temperature of $38^{\circ} \mathrm{C}$. Subsequent comparator readings were taken after removal of the container from the heat room to room temperature $16-20$ hours before measuring. Expansions of the concrete prisms were measured periodically as per test standard. It should be noted that every time a measurement was taken, the buckets always contained water but not touching the prisms. 


\subsubsection{Concrete mixes}

Phase 1 focused on evaluating the reactivity of the RCA and the efficacy of different SCMs to prevent ASR. The mixes used in Phase 1 are listed on Table 4. Alkalis content were calculated based only on the alkalis content of the Portland cement. No alkalis were taken into calculations from the alkali contributed from the RCA or the SCMs.

Phase 2 focused on the efficacy of the lithium nitrate to mitigate ASR expansion in concrete prisms with and without SCMs. Different molar ratios of $\mathrm{Li} / \mathrm{Na}+\mathrm{K}$ calculated based on the cement alkali content was investigated to evaluate the optimum dosage of $\mathrm{LiNO}_{3}$ for use with the ASR- affected RCA. Ternary Blends of silica with slag that failed to suppress the ASR expansion in Phase 1 were investigated with addition of different dosages of $\mathrm{LiNO}_{3}$.

In attempt to investigate the efficacy of introducing lithium nitrate to the ASR-affected RCA before used in concrete, 4 samples were prepared by pre-soaking the RCA with half of the mixing water and all the dosage of the lithium nitrate for 24 hour prior to mixing.

Dilution of the RCA in concrete mix was also investigated by blending the RCA with natural non-reactive limestone to evaluate the efficacy of partial replacement of the coarse aggregate in suppressing the ASR in concrete. Dilution of virgin aggregate (Spratt) was also investigated for use as a benchmark to which the dilution of RCA can be compared.

Two RCA non-reactive aggregates were tested to evaluate the swelling effect due the presence of paste or mortar on the overall expansion of the samples. 
In addition, the efficacies of ternary blends at replacement levels higher than those used in Phase 1 were investigated. Also, the blends of high calcium fly ahs and slag were investigated. The mixes investigated in Phase 2 are listed on Tables 5 and 6 . 
Table 4: Mix Design for ASR Prisms - Phase 1

\begin{tabular}{|c|c|c|c|c|c|c|c|c|c|c|c|c|c|c|c|c|c|c|c|}
\hline \multirow{2}{*}{\multicolumn{2}{|c|}{$\begin{array}{l}\text { Binary } \\
\text { Blends }\end{array}$}} & \multicolumn{10}{|c|}{$\begin{array}{l}\text { RCA } \\
\text { Mixes }\end{array}$} & \multicolumn{5}{|c|}{$\begin{array}{l}\text { Jobe } \\
\text { Mixes }\end{array}$} & \multicolumn{3}{|c|}{$\begin{array}{l}\text { Spratt } \\
\text { Mixes }\end{array}$} \\
\hline & & 5 & 8 & 10 & 15 & 20 & 25 & 30 & 35 & 40 & 50 & 7 & 10 & 15 & 20 & 25 & 15 & 20 & 25 \\
\hline \multicolumn{2}{|c|}{ Fly ash F, LA } & & & & & $\mathrm{X}$ & $\mathrm{X}$ & $\mathrm{X}$ & & & & & & & & & & & \\
\hline \multicolumn{2}{|c|}{ Fly ash F, HA } & & & & $\mathrm{X}$ & $\mathrm{X}$ & $\mathrm{X}$ & & $\mathrm{X}$ & & & & & $\mathrm{X}$ & $\mathrm{X}$ & $\mathrm{X}$ & $\mathrm{X}$ & $\mathrm{X}$ & $\mathrm{X}$ \\
\hline \multicolumn{2}{|c|}{ Fly ash CI, LA } & & & & & $\mathrm{X}$ & & $\mathrm{X}$ & & & & & & & & & & & \\
\hline \multicolumn{2}{|c|}{ Fly ash CH, LA \#1 } & & & & & & $\mathrm{X}$ & $\mathrm{X}$ & & & $\mathrm{X}$ & & & & & & & & \\
\hline \multicolumn{2}{|c|}{ Silica Fume } & $\mathrm{X}$ & $\mathrm{X}$ & $\mathrm{X}$ & & & & & & & & $\mathrm{X}$ & $\mathrm{X}$ & & & & & & \\
\hline \multicolumn{2}{|c|}{ Slag } & & & & & & $\mathrm{X}$ & $\mathrm{X}$ & & & $\mathrm{X}$ & & & & & & & & \\
\hline \multicolumn{2}{|c|}{$\begin{array}{l}\text { Ternary } \\
\text { Blends }\end{array}$} & & & & & & & & & & & & & & & & & & \\
\hline $5 \% \mathrm{SF}$ & FA F LA & & & & $\mathrm{X}$ & $\mathrm{X}$ & & $\mathrm{X}$ & & & & & & & $\mathrm{X}$ & & & & \\
\hline $5 \% \mathrm{SF}$ & FA F HA & & & & & $\mathrm{X}$ & $\mathrm{X}$ & & & & & & & & & . & & $\mathrm{X}$ & $\mathrm{X}$ \\
\hline $5 \% \mathrm{SF}$ & FA CI LA & & & & & $\mathrm{X}$ & $\mathrm{X}$ & & & & & & & & & & & & \\
\hline $5 \% \mathrm{SF}$ & FA CH LA & & & & & $\mathrm{X}$ & $\mathrm{X}$ & $\mathrm{X}$ & & & & & & & & W & & & \\
\hline $5 \% \mathrm{SF}$ & Slag & & & & & & $\mathrm{X}$ & $\mathrm{X}$ & & $\mathrm{X}$ & & & & & & & & & \\
\hline $5 \% \mathrm{SF}$ & FA CH LA \#3 & & & & & & & & & & & & & & & $\mathrm{X}$ & & & \\
\hline $3 \% \mathrm{SF}$ & FA CH LA \#2 & & & & & & & & & & & & & & & $\mathrm{X}$ & & & \\
\hline
\end{tabular}


Table 5: Mix Design for ASR Prisms - Phase 2

\begin{tabular}{|c|c|c|c|c|c|c|c|c|c|c|c|c|c|c|c|c|}
\hline & & \multicolumn{11}{|c|}{$\begin{array}{c}\text { RCA } \\
\text { Mixes }\end{array}$} & \multicolumn{4}{|c|}{$\begin{array}{l}\text { Spratt } \\
\text { Mixes }\end{array}$} \\
\hline & & 0 & 5 & 10 & 15 & 20 & 25 & 30 & 35 & 40 & 45 & 50 & 0 & 15 & 20 & 25 \\
\hline \multicolumn{2}{|c|}{$\begin{array}{l}\text { Ternary } \\
\text { Blends }\end{array}$} & & & & & & & & & & & & & & & \\
\hline $5 \% \mathrm{SF}$ & FA F LA & & & & & & $\mathrm{X}$ & $\mathrm{X}$ & & & & & & & & \\
\hline $5 \%$ SF & Slag & & & & & & & & & & $\mathrm{X}$ & & & & & \\
\hline $20 \%$ FA F LA & Slag & & & & & & & $\mathrm{X}$ & & & & & & & & \\
\hline
\end{tabular}

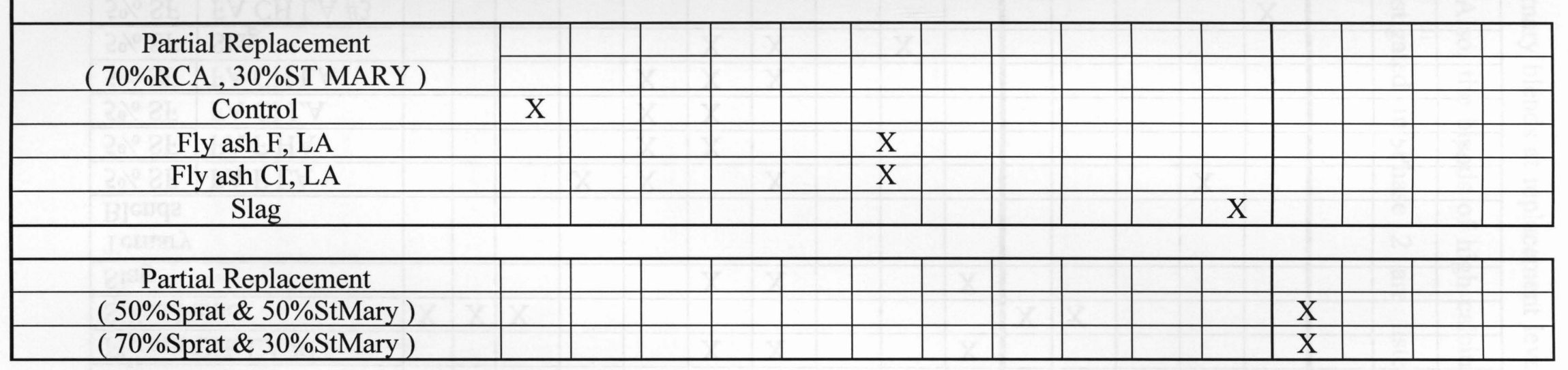


Table 6: Mix Design for ASR Prisms with Lithium- Phase 2

\begin{tabular}{|c|c|c|c|c|c|c|c|c|}
\hline \multirow{2}{*}{ Mixes } & \multicolumn{8}{|c|}{ Lithium molar Ratio $\mathrm{Li} /(\mathrm{Na}+\mathrm{K})$ of Portland cement } \\
\hline & 0.5 & 0.74 & 1 & 1.5 & 2.25 & 3 & 4 & 5 \\
\hline RCA control & & $\mathrm{X}$ & $\mathrm{X}$ & $\mathrm{X}$ & $\mathrm{X}$ & $\mathrm{X}$ & $\mathrm{X}$ & $\mathrm{X}$ \\
\hline RCA Pre-soaked & $\mathrm{X}$ & $\mathrm{X}$ & $\mathrm{X}$ & $\mathrm{X}$ & & & & \\
\hline RCA with $20 \%$ Fly Ash Type "F" LC, LA & $\mathrm{X}$ & $\mathrm{X}$ & $\mathrm{X}$ & $\mathrm{X}$ & & & & \\
\hline RCA with 25\% Fly Ash Type HC, LA & $\mathrm{X}$ & $\mathrm{X}$ & $\mathrm{X}$ & $\mathrm{X}$ & & & & \\
\hline RCA with $40 \%$ Fly Ash Type HC, LA & $\mathrm{X}$ & & & & & & & \\
\hline RCA with $30 \%$ Slag & $\mathrm{X}$ & $\mathrm{X}$ & $\mathrm{X}$ & $\mathrm{X}$ & & & & \\
\hline RCA with $50 \%$ Slag & $\mathrm{X}$ & & & & & & & \\
\hline RCA with $5 \%$ Silica \& $30 \%$ Slag & $\mathrm{X}$ & $\mathrm{X}$ & $\mathrm{X}$ & $\mathrm{X}$ & & & & \\
\hline
\end{tabular}




\subsection{Scanning Electron Microscopy (SEM)}

Polished thin sections were prepared and sputtered with carbon in an Edwards Vacuum Coating System Model \# 306A using ultra pure Carbon, Grade UF4S. The sections were analysed in a JEOL JSM6380LV scanning electron microscope equipped with Oxford INCAx-sight Energy Dispersive X-Ray analysis (EDS) System as seen in Figure 12. The backscattered electron images (BSE) were taken at an accelerated voltage of $20 \mathrm{Kv}$ under high vacuum of about $1^{-4}$ Torr and probe current in the range from $1 \mathrm{pA}$ to $1 \mu \mathrm{A}$.

Two samples were prepared from the RCA of size between $9.5-13.2 \mathrm{~mm}$ to investigate the amount of ASR gel that already exists in the coarse aggregates before usage in new concrete. Another Sample was prepared from a concrete prism with ASR-affected RCA after 2 years passed on ASR Concrete Prism testing. This was to investigate the changes that happened during testing and the nature of the ASR Gel formation.

Three samples were prepared from RCA particles of size $9.5-13.2 \mathrm{~mm}$ after left in alkaline solution of $0.7 \mathrm{M}-(\mathrm{Na}+\mathrm{K})$ for 4 weeks; one with $0.7 \mathrm{M}-(\mathrm{Na}+\mathrm{K})$ without lithium, and the other two samples with $0.7 \mathrm{M}-(\mathrm{Na}+\mathrm{K})$ with lithium at molar ratio of $\mathrm{Li} /(\mathrm{Na}+\mathrm{K})$ of $1: 1$.

This was performed to investigate the differences of the gel composition in absence and presence of the $\mathrm{LiNO}_{3}$ and the distribution of the alkalis in the RCA particles due releasing or absorbing of alkalis from the leaching solutions. 


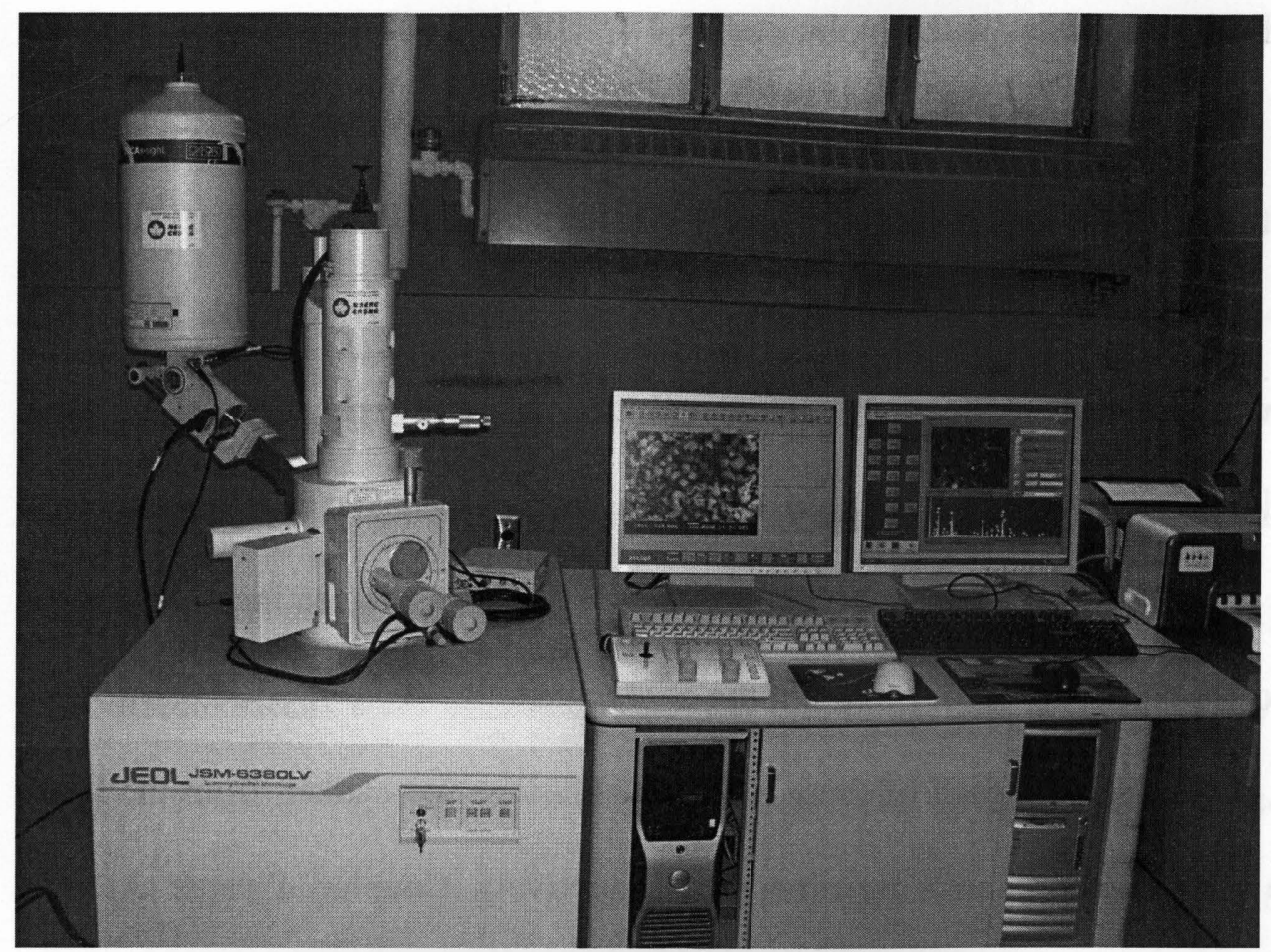

Figure 12: Scanning Electron Microscope - SEM

\subsection{Alkali Contribution Test}

This test was conducted to evaluate the available alkalis from the RCA to the pore solution when used in new concrete. Spratt aggregate is known to contain an amount of alkalis but not readily available to pore solution (Chris Rogers- personal communication). When RCA aggregate was ground and sieved to pass from $300 \mu \mathrm{m}$ and retained on $150 \mu \mathrm{m}$ and examined by XRF, the total alkalis from the RCA was $0.57 \%$ by mass. Some of these alkalis are not soluble and thus they don't contribute to the ASR in concrete. Hence, leaching solutions with different molar of $0,0.25,0.4$ and 0.7 concentrations were used to evaluate the available soluble alkalis from the RCA. 
Furthermore, lithium nitrate with molar ratio $1: 1[\mathrm{Li} /(\mathrm{Na}+\mathrm{K})]$ was prepared to investigate the difference of the consumption or contribution of alkalis from RCA in the presence of Lithium in the test solution. Three different sizes of RCA were used: 9.5$13.2 \mathrm{~mm}, 4.75-9.5 \mathrm{~mm}$ and $150 \mu \mathrm{m}-300 \mu \mathrm{m}$.

Each sample was prepared with aggregate to solution ratio of $1: 10$ by weight. The samples were immersed into the solution and maintained on a shaker at temperature of $38^{\circ} \mathrm{C}$ in closed containers for 4 weeks. RCA moisture content was determined at the time of the immersion to calculate the dry mass of the aggregate.

After 4 weeks, one sample of each of these leaching solutions were taken from the large size aggregate $(9.5-13.2 \mathrm{~mm})$ and examined by Inductively Coupled Plasma Atomic Emission Spectrometry (ICP AES). The compositions of the soaking solutions were compared to the compositions of the original solution. An increase in the concentration of a particular ion $(\mathrm{Na}, \mathrm{K}$ or $\mathrm{Li})$ indicated that the $\mathrm{RCA}$ released this ion into the solution. $\mathrm{A}$ reduction in concentrations indicated that the RCA absorbed alkalis from the soaking solution. The amount of the contributed or absorbed (negative contribution) ions were calculated and presented as a percentage of the dry mass of the RCA. 


\section{Chapter 4}

\section{Results and discussion}

\subsection{ASR concrete prisms}

\subsubsection{Reactivity of RCA}

ASR expansions in concrete prisms were measured periodically according to ASTM C1293. Expansions of the tested blends are listed in Appendix A. It was expected that the ASR affected RCA shall have less reactivity due to the consumption of the reactive silica during the past service life. Also, it was expected due to carbonation of its content of the ASR gel that it may possess less tendency to absorb water causing swelling and rupture of the new concrete. In the contrary, the RCA concrete showed even higher expansion at the early age and continued with the same rate of expansion compared to the natural reactive aggregate. Furthermore, it is expected that the RCA concrete will continue to expand more than the virgin Spratt aggregate after the test period of 2 years as can be seen from the expansion curve in Figure 12. It is believed that the swelling of the old paste was one of the major causes of the expansion of the RCA rather than the new ASR gel formation and the swelling of the old gel.

It was similarly noticed when we tested two other non-reactive RCA aggregates. The two aggregate samples obtained expansion values between $0.028 \%$ and $0.035 \%$ at 1 year respectively as seen in Figure 13. Also, the non-reactive RCAs were soaked in half of the mixing water for $24 \mathrm{hr}$ before used in concrete to evaluate the reduction of the swelling of the RCA paste. It was noticed that a slight improvement occurred but was not enough to prevent the further swelling afterwards. 
The RCA aggregate was found to have many cracks on its surface due to the demolition process as seen in Figure 14. These cracks facilitate the water and the alkali ions to penetrate to the old ASR gel. Also, the demolishing process introduces new surfaces of the un-reacted reactive silica. These new surfaces are readily introduced to the ASR gel formation process due to the high alkalis retained in the RCA in addition to the alkalis from the cementing materials.

It was previously reported by Shehata \& Thomas (2000) that the Spratt aggregate reaches acceptable expansion at an alkali content of approximately $0.7 \% \mathrm{Na}_{2} \mathrm{Oe}$. But, in case of the reactive RCA, it would require more preventative measures to reduce the expansion to the ASTM expansion limit of $0.04 \%$. The Use of SCMs and dilution of the RCA with natural non-reactive aggregate are measures to be considered to reduce the effect of the swelling of RCA concrete.

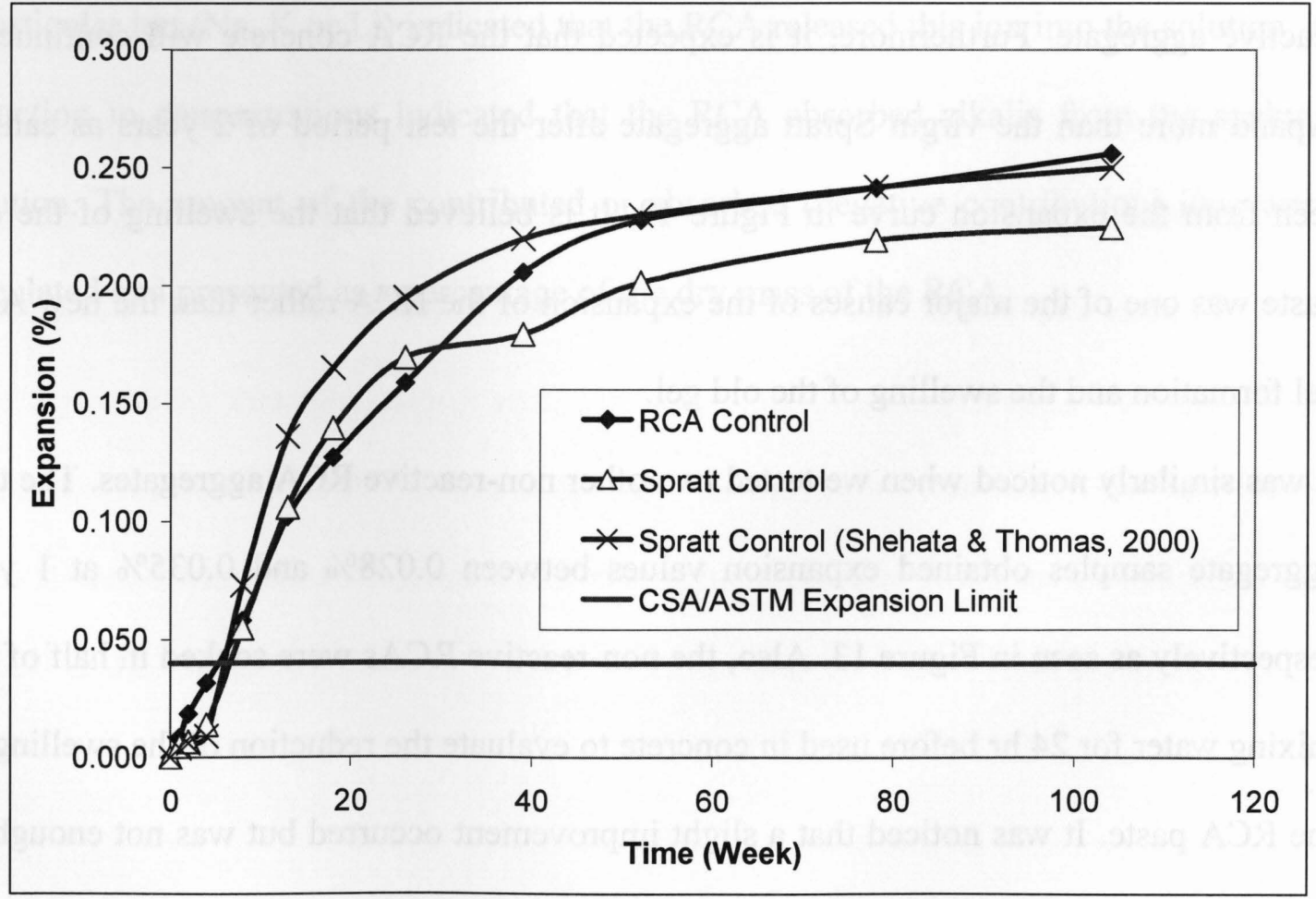

Figure 12: RCA and Spratt aggregate concrete prisms expansions 


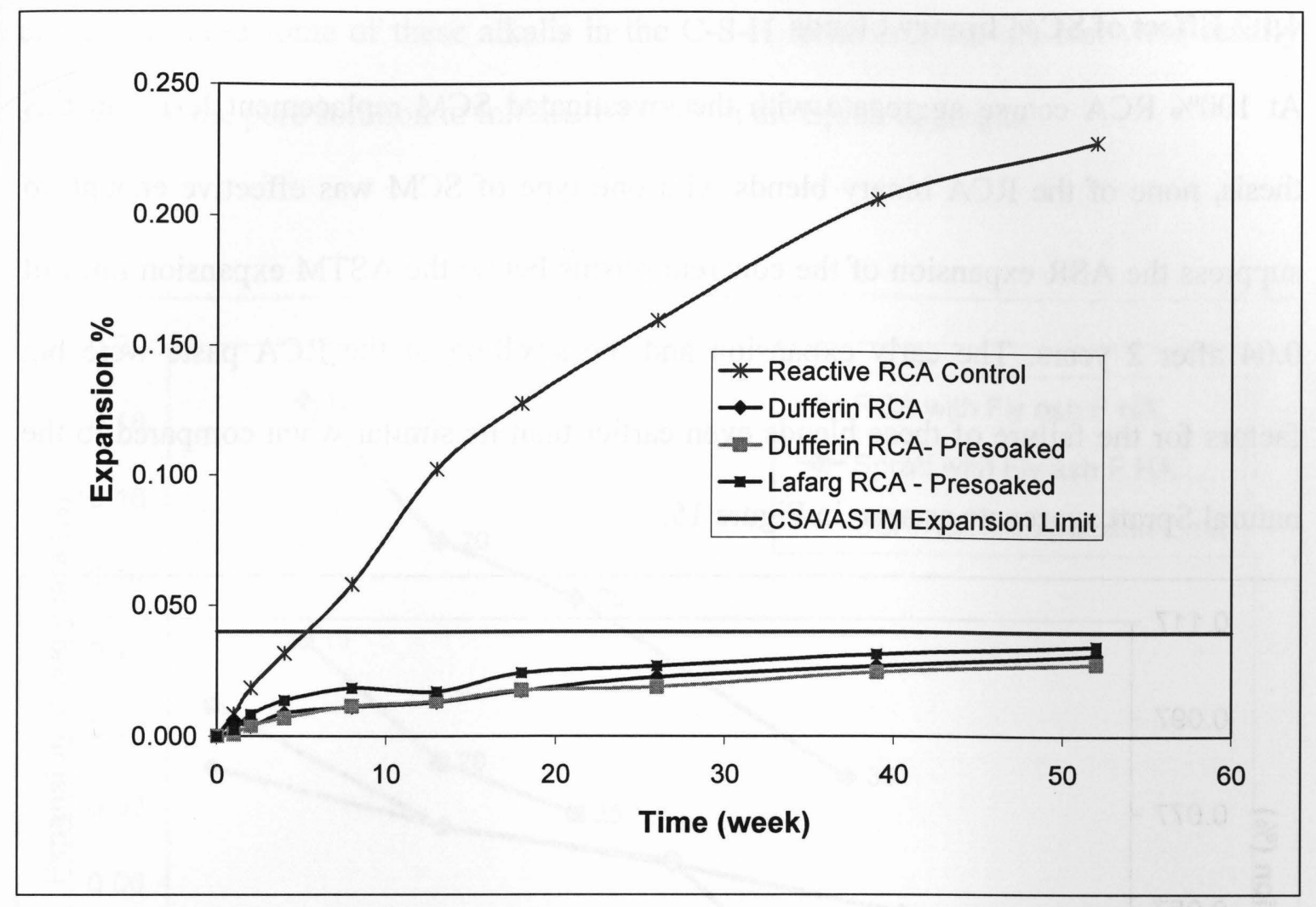

Figure 13: Comparison of the ASR concrete prisms expansions between the ASR affected RCA and two non Reactive RCAs

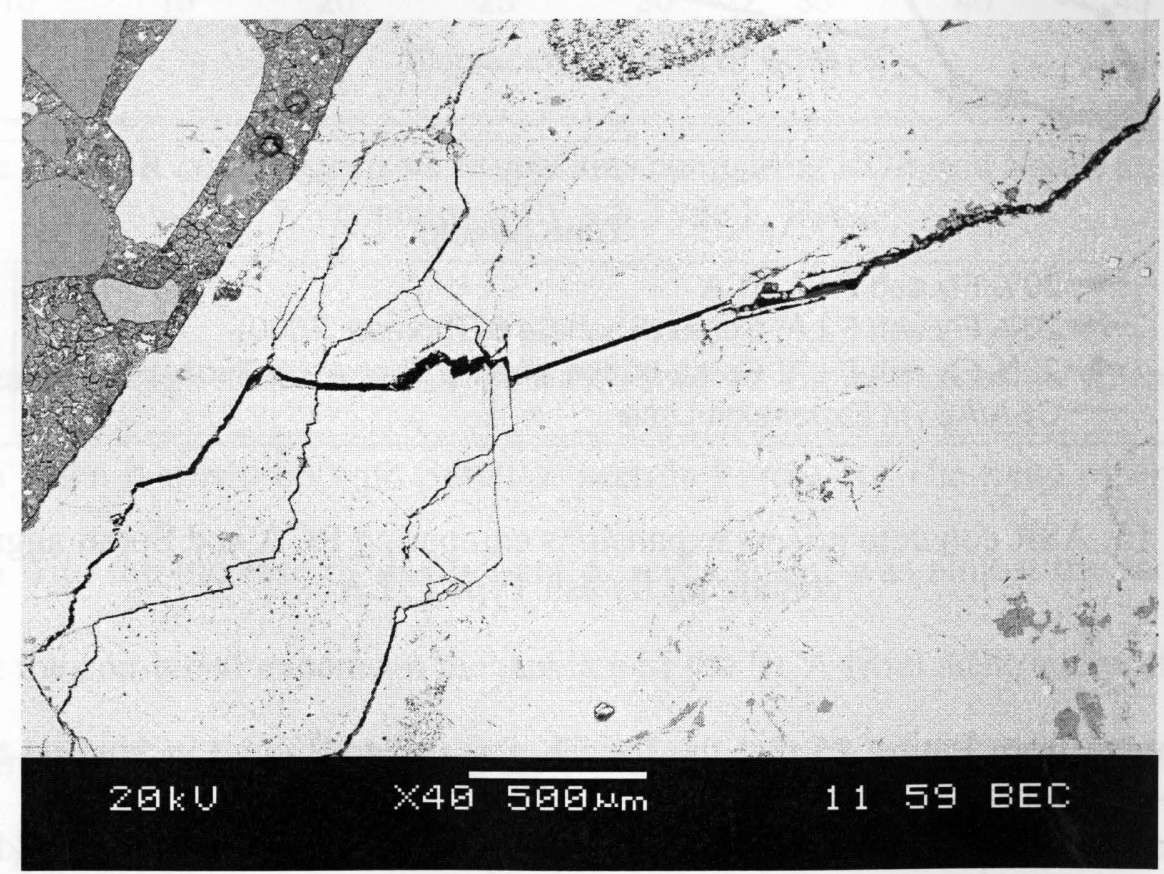

Figure 14: RCA Mechanical cracks 


\subsubsection{Effect of SCM binary blends}

At $100 \%$ RCA coarse aggregate with the investigated SCM replacement levels in this thesis, none of the RCA binary blends with one type of SCM was effective enough to suppress the ASR expansion of the concrete prisms below the ASTM expansion limit of 0.04 after 2 years. The early expansion and the swelling of the RCA paste were big factors for the failure of these blends even earlier than its similar when compared to the natural Spratt aggregate as seen in Figure 15.

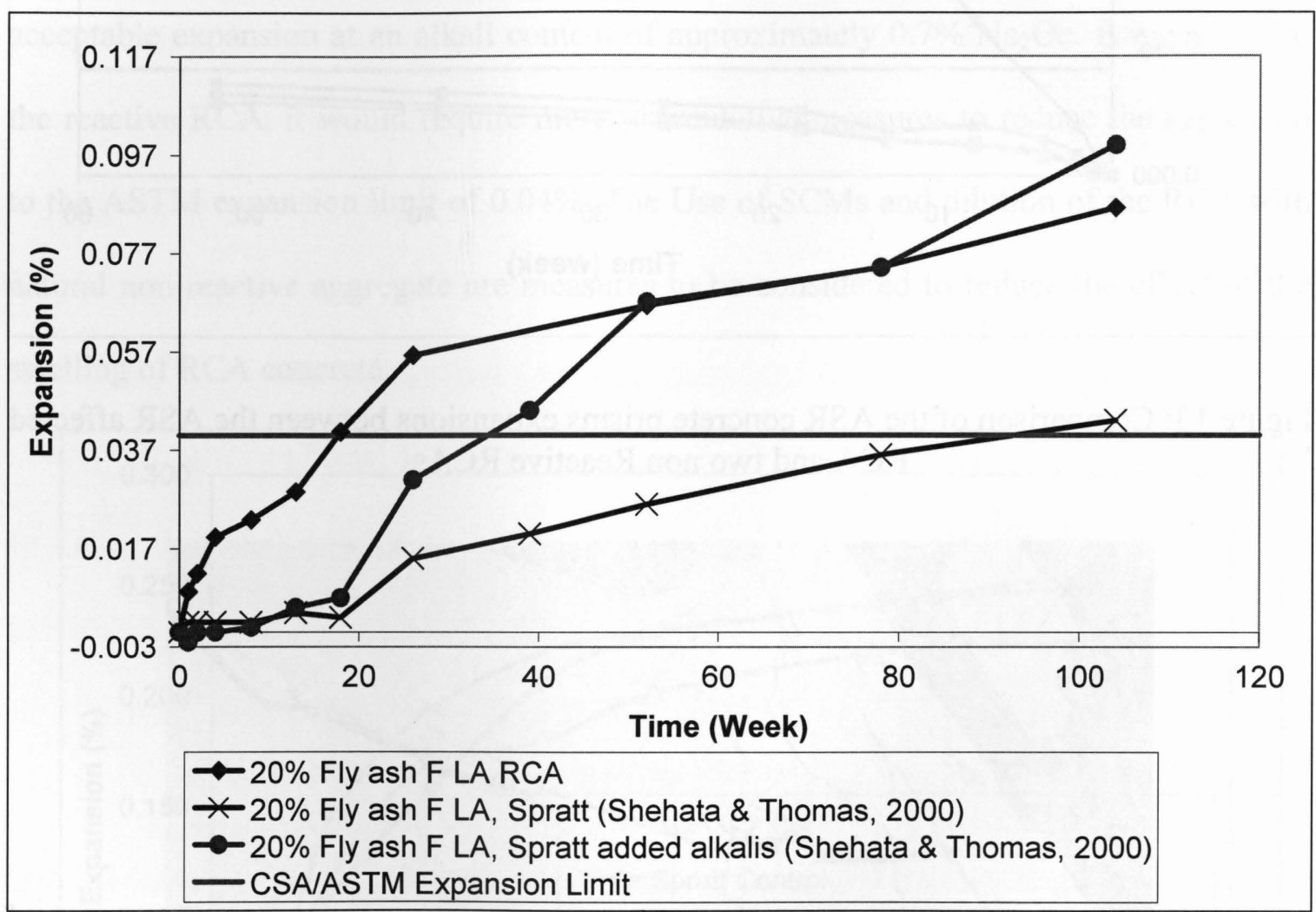

Figure 15: ASR concrete prisms expansions comparing RCA and Spratt aggregate containing fly ash Type F, LA

It is also noted from Figure 15 that the fly ash was more efficient in binding the alkalis when presented from the cementing material than when it was introduced as added alkalis to the mixing water. With the increased alkalinity from the added alkalis, the fly ash 
could only bind some of these alkalis in the C-S-H formation but the rest were readily available in the pore solution to initiate the ASR in the Spratt aggregate.

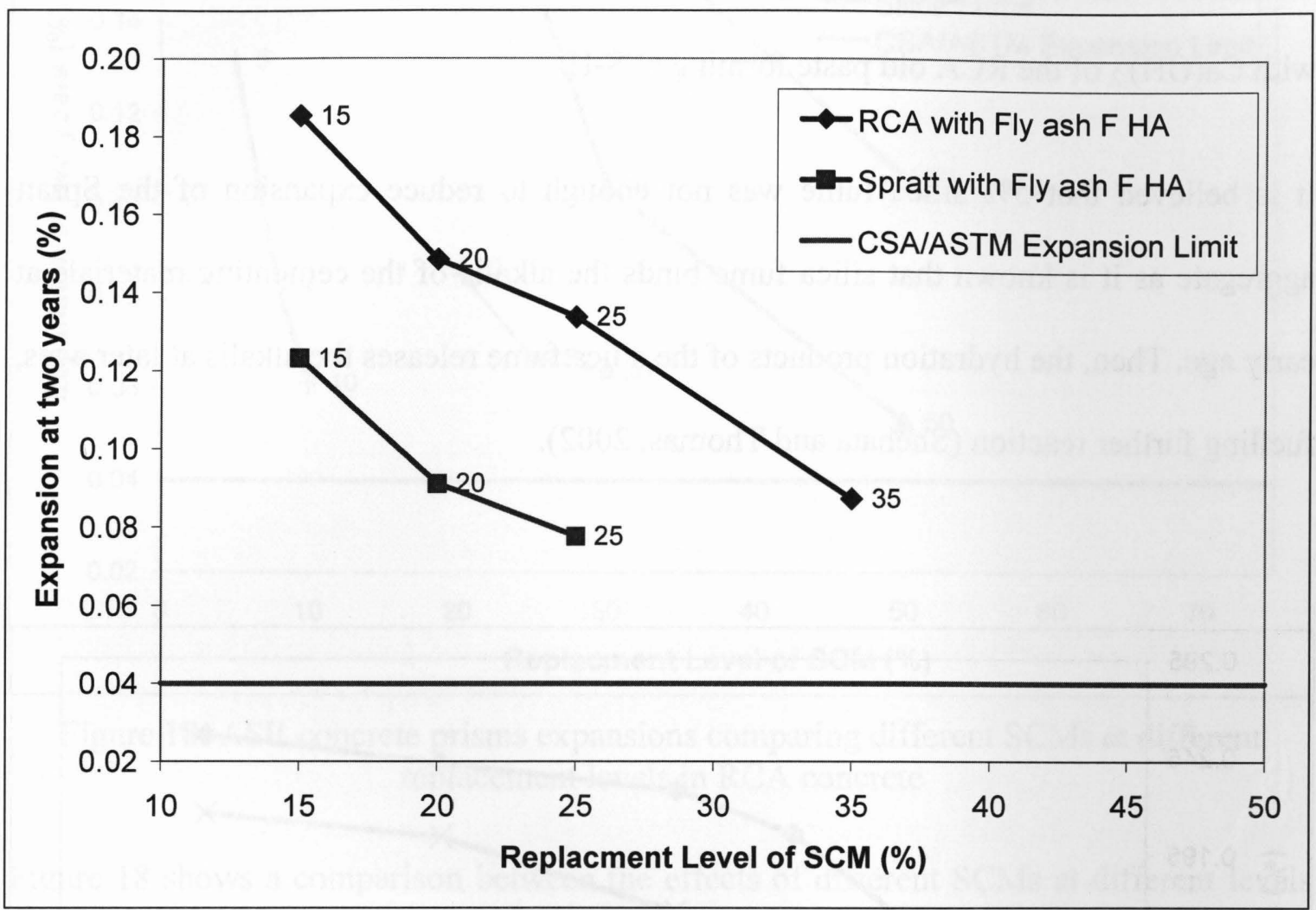

Figure 16: ASR concrete prisms expansions comparing RCA and Spratt aggregate containing fly ash Type F, HA

The low calcium high alkali fly ash type F HA showed higher expansion when used with RCA than when it was used with Spratt as seen in Figure 16. The trend of lowering the expansion with the increase of the amount of replacement was almost the same in both cases. But the combined expansion mechanism of the RCA from ASR and paste swelling is presenting a difference of $0.056 \%$ of the expansions.

However, this was not the case when compared the effect of $5 \%$ replacement with silica fume as seen in Figure 17. RCA showed higher expansion in the early age more than the 
Spratt aggregate as it was expected like the other SCMs. But after 26 weeks the Spratt aggregate showed higher expansion than the RCA. This could be attributed to the effect of the silica fume to enhance the permeability of the concrete with RCA reducing the amount of water reaching the aggregate and hence, its swelling. The silica tends to bind with $\mathrm{Ca}(\mathrm{OH})_{2}$ of the RCA old paste forming C-S-H.

It is believed that $5 \%$ silica fume was not enough to reduce expansion of the Spratt aggregate as it is known that silica fume binds the alkalis of the cementing materials at early age. Then, the hydration products of the silica fume releases the alkalis at later ages, fuelling further reaction (Shehata and Thomas, 2002).

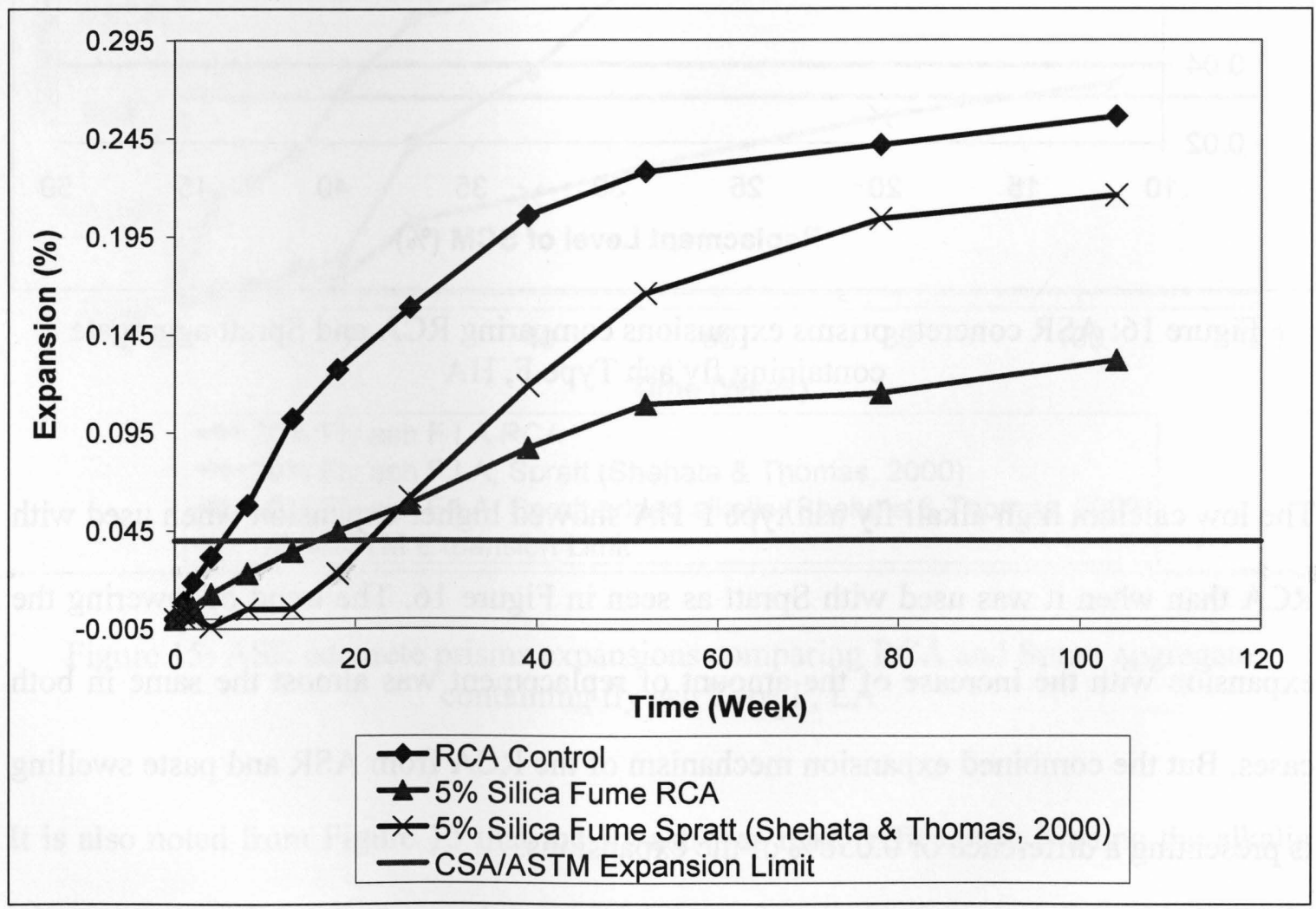

Figure 17: ASR concrete prisms expansions comparing RCA and Spratt aggregate containing $5 \%$ silica fume 


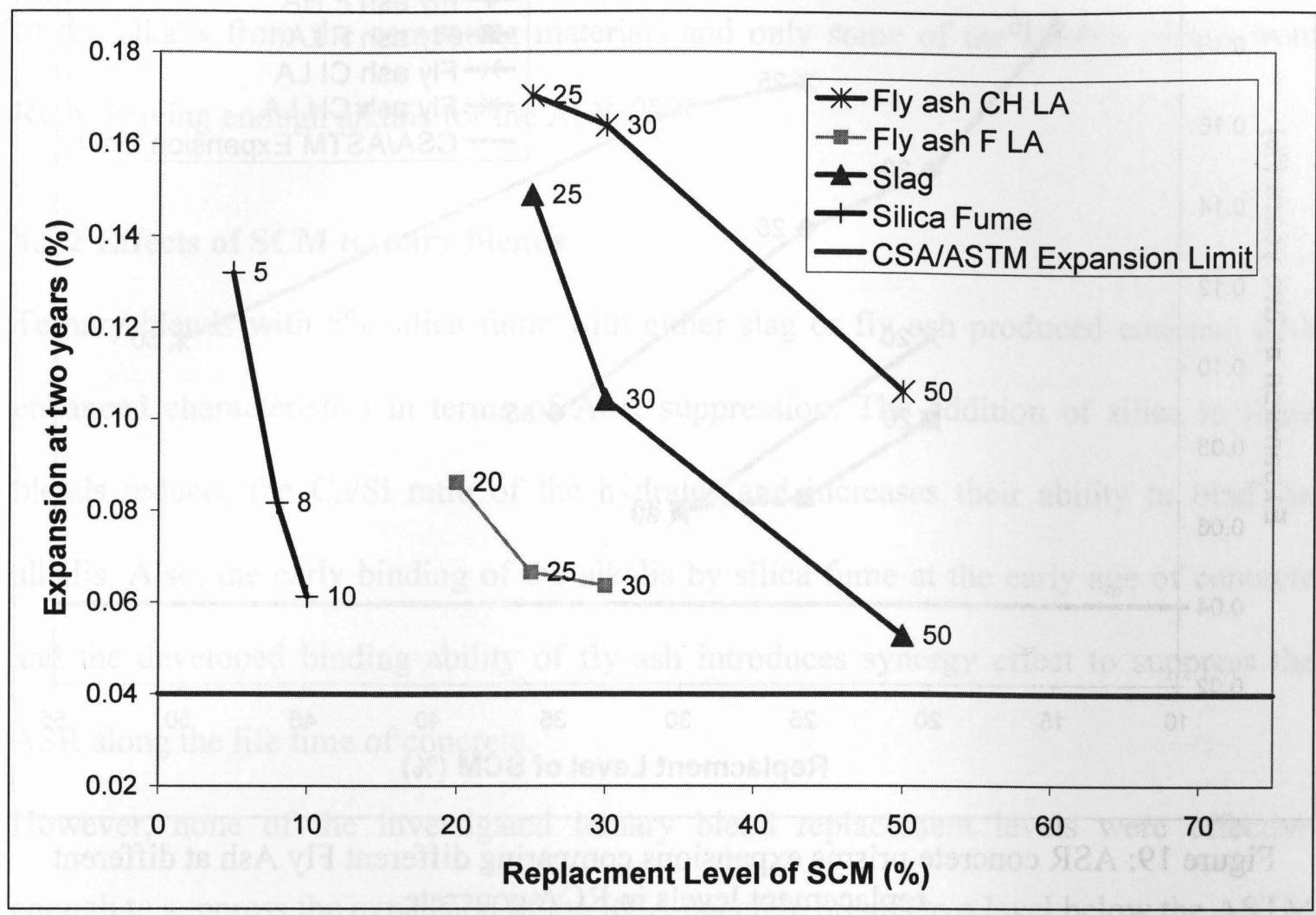

Figure 18: ASR concrete prisms expansions comparing different SCMs at different replacement levels in RCA concrete

Figure 18 shows a comparison between the effects of different SCMs at different levels of replacements to suppress the ASR expansion in RCA concrete prisms. It can be deduced that a replacement level of almost $60 \%$ of slag would be required to maintain the expansion of the RCA concrete prisms at acceptable limit.

A $10 \%$ replacement with silica fume was not sufficient to reduce the expansion and a higher replacement level may be required. This may not be suitable due the low workability of such produced concrete with RCA. However, it still may not be effective to suppress the swelling effect of the RCA concrete. Also, it may not be suitable from the workability prospective of the RCA concrete. 


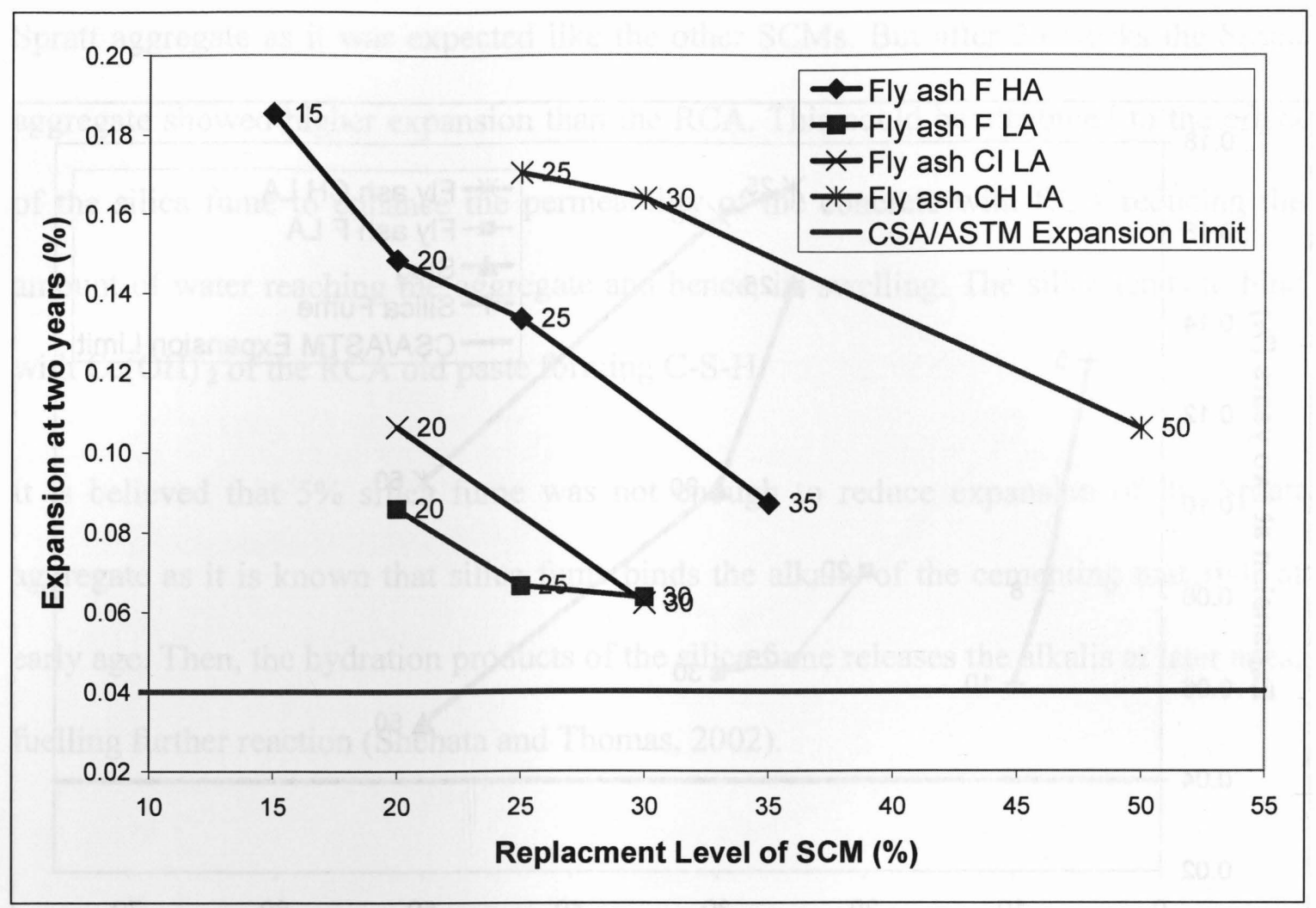

Figure 19: ASR concrete prisms expansions comparing different Fly Ash at different replacement levels in RCA concrete

Figure 19 shows the effect of different types of fly ashes at different replacement levels in ASR affected RCA concrete. The fly ashes with the low and medium calcium and low alkali content showed superior performance than the high calcium and high alkali fly ashes at 2 years. As previously reported by Shehata and Thomas (2000), the lower the calcium content of the fly ash the better its efficacy to suppress ASR. Also, the alkalis from the ashes contribute partially to raise the alkalinity of the pore solution. Hence, the high alkali fly ashes are less effective in reducing alkalis available for ASR in concrete when compared to its counterpart with low alkalis content. Fly ash binds alkalis from the pore solution in their C-S-H, but the high alkalis concentrations contained in the RCA aggregate are readily consumed by the reactive silica to form the ASR gel in the presence 
of the high calcium of the old paste. On other words, the binding was only viable to some of the alkalis from the cementing materials and only some of the soluble alkalis from RCA, leaving enough alkalis for the ASR.

\subsubsection{Effects of SCM ternary blends}

Ternary blends with $5 \%$ silica fume with either slag or fly ash produced concrete with enhanced characteristics in terms of ASR suppression. The addition of silica to these blends reduces the $\mathrm{Ca} / \mathrm{Si}$ ratio of the hydrates and increases their ability to bind the alkalis. Also, the early binding of the alkalis by silica fume at the early age of concrete and the developed binding ability of fly ash introduces synergy effect to suppress the ASR along the life time of concrete.

However, none of the investigated ternary blend replacement levels were effective enough to suppress the expansion of the RCA concrete prisms to a level below the ASTM expansion limit. Though, the Ternary blends with $5 \%$ silica and $25 \%$ fly ash CI LA marginally met the expansion limit as can be seen from Figure 20 .

Similar replacement levels of $25 \%$ and $30 \%$ of fly ash F LA with $5 \%$ silica are still under investigation and only complete $1 \frac{1}{2}$ year of the test period. These samples had expansion of $0.04 \%$ and $0.037 \%$ respectively after 78 weeks and are expected to be within the same range of expansion just above $0.04 \%$ as seen in Figure 20

Also, a replacement level of $45 \%$ slag with $5 \%$ silica was investigated and produced an expansion of $0.049 \%$ after 78 weeks which show a minimal improve in reducing expansion compared to the mix of $40 \%$ slag with $5 \%$ silica as seen in Figure 20. 


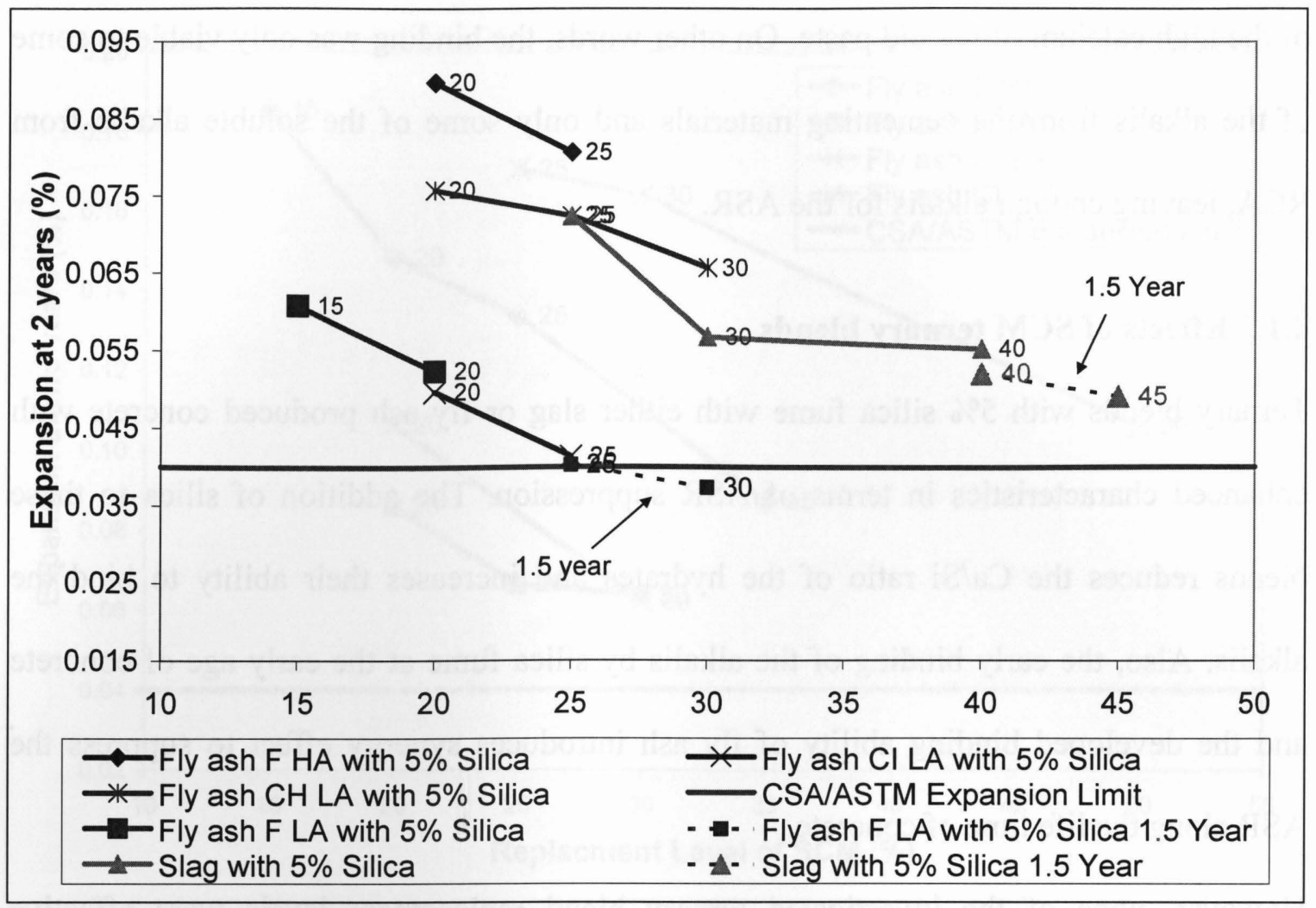

Figure 20: ASR concrete prisms expansions comparing different Fly Ash at different ternary blends replacement levels in RCA concrete

The addition of $5 \%$ silica with slag to blends reduced the expansion of the concrete prism to $50 \%$ of the samples with only slag replacements as seen in Figure 21 . But, it is noted that the expansion reduction rate when $5 \%$ silica was added to $25 \%$ and $30 \%$ of slag is much higher than when it was added to $40 \%$ slag or more.

The high calcium low alkali fly ash performance was much improved by adding $5 \%$ silica to these blends. The reduction of expansion was almost $60 \%$ of the samples with fly ash only. Though, it was not enough to suppress the expansion below the ASTM limit. 


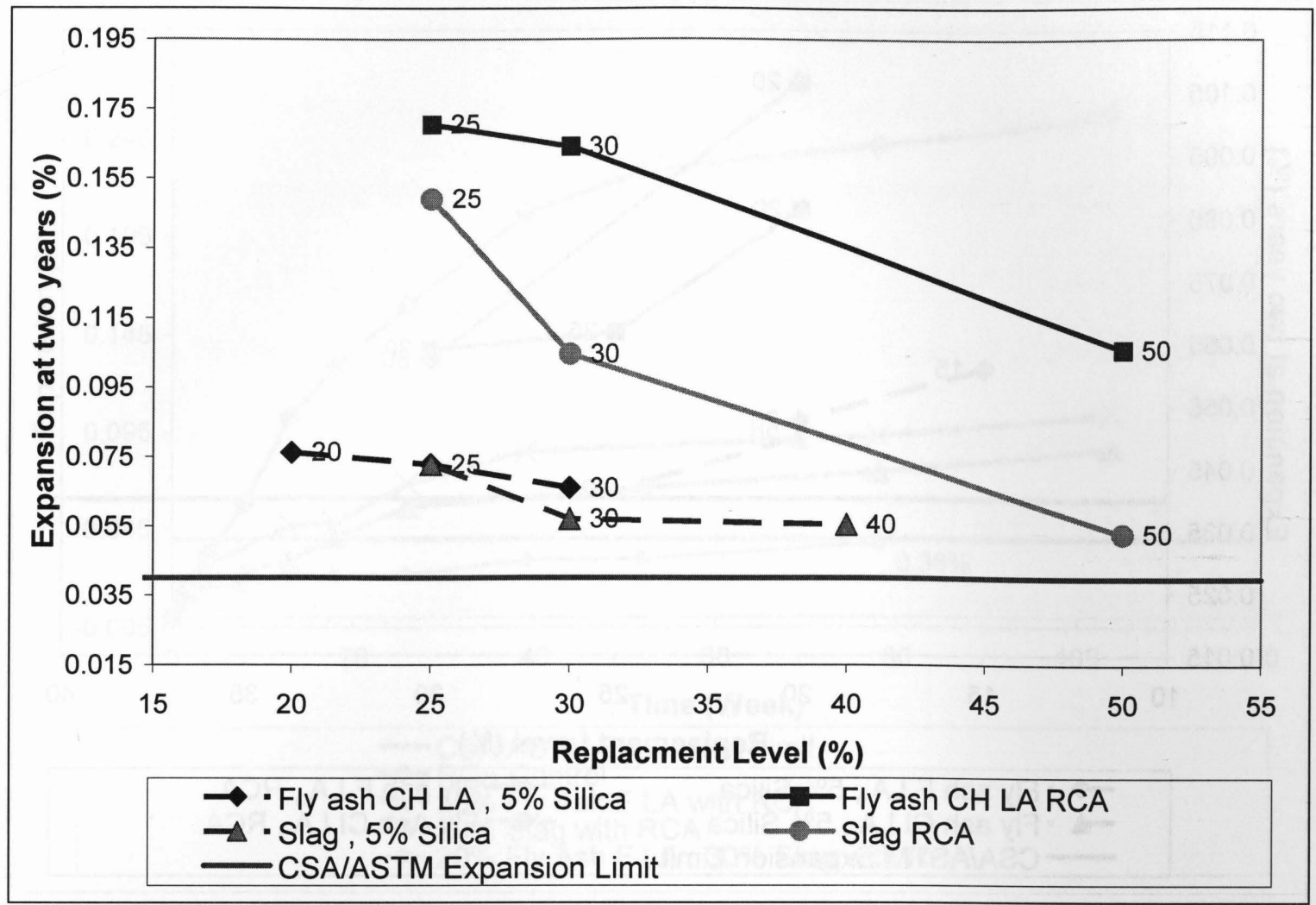

Figure 21: ASR concrete prisms expansions comparing ternary blends versus binary blends in RCA concrete

Figure 22 shows the improvement of adding $5 \%$ silica fume to both moderate and low calcium fly ashes in the ternary blends. The expansion reduction was even higher in case of the moderate calcium low alkali fly ash type CI than the low calcium fly ash type F. Both of these fly ashes have low alkali content as seen in Table 3. But, this may be attributable to the fineness of the fly ash type CI that enabled it to perform better when reducing the overall $\mathrm{Ca} / \mathrm{Si}$ ratio of the blend by adding $5 \%$ silica. 


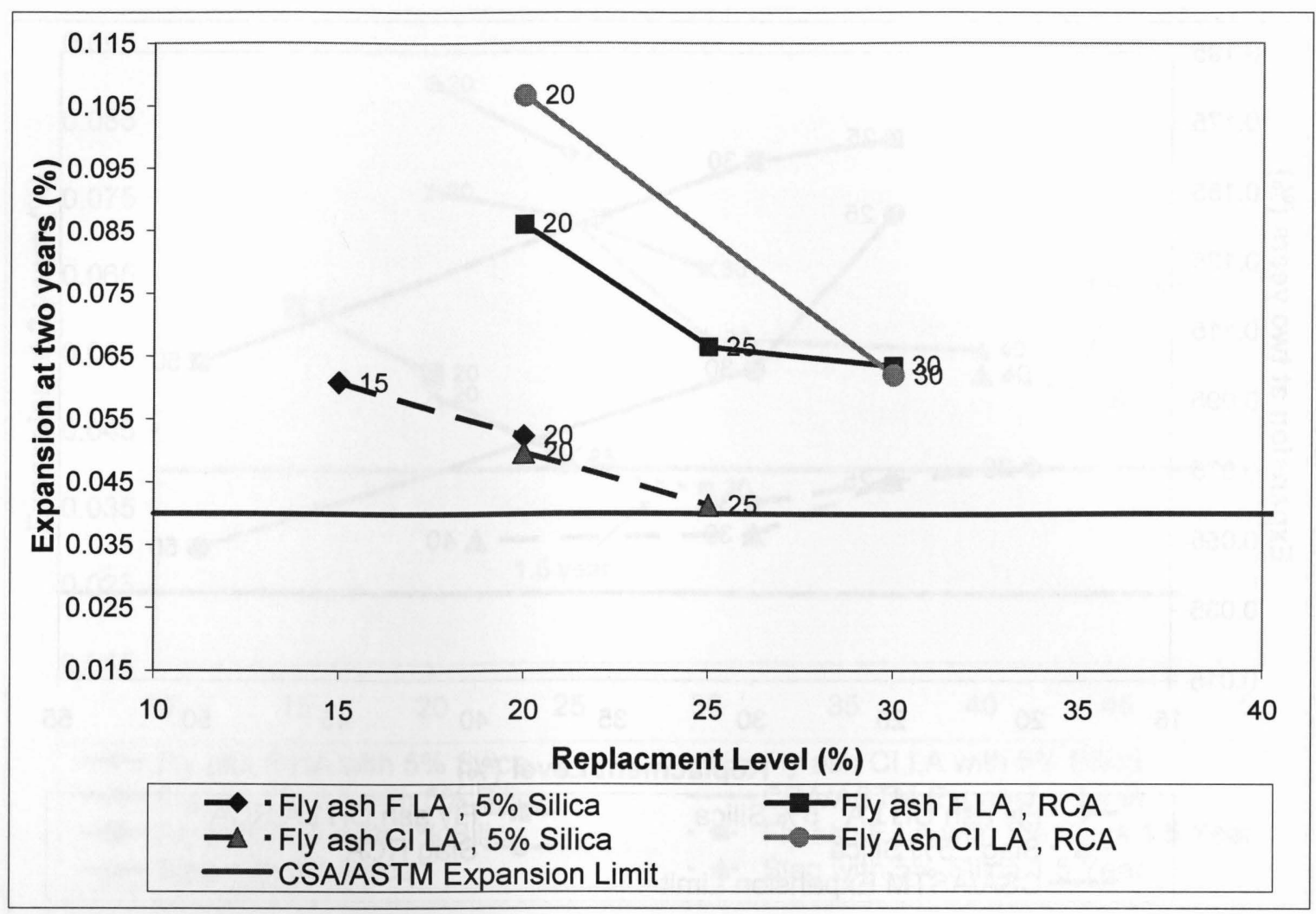

Figure 22: ASR concrete prisms expansions comparing ternary blends versus binary blends in RCA concrete

Figure 23 shows another combination of ternary blends that was investigated in this study using $20 \%$ fly ash F LA with $30 \%$ slag replacement. The concrete prisms expansions didn't complete the test period but it provides a good indication of the expected success that may be obtained from this blend. The synergy shown in suppressing the expansion in the concrete prisms gives hope that this combination may produce RCA concrete within the acceptable expansion limit of $0.04 \%$ after 2 years. 


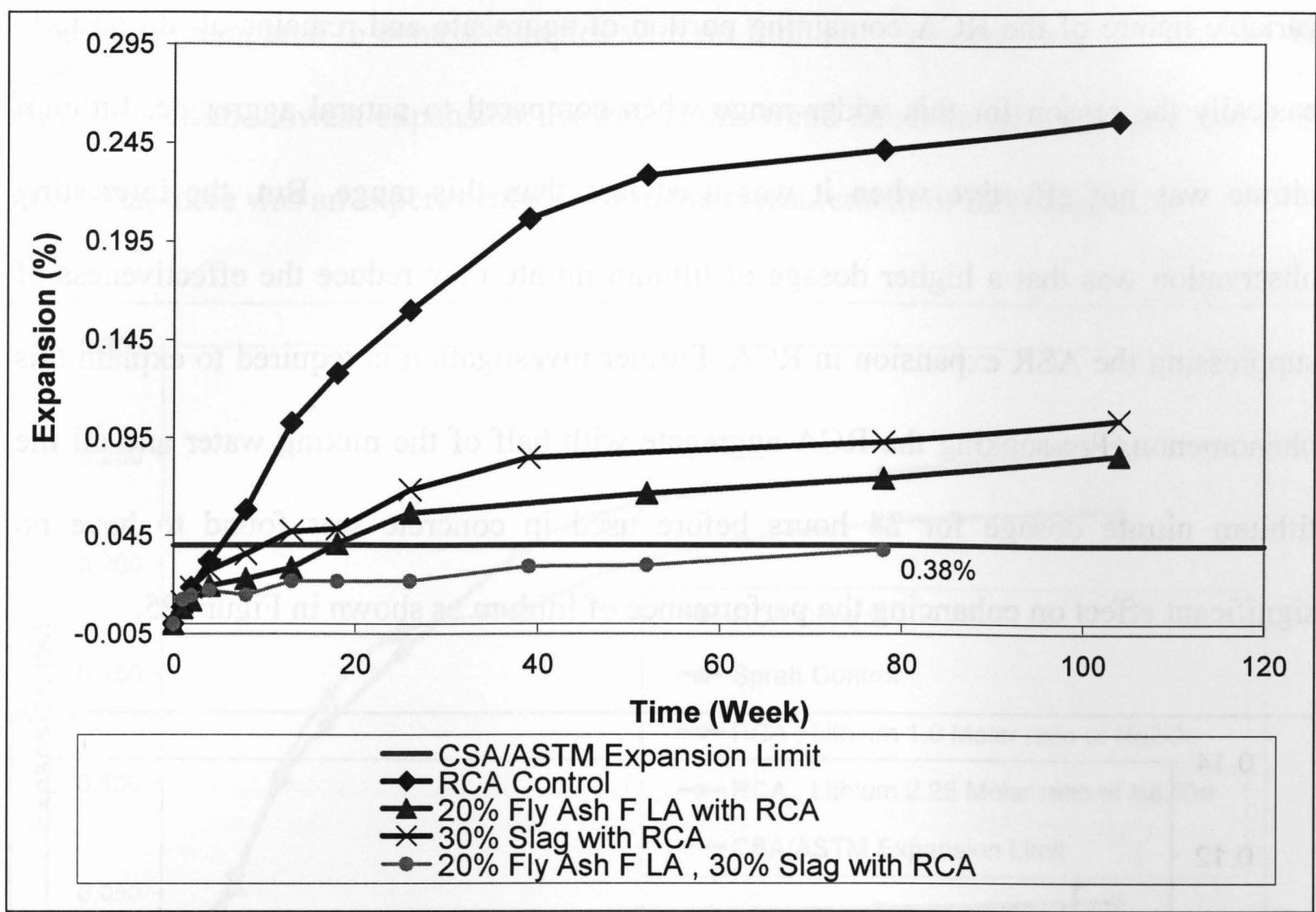

Figure 23: ASR concrete prisms expansions comparing ternary blends versus binary blends in RCA concrete

\subsection{ASR concrete prisms test for blends containing lithium nitrate}

\subsubsection{Effect of lithium nitrate on RCA reactivity}

Lithium nitrate was known to be effective in suppressing the ASR reaction in some natural reactive aggregates. The appropriate dosage of Lithium was found to be varying from one reactive aggregate to the other with no correlation with the aggregate reactivity or the petrographic nature of the aggregate. In some research work on natural aggregate the optimum dosage was found to lie between 0.74 and $1.04[\mathrm{Li}]$ : $[\mathrm{Na}+\mathrm{K}]$ molar ratios (Tremblay et al, 2007). The investigated ASR affected RCA was found to require a higher molar ratio to suppress the expansion in ASR concrete prisms as seen in Figure 24. The range of the Lithium nitrate dosage required varied between 1 to 2 molar ratios. The 
variable nature of the RCA containing portion of aggregate and remains of old paste is basically the reason for this wider range when compared to natural aggregate. Lithium nitrate was not effective when it was used less than this range. But, the interesting observation was that a higher dosage of lithium nitrate may reduce the effectiveness of suppressing the ASR expansion in RCA. Further investigation is required to explain this phenomenon. Pre-soaking the RCA aggregate with half of the mixing water and all the lithium nitrate dosage for 24 hours before used in concrete was found to have no significant effect on enhancing the performance of lithium as shown in Figure 25.

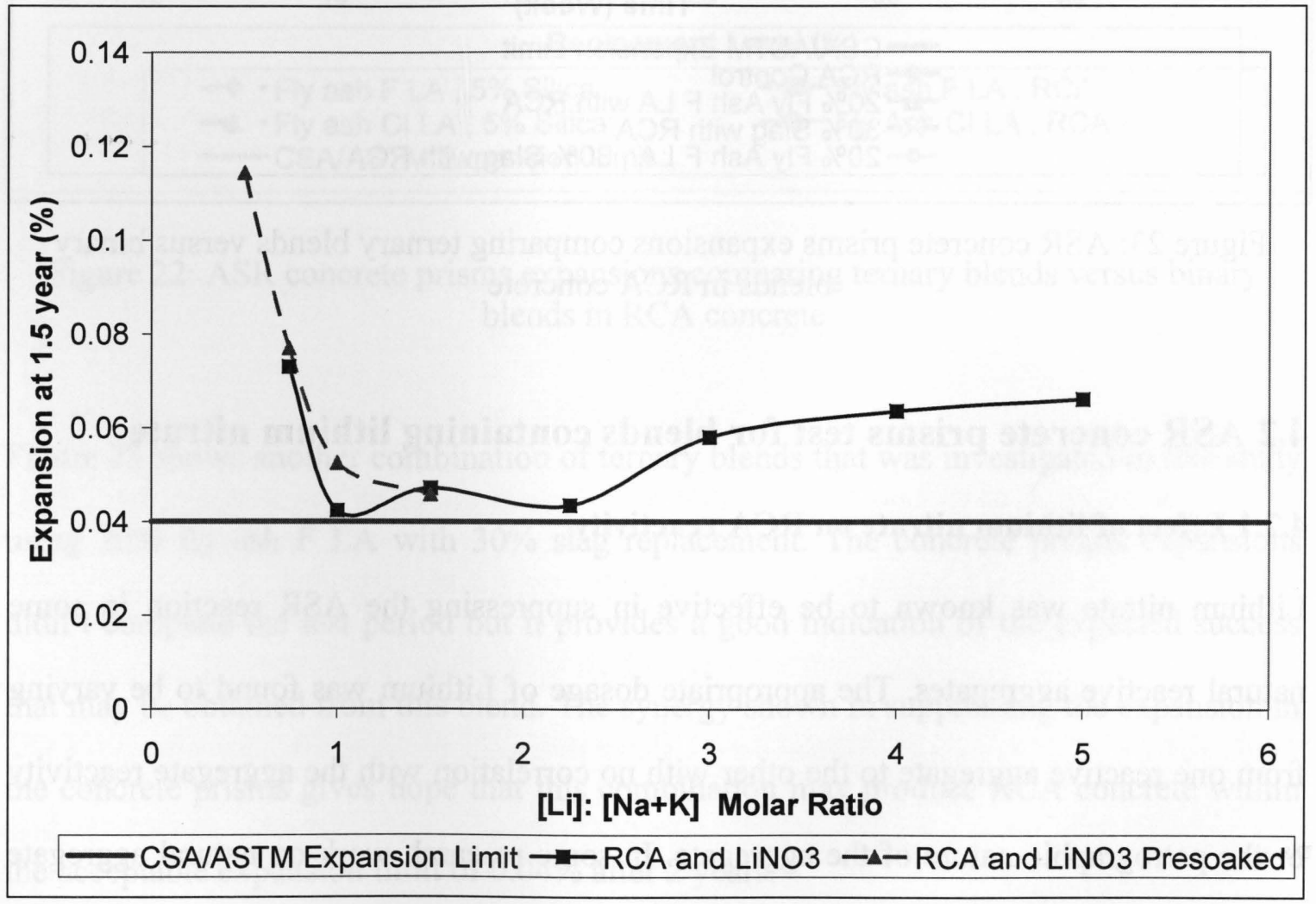

Figure 24: ASR concrete prisms expansions of RCA with different Molar Ratio of [Li]: $[\mathrm{Na}+\mathrm{K}]$

All the tested lithium dosages resulted in concrete expansion higher than the $0.04 \%$ at the age of 78 weeks. However, there was a considerable reduction of the concrete prism 
expansions compared to control samples with no lithium. The sample at $1: 1 \mathrm{Li}: \mathrm{Na}+\mathrm{K}$ ratio showed the lowest expansion. However, this trend needs to be confirmed and it is likely that there was an experimental error in the measurement of this sample.

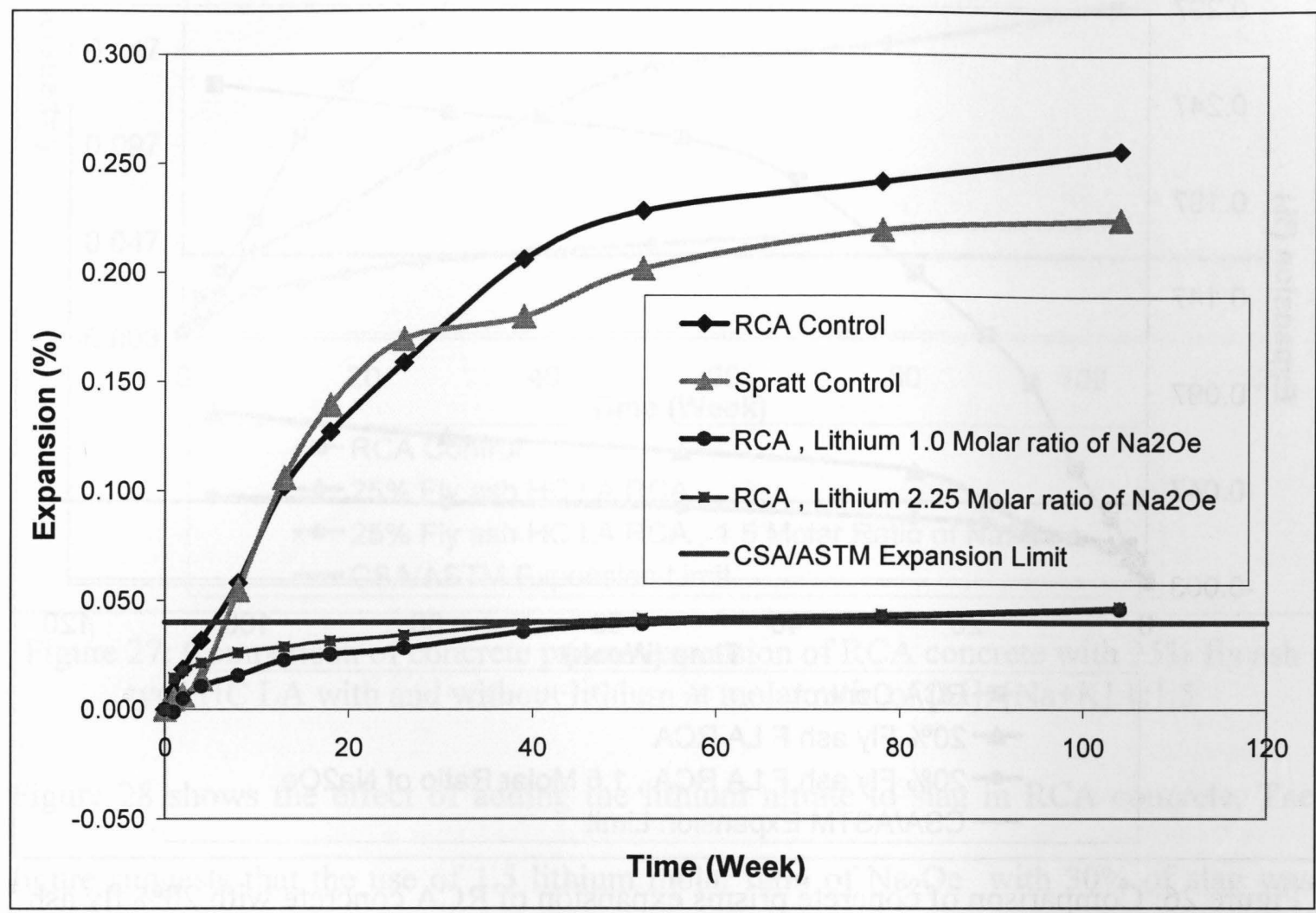

Figure 25: Comparison of concrete prisms expansion of RCA concrete with and without lithium at molar ratio of $[\mathrm{Li}]:[\mathrm{Na}+\mathrm{K}] 1: 1$

\subsubsection{Effect of using lithium nitrate with SCMs}

As discussed previously, fly ashes of low and high calcium content with low alkalis were not capable of suppressing the expansion of the RCA to the specified limit when used in binary blends. The use of lithium nitrate in combination of these fly ashes provided a synergy suppression effect on the concrete prisms expansion; the expansion was less than $50 \%$ of the samples with fly ash alone. Figure 26 shows the comparison of using $20 \%$ of Fly ash type F LA with and without lithium. The expansion of the sample with low 
calcium fly ash and lithium can be considered to marginally meet the $0.04 \%$ expansion limit. Perhaps higher level of either materials or using fly ash of higher fineness may be able to reduce the expansion to lower than $0.04 \%$.

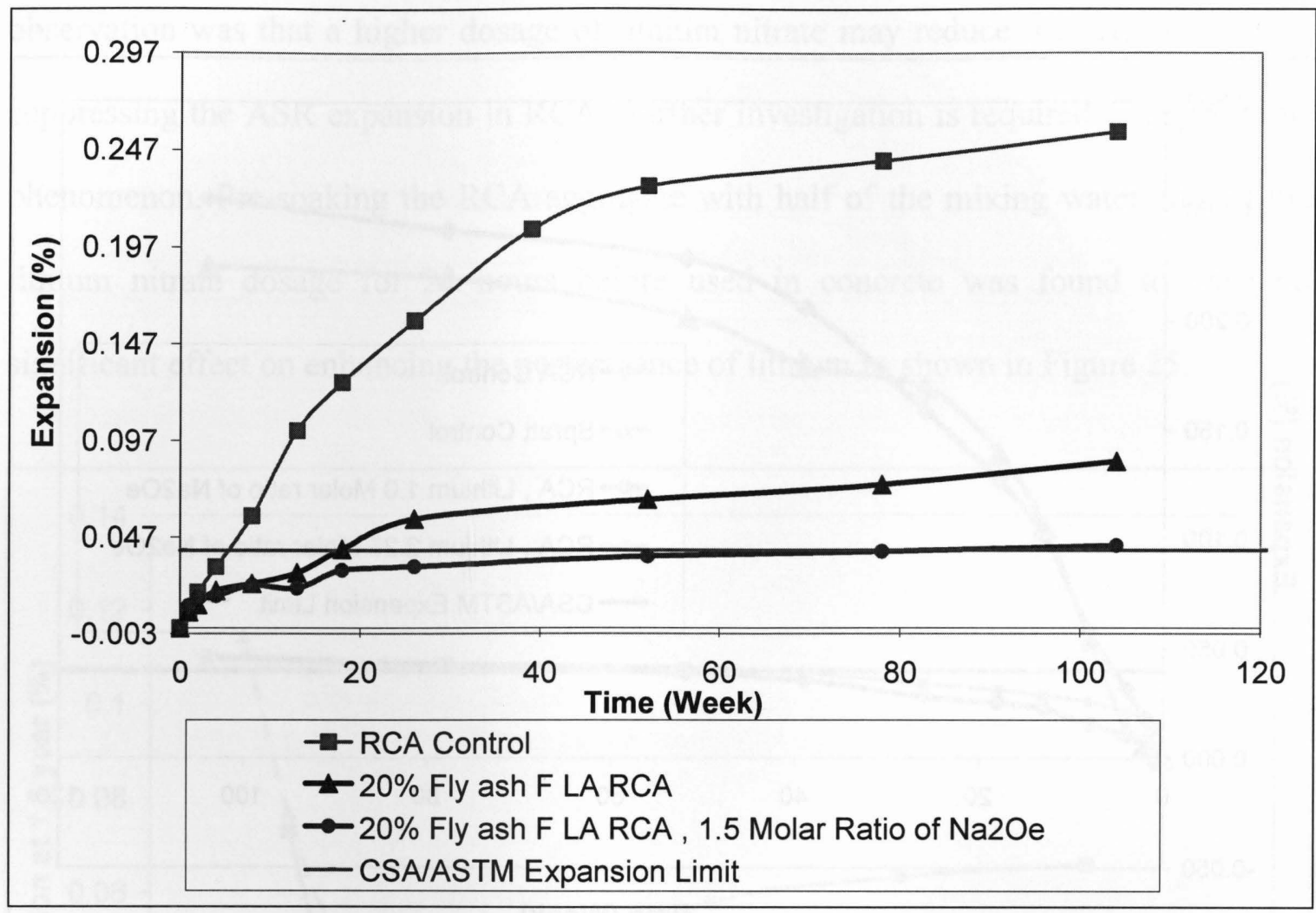

Figure 26: Comparison of concrete prisms expansion of RCA concrete with $20 \%$ fly ash type F LA with and without lithium at molar ratio of [Li]: $[\mathrm{Na}+\mathrm{K}]$ 1:1.5

Lithium and high calcium fly ash was not effective in limiting the expansion to lower or close to $0.04 \%$. However, a significant reduction in the expansion was achieved when lithium (at a ratio of 1:1.5) was added to high-calcium fly ahs as shown in Figure 27. 


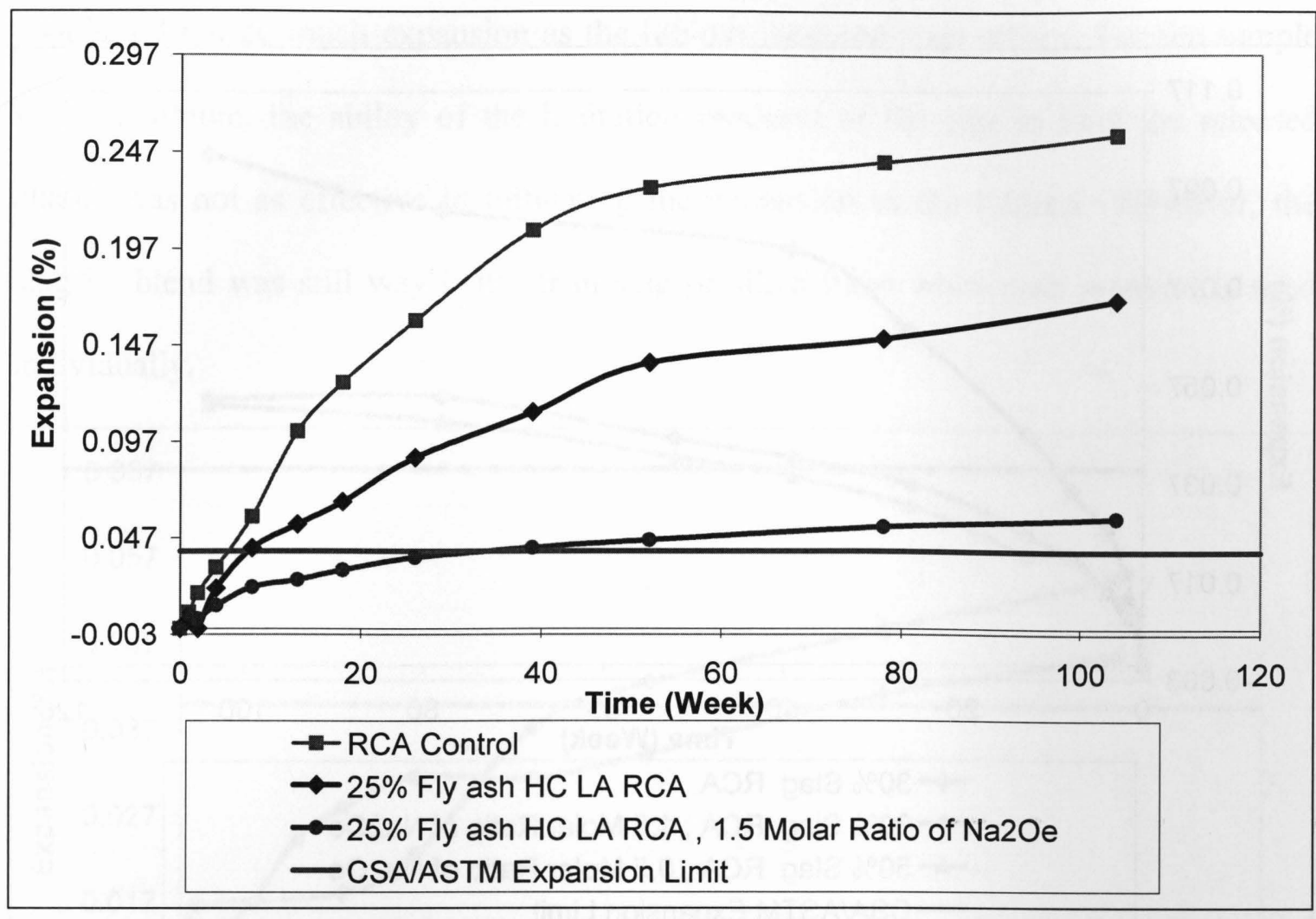

Figure 27: Comparison of concrete prisms expansion of RCA concrete with $25 \%$ fly ash type HC LA with and without lithium at molar ratio of [Li]: [Na+K] 1:1.5

Figure 28 shows the effect of adding the lithium nitrate to slag in RCA concrete. The figure suggests that the use of 1.5 lithium molar ratio of $\mathrm{Na}_{2} \mathrm{Oe}$ with $30 \%$ of slag was almost of the same effect as using only 0.5 lithium molar ratio with $50 \%$ slag.

The Lithium use in combination with SCMs was not effective in lowering the expansion to acceptable limit. It is believed that the high alkali concentrations retained in the RCA and the swelling of the old gel are predominantly causing the inability of these preventive measures to counteract the expansion. More effective measures may require more lithium and higher SCMs replacement levels to control that expansive action of the RCA. However, higher levels may not be practical from the economical standpoint. Also, as it was mentioned previously in the literature review, excess use of SCM can lead to other deleterious effects of salt scaling. 


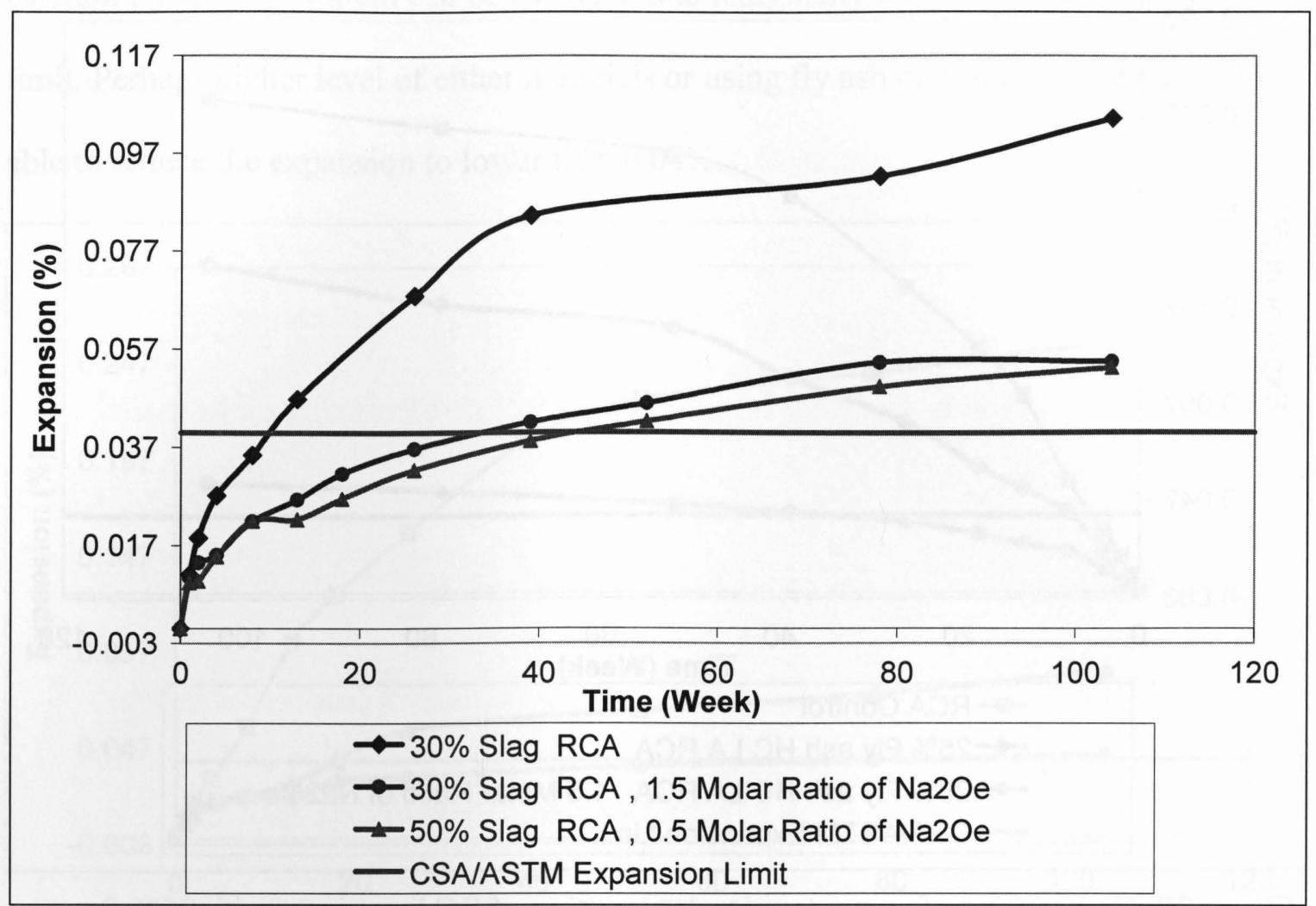

Figure 28: Comparison of concrete prisms expansion of RCA concrete with Slag replacements with and without lithium

Ternary blends with $5 \%$ silica and $30 \%$ slag was also investigated with and without lithium as seen in Figure 29. It was expected that the addition of $5 \%$ silica may be effective in lowering the permeability and pore solution alkalinity of the RCA-concrete and reduces its expansion furthermore than the binary blends. However, this also was not enough to counteract the expansion of the RCA concrete prisms to acceptable limits.

The early expansion of this blend was higher when lithium was used up to 28 weeks. Afterwards, the lithium sample maintained a steady rate of expansion while the nolithium sample slid to a little higher expansion. Then, both maintained the same rate of expansion. It may be deduced that silica tend to release alkalis at a later age and bind with the released $\mathrm{Ca}(\mathrm{OH})_{2}$ of the hydration products. At the presence of lithium, the released 
alkalis did not do much expansion as the lithium hindered their effects. For the sample without lithium, the ability of the hydration products of the slag to bind the released alkalis was not as effective in mitigating the expansion as the lithium. However, the slag/SF blend was still way better than slag or silica fume when each material is used individually.

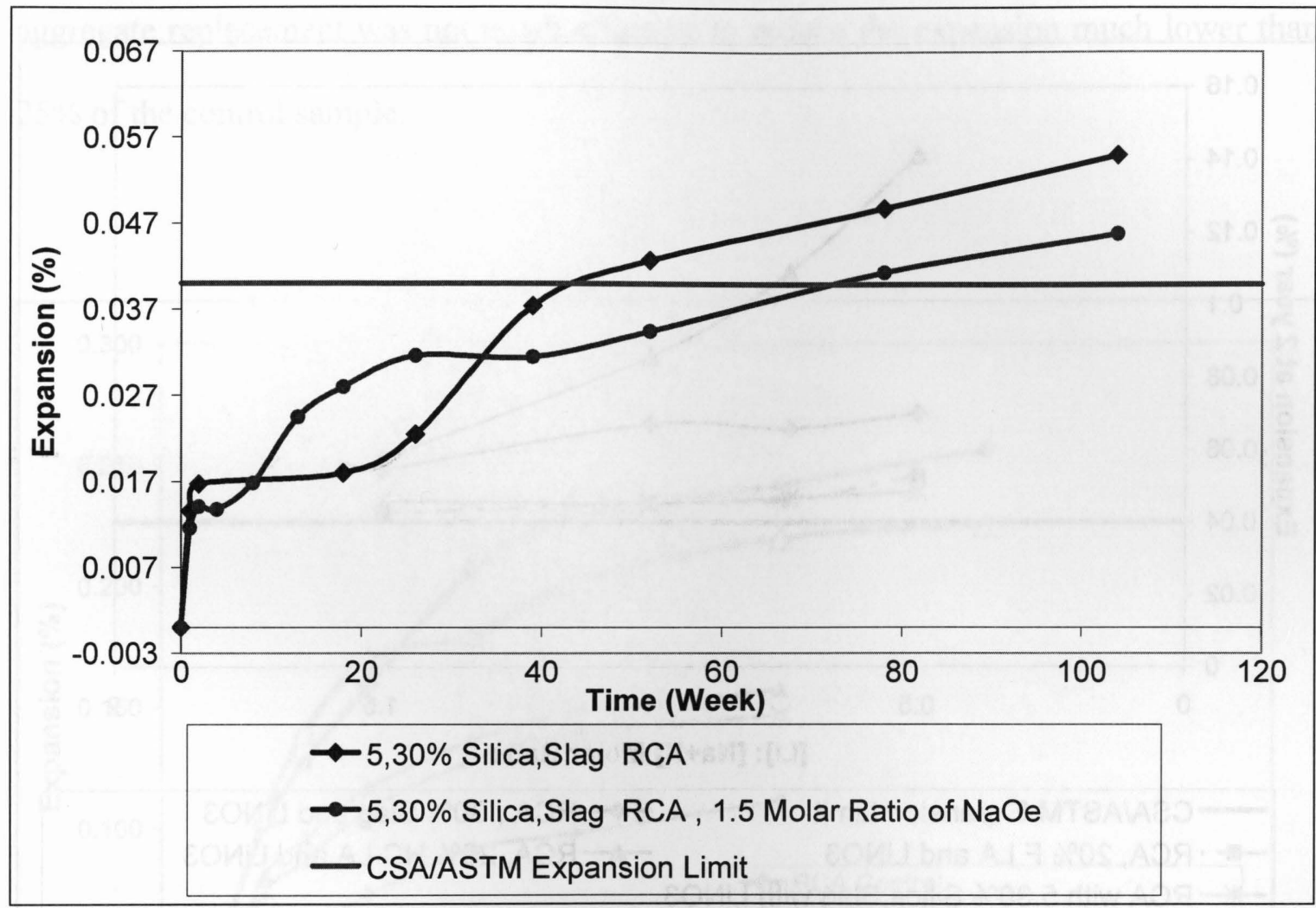

Figure 29: Comparison of concrete prisms expansion of RCA concrete with ternary blend of $5 \%$ silica and $30 \%$ slag replacements with and without lithium

Figure 30 provides a comparison of the efficacy of some SCM blends used with lithium at different molar ratios of $[\mathrm{Li}]:[\mathrm{Na}+\mathrm{K}]$ of the Portland cement. The figure shows that the addition of lithium was not effective with the silica/slag combination. Also, it shows that introducing lithium nitrate to $30 \%$ slag or $20 \%$ fly ash F LA slightly reduced the expansion, particularly with the increase of the lithium nitrate added to the mix. However, with the high calcium fly ash with low alkali HC LA, the expansion was 
dramatically improved with increasing the lithium dosage. It is the author's opinion that this may be attributed to the less ability of the high calcium fly ahs to bind the lithium in its hydration products compared to the other types of SCMs. This synergy effect of lithium and this type of fly ash reducing the available soluble alkalis in the system enhanced the reduction of expansion due ASR.

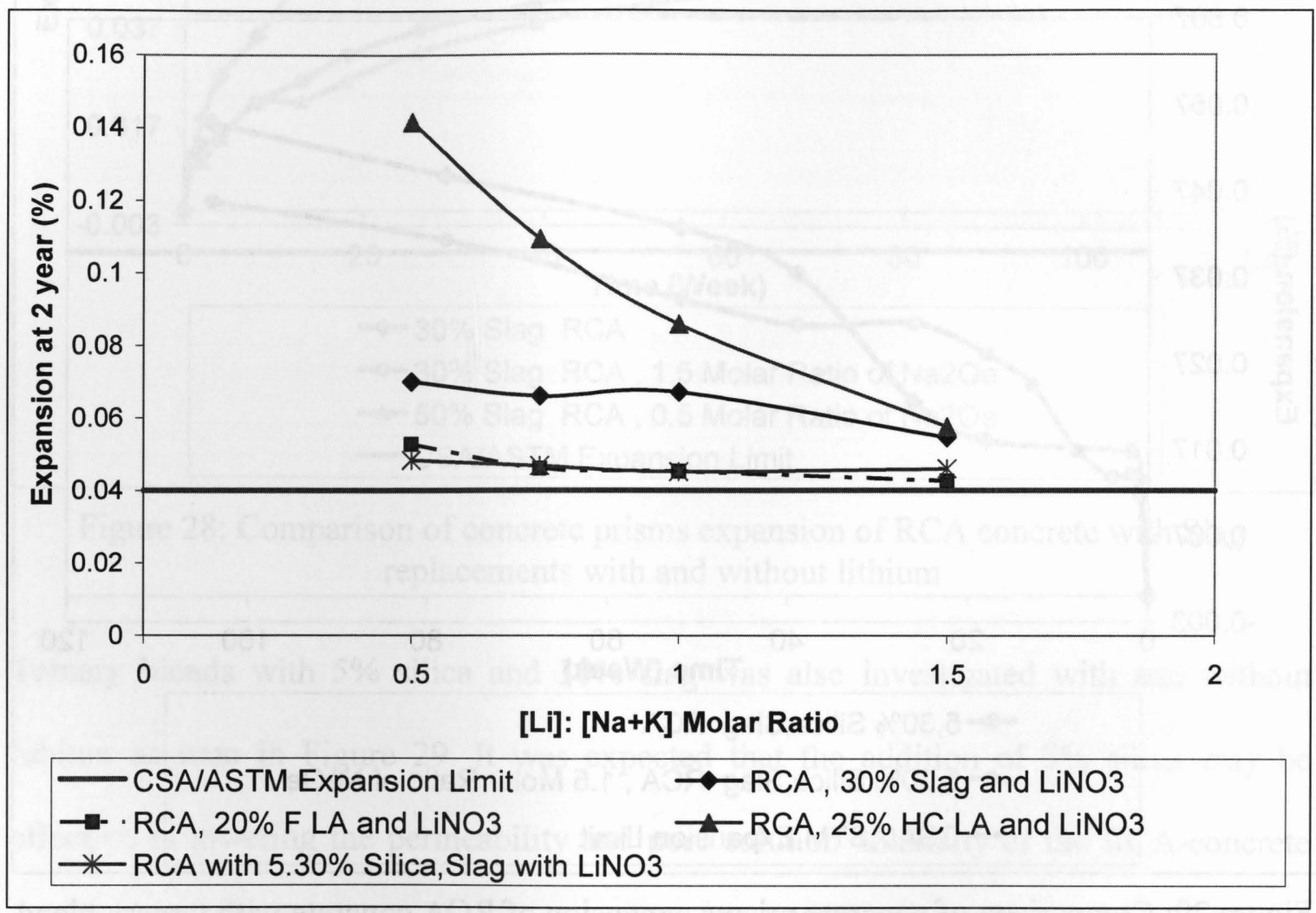

Figure 30: Comparison of concrete prisms expansion of RCA with fly ashes and slag binary and ternary blends at different molar ratio of [Li]: [Na+K]

\subsubsection{Dilution effect of the reactive aggregate}

As seen from the concrete prism expansions, the SCMs and the lithium nitrate were not enough to suppress the expansions in concrete containing reactive RCA. Hence, dilution of the aggregate was investigated to reduce the source of the deleterious effect from concrete. For other practical considerations, RCA is usually used in concrete as part of 
the total coarse aggregate. So, the concept of diluting the RCA content in concrete is a feasible option from the construction standpoint. As seen in Figure 31, dilution of the virgin Spratt aggregate with 30\% replacement with non reactive natural aggregate was useful to reduce $25 \%$ of the concrete prisms expansion while it reduced almost $50 \%$ of the expansion in case of RCA dilution. Further dilution of Spratt with $50 \%$ coarse aggregate replacement was not much effective to reduce the expansion much lower than $25 \%$ of the control sample.

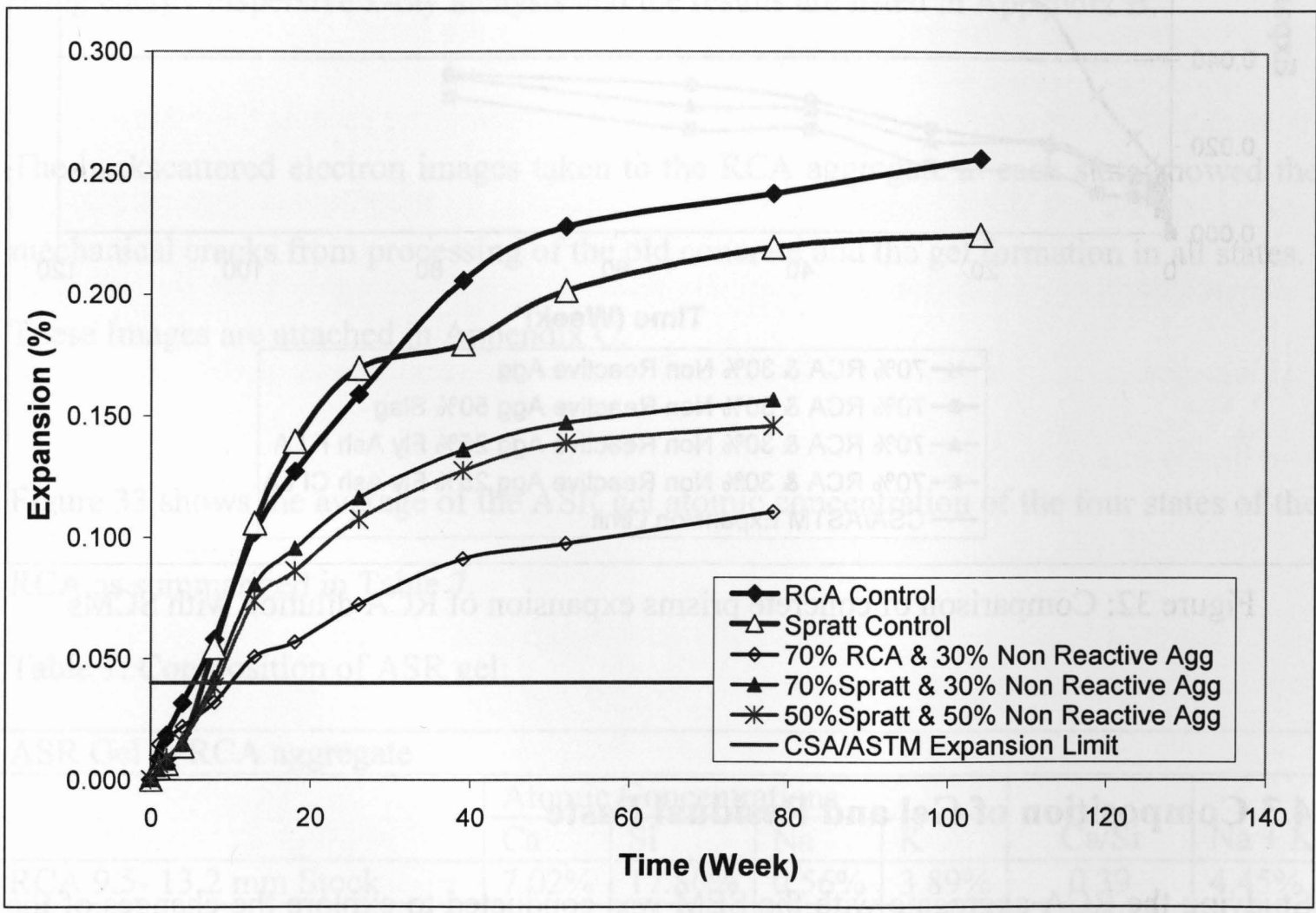

Figure 31: Comparison of concrete prisms expansion of RCA and Spratt when coarse aggregate replacement with non reactive aggregate is used for dilution 
Dilution of the RCA was also investigated with SCM replacements of 25\% fly Ash F LA, $25 \%$ fly Ash CI LA and 50\% slag in binary blends. The expansions of these samples are expected to satisfy the ASTM limit at 2 years as it can be exported from the expansion curves in Figure 32.

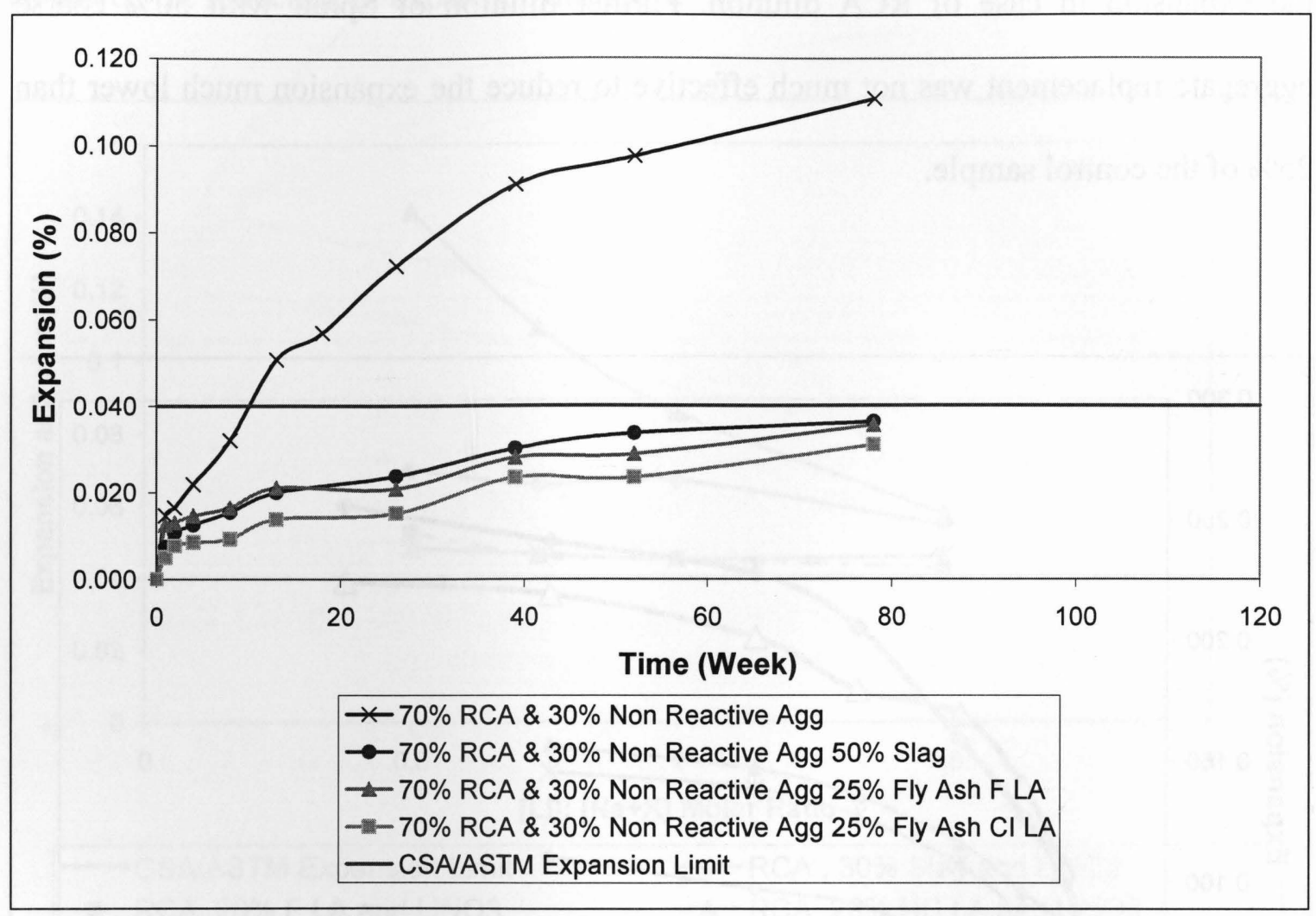

Figure 32: Comparison of concrete prisms expansion of RCA dilution with SCMs

\subsection{Composition of Gel and Residual Paste}

Studying the RCA aggregate with the SEM was conducted to explore the changes of the RCA gel and paste after soaking in $0.7 \mathrm{M}$-solution with and without lithium at [Li]: $[\mathrm{Na}+\mathrm{K}]$ ratio of 1:1. RCA aggregate samples were prepared from aggregate of the 
size from 9.5-13.2 mm. Four Types of RCA samples were chosen for this study based on their service exposure as follows:

- ASR-affected RCA stock pile

- ASR-affected RCA used in concrete prism - Prism was broken and a sample was taken.

- ASR-affected RCA in 0.7 Molarity without lithium for 4 weeks

- ASR-affected RCA in 0.7 Molarity with [Li]:[Na+K] of $1: 1$ for 4 weeks

Quantitative atomic concentrations of the ASR gel and the RCA paste were performed using energy dispersive x-ray analysis and the results are listed in Appendix B.

The backscattered electron images taken to the RCA aggregate at each state showed the mechanical cracks from processing of the old concrete and the gel formation in all states.

These Images are attached in Appendix C.

Figure 33 shows the average of the ASR gel atomic concentration of the four states of the RCA as summarized in Table 7.

Table 7: Composition of ASR gel:

\begin{tabular}{|c|c|c|c|c|c|c|}
\hline \multicolumn{7}{|l|}{ ASR Gel in RCA aggregate } \\
\hline & \multicolumn{4}{|c|}{ Atomic Concentrations } & \multirow[b]{2}{*}{$\mathrm{Ca} / \mathrm{Si}$} & \multirow[b]{2}{*}{$\mathrm{Na}+\mathrm{K}$} \\
\hline & $\mathrm{Ca}$ & $\mathrm{Si}$ & $\mathrm{Na}$ & $\mathrm{K}$ & & \\
\hline RCA 9.5- $13.2 \mathrm{~mm}$ Stock & $7.02 \%$ & $17.80 \%$ & $0.56 \%$ & $3.89 \%$ & 0.39 & $4.45 \%$ \\
\hline RCA in concrete prism & $5.88 \%$ & $20.72 \%$ & $1.09 \%$ & $4.72 \%$ & 0.28 & $5.81 \%$ \\
\hline $\begin{array}{l}\text { RCA in solution } 0.7 \text { Molarity } \\
\text { of } \mathrm{Li}:(\mathrm{Na}+\mathrm{K}) 1: 1\end{array}$ & $4.64 \%$ & $21.88 \%$ & $0.83 \%$ & $2.49 \%$ & 0.23 & $3.32 \%$ \\
\hline $\begin{array}{l}\text { RCA in solution } 0.7 \text { Molarity } \\
\text { without Lithium }\end{array}$ & $7.54 \%$ & $19.17 \%$ & $0.30 \%$ & $2.94 \%$ & 0.40 & $3.24 \%$ \\
\hline
\end{tabular}


Figure 34 shows the average of the RCA paste atomic concentration of the four states of the RCA summarized in Table 8 .

Table 8: Alkali content of RCA Paste:

\begin{tabular}{|l|l|l|l|l|l|}
\hline RCA Paste & \multicolumn{5}{|l|}{} \\
\cline { 2 - 6 } & $\mathrm{Ca}$ & $\mathrm{Si}$ & $\mathrm{Na}$ & $\mathrm{K}$ & $\mathrm{Na}+\mathrm{K}$ \\
\hline RCA 13.2 Agg Stock & 11.02 & 11.78 & 0.53 & 0.34 & $0.87 \%$ \\
\hline RCA in concrete prism & 11.72 & 12.72 & 0.65 & 0.40 & $1.05 \%$ \\
\hline $\begin{array}{l}\text { RCA in solution 0.7 Molarity of Li: ( Na }+ \\
\text { K) 1:1 }\end{array}$ & 14.24 & 9.66 & 0.09 & 0.11 & $0.20 \%$ \\
\hline $\begin{array}{l}\text { RCA in solution 0.7 Molarity without } \\
\text { Lithium }\end{array}$ & 17.76 & 6.81 & 0.15 & 0.15 & $0.30 \%$ \\
\hline
\end{tabular}

The above tables and the following figures illustrate that the RCA ASR gel gained 1.36\% more alkalis when used in concrete prism. This is normally the case as the alkalis in the second service life of the aggregate is due the exposure to the alkaline pore solution of the new concrete in addition to the alkalis retained in the aggregate from the previous service cycle. This was also manifested in the alkalis concentrations of the paste which was $0.18 \%$ higher in the second service life in the concrete prism. 


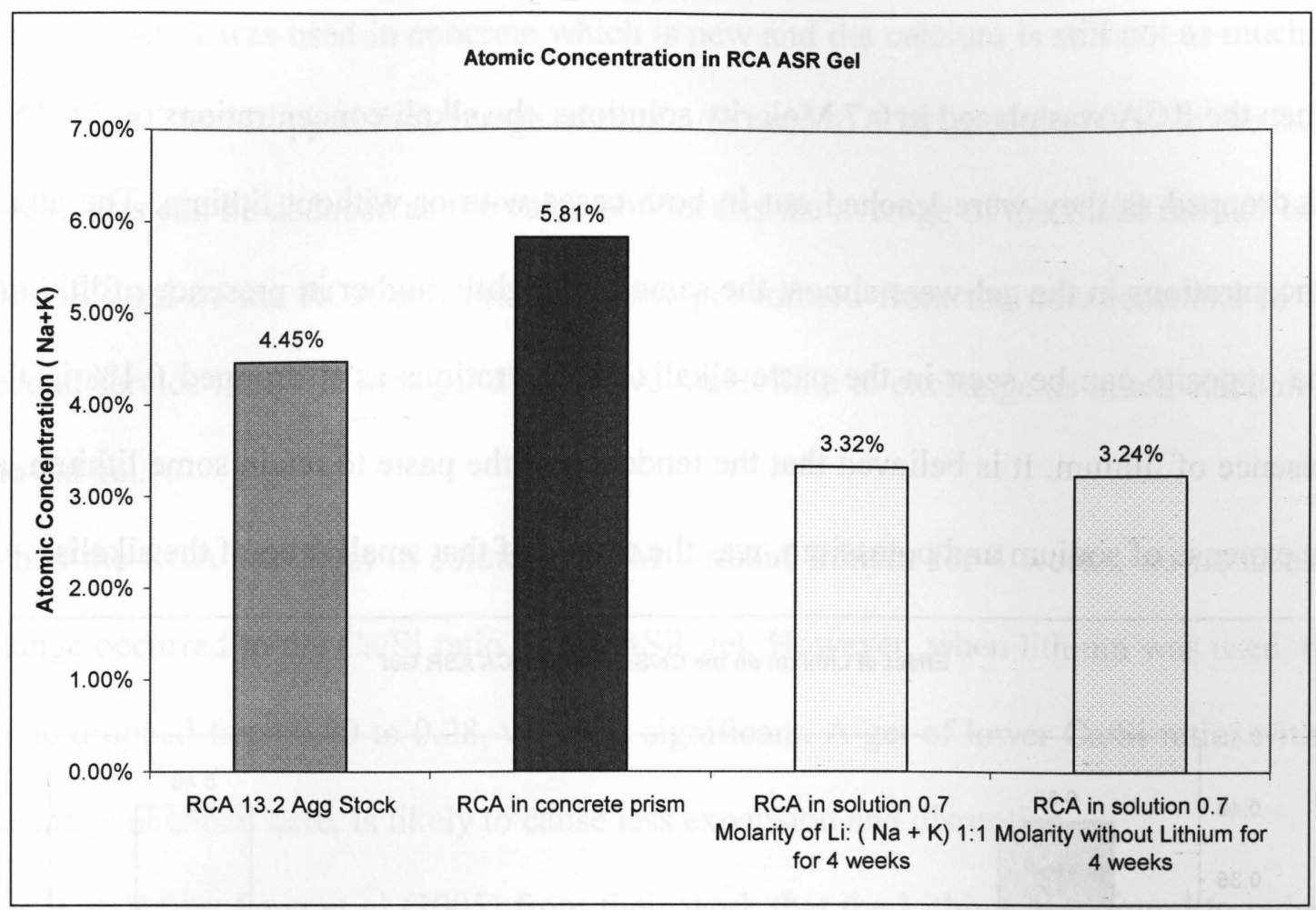

Figure 32: Atomic concentrations in RCA ASR gel

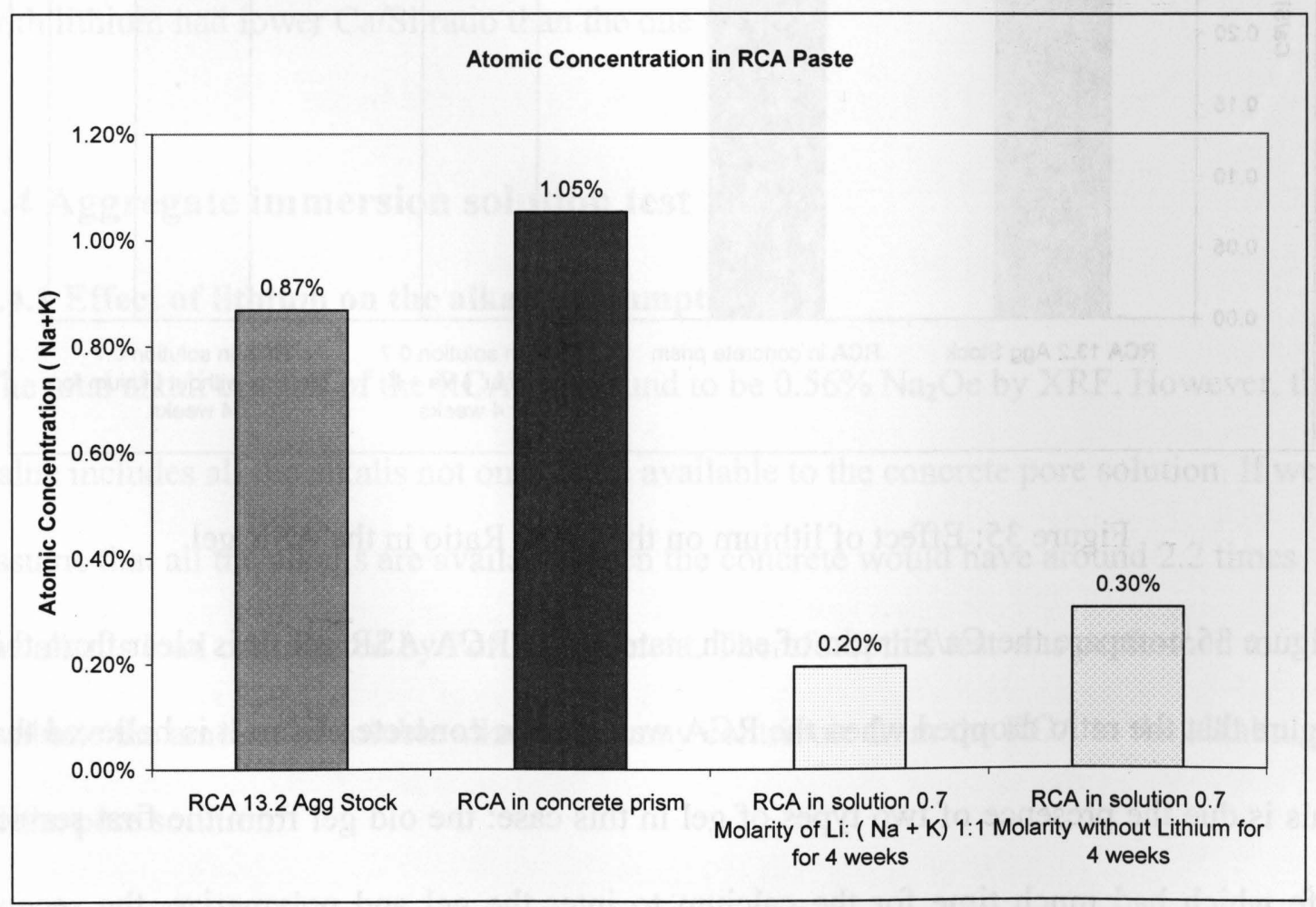

Figure 33: Atomic concentrations in RCA Paste 
When the RCA was placed in 0.7 Molarity solutions, the alkali concentrations of the ASR gel dropped as they were leached out in both cases with or without lithium. The alkali concentrations in the gel were almost the same but slightly higher in presence of lithium. The opposite can be seen in the paste alkalis concentrations as it dropped $0.1 \%$ in the presence of lithium. It is believed that the tendency of the paste to retain some lithium, at the expense of sodium and potassium, was the reason of that small drop of the alkalis.

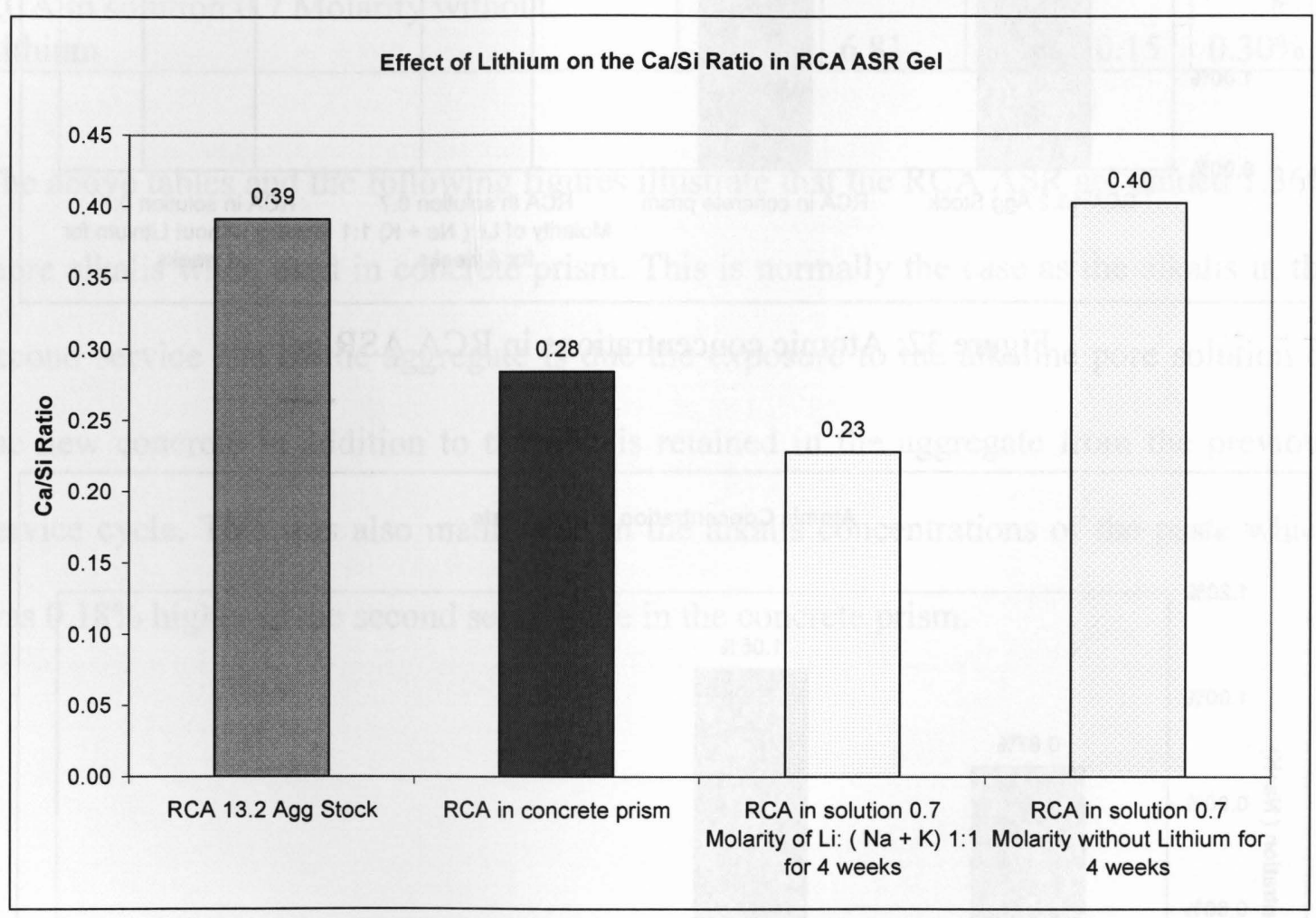

Figure 35: Effect of lithium on the $\mathrm{Ca} / \mathrm{Si}$ Ratio in the ASR gel

Figure 35 compare the $\mathrm{Ca} / \mathrm{Si}$ ratio of each state of the RCA ASR gel. It is clear from this figure that the ratio dropped when the RCA was used in concrete prism. It is believed that this is due the presence of two types of gel in this case: the old gel from the first service life which had much time for the calcium to inter the gel and polymerize, the second 
when the RCA was used in concrete which is new and the calcium is still not as much as the old gel. That dropped the average of the $\mathrm{Ca} / \mathrm{Si}$ ratio to 0.28 instead of 0.39 in the $\mathrm{RCA}$ stock. This can be deduced as the value obtained is the average of the $\mathrm{Ca} / \mathrm{Si}$ ratio of both old ASR gel of the RCA and the new ASR gel formed from the new reactions in the second service life. The new gel didn't have much time to exchange as much calcium as the old gel.

When the RCA was kept in solution $0.7 \mathrm{M}$ without lithium for 4 weeks, no noticeable change occurred to the $\mathrm{Ca} / \mathrm{Si}$ ratio of the ASR gel. However, when lithium was used, the value dropped from 0.40 to 0.28 , which is significant. A gel of lower $\mathrm{Ca} / \mathrm{Si}$ ratio, within the range obtained here, is likely to cause less expansion and disruption.

It was stated by Feng et al (2005) from their work that the Lithium was found to reduce the silica dissolution. This could be the reason why the sample placed in $0.7 \mathrm{M}$ solution with lithium had lower $\mathrm{Ca} / \mathrm{Si}$ ratio than the one without.

\subsection{Aggregate immersion solution test}

\subsubsection{Effect of lithium on the alkali consumption}

The total alkali content of the RCA was found to be $0.56 \% \mathrm{Na}_{2} \mathrm{Oe}$ by XRF. However, this value includes all the alkalis not only those available to the concrete pore solution. If we assume that all the alkalis are available, then the concrete would have around 2.2 times the alkalis load contributed by Portland cement. Therefore, this test was performed to evaluate the amount of soluble alkalis that may contribute from the RCA to the alkalinity of the pore solution. 
Figure 36 presents the amount of the contributed or absorbed (negative contribution) ions as a percentage of the dry mass of the RCA. It was found that the amount of available water-soluble alkalis of the RCA ranges from $0.13 \%$ to $0.16 \%$ of the dry mass of RCA. It was also found that at 0.25 Molarity the alkalis concentration are in equilibrium between the RCA and the leaching solution. This caused the alkalis neither to be leached out of the RCA nor to be consumed from the immersion solution. Furthermore, it was found that the alkalis consumed by the RCA are much less when lithium is used in the immersing solutions. It should be noted that it is likely that some ASR reaction continues while the $\mathrm{RCA}$ is placed in the solution. Indeed all ingredients for the reaction to proceed are available, reactive silica, alkalis and calcium hydroxide which is leached from RCA. The alkalis removed from the solutions are those likely to be used in fuelling reaction as the ability of the residual paste in RCA to retain alkali is not high, as will be shown later. The fact that less alkalis $(\mathrm{Na}+\mathrm{K})$ were removed from solution when lithium was available confirmed that the use of lithium reduces the alkalis absorbed by the reactive aggregates. This in turn reduces the formation of expansive ASR gel. 


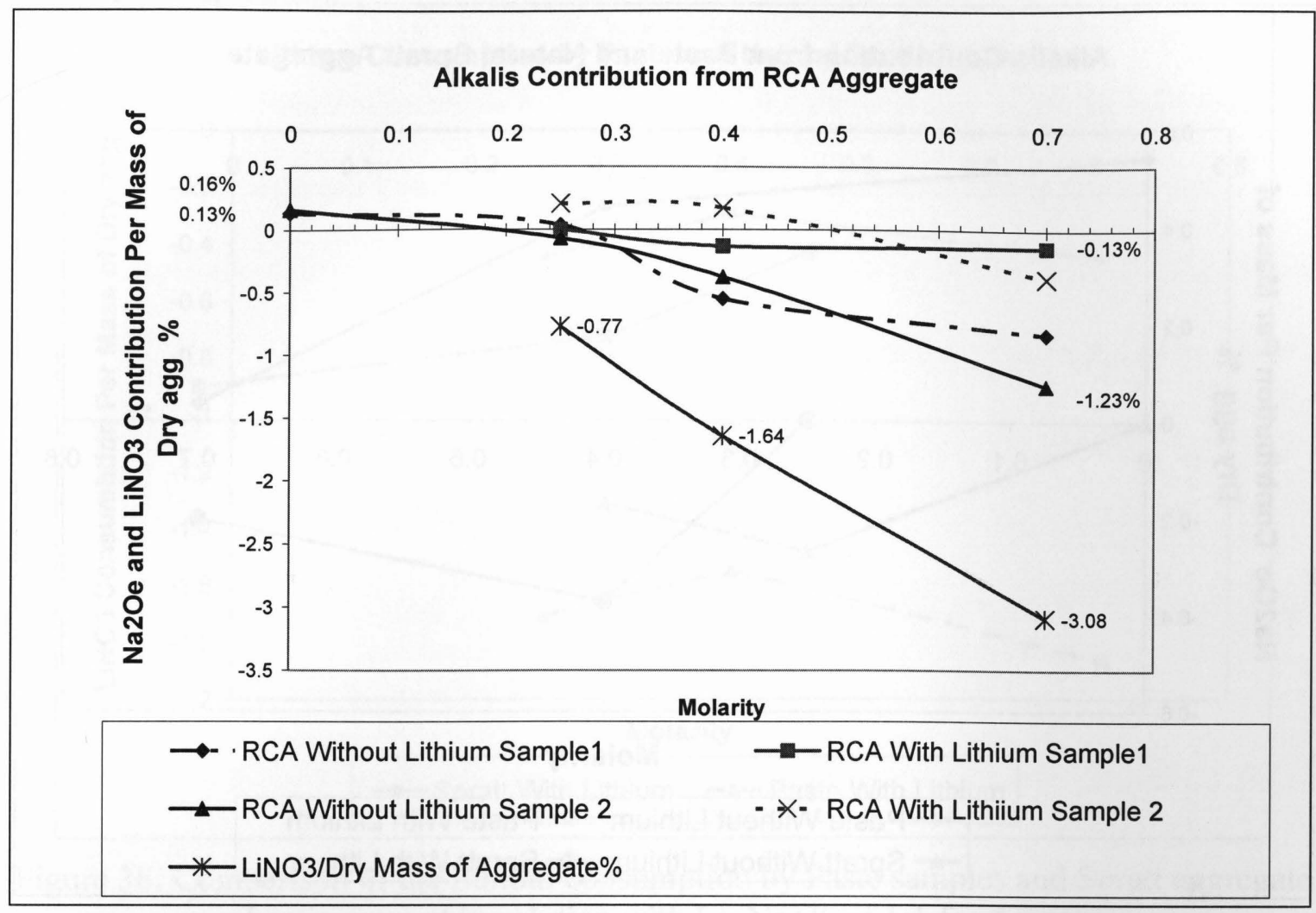

Figure 36: Comparison of alkali consumption when RCA was immersed for 6 month in alkali solution with lithium of $\mathrm{Li}: \mathrm{Na}+\mathrm{K}$ of $1: 1$ and when immersed in alkali solution without lithium

For better understanding of the role of the residual paste and aggregate portions of the RCA in terms of their characteristics to release or consume alkalis, paste and Spratt samples were soaked in solutions of the same Molarity as those used with the samples of the RCA. For the Spratt samples, $\mathrm{Ca}(\mathrm{OH})_{2}$ was added to the immersing solution to mimic the composition of the pore solution around the aggregate in actual concrete. As shown in Figure 37 , the paste mainly contributed alkalis to the host solution. This confirms that the alkalis that were bound by RCA were mainly consumed in ASR reaction or perhaps bound by the gel. The Spratt consumed some alkalis which could be due to some binding of alkali cations by the reactive silica initiating the first stages of ASR. 


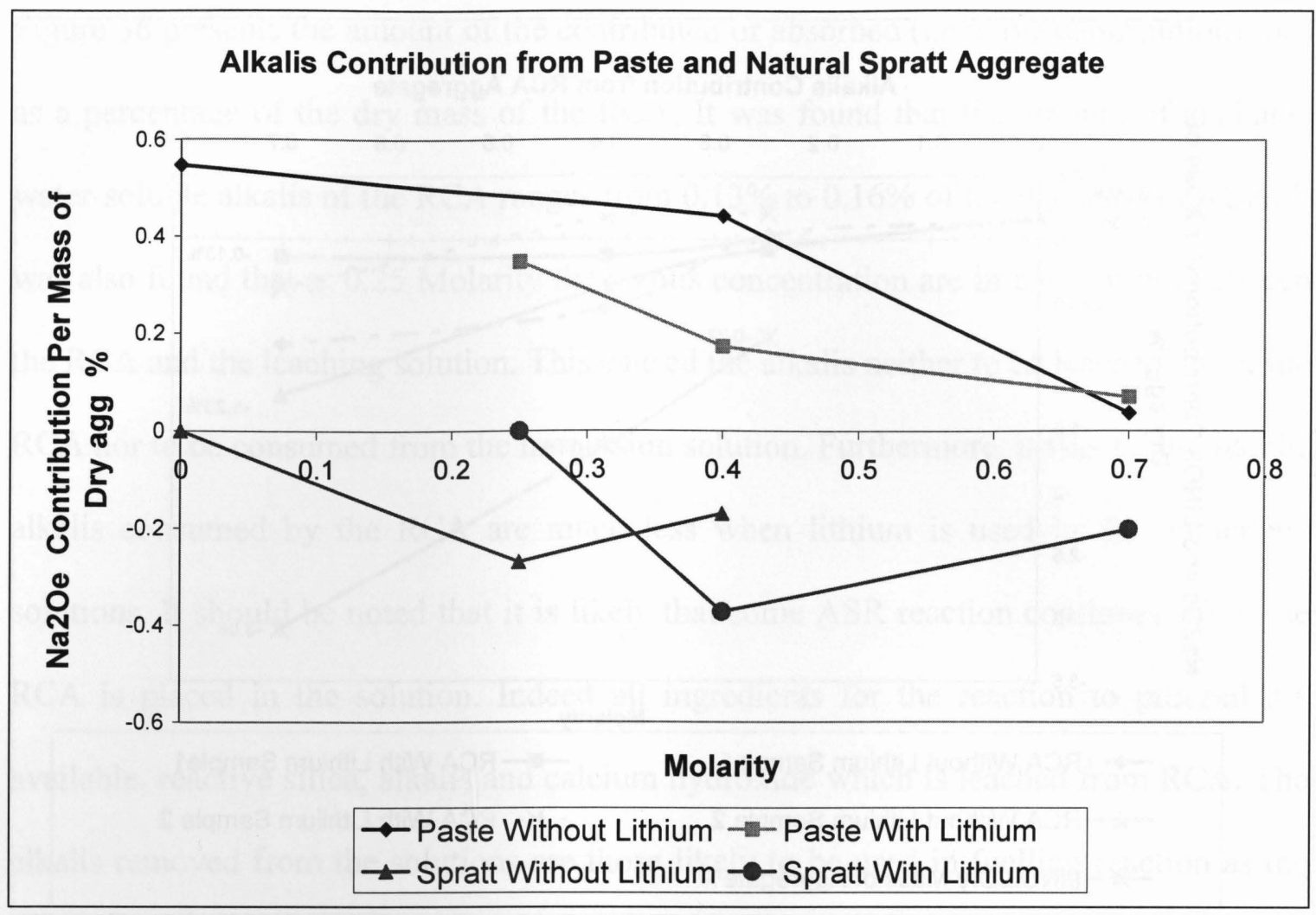

Figure 37: Comparison of alkalis consumption by the Paste and Spratt aggregate when immersed for 4 weeks in alkali solution with lithium of $\mathrm{Li}$ : $\mathrm{Na}+\mathrm{K}$ of $1: 1$ and when immersed in alkali solution without lithium

Both Spratt and the paste didn't have much difference in their alkalis release or consumption with or without lithium in the immersing solutions. Furthermore, the amount of the lithium consumed by the unit mass of the paste was almost 4 times the amount consumed by the unit mass of the Spratt aggregate as can be seen in Figure 38. It should be noted that the paste used here is control PC paste with no SCM to represent the residual paste of RCA. If $\mathrm{PC}+\mathrm{SCM}$ paste was used, the paste could have bound more of both alkalis and lithium. 


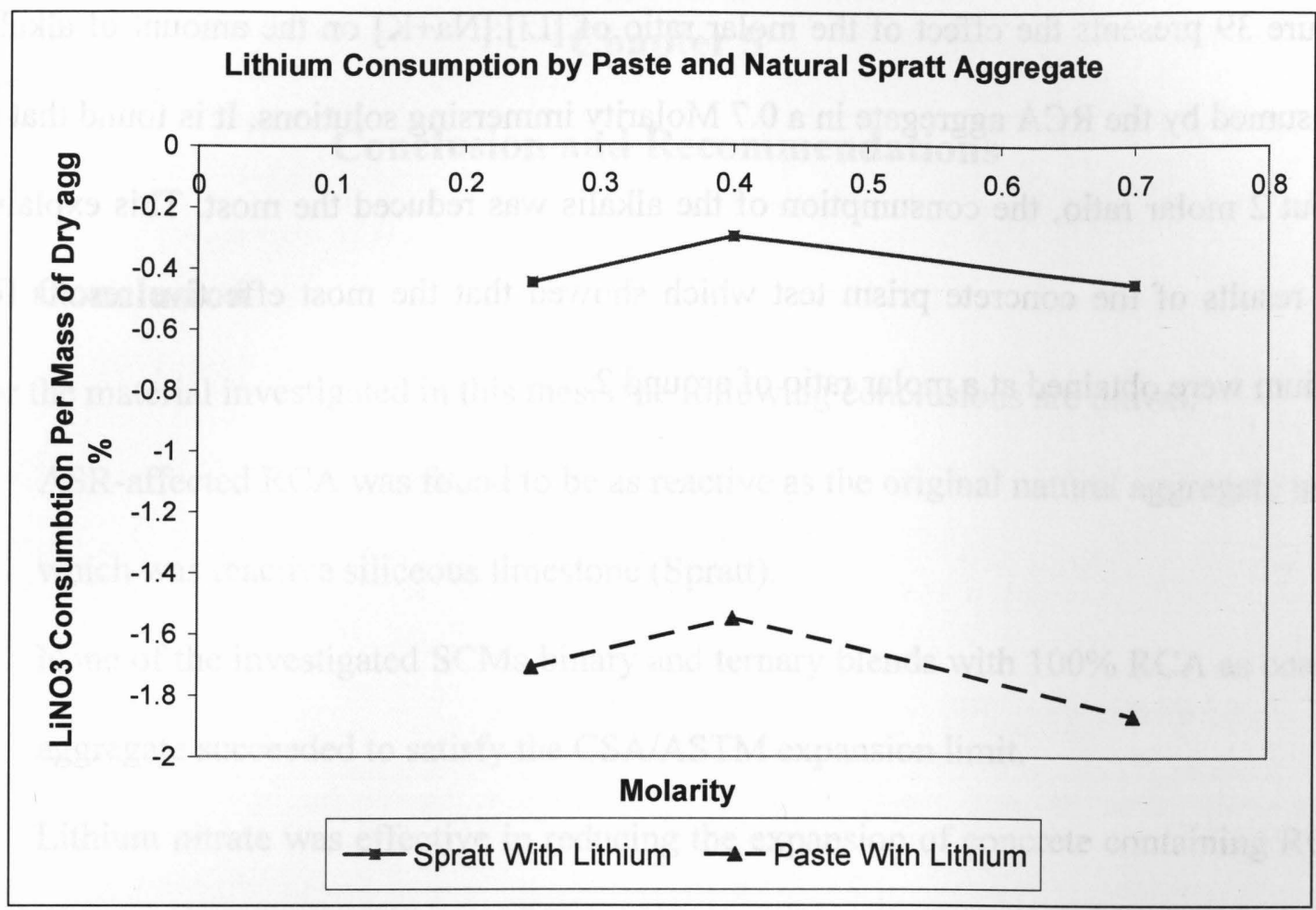

Figure 38: Comparison of the lithium consumption by Paste samples and Spratt aggregate when immersed in solution with $\mathrm{Li}: \mathrm{Na}+\mathrm{K}$ of $1: 1$ for 4 weeks

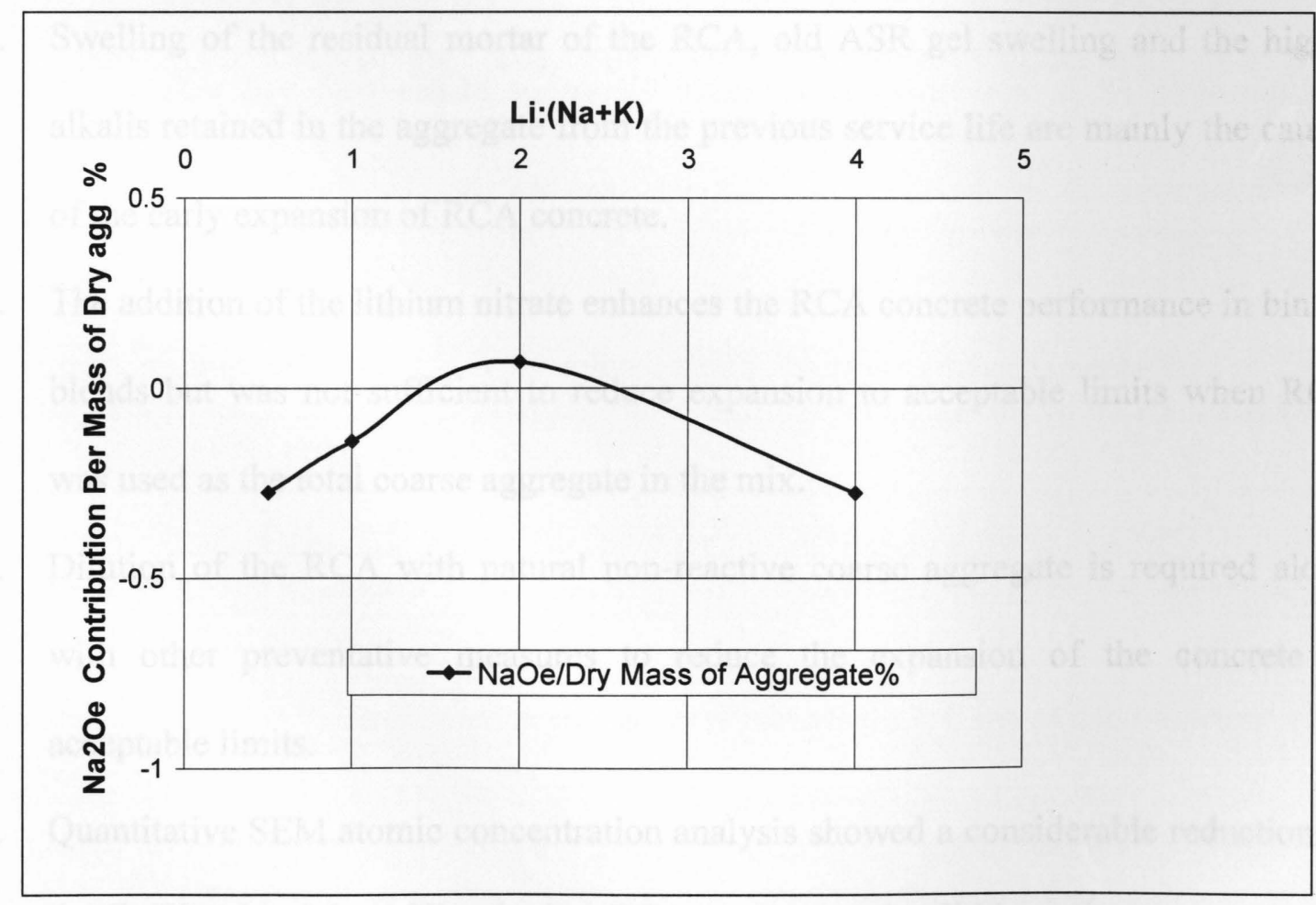

Figure 39: Effect of $\mathrm{Li}:(\mathrm{Na}+\mathrm{K})$ Molar Ratio on the Alkali contribution or Consumption From RCA in 0.7 Molarity Solution 
Figure 39 presents the effect of the molar ratio of $[\mathrm{Li}]:[\mathrm{Na}+\mathrm{K}]$ on the amount of alkalis consumed by the RCA aggregate in a 0.7 Molarity immersing solutions. It is found that at about 2 molar ratio, the consumption of the alkalis was reduced the most. This explains the results of the concrete prism test which showed that the most effective results for lithium were obtained at a molar ratio of around 2. 


\section{Chapter 5}

\section{Conclusion and Recommendations}

\subsection{Conclusion}

For the material investigated in this thesis the following conclusions are drawn:

1. ASR-affected RCA was found to be as reactive as the original natural aggregate used which was reactive siliceous limestone (Spratt).

2. None of the investigated SCMs binary and ternary blends with $100 \%$ RCA as coarse aggregate succeeded to satisfy the CSA/ASTM expansion limit.

3. Lithium nitrate was effective in reducing the expansion of concrete containing RCA but the range of dosages presented in this study did not suppress the expansion to the allowable limit.

4. Swelling of the residual mortar of the RCA, old ASR gel swelling and the higher alkalis retained in the aggregate from the previous service life are mainly the causes of the early expansion of RCA concrete.

5. The addition of the lithium nitrate enhances the RCA concrete performance in binary blends but was not sufficient to reduce expansion to acceptable limits when RCA was used as the total coarse aggregate in the mix.

6. Dilution of the RCA with natural non-reactive coarse aggregate is required along with other preventative measures to reduce the expansion of the concrete to acceptable limits.

7. Quantitative SEM atomic concentration analysis showed a considerable reduction of the $\mathrm{Ca} / \mathrm{Si}$ ratio of the ASR gel when RCA was exposed to lithium nitrate. 
8. The addition of lithium nitrate to ternary blends of silica and slag didn't improve the reduction of the concrete expansion. However, the use of lithium with high calcium fly ash showed significant improvement.

9. The synergy effect of lithium nitrate with high calcium low alkalis fly ash is effective in reducing the RCA concrete expansion dramatically and can be a very successful approach if used with dilution of the coarse aggregate. However, the investigate blend with $100 \%$ RCA did not satisfy the ASTM expansion limit.

\subsection{Recommendations}

This study presented preliminary steps in understanding the mechanism of expansion in concrete containing reactive RCA. The study also looked at the mechanism by which lithium reduces the expansion in concrete with reactive aggregates. Further mechanistic work is recommended. Such work should include investigating the pore solution of the concrete with RCA and binary and ternary blends of SCMs with and without lithium nitrate. 


\section{$\underline{\text { Reference }}$}

Ajdukiewicz A., Kliszczewicz A., (2002), Influence of recycled aggregates on mechanical properties of HS/HPC, Cement \& Concrete Composites, vol. 24, no. 2, pp. 269-279

Bérubé M., Duchesne J., Dorion J.F., Rivest M., (2002), Laboratory assessment of alkali contribution by aggregates to concrete and application to concrete structures affected by alkali-silica reactivity, Cement and Concrete Research, vol. 32, no. 8, pp. 1215-1227

Bilodeau A., Sivasundaram V., Painter K. and Malhotra V., (1994), Durability of Concrete Incorporating High Volumes of Fly Ash from Sources in the U.S., ACI Materials Journal, vol. 91, pp. 3

Bleszynski R., Hooton D., Thomas M. and Rogers C., (2002), Durability of Ternary Blend Concrete with Silica Fume and Blast-Furnace Slag: Laboratory and Outdoor Exposure Site Studies, ACI Materials Journal, vol. 99, Issue 5, pp. 499

Boddy A.M., Hooton R.D. and Thomas M.D.A.,(2003), The effect of the silica content of silica fume on its ability to control alkali-silica reaction, Cement and Concrete Research, vol. 33, Issue 8, pp. 1263-1268

Chini A., Kuo S., Armaghani J.M., Duxbury P., (2001), Test of Recycled Concrete Aggregate in Accelerated Test Track, Journal of Transportation Engineering, vol. 127, Issue 6, pp. 486-492

Christidis C., "Durability of concrete containing aggregate produced from recycled concrete affected by alkali-silica reaction", (2006), Ryerson University, Toronto, Canada.

David R. Wilburn and Thomas G. Goonan, (1998), "Economic Assessments for Construction Applications-A, Materials Flow Analysis”, U.S. GEOLOGICAL SURVEY CIRCULAR 1176, publication.

Diamond, S., and Ong, S. (1992), "The mechanisms of lithium effects on ASR", Proceedings of the $9^{\text {th }}$ international conference on Alkali-aggregate reaction, London, 69278.

Diamond S., (1997), "alkali silica reaction-some paradoxes", Cement and Concrete composites, 19 (5-6), 391-401.

Diamond S., (1999), "Unique response of $\mathrm{LiNO}_{3}$ as an alkali silica reaction-preventive admixture", Cement and Concrete Research, vol. 29, no. 8, pp. 1271-1275 
Duchense, J. and Bérubé M., (1994), “Available Alkalis from Supplementary Cementing Materials”, ACI Materials Journal, pp. 289-299

Duchense, J. and Bérubé M., (1994), “The Effectiveness of Supplementary Cementing Materials in Suppressing Expansion Due to ASR: Another Look at the Reaction Mechanisms Part 2: Pore Solution Chemistry”, Cement and Concrete Research, Vol. 24, No.2, pp. 221230

Duchense, J. and Bérubé M., (1994), “The Effectiveness of Supplementary Cementing Materials in Suppressing Expansion Due to ASR: Another Look at the Reaction Mechanisms Part 1: Concrete Expansion and Portlandite Depletion", Cement and Concrete Research, Vol. 24, pp. 73-82

Duchesne J. \& Bérubé M., (2001), “Long-term effectiveness of supplementary cementing materials against alkali-silica reaction", Cement and Concrete Research, vol. 31, no. 7, pp. 1057-1063

Fournier B., Bilodeau A., Malhotra V.M., , (1995), CANMET/Industry research consortium on alkali- aggregate reactivity, in: CANMET/ACI International Workshop on Alkali Aggregate Reactions in Concrete, Natural Resources, Canada, pp. 169- 180.

Fournier B. \& Bérubé M., (2000), Alkali-aggregate reaction in concrete: a review of basic concepts and engineering implications, NRC Canada, vol. 27, pp. 167-191

Fournier B. \& Bérubé M., M.A., (2001), “Utilization of Lithium to mitigate ASR”: Proceedings ACI Progress in concrete, Montreal, Canada, 12p.

Fournier B., Chevrier R., De Grosbois M., Lisella R., Folliard K., Ideker J., Shehata M., Thomas M., Baxter S., (2004), "The accelerated concrete prism test $60 C^{\circ}$ : Variability of the test method and proposed expansion limits", Proceeding $12^{\text {th }}$ International Conference On alkali aggregate reaction, Beijing, China, Vol. 1, pp314-323.

Gomez-Soberon J.M.V., (2002), Porosity of recycled concrete with substitution of recycled concrete aggregate An experimental study, Cement and Concrete Research, vol. 32 , no. 8, pp. 1301-1311

Hobbs D.W., (1988), “Alkali-Silica Reaction in Concrete”, Thomas Telford, London, pp. 183

Hooton R.D., (1993), "Influence of Silica Fume Replacement of Cement on Physical Properties and Resistance to Sulphate Attack, Freezing and Thawing, and Alkali-Silica Reactivity”, ACI Materials Journal, pp. 143-151

Hooton R.D., (2000), Canadian use of Ground Granulated Blast-furnace Slag as a Supplement Cementing for Enhanced Performance of Concrete, Canadian Journal of Civil Engineering, vol.27, no.4, pp. 754-760 
Kosmatka H., Kerkhoff B., Panarese W., Macleod N., McGrath R., (2002), “ Design and Control of Concrete Mixtures $-7^{\text {th }}$ Canadian Edition", Cement Association of Canada.

Kurtis K., Monteiro P., Meyer-Ilse W., (2000), "Examination of the effect of LiCl on ASR gel expansion". Proceedings of the $11^{\text {th }}$ International Conference on Alkali-Aggregate Reaction, Quebec, pub. by CANMET, Ottawa:. 51-60

McCoy W.J., Caldwell A.G., (1951), "New approach in inhibiting alkali-aggregate expansion”, ACI Materials Journal, 22(9): 693-706.

McGovern M., (2002), “Concrete Technology Today”, Portland Cement Association, Vol. 23, No. 2

Mindess S., Young J.F., Darwin D., (2003), “Concrete $2^{\text {nd }}$ edition”, Prentice Hall

Mo X. , Yu C. , Xu Z., (2003), Long-term effectiveness and mechanism of LiOH in inhibiting alkali-silica reaction, Cement and Concrete Research, vol. 33, no. 1, pp. 115119

Naik T., Singh S., Ramme B., (1998), "Mechanical Properties and Durability of Concrete Made with Blended Fly Ash”, ACI Materials Journal, vol. 95, Issue 4, pp. 454

Neville A.M., (1996), "Properties of Concrete $4^{\text {th }}$ edition", Pearson Education.

Neville, A.M., (2006), "Concrete: Neville's insights and issues", Thomas Telford Ltd.

Neito, P., and Zanni, H. (1997). "Polymerization of alkaline-calcium-silicate hydrates obtained by interaction between alkali-silica solution and calcium compounds. Si nuclear magnetic resonance study", Journal of Material Science, 32(13), 3419-3425.

Otsuki N. , Miyazato S., Yodsudjai W., (2003), Influence of Recycled Aggregate on Interfacial Transition Zone, Strength, Chloride Penetration and Carbonation of Concrete, Journal of Materials in Civil Engineering, vol. 15, Issue 5, pp. 443-451

Park T., (2003), "Application of Construction and Building Debris as Base and Sub-base Materials in Rigid Pavement", Journal of Transportation Engineering, vol. 129, Issue 5, pp. $558-563$

Prieur M., Nikitine N., (2006), "Shrinkage Behaviour and Properties of Concrete Containing Supplementary Cementing Materials and Recycled Concrete Aggregate", Ryerson University Department of Engineering and Applied Science Faculty of Civil Engineering 
Rance R., Debray L., (1992), "Reference test methods and performance criterion for concrete structures", Proceedings of the $9^{\text {th }}$ International Conference on Alkali aggregate reaction in concrete, vol.1, concrete society, London, pp.110-116

Ramyar K., Copuroglu O., Andic O”, Fraaij A.L.A., (2004), Comparison of alkali-silica reaction products of fly ash or lithium-salt-bearing mortar under long-term accelerated curing, Cement and Concrete Research 34 - 1179-1183.

Rogers C. , Grattan-Bellew P.E. , Hooton R.D. , Ryell J., Thomas M.D.A.,(2000), “Alkali-aggregate reactions in Ontario", NRC Canada, vol. 27, pp.246-260

Sagoe-Crentsil K.K. \& Brown T. \& Taylor A.H, (2001), "Performance of Concrete made with Commercially Produced Coarse Recycled Concrete Aggregate", Cement and Concrete Research, vol. 31, no. 5, pp. 707-712

Scott IV, H. C., and Gress, D. L., (2004), "Mitigating Alkali Silica Reaction in Recycled Concrete” ACI Special Publication, SP 219-05, pp: 61-76.

Shehata M. H. \& Thomas M.D.A., R.F. Bleszynski, (1999), "The effect of fly ash composition on the chemistry of pore solution". Cement and concrete research (29): 1915-1920.

Shehata M. H. \& Thomas M.D.A., (2000), "The effect of fly ash composition on the expansion of concrete due to alkali-silica reaction", Cement and Concrete Research, vol. 30, Issue 7, pp. 1063-1072

Shehata M. H. \& Thomas M.D.A., (2002), "Use of ternary blends containing silica fume and fly ash to suppress expansion due to alkali-silica reaction in concrete", Cement and Concrete Research, vol. 32, Issue 3, pp. 341-349

Shehata M. , Thomas M.D.A, (2006), Alkali release characteristics of blended cements, Cement and Concrete Research, vol. 36, Issue 6, pp. 1166-1175

Shomglin K., Turanli L., Wenk H. , Monteiro P.J.M. , Sposito G., (2003), "The effects of potassium and rubidium hydroxide on the alkali-silica reaction", Cement and Concrete Research, vol. 33, no. 11, pp. 1825-1830

Stanton, T. E., (1940), "Expansion of Concrete Through Reaction Between Cement and Aggregate”, Proceedings, ASCE, V. 66, No. 10, pp. 1781-1811

Stark D., (1992)," Lithium salt admixtures - an alternative method to prevent expansive alkali-silica reactivity", Proceedings of the $9^{\text {th }}$ International Conference on AAR in Concrete, London, UK, pp. 1017-1025. 
Stark D., (1994), "Alkali - silica reaction in concrete", in: P. Klieger, J.F. Lamond (Eds.), Significance of Tests and Properties of Concrete and Concrete Making Materials, STP 169C, ASTM Publications, Philadelphia, PA, pp. 365- 371.

Stokes D.B., Wang H.H., Diamond, "A lithium- based admixture for ASR control that does not increase the pore solution $p H$ ", Proceedings the $5^{\text {th }}$ CANMET/ACI international conference on superplasticizers and other chemical admixtures in concrete, 1997, Roma, Italy, ACI SP 173, pp.855-868.

Swamy, R.N., (2003), "The alkali-silica reaction in concrete", Taylor, Francis e-Library.

Tremblay C., Bérubé M., Fournier B., Thomas M.D.A., Folliard K.J., (2007), "Effectiveness of lithium-based products in concrete made with Canadian natural aggregates susceptible to alkali-silica reactivity", ACI Materials Journal, 195-205.

Thomas M. D. A. , Fournier B. , Folliard K. , Ideker J., Shehata M., (2006), "Test methods for evaluating preventative measures for controlling expansion due to alkalisilica reaction in concrete", Cement and Concrete Research

Thomas M. D. A., Innis F.A., (1998), "Effect of Slag on Expansion Due to AlkaliAggregate Reaction in Concrete", ACI Materials Journal, vol. 95, Issue 6, pp. 716

Topcu I.B., (1997), "Physical and Mechanical Properties of Concretes Produced with Waste Concrete", Cement and Concrete Research, vol. 27, no. 12, pp. 1817-1823

Touma W.E., Fowler D.F., Carrasquillo R.L., (2001), "Alkali silica reaction in Portland cement concrete, Testing methods and mitigation alternatives", report ICAR 301-1F, International Centre for aggregates research, Austin, Texas, 520pp.

U.S. Army Corps of Engineers, (2004), "Reuse of Concrete Materials from Building Demolition”, Public Works Technical Bulletin 200-1-27

Fenga X., Thomas M.D.A., Bremner T.W., Balcom B.J., Folliard K.J., (2005), "effect of Lithium Nitrate on ASR induced expansion and dissolution of silica", cement and concrete research.

Zaharieva R., Buyle-Bodin F. , Skoczylas F., Wirquin E., (2003), Assessment of the surface permeation properties of recycled aggregate concrete, Cement \& Concrete Composites, vol. 25 , no. 2, pp. 223-232.

Zaharieva R. , Buyle-Bodin F., Wirquin E., (2004), "Frost resistance of recycled aggregate concrete", Cement \& Concrete Composites, vol. 34, no. 10, pp. 1927-1932 


\section{Appendix A: Expansion of Concrete Prisms}

\section{Phase1:}

\begin{tabular}{|c|c|c|c|c|c|c|c|c|c|c|c|}
\hline \multicolumn{12}{|c|}{ RCA Expansion \% } \\
\hline & \multicolumn{11}{|c|}{ CONTROL } \\
\hline $\begin{array}{c}\text { Bucket } \\
\#\end{array}$ & $\# 9$ & $\# 47$ & $\# 1$ & $\# 6$ & $\# 2$ & $\# 13$ & $\# 22$ & $\# 72$ & $\# 15$ & \#66 & $\# 65$ \\
\hline Type & 0.69 Con & 0.69 Con & $\begin{array}{c}60: 40 \\
\text { Con }\end{array}$ & 0.70 Con & 0.69 Con & 0.69 Con & 0.69 Con & 0.69 Con & $\begin{array}{l}0.69 \\
\text { Con }\end{array}$ & $\begin{array}{c}60: 40 \\
\text { Con }\end{array}$ & $\begin{array}{c}60: 40 \\
\text { Con }\end{array}$ \\
\hline $\mathrm{Na}_{2} \mathrm{O}_{\mathrm{e}}$ & $\begin{array}{c}2.31 \\
\left(\mathrm{~kg} / \mathrm{m}^{3}\right)\end{array}$ & $\begin{array}{c}3.36 \\
\left(\mathrm{~kg} / \mathrm{m}^{3}\right)\end{array}$ & $\begin{array}{c}5.25 \\
\left(\mathrm{~kg} / \mathrm{m}^{3}\right)\end{array}$ & $\begin{array}{c}5.25 \\
\left(\mathrm{~kg} / \mathrm{m}^{3}\right)\end{array}$ & $\begin{array}{c}5.25 \\
\left(\mathrm{~kg} / \mathrm{m}^{3}\right)\end{array}$ & $\begin{array}{c}5.25 \\
\left(\mathrm{~kg} / \mathrm{m}^{3}\right)\end{array}$ & $\begin{array}{c}5.25 \\
\left(\mathrm{~kg} / \mathrm{m}^{3}\right)\end{array}$ & $\begin{array}{c}5.25 \\
\left(\mathrm{~kg} / \mathrm{m}^{3}\right)\end{array}$ & $\begin{array}{c}6.30 \\
\left(\mathrm{~kg} / \mathrm{m}^{3}\right)\end{array}$ & $\begin{array}{c}5.25 \\
\left(\mathrm{~kg} / \mathrm{m}^{3}\right)\end{array}$ & $\begin{array}{c}5.25 \\
\left(\mathrm{~kg} / \mathrm{m}^{3}\right)\end{array}$ \\
\hline & $\begin{array}{c}0.55 \\
\text { Alkali }\end{array}$ & $\begin{array}{c}0.80 \\
\text { Alkali }\end{array}$ & $\begin{array}{c}1.25 \\
\text { Alkali }\end{array}$ & $\begin{array}{c}1.25 \\
\text { Alkali }\end{array}$ & $\begin{array}{c}1.25 \\
\text { Alkali }\end{array}$ & $\begin{array}{c}1.25 \\
\text { Alkali }\end{array}$ & $\begin{array}{c}1.25 \\
\text { Alkali }\end{array}$ & $\begin{array}{c}1.25 \\
\text { Alkali }\end{array}$ & $\begin{array}{c}1.5 \\
\text { Alkali }\end{array}$ & $\begin{array}{c}1.25 \\
\text { Alkali }\end{array}$ & $\begin{array}{c}1.25 \\
\text { Alkali }\end{array}$ \\
\hline Weeks & & & & & & & $\begin{array}{c}\text { Ottawa } \\
\text { Sand }\end{array}$ & WASHED & & $\begin{array}{l}\text { FINE } \\
\text { AGG. }\end{array}$ & N.A. \\
\hline 0 & 0.000 & 0.000 & 0.000 & 0.000 & 0.000 & 0.000 & 0.000 & 0.000 & 0.000 & 0.000 & 0.000 \\
\hline 1 & 0.009 & 0.010 & 0.018 & 0.021 & 0.007 & 0.008 & 0.016 & 0.012 & 0.010 & 0.010 & 0.005 \\
\hline 2 & 0.020 & 0.017 & 0.029 & 0.025 & 0.011 & 0.018 & 0.027 & 0.022 & 0.015 & 0.015 & 0.007 \\
\hline 4 & 0.025 & 0.032 & 0.036 & 0.035 & 0.020 & 0.032 & 0.035 & 0.021 & 0.025 & 0.018 & 0.009 \\
\hline 8 & 0.036 & 0.041 & 0.066 & 0.067 & 0.037 & 0.058 & 0.058 & 0.046 & 0.053 & 0.030 & 0.015 \\
\hline 13 & 0.049 & 0.059 & 0.101 & 0.122 & 0.085 & 0.102 & 0.082 & 0.076 & 0.097 & 0.040 & 0.024 \\
\hline 18 & 0.056 & 0.080 & 0.123 & 0.157 & 0.118 & 0.127 & 0.111 & 0.101 & 0.125 & 0.046 & 0.026 \\
\hline 26 & 0.062 & 0.107 & 0.144 & 0.192 & 0.146 & 0.159 & 0.000 & 0.134 & 0.164 & 0.057 & 0.031 \\
\hline 39 & 0.081 & 0.127 & 0.161 & 0.223 & 0.187 & 0.206 & 0.203 & 0.171 & 0.211 & 0.051 & 0.034 \\
\hline 52 & 0.098 & 0.122 & 0.177 & 0.244 & 0.205 & 0.228 & 0.235 & 0.190 & 0.237 & 0.066 & 0.044 \\
\hline 78 & 0.089 & 0.133 & 0.188 & 0.259 & 0.219 & 0.242 & 0.275 & 0.206 & 0.255 & 0.086 & 0.063 \\
\hline 104 & 0.100 & 0.145 & 0.201 & 0.276 & 0.240 & 0.256 & 0.294 & 0.217 & 0.275 & 0.089 & 0.067 \\
\hline
\end{tabular}




\begin{tabular}{|c|c|c|c|c|c|c|c|c|c|c|c|}
\hline \multicolumn{12}{|c|}{ RCA Expansion \% } \\
\hline & \multicolumn{3}{|c|}{ SILICA } & \multicolumn{4}{|c|}{ FLY ASH Type F, HA } & \multicolumn{4}{|c|}{ FLY ASH Type F, LA } \\
\hline Bucket \# & $\# 3$ & $\# 8$ & $\# 14$ & $\# 10$ & $\# 16$ & $\# 17$ & $\# 68$ & \#48 & $\# 49$ & $\# 73$ & \#50 \\
\hline Type & $\begin{array}{l}0.69 \\
\text { RCA }\end{array}$ & $\begin{array}{l}0.69 \\
\text { RCA }\end{array}$ & $\begin{array}{r}0.69 \\
\text { RCA }\end{array}$ & $\begin{array}{c}\text { Type F, } \\
\text { HA }\end{array}$ & $\begin{array}{c}\text { Type F, } \\
\text { HA }\end{array}$ & $\begin{array}{c}\text { Type F, } \\
\text { HA }\end{array}$ & $\begin{array}{c}\text { Type F, } \\
\text { HA }\end{array}$ & $\begin{array}{c}\text { Type F, } \\
\text { LA }\end{array}$ & $\begin{array}{c}\text { Type F, } \\
\text { LA }\end{array}$ & $\begin{array}{c}\text { Type F, } \\
\text { LA }\end{array}$ & $\begin{array}{c}\text { Type F, } \\
\text { LA }\end{array}$ \\
\hline $\mathrm{Na}_{2} \mathrm{O}_{\mathrm{e}}$ & $\begin{array}{c}4.99 \\
\left(\mathrm{~kg} / \mathrm{m}^{3}\right)\end{array}$ & $\begin{array}{c}4.83 \\
\left(\mathrm{~kg} / \mathrm{m}^{3}\right)\end{array}$ & $\begin{array}{c}4.73 \\
\left(\mathrm{~kg} / \mathrm{m}^{3}\right)\end{array}$ & $\begin{array}{c}4.46 \\
\left(\mathrm{~kg} / \mathrm{m}^{3}\right)\end{array}$ & $\begin{array}{c}4.20 \\
\left(\mathrm{~kg} / \mathrm{m}^{3}\right)\end{array}$ & $\begin{array}{c}3.94 \\
\left(\mathrm{~kg} / \mathrm{m}^{3}\right)\end{array}$ & $\begin{array}{c}3.41 \\
\left(\mathrm{~kg} / \mathrm{m}^{3}\right)\end{array}$ & $\begin{array}{c}4.20 \\
\left(\mathrm{~kg} / \mathrm{m}^{3}\right)\end{array}$ & $\begin{array}{c}3.94 \\
\left.\mathrm{~kg} / \mathrm{m}^{3}\right)\end{array}$ & $\begin{array}{c}3.94 \\
\left(\mathrm{~kg} / \mathrm{m}^{3}\right)\end{array}$ & $\begin{array}{c}3.68 \\
\left(\mathrm{~kg} / \mathrm{m}^{3}\right)\end{array}$ \\
\hline & $5 \% \mathrm{SF}$ & $8 \% \mathrm{SF}$ & $10 \% \mathrm{SF}$ & $15 \% \mathrm{FA}$ & $20 \% \mathrm{FA}$ & $25 \% \mathrm{FA}$ & $35 \%$ FA & $\begin{array}{c}20 \% \\
\text { FA }\end{array}$ & $\begin{array}{c}25 \% \\
\text { FA }\end{array}$ & $\begin{array}{c}25 \% \\
\text { FA } \\
\end{array}$ & $\begin{array}{c}30 \% \\
\text { FA }\end{array}$ \\
\hline Weeks & & & & & & & & & & WASHED & \\
\hline 0 & 0.000 & 0.000 & 0.000 & 0.000 & 0.000 & 0.000 & 0.000 & 0.000 & 0.000 & 0.000 & 0.000 \\
\hline 1 & 0.003 & -0.001 & -0.004 & 0.005 & 0.008 & 0.012 & 0.015 & 0.008 & 0.008 & 0.011 & 0.007 \\
\hline 2 & 0.006 & -0.002 & -0.001 & 0.006 & 0.009 & 0.014 & 0.013 & 0.012 & 0.010 & 0.016 & 0.016 \\
\hline 4 & 0.013 & 0.006 & 0.002 & 0.018 & 0.021 & 0.018 & 0.000 & 0.019 & 0.017 & 0.015 & 0.018 \\
\hline 8 & 0.023 & 0.014 & 0.009 & 0.037 & 0.030 & 0.031 & 0.007 & 0.023 & 0.017 & 0.020 & 0.021 \\
\hline 13 & 0.034 & 0.022 & 0.012 & 0.050 & 0.043 & 0.042 & 0.019 & 0.029 & 0.021 & 0.032 & 0.028 \\
\hline 18 & 0.045 & 0.028 & 0.016 & 0.061 & 0.050 & 0.049 & 0.000 & 0.041 & 0.031 & 0.039 & 0.033 \\
\hline 26 & 0.059 & 0.031 & 0.026 & 0.079 & 0.071 & 0.065 & 0.029 & 0.056 & 0.042 & 0.038 & 0.038 \\
\hline 39 & 0.087 & 0.050 & 0.037 & 0.115 & 0.096 & 0.084 & 0.048 & 0.072 & 0.050 & 0.047 & 0.052 \\
\hline 52 & 0.110 & 0.065 & 0.050 & 0.144 & 0.124 & 0.103 & 0.060 & 0.066 & 0.049 & 0.053 & 0.051 \\
\hline 78 & 0.115 & 0.066 & 0.051 & 0.159 & 0.129 & 0.117 & 0.074 & 0.074 & 0.055 & 0.056 & 0.058 \\
\hline 104 & 0.132 & 0.082 & 0.061 & 0.185 & 0.149 & 0.134 & 0.087 & 0.086 & 0.067 & 0.062 & 0.064 \\
\hline
\end{tabular}




\begin{tabular}{|c|c|c|c|c|c|c|c|c|}
\hline \multicolumn{9}{|c|}{ RCA Expansion \% } \\
\hline & \multicolumn{2}{|c|}{ FLY ASH CI, LA } & \multicolumn{3}{|c|}{ FLY ASH Type CH LA } & \multicolumn{3}{|c|}{ SLAG } \\
\hline Bucket \# & $\# 45$ & $\# 46$ & $\# 18$ & $\# 19$ & $\# 20$ & $\# 35$ & $\# 32$ & \#26 \\
\hline Type & Type CI, LA & Type CI, LA & Type $\mathrm{CH}$ & Type $\mathrm{CH}$ & Type $\mathrm{CH}$ & $0.69 \mathrm{RCA}$ & $0.69 \mathrm{RCA}$ & $0.69 \mathrm{RCA}$ \\
\hline $\mathrm{Na}_{2} \mathrm{O}_{\mathrm{e}}$ & $\begin{array}{c}4.20 \\
\left(\mathrm{~kg} / \mathrm{m}^{3}\right)\end{array}$ & $\begin{array}{c}3.68 \\
\left(\mathrm{~kg} / \mathrm{m}^{3}\right)\end{array}$ & $\begin{array}{c}3.94 \\
\left(\mathrm{~kg} / \mathrm{m}^{3}\right)\end{array}$ & $\begin{array}{c}3.68 \\
\left(\mathrm{~kg} / \mathrm{m}^{3}\right)\end{array}$ & $\begin{array}{c}2.63 \\
\left(\mathrm{~kg} / \mathrm{m}^{3}\right)\end{array}$ & $\begin{array}{c}3.94 \\
\left(\mathrm{~kg} / \mathrm{m}^{3}\right) \\
\end{array}$ & $\begin{array}{c}3.68 \\
\left(\mathrm{~kg} / \mathrm{m}^{3}\right) \\
\end{array}$ & $\begin{array}{c}2.63 \\
\left(\mathrm{~kg} / \mathrm{m}^{3}\right)\end{array}$ \\
\hline & $20 \%$ FA & $30 \% \mathrm{FA}$ & $25 \% \mathrm{FA}$ & $30 \% \mathrm{FA}$ & $50 \% \mathrm{FA}$ & $25 \%$ Slag & $30 \%$ Slag & $50 \%$ Slag \\
\hline Weeks & & & & & & & & \\
\hline 0 & 0.000 & 0.000 & 0.000 & 0.000 & 0.000 & 0.000 & 0.000 & 0.000 \\
\hline 1 & 0.012 & 0.005 & 0.005 & 0.005 & 0.001 & 0.008 & 0.011 & 0.010 \\
\hline 2 & 0.015 & 0.005 & 0.000 & 0.000 & 0.021 & 0.019 & 0.019 & 0.018 \\
\hline 4 & 0.015 & 0.005 & 0.021 & 0.022 & 0.024 & 0.032 & 0.027 & 0.022 \\
\hline 8 & 0.026 & 0.013 & 0.042 & 0.034 & 0.027 & 0.044 & 0.035 & 0.028 \\
\hline 13 & 0.037 & 0.017 & 0.054 & 0.051 & 0.036 & 0.059 & 0.047 & 0.025 \\
\hline 18 & 0.049 & 0.026 & 0.065 & 0.063 & 0.042 & 0.070 & 0.048 & 0.028 \\
\hline 26 & 0.062 & 0.034 & 0.088 & 0.082 & 0.054 & 0.089 & 0.068 & 0.000 \\
\hline 39 & 0.078 & 0.047 & 0.112 & 0.108 & 0.065 & 0.107 & 0.084 & 0.041 \\
\hline 52 & 0.071 & 0.036 & 0.137 & 0.138 & 0.083 & 0.124 & 0.100 & 0.042 \\
\hline 78 & 0.089 & 0.047 & 0.150 & 0.139 & 0.088 & 0.133 & 0.092 & 0.050 \\
\hline 104 & 0.107 & 0.062 & 0.170 & 0.164 & 0.106 & 0.149 & 0.104 & 0.053 \\
\hline
\end{tabular}




\begin{tabular}{|c|c|c|c|c|c|c|c|}
\hline \multicolumn{8}{|c|}{ RCA Expansion \% } \\
\hline \multicolumn{8}{|c|}{ Ternary Blends } \\
\hline & \multicolumn{2}{|c|}{ FLY ASH F, HA } & \multicolumn{2}{|c|}{ FLY ASH F, LA } & \multicolumn{3}{|c|}{ FLY ASH CI, LA } \\
\hline Bucket \# & \#33 & \#34 & \#51 & \#52 & $\# 53$ & $\# 55$ & $\# 69$ \\
\hline Type & Type F, HA & Type F, HA & Type F, LA & Type F, LA & Type CI & Type CI & Type CI \\
\hline $\mathrm{Na}_{2} \mathrm{O}_{\mathrm{e}}$ & $\begin{array}{c}3.94 \\
\left(\mathrm{~kg} / \mathrm{m}^{3}\right)\end{array}$ & $\begin{array}{c}3.68 \\
\left(\mathrm{~kg} / \mathrm{m}^{3}\right)\end{array}$ & $\begin{array}{c}4.20 \\
\left(\mathrm{~kg} / \mathrm{m}^{3}\right)\end{array}$ & $\begin{array}{c}3.94 \\
\left(\mathrm{~kg} / \mathrm{m}^{3}\right)\end{array}$ & $\begin{array}{c}3.94 \\
\left(\mathrm{~kg} / \mathrm{m}^{3}\right)\end{array}$ & $\begin{array}{c}3.68 \\
\left(\mathrm{~kg} / \mathrm{m}^{3}\right)\end{array}$ & $\begin{array}{c}3.68 \\
\left(\mathrm{~kg} / \mathrm{m}^{3}\right)\end{array}$ \\
\hline & $5 \%$ Silica & 5\% Silica & $5 \%$ Silica & $5 \%$ Silica & $5 \%$ Silica & $5 \%$ Silica & $5 \%$ Silica \\
\hline & $20 \% \mathrm{FA}$ & $25 \% \mathrm{FA}$ & $15 \% \mathrm{FA}$ & $20 \% \mathrm{FA}$ & $20 \% \mathrm{FA}$ & $25 \% \mathrm{FA}$ & $25 \%$ FA \\
\hline Weeks & & & & & & & \\
\hline 0 & 0.000 & 0.000 & 0.000 & 0.000 & 0.000 & 0.000 & 0.000 \\
\hline 1 & 0.008 & 0.012 & 0.003 & 0.010 & 0.003 & 0.000 & -0.001 \\
\hline 2 & 0.011 & 0.011 & 0.010 & 0.012 & 0.004 & 0.002 & -0.003 \\
\hline 4 & 0.014 & 0.016 & 0.012 & 0.009 & 0.006 & 0.005 & -0.013 \\
\hline 8 & 0.014 & 0.019 & 0.014 & 0.011 & 0.009 & 0.014 & -0.005 \\
\hline 13 & 0.026 & 0.026 & 0.021 & 0.018 & 0.013 & 0.016 & 0.008 \\
\hline 18 & 0.028 & 0.026 & 0.028 & 0.025 & 0.020 & 0.019 & 0.000 \\
\hline 26 & 0.042 & 0.046 & 0.031 & 0.026 & 0.022 & 0.027 & 0.009 \\
\hline 39 & 0.055 & 0.055 & 0.047 & 0.041 & 0.038 & 0.023 & 0.021 \\
\hline 52 & 0.061 & 0.068 & 0.046 & 0.039 & 0.035 & 0.033 & 0.029 \\
\hline 78 & 0.073 & 0.065 & 0.054 & 0.048 & 0.043 & 0.035 & 0.032 \\
\hline 104 & 0.090 & 0.081 & 0.061 & 0.052 & 0.050 & 0.041 & 0.038 \\
\hline
\end{tabular}




\begin{tabular}{|c|c|c|c|c|c|c|c|}
\hline \multicolumn{8}{|c|}{ RCA Expansion \% } \\
\hline \multicolumn{8}{|c|}{ Ternary Blends } \\
\hline & \multicolumn{3}{|c|}{ FLY ASH Type CH LA } & \multicolumn{4}{|c|}{ SLAG } \\
\hline Bucket \# & \#29 & $\# 30$ & \#31 & $\# 54$ & $\# 56$ & $\# 70$ & $\# 71$ \\
\hline Type & Type CH & Type CH & Type CH & & & & \\
\hline $\mathrm{Na}_{2} \mathrm{O}_{\mathrm{e}}$ & $\begin{array}{c}3.94 \\
\left(\mathrm{~kg} / \mathrm{m}^{3}\right)\end{array}$ & $\begin{array}{c}3.68 \\
\left(\mathrm{~kg} / \mathrm{m}^{3}\right)\end{array}$ & $\begin{array}{c}3.41 \\
\left(\mathrm{~kg} / \mathrm{m}^{3}\right)\end{array}$ & $\begin{array}{c}3.68 \\
\left(\mathrm{~kg} / \mathrm{m}^{3}\right)\end{array}$ & $\begin{array}{c}3.41 \\
\left(\mathrm{~kg} / \mathrm{m}^{3}\right)\end{array}$ & $\begin{array}{c}3.41 \\
\left(\mathrm{~kg} / \mathrm{m}^{3}\right)\end{array}$ & $\begin{array}{c}2.89 \\
\left(\mathrm{~kg} / \mathrm{m}^{3}\right)\end{array}$ \\
\hline & $5 \%$ Silica & $5 \%$ Silica & $5 \%$ Silica & $5 \%$ Silica & $5 \%$ Silica & 5\% Silica & $5 \%$ Silica \\
\hline & $20 \% \mathrm{FA}$ & $25 \%$ FA & $30 \% \mathrm{FA}$ & $25 \%$ Slag & $30 \%$ Slag & $30 \%$ Slag & $40 \%$ Slag \\
\hline \multicolumn{8}{|l|}{ Weeks } \\
\hline 0 & 0.000 & 0.000 & 0.000 & 0.000 & 0.000 & 0.000 & 0.000 \\
\hline 1 & 0.004 & 0.001 & -0.002 & 0.010 & 0.007 & 0.014 & 0.016 \\
\hline 2 & 0.008 & 0.003 & 0.000 & 0.017 & 0.006 & 0.017 & 0.020 \\
\hline 4 & 0.010 & 0.007 & 0.007 & 0.018 & 0.013 & 0.006 & 0.014 \\
\hline 8 & 0.012 & 0.010 & 0.008 & 0.025 & 0.020 & 0.008 & 0.017 \\
\hline 13 & 0.019 & 0.015 & 0.012 & 0.033 & 0.024 & 0.016 & 0.020 \\
\hline 18 & 0.027 & 0.023 & 0.015 & 0.042 & 0.028 & 0.000 & 0.000 \\
\hline 26 & 0.039 & 0.032 & 0.023 & 0.045 & 0.036 & 0.022 & 0.029 \\
\hline 39 & 0.057 & 0.045 & 0.033 & 0.062 & 0.034 & 0.037 & 0.042 \\
\hline 52 & 0.046 & 0.040 & 0.030 & 0.060 & 0.044 & 0.043 & 0.047 \\
\hline 78 & 0.063 & 0.059 & 0.053 & 0.064 & 0.050 & 0.049 & 0.052 \\
\hline 104 & 0.076 & 0.072 & 0.066 & 0.072 & 0.057 & 0.055 & 0.055 \\
\hline
\end{tabular}




\begin{tabular}{|c|c|c|c|c|c|c|c|c|}
\hline \multicolumn{9}{|c|}{ JOBE Expansion \% } \\
\hline & \multicolumn{4}{|c|}{ TAYLORVILLE } & \multirow{3}{*}{$\begin{array}{c}\text { DEELY } \\
\text { BLEND } \\
\# 57\end{array}$} & \multirow{3}{*}{$\begin{array}{c}\text { COMANCHE } \\
\text { BLEND } \\
\# 58\end{array}$} & \multirow{2}{*}{\multicolumn{2}{|c|}{$\begin{array}{c}\text { ST. LAWRENCE } \\
\text { SILICA }\end{array}$}} \\
\hline & \multicolumn{3}{|c|}{ FLYASH } & \multirow{2}{*}{$\begin{array}{c}\text { BLEND } \\
\# 44\end{array}$} & & & & \\
\hline Bucket \# & $\# 41$ & $\# 42$ & $\# 43$ & & & & $\# 59$ & $\# 60$ \\
\hline Type & Type F, HA & Type F, HA & Type F, HA & Type F, HA & & & & \\
\hline $\mathrm{Na}_{2} \mathrm{O}_{\mathrm{e}}$ & $\begin{array}{c}4.46 \\
\left(\mathrm{~kg} / \mathrm{m}^{3}\right)\end{array}$ & $\begin{array}{c}4.20 \\
\left(\mathrm{~kg} / \mathrm{m}^{3}\right)\end{array}$ & $\begin{array}{c}3.94 \\
\left(\mathrm{~kg} / \mathrm{m}^{3}\right)\end{array}$ & $\begin{array}{c}3.94 \\
\left(\mathrm{~kg} / \mathrm{m}^{3}\right)\end{array}$ & $\begin{array}{c}3.78 \\
\left(\mathrm{~kg} / \mathrm{m}^{3}\right)\end{array}$ & $\begin{array}{c}3.68 \\
\left(\mathrm{~kg} / \mathrm{m}^{3}\right)\end{array}$ & $\begin{array}{c}4.88 \\
\left(\mathrm{~kg} / \mathrm{m}^{3}\right)\end{array}$ & $\begin{array}{c}4.73 \\
\left(\mathrm{~kg} / \mathrm{m}^{3}\right)\end{array}$ \\
\hline & $15 \% \mathrm{FA}$ & $20 \% \mathrm{FA}$ & $25 \% \mathrm{FA}$ & $5 \%$ Silica & 3\% Silica & $5 \%$ Silica & 7\% Silica & $10 \%$ Silica \\
\hline & & & & $20 \% \mathrm{FA}$ & $25 \% \mathrm{FA}$ & $25 \% \mathrm{FA}$ & & \\
\hline Weeks & & & & & & & & \\
\hline 0 & 0.000 & 0.000 & 0.000 & 0.000 & 0.000 & 0.000 & 0.000 & 0.000 \\
\hline 1 & 0.002 & 0.001 & 0.002 & -0.003 & -0.001 & -0.008 & 0.000 & -0.001 \\
\hline 2 & 0.012 & 0.009 & 0.004 & -0.003 & -0.001 & -0.006 & 0.005 & 0.001 \\
\hline 4 & 0.039 & 0.011 & 0.007 & -0.001 & 0.006 & 0.000 & 0.014 & 0.009 \\
\hline 8 & 0.124 & 0.044 & 0.010 & 0.004 & 0.011 & 0.001 & 0.019 & 0.014 \\
\hline 13 & 0.205 & 0.092 & 0.029 & 0.005 & 0.016 & 0.008 & 0.028 & 0.020 \\
\hline 18 & 0.272 & 0.142 & 0.056 & 0.010 & 0.019 & 0.012 & 0.042 & 0.024 \\
\hline 26 & 0.341 & 0.200 & 0.088 & 0.014 & 0.031 & 0.020 & 0.208 & 0.028 \\
\hline 39 & 0.455 & 0.287 & 0.146 & 0.029 & 0.022 & 0.026 & 0.366 & 0.019 \\
\hline 52 & 0.452 & 0.320 & 0.151 & 0.026 & 0.038 & 0.065 & 0.421 & 0.022 \\
\hline 78 & 0.560 & 0.412 & 0.244 & 0.065 & 0.082 & 0.168 & 0.484 & 0.175 \\
\hline 104 & 0.573 & 0.431 & 0.274 & 0.122 & 0.154 & 0.263 & 0.493 & 0.299 \\
\hline
\end{tabular}




\begin{tabular}{|c|c|c|c|c|c|c|c|c|c|c|}
\hline \multicolumn{11}{|c|}{ SPRATT Expansion \% } \\
\hline & \multicolumn{2}{|c|}{ CONTROL } & \multicolumn{5}{|c|}{ FLYASH } & \multicolumn{3}{|c|}{ BLEND } \\
\hline Bucket \# & $\# 67$ & $\# 74$ & $\# 61$ & $\# 62$ & $\# 63$ & $\# 23$ & $\# 24$ & $\# 75$ & $\# 64$ & $\# 28$ \\
\hline Type & $\begin{array}{c}60: 40 \\
\text { Con }\end{array}$ & $\begin{array}{c}60: 40 \\
\text { Con }\end{array}$ & $\begin{array}{c}\text { Type F, } \\
\text { HA }\end{array}$ & $\begin{array}{c}\text { Type F, } \\
\text { HA }\end{array}$ & $\begin{array}{c}\text { Type F, } \\
\text { HA }\end{array}$ & $\begin{array}{c}\text { Type } F, \\
\text { HA }\end{array}$ & $\begin{array}{c}\text { Type F, } \\
\text { HA }\end{array}$ & $\begin{array}{c}\text { Type F, } \\
\text { HA }\end{array}$ & $\begin{array}{c}\text { Type F, } \\
\text { HA }\end{array}$ & $\begin{array}{c}\text { Type F, } \\
\text { HA }\end{array}$ \\
\hline $\mathrm{Na}_{2} \mathrm{O}_{\mathrm{e}}$ & $\begin{array}{c}5.25 \\
\left(\mathrm{~kg} / \mathrm{m}^{3}\right)\end{array}$ & $\begin{array}{c}5.25 \\
\left(\mathrm{~kg} / \mathrm{m}^{3}\right)\end{array}$ & $\begin{array}{c}4.46 \\
\left(\mathrm{~kg} / \mathrm{m}^{3}\right)\end{array}$ & $\begin{array}{c}4.20 \\
\left(\mathrm{~kg} / \mathrm{m}^{3}\right)\end{array}$ & $\begin{array}{c}3.94 \\
\left(\mathrm{~kg} / \mathrm{m}^{3}\right)\end{array}$ & $\begin{array}{c}4.46 \\
\left(\mathrm{~kg} / \mathrm{m}^{3}\right)\end{array}$ & $\begin{array}{c}3.94 \\
\left(\mathrm{~kg} / \mathrm{m}^{3}\right)\end{array}$ & $\begin{array}{c}3.94 \\
\left(\mathrm{~kg} / \mathrm{m}^{3}\right)\end{array}$ & $\begin{array}{c}3.94 \\
\left(\mathrm{~kg} / \mathrm{m}^{3}\right)\end{array}$ & $\begin{array}{c}3.68 \\
\left(\mathrm{~kg} / \mathrm{m}^{3}\right)\end{array}$ \\
\hline & $\begin{array}{c}1.25 \\
\text { Alkali }\end{array}$ & $\begin{array}{c}1.25 \\
\text { Alkali }\end{array}$ & $15 \% \mathrm{FA}$ & $20 \% \mathrm{FA}$ & $25 \% \mathrm{FA}$ & $15 \% \mathrm{FA}$ & $25 \% \mathrm{FA}$ & $5 \%$ Silica & $5 \%$ Silica & $5 \%$ Silica \\
\hline & & & & & & & & $20 \%$ FA & $20 \%$ FA & $25 \% \mathrm{FA}$ \\
\hline Weeks & & & & & & & & & & \\
\hline 0 & 0.000 & 0.000 & 0.000 & 0.000 & 0.000 & 0.000 & 0.000 & 0.000 & 0.000 & 0.000 \\
\hline 1 & 0.005 & 0.005 & -0.002 & -0.005 & 0.004 & 0.002 & 0.002 & -0.005 & -0.004 & -0.002 \\
\hline 2 & 0.007 & 0.002 & -0.001 & -0.004 & 0.003 & 0.007 & 0.006 & -0.005 & -0.001 & 0.000 \\
\hline 4 & 0.014 & 0.002 & 0.006 & 0.002 & 0.008 & 0.008 & 0.002 & -0.010 & -0.001 & -0.001 \\
\hline 8 & 0.055 & 0.023 & 0.011 & 0.006 & 0.012 & 0.016 & 0.011 & -0.005 & 0.004 & 0.003 \\
\hline 13 & 0.106 & 0.083 & 0.023 & 0.015 & 0.022 & 0.026 & 0.016 & 0.002 & 0.012 & 0.010 \\
\hline 18 & 0.140 & 0.123 & 0.040 & 0.023 & 0.029 & 0.036 & 0.023 & 0.001 & 0.015 & 0.015 \\
\hline 26 & 0.170 & 0.163 & 0.055 & 0.031 & 0.044 & 0.053 & 0.033 & 0.005 & 0.024 & 0.017 \\
\hline 39 & 0.180 & 0.200 & 0.069 & 0.039 & & 0.047 & 0.025 & 0.010 & 0.015 & 0.019 \\
\hline 52 & 0.202 & 0.214 & 0.085 & 0.054 & 0.048 & 0.074 & 0.046 & 0.016 & 0.015 & 0.020 \\
\hline 78 & 0.219 & 0.220 & 0.110 & 0.080 & 0.071 & 0.096 & 0.067 & 0.018 & 0.031 & 0.033 \\
\hline 104 & 0.225 & 0.227 & 0.123 & 0.091 & 0.078 & 0.104 & 0.073 & 0.024 & 0.036 & 0.036 \\
\hline
\end{tabular}




\section{Phase2:}

\begin{tabular}{|c|c|c|c|c|}
\hline \multicolumn{5}{|c|}{ RCA Expansion \% } \\
\hline \multicolumn{5}{|c|}{ Ternary Blends } \\
\hline & FLY ASH Type F LA & \multicolumn{2}{c|}{ SLAG } \\
\hline Bucket \# & $\# 30$ & $\# 31$ & $\# 32$ & $20 \%$ F LA \\
\hline & $5 \%$ Silica & $5 \%$ Silica & $5 \%$ Silica & $30 \%$ Slag \\
\hline & $20 \%$ FA & $25 \%$ F LA & $45 \%$ Slag & \\
\hline Weeks & & & & 0.000 \\
\hline 0 & 0.000 & 0.000 & 0.000 & 0.012 \\
\hline 1 & 0.012 & 0.010 & 0.013 & 0.014 \\
\hline 2 & 0.013 & 0.011 & 0.016 & 0.017 \\
\hline 4 & 0.017 & 0.015 & 0.022 & 0.015 \\
\hline 8 & 0.016 & 0.014 & 0.021 & 0.022 \\
\hline 13 & 0.024 & 0.022 & 0.030 & 0.021 \\
\hline 18 & 0.023 & 0.021 & 0.030 & 0.029 \\
\hline 26 & 0.024 & 0.022 & 0.031 & 0.030 \\
\hline 39 & 0.032 & 0.029 & 0.040 & 0.038 \\
\hline 52 & 0.033 & 0.031 & 0.041 & \\
\hline 78 & 0.040 & 0.037 & 0.049 & \\
\hline 104 & & & & \\
\hline
\end{tabular}




\begin{tabular}{|c|c|c|c|c|c|c|c|c|c|c|c|}
\hline \multicolumn{12}{|c|}{ RCA With Lithium Expansion \% } \\
\hline & \multicolumn{11}{|c|}{ CONTROL } \\
\hline Bucket \# & $\# 1$ & $\# 2$ & $\# 3$ & $\# 4$ & $\# 27$ & $\# 28$ & \#29 & $\# 5$ & \#6 & $\# 7$ & $\# 8$ \\
\hline $\mathrm{Li} / \mathrm{Na}+\mathrm{K}$ & 0.74 & 1.0 & 1.5 & 2.25 & 3 & 4 & 5 & 0.5 & 0.74 & 1.0 & 1.5 \\
\hline Weeks & & & & & & & & $\begin{array}{c}\text { Pre } \\
\text { Soaked }\end{array}$ & $\begin{array}{c}\text { Pre } \\
\text { Soaked }\end{array}$ & $\begin{array}{c}\text { Pre } \\
\text { Soaked }\end{array}$ & $\begin{array}{c}\text { Pre } \\
\text { Soaked } \\
\end{array}$ \\
\hline 0 & 0.000 & 0.000 & 0.000 & 0.000 & 0.000 & 0.000 & 0.000 & 0.000 & 0.000 & 0.000 & 0.000 \\
\hline 1 & 0.013 & -0.001 & 0.014 & 0.014 & 0.022 & 0.020 & 0.022 & 0.010 & 0.009 & 0.009 & 0.010 \\
\hline 2 & 0.019 & 0.005 & 0.019 & 0.018 & 0.028 & 0.026 & 0.029 & 0.015 & 0.013 & 0.013 & 0.014 \\
\hline 4 & 0.027 & 0.011 & 0.023 & 0.021 & 0.031 & 0.029 & 0.033 & 0.020 & 0.020 & 0.020 & 0.019 \\
\hline 8 & 0.033 & 0.016 & 0.029 & 0.026 & 0.040 & 0.038 & 0.037 & 0.042 & 0.039 & 0.035 & 0.034 \\
\hline 13 & 0.042 & 0.023 & 0.033 & 0.029 & 0.044 & 0.044 & 0.046 & 0.053 & 0.043 & 0.031 & 0.031 \\
\hline 18 & 0.047 & 0.025 & 0.035 & 0.031 & 0.046 & 0.045 & 0.049 & 0.063 & 0.050 & 0.035 & 0.034 \\
\hline 26 & 0.055 & 0.028 & 0.037 & 0.034 & 0.047 & 0.047 & 0.051 & 0.077 & 0.057 & 0.039 & 0.036 \\
\hline 39 & 0.063 & 0.036 & 0.043 & 0.039 & 0.049 & 0.050 & 0.054 & 0.092 & 0.063 & 0.042 & 0.037 \\
\hline 52 & 0.069 & 0.039 & 0.046 & 0.042 & 0.051 & 0.053 & 0.059 & 0.101 & 0.069 & 0.046 & 0.040 \\
\hline 78 & 0.073 & 0.042 & 0.047 & 0.043 & 0.058 & 0.064 & 0.066 & 0.114 & 0.077 & 0.053 & 0.046 \\
\hline 104 & 0.079 & 0.046 & 0.050 & 0.047 & & & & 0.118 & 0.081 & 0.054 & 0.047 \\
\hline
\end{tabular}




\begin{tabular}{|c|c|c|c|c|c|c|c|c|c|}
\hline \multicolumn{10}{|c|}{ RCA With Lithium Expansion \% } \\
\hline & \multicolumn{7}{|c|}{ FLY ASH F LA } & \multicolumn{7}{c|}{ FLY ASH Type CH LA } \\
\hline Bucket \# & $\# 9$ & $\# 10$ & $\# 11$ & $\# 12$ & $\# 13$ & $\# 14$ & $\# 15$ & $\# 16$ & $\# 17$ \\
\hline $\mathrm{Li} / \mathrm{Na}+\mathrm{K}$ & 0.5 & 0.74 & 1.0 & 1.5 & 0.5 & 0.5 & 0.74 & 1.0 & 1.5 \\
\hline & $\begin{array}{c}20 \% \mathrm{~F} \\
\text { LA }\end{array}$ & $\begin{array}{c}20 \% \mathrm{~F} \\
\text { LA }\end{array}$ & $\begin{array}{c}20 \% \mathrm{~F} \\
\text { LA }\end{array}$ & $\begin{array}{c}20 \% \mathrm{~F} \\
\text { LA }\end{array}$ & $\begin{array}{c}40 \% \\
\text { CH LA }\end{array}$ & $\begin{array}{c}25 \% \\
\text { CH LA }\end{array}$ & $\begin{array}{c}25 \% \\
\text { CH LA }\end{array}$ & $\begin{array}{c}25 \% \\
\text { CH LA }\end{array}$ & $\begin{array}{c}25 \% \\
\text { CH LA }\end{array}$ \\
\hline Weeks & & & & & & & & & \\
\hline 0 & 0.000 & 0.000 & 0.000 & 0.000 & 0.000 & 0.000 & 0.000 & 0.000 & 0.000 \\
\hline 1 & 0.010 & 0.010 & 0.010 & 0.012 & 0.000 & 0.008 & 0.007 & 0.005 & 0.007 \\
\hline 2 & 0.015 & 0.013 & 0.016 & 0.016 & 0.000 & 0.012 & 0.007 & 0.007 & 0.005 \\
\hline 4 & 0.018 & 0.016 & 0.017 & 0.017 & 0.006 & 0.017 & 0.015 & 0.014 & 0.012 \\
\hline 8 & 0.022 & 0.019 & 0.020 & 0.022 & 0.016 & 0.031 & 0.023 & 0.021 & 0.021 \\
\hline 13 & 0.026 & 0.020 & 0.021 & 0.020 & 0.023 & 0.043 & 0.033 & 0.030 & 0.025 \\
\hline 18 & 0.031 & 0.026 & 0.030 & 0.030 & 0.031 & 0.056 & 0.041 & 0.035 & 0.030 \\
\hline 26 & 0.036 & 0.030 & 0.033 & 0.032 & 0.044 & 0.078 & 0.056 & 0.044 & 0.037 \\
\hline 39 & 0.040 & 0.033 & 0.032 & 0.030 & 0.051 & 0.093 & 0.070 & 0.055 & 0.042 \\
\hline 52 & 0.045 & 0.038 & 0.038 & 0.037 & 0.067 & 0.111 & 0.081 & 0.063 & 0.046 \\
\hline 78 & 0.053 & 0.047 & 0.041 & 0.039 & 0.081 & 0.126 & 0.100 & 0.077 & 0.053 \\
\hline 104 & 0.053 & 0.046 & 0.045 & 0.043 & 0.092 & 0.141 & 0.109 & 0.086 & 0.057 \\
\hline
\end{tabular}




\begin{tabular}{|c|c|c|c|c|c|}
\hline \multicolumn{7}{|c|}{ RCA With Lithium Expansion \% } \\
\hline & \multicolumn{5}{|c|}{ SLAG } \\
\hline Bucket \# & $\# 18$ & $\# 19$ & $\# 20$ & $\# 21$ & $\# 22$ \\
\hline $\mathrm{Li} / \mathrm{Na}+\mathrm{K}$ & 0.5 & 0.5 & 0.74 & 1 & 1.5 \\
\hline Weeks & $50 \%$ Slag & $30 \%$ Slag & $30 \%$ Slag & $30 \%$ Slag & $30 \%$ Slag \\
\hline 0 & & & & & \\
\hline 1 & 0.000 & 0.000 & 0.000 & 0.000 & 0.000 \\
\hline 2 & 0.009 & 0.004 & 0.007 & 0.009 & 0.010 \\
\hline 4 & 0.010 & 0.012 & 0.013 & 0.017 & 0.014 \\
\hline 8 & 0.015 & 0.013 & 0.015 & 0.018 & 0.015 \\
\hline 13 & 0.022 & 0.022 & 0.025 & 0.026 & 0.022 \\
\hline 18 & 0.022 & 0.028 & 0.030 & 0.033 & 0.026 \\
\hline 26 & 0.027 & 0.034 & 0.036 & 0.038 & 0.032 \\
\hline 39 & 0.032 & 0.043 & 0.043 & 0.045 & 0.037 \\
\hline 52 & 0.038 & 0.051 & 0.050 & 0.051 & 0.042 \\
\hline 78 & 0.042 & 0.058 & 0.056 & 0.055 & 0.046 \\
\hline 104 & 0.049 & 0.069 & 0.065 & 0.066 & 0.054 \\
\hline & 0.053 & 0.070 & 0.066 & 0.067 & 0.054 \\
\hline
\end{tabular}




\begin{tabular}{|c|c|c|c|c|}
\hline \multicolumn{5}{|c|}{ RCA Expansion \% } \\
\hline \multicolumn{5}{|c|}{ Ternary Blends } \\
\hline Bucket \# & $\# 23$ & $\# 24$ & $\# 25$ & $\# 26$ \\
\hline $\mathrm{Li} / \mathrm{Na}+\mathrm{K}$ & 0.5 & 0.74 & 1 & 1.5 \\
\hline & $5 \%$ Silica & $5 \%$ Silica & $5 \%$ Silica & $5 \%$ Silica \\
\hline & $30 \%$ Slag & $30 \%$ Slag & $30 \%$ Slag & $30 \%$ Slag \\
\hline Weeks & & & & \\
\hline 0 & 0.000 & 0.000 & 0.000 & 0.000 \\
\hline 1 & 0.008 & 0.007 & 0.009 & 0.012 \\
\hline 2 & 0.010 & 0.012 & 0.011 & 0.014 \\
\hline 4 & 0.013 & 0.012 & 0.013 & 0.014 \\
\hline 8 & 0.015 & 0.015 & 0.015 & 0.017 \\
\hline 13 & 0.022 & 0.021 & 0.023 & 0.024 \\
\hline 18 & 0.026 & 0.025 & 0.024 & 0.028 \\
\hline 26 & 0.032 & 0.029 & 0.031 & 0.032 \\
\hline 39 & 0.031 & 0.031 & 0.030 & 0.031 \\
\hline 52 & 0.037 & 0.036 & 0.034 & 0.034 \\
\hline 78 & 0.044 & 0.041 & 0.041 & 0.041 \\
\hline 104 & 0.048 & 0.047 & 0.045 & 0.046 \\
\hline
\end{tabular}




\begin{tabular}{|c|c|c|c|c|}
\hline \multicolumn{5}{|c|}{ RCA Dilution Expansions \% } \\
\hline \multicolumn{7}{|c|}{$\mathbf{7 0 \%}$ RCA $\mathbf{3 0} \%$ Non reactive natural aggregate (St Mary) } \\
\hline Bucket \# & \#34 & \#35 & \#36 & \#37 \\
\hline & Control & $25 \%$ Fly Ash & $25 \%$ Fly Ash & $50 \%$ Slag \\
\hline Type & - & F LA & CI LA & \\
\hline Weeks & & & & 0.000 \\
\hline 0 & 0.000 & 0.000 & 0.000 & 0.007 \\
\hline 1 & 0.015 & 0.013 & 0.005 & 0.011 \\
\hline 2 & 0.017 & 0.013 & 0.008 & 0.013 \\
\hline 4 & 0.022 & 0.015 & 0.009 & 0.015 \\
\hline 8 & 0.032 & 0.017 & 0.009 & 0.020 \\
\hline 13 & 0.051 & 0.021 & 0.014 & 0.017 \\
\hline 18 & 0.057 & 0.018 & 0.011 & 0.024 \\
\hline 26 & 0.072 & 0.021 & 0.015 & 0.030 \\
\hline 39 & 0.091 & 0.028 & 0.023 & 0.034 \\
\hline 52 & 0.097 & 0.029 & 0.023 & 0.036 \\
\hline 78 & 0.111 & 0.035 & 0.031 & \\
\hline 104 & & & & \\
\hline
\end{tabular}


Spratt / St Mary Dilution Expansions \%

\begin{tabular}{|c|c|c|}
\hline \multicolumn{3}{|c|}{ Spratt / St Mary Dilution Expansions \% } \\
\hline & $\mathbf{5 0 \%}$ Spratt \& 50\% St Mary & $\mathbf{7 0 \%}$ Spratt \& 30\% St Mary \\
\hline Bucket \# & $\# 38$ & \\
\hline & & \\
\hline Weeks & & 0.000 \\
\hline 0 & 0.000 & 0.004 \\
\hline 1 & 0.007 & 0.007 \\
\hline 2 & 0.009 & 0.015 \\
\hline 4 & 0.015 & 0.042 \\
\hline 8 & 0.038 & 0.081 \\
\hline 13 & 0.074 & 0.095 \\
\hline 18 & 0.086 & 0.116 \\
\hline 26 & 0.107 & 0.136 \\
\hline 39 & 0.127 & 0.147 \\
\hline 52 & 0.139 & 0.157 \\
\hline 78 & 0.146 & \\
\hline 104 & & \\
\hline
\end{tabular}




\begin{tabular}{|c|c|c|c|c|}
\hline \multicolumn{5}{|c|}{ Non Reactive RCA Expansion \% } \\
\hline & Dufferin & Lafarg & Dufferin & Lafarg \\
\hline Bucket \# & $\# 40$ & $\# 41$ & $\# 42$ & $\# 43$ \\
\hline & & & Pre Soaked & Pre Soaked \\
\hline Weeks & & & & \\
\hline 0 & 0.000 & 0.000 & 0.000 & 0.000 \\
\hline 1 & 0.006 & 0.005 & 0.001 & 0.002 \\
\hline 2 & 0.004 & -0.001 & 0.004 & 0.008 \\
\hline 4 & 0.009 & 0.000 & 0.007 & 0.014 \\
\hline 8 & 0.011 & 0.002 & 0.011 & 0.018 \\
\hline 13 & 0.013 & 0.003 & 0.013 & 0.017 \\
\hline 18 & 0.017 & 0.007 & 0.018 & 0.024 \\
\hline 26 & 0.023 & 0.010 & 0.019 & 0.027 \\
\hline 39 & 0.027 & 0.012 & 0.025 & 0.031 \\
\hline 52 & 0.031 & 0.017 & 0.028 & 0.035 \\
\hline 78 & & & & \\
\hline 104 & & & & \\
\hline
\end{tabular}




\section{Appendix B: Atomic Concentrations}

\begin{tabular}{|c|c|c|c|c|c|c|c|c|c|c|c|c|c|c|}
\hline & \multirow[b]{2}{*}{ sample \# } & \multicolumn{10}{|c|}{ Atomic Concentrations } & \multirow[b]{2}{*}{ Total } & \multirow[b]{2}{*}{$\mathrm{Ca} / \mathrm{Si}$} & \multirow[b]{2}{*}{$\mathrm{Na}+\mathrm{K}$} \\
\hline & & 0 & $\mathrm{Na}$ & $\mathrm{Mg}$ & $\mathrm{AL}$ & $\mathrm{Si}$ & $\mathrm{P}$ & $\mathrm{S}$ & $\mathrm{K}$ & $\mathrm{Ca}$ & $\mathrm{Fe}$ & & & \\
\hline Gel-1 & $\# 4$ & $70.43 \%$ & $0.94 \%$ & $0.17 \%$ & & $18.16 \%$ & & & $2.86 \%$ & $7.44 \%$ & & $100.00 \%$ & 0.41 & $3.80 \%$ \\
\hline & & & & & & & & & & & & & & \\
\hline & $\# 7$ & $73.68 \%$ & $0.31 \%$ & & & $16.46 \%$ & & & $3.28 \%$ & $6.27 \%$ & & $100.00 \%$ & 0.38 & $3.59 \%$ \\
\hline Gel -2 & \#7 & $64.07 \%$ & $0.39 \%$ & t & & $19.65 \%$ & $0.55 \%$ & & $4.93 \%$ & $10.41 \%$ & & $100.00 \%$ & 0.53 & $5.32 \%$ \\
\hline Gel-2 & $\# 7$ & $69.44 \%$ & $0.43 \%$ & & & $18.17 \%$ & & & $3.95 \%$ & $8.02 \%$ & & $100.01 \%$ & 0.44 & $4.38 \%$ \\
\hline & $\# 7$ & $71.60 \%$ & $0.37 \%$ & & & $17.70 \%$ & & & $3.71 \%$ & $6.60 \%$ & & $99.98 \%$ & 0.37 & $4.08 \%$ \\
\hline & & & & & & & & & & & & & & \\
\hline & $\# 7$ & $71.85 \%$ & $0.92 \%$ & & & $17.66 \%$ & & $0.41 \%$ & $3.62 \%$ & $5.54 \%$ & & $100.00 \%$ & 0.31 & $4.54 \%$ \\
\hline Gel -3 & $\# 7$ & $72.06 \%$ & $0.64 \%$ & & & $16.00 \%$ & & $2.04 \%$ & $4.51 \%$ & $4.76 \%$ & & $100.01 \%$ & 0.30 & $5.15 \%$ \\
\hline Gel -z & $\# 7$ & $69.99 \%$ & $0.99 \%$ & & & $18.78 \%$ & & $0.67 \%$ & $3.85 \%$ & $5.72 \%$ & & $100.00 \%$ & 0.30 & $4.84 \%$ \\
\hline & $\# 7$ & $70.23 \%$ & $0.86 \%$ & $1.01 \%$ & & $17.01 \%$ & & $1.63 \%$ & $4.01 \%$ & $5.25 \%$ & & $100.00 \%$ & 0.31 & $4.87 \%$ \\
\hline & & & & & & & & & & & & & & \\
\hline & $\# 7$ & $73.61 \%$ & $0.30 \%$ & & & $16.40 \%$ & $0.14 \%$ & & $3.28 \%$ & $6.26 \%$ & & $99.99 \%$ & 0.38 & $3.58 \%$ \\
\hline Gel -4 & $\# 7$ & $64.07 \%$ & $0.39 \%$ & & & $19.65 \%$ & $0.55 \%$ & & $4.93 \%$ & $10.41 \%$ & & $100.00 \%$ & 0.53 & $5.32 \%$ \\
\hline Gel -4 & $\# 7$ & $69.34 \%$ & $0.42 \%$ & & & $18.09 \%$ & $0.20 \%$ & & $3.94 \%$ & $8.00 \%$ & & $99.99 \%$ & 0.44 & $4.36 \%$ \\
\hline & $\# 7$ & $71.55 \%$ & $0.37 \%$ & & & $17.64 \%$ & $0.15 \%$ & & $3.70 \%$ & $6.59 \%$ & & $100.00 \%$ & 0.37 & $4.07 \%$ \\
\hline & & & & & & & & & & & & & & \\
\hline & verage & $70.15 \%$ & $0.56 \%$ & $0.59 \%$ & & $17.80 \%$ & $0.32 \%$ & $1.19 \%$ & $3.89 \%$ & $7.02 \%$ & & $100.00 \%$ & 0.39 & $4.45 \%$ \\
\hline & SD & $3.03 \%$ & $0.27 \%$ & $0.59 \%$ & & $1.15 \%$ & $0.21 \%$ & $0.77 \%$ & $0.61 \%$ & $1.80 \%$ & & $0.01 \%$ & 0.07842986 & 0.00616 \\
\hline
\end{tabular}

RCA Stock - SEM Samples 


\begin{tabular}{|c|c|c|c|c|c|c|c|c|c|c|c|c|c|c|}
\hline & & \multicolumn{10}{|c|}{ Atomic Concentrations } & \multirow[b]{2}{*}{ Total } & \multirow[b]{2}{*}{$\mathrm{Ca} / \mathrm{Si}$} & \multirow[b]{2}{*}{$\mathrm{Na}+\mathrm{K}$} \\
\hline 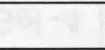 & sample \# & 0 & $\mathrm{Na}$ & $\mathrm{Mg}$ & $\mathrm{AL}$ & $\mathrm{Si}$ & $\mathrm{P}$ & $S$ & $\mathrm{~K}$ & $\mathrm{Ca}$ & $\mathrm{Fe}$ & & & \\
\hline Gel-1 & $\# 1$ & $59.33 \%$ & $1.34 \%$ & $0.20 \%$ & $0.48 \%$ & $21.64 \%$ & & & $6.18 \%$ & $10.56 \%$ & $0.27 \%$ & $100.00 \%$ & 0.49 & $7.52 \%$ \\
\hline \multirow{2}{*}{ Gel-2 } & $\# 1$ & $67.99 \%$ & $1.24 \%$ & $0.35 \%$ & & $20.24 \%$ & & & $4.56 \%$ & $5.61 \%$ & & $99.99 \%$ & 0.28 & $5.80 \%$ \\
\hline & $\# 1$ & $67.61 \%$ & $1.41 \%$ & & & $18.99 \%$ & & & $4.76 \%$ & $7.24 \%$ & & $100.01 \%$ & 0.38 & $6.17 \%$ \\
\hline & & & & & & & & & & & & & & \\
\hline \multirow{4}{*}{ Gel-3 } & \#1 & $69.18 \%$ & $0.92 \%$ & $0.09 \%$ & & $20.19 \%$ & & & $4.43 \%$ & $5.19 \%$ & & $100.00 \%$ & 0.26 & $5.35 \%$ \\
\hline & $\# 1$ & $69.38 \%$ & $0.82 \%$ & $0.13 \%$ & & $20.23 \%$ & & & $4.14 \%$ & $5.30 \%$ & & $100.00 \%$ & 0.26 & $4.96 \%$ \\
\hline & $\# 1$ & $64.64 \%$ & $0.98 \%$ & $0.10 \%$ & & $23.46 \%$ & & & $4.92 \%$ & $5.91 \%$ & & $100.01 \%$ & 0.25 & $5.90 \%$ \\
\hline & $\# 1$ & $68.28 \%$ & $1.34 \%$ & $0.27 \%$ & & $20.64 \%$ & & & $4.40 \%$ & $5.08 \%$ & & $100.01 \%$ & 0.25 & $5.74 \%$ \\
\hline & & & & & & & & & & & & & & \\
\hline \multirow{4}{*}{ Gel-4 } & $\# 1$ & $67.12 \%$ & $1.10 \%$ & $0.26 \%$ & & $21.64 \%$ & & & $4.65 \%$ & $5.22 \%$ & & $99.99 \%$ & 0.24 & $5.75 \%$ \\
\hline & $\# 1$ & $69.95 \%$ & $0.84 \%$ & $0.28 \%$ & & $19.93 \%$ & & & $4.35 \%$ & $4.66 \%$ & & $100.01 \%$ & 0.23 & $5.19 \%$ \\
\hline & \#1 & $68.66 \%$ & $0.89 \%$ & $0.19 \%$ & & $20.58 \%$ & & & $4.76 \%$ & $4.92 \%$ & & $100.00 \%$ & 0.24 & $5.65 \%$ \\
\hline & \#1 & $68.46 \%$ & $1.16 \%$ & $0.23 \%$ & & $20.42 \%$ & & & $4.73 \%$ & $4.99 \%$ & & $99.99 \%$ & 0.24 & $5.89 \%$ \\
\hline \multicolumn{2}{|c|}{ Average } & $67.33 \%$ & $1.09 \%$ & $0.21 \%$ & & $20.72 \%$ & & & $4.72 \%$ & $5.88 \%$ & $0.27 \%$ & $100.00 \%$ & 0.28 & $5.81 \%$ \\
\hline \multicolumn{2}{|c|}{ SD } & $3.00 \%$ & $0.22 \%$ & $0.08 \%$ & & $1.17 \%$ & & & $0.54 \%$ & $1.70 \%$ & & $0.01 \%$ & 0.08 & $0.66 \%$ \\
\hline
\end{tabular}

RCA in concrete prism - SEM Samples 


\begin{tabular}{|c|c|c|c|c|c|c|c|c|c|c|c|c|c|c|}
\hline & & \multicolumn{10}{|c|}{ Atomic Concentrations } & \multirow[b]{2}{*}{ Total } & \multirow[b]{2}{*}{$\mathrm{Ca} / \mathrm{Si}$} & \multirow[b]{2}{*}{$\mathrm{Na}+\mathrm{K}$} \\
\hline & sample \# & 0 & $\mathrm{Na}$ & $\mathrm{Mg}$ & $\mathrm{AL}$ & $\mathrm{Si}$ & $\mathrm{P}$ & $S$ & $\mathrm{~K}$ & $\mathrm{Ca}$ & $\mathrm{Fe}$ & & & \\
\hline \multirow{4}{*}{ Gel-1 } & \#4 & $68.60 \%$ & $1.42 \%$ & & & $23.86 \%$ & $0.92 \%$ & $0.87 \%$ & $1.40 \%$ & $2.93 \%$ & & $100.00 \%$ & 0.12279966 & $2.82 \%$ \\
\hline & $\# 4$ & $68.13 \%$ & $1.05 \%$ & $0.75 \%$ & & $19.58 \%$ & $3.18 \%$ & $0.33 \%$ & $0.93 \%$ & $6.04 \%$ & & $99.99 \%$ & 0.30847804 & $1.98 \%$ \\
\hline & $\# 4$ & $65.92 \%$ & $1.13 \%$ & $0.33 \%$ & & $24.25 \%$ & $2.00 \%$ & $0.94 \%$ & $1.48 \%$ & $3.93 \%$ & & $99.98 \%$ & 0.16206186 & $2.61 \%$ \\
\hline & $\# 4$ & $69.00 \%$ & $1.00 \%$ & $0.28 \%$ & & $23.75 \%$ & $1.51 \%$ & $1.04 \%$ & $0.92 \%$ & $2.48 \%$ & & $99.98 \%$ & 0.10442105 & $1.92 \%$ \\
\hline \multirow{5}{*}{ Gel-2 } & $\# 4$ & $67.19 \%$ & $0.23 \%$ & $0.37 \%$ & & $25.22 \%$ & $2.18 \%$ & $0.24 \%$ & $1.75 \%$ & $2.81 \%$ & & $99.99 \%$ & 0.11141951 & $1.98 \%$ \\
\hline & $\# 4$ & $65.52 \%$ & $0.29 \%$ & $0.13 \%$ & & $26.94 \%$ & $1.80 \%$ & $0.38 \%$ & $1.93 \%$ & $3.02 \%$ & & $100.01 \%$ & 0.11210097 & $2.22 \%$ \\
\hline & \#4 & $64.71 \%$ & $0.24 \%$ & $0.27 \%$ & & $28.02 \%$ & $1.79 \%$ & $0.27 \%$ & $1.84 \%$ & $2.87 \%$ & & $100.01 \%$ & 0.10242684 & $2.08 \%$ \\
\hline & $\# 4$ & $64.91 \%$ & $0.24 \%$ & $0.21 \%$ & & $27.96 \%$ & $2.04 \%$ & $0.26 \%$ & $1.41 \%$ & $2.96 \%$ & & $99.99 \%$ & 0.10586552 & $1.65 \%$ \\
\hline & $\# 4$ & $65.38 \%$ & $0.41 \%$ & $0.31 \%$ & & $25.60 \%$ & $2.17 \%$ & $0.28 \%$ & $2.10 \%$ & $3.74 \%$ & & $99.99 \%$ & 0.14609375 & $2.51 \%$ \\
\hline \multirow{4}{*}{ Gel-3 } & $\# 4$ & $69.00 \%$ & $1.00 \%$ & $0.28 \%$ & & $23.75 \%$ & $1.51 \%$ & $1.04 \%$ & $0.92 \%$ & $2.48 \%$ & & $99.98 \%$ & 0.10442105 & $1.92 \%$ \\
\hline & \#4 & $65.92 \%$ & $1.13 \%$ & $0.33 \%$ & & $24.25 \%$ & $2.00 \%$ & $0.94 \%$ & $1.48 \%$ & $3.93 \%$ & & $99.98 \%$ & 0.16206186 & $2.61 \%$ \\
\hline & $\# 4$ & $68.13 \%$ & $1.05 \%$ & $0.75 \%$ & & $19.58 \%$ & $3.18 \%$ & $0.33 \%$ & $0.93 \%$ & $6.04 \%$ & & $99.99 \%$ & 0.30847804 & $1.98 \%$ \\
\hline & $\# 4$ & $68.44 \%$ & $1.36 \%$ & $0.24 \%$ & & $23.85 \%$ & $0.92 \%$ & $0.86 \%$ & $1.40 \%$ & $2.93 \%$ & & $100.00 \%$ & 0.12285115 & $2.76 \%$ \\
\hline \multirow{4}{*}{ Gel-4 } & \#2 & $70.97 \%$ & $1.43 \%$ & $1.17 \%$ & & $18.86 \%$ & & & $2.90 \%$ & $4.68 \%$ & & $100.01 \%$ & 0.24814422 & $4.33 \%$ \\
\hline & \#2 & $71.17 \%$ & $1.03 \%$ & $1.00 \%$ & & $19.99 \%$ & & & $2.85 \%$ & $3.96 \%$ & & $100.00 \%$ & 0.19809905 & $3.88 \%$ \\
\hline & $\# 2$ & $68.36 \%$ & $1.07 \%$ & $0.88 \%$ & & $22.35 \%$ & & & $3.03 \%$ & $4.32 \%$ & & $100.01 \%$ & 0.19328859 & $4.10 \%$ \\
\hline & $\# 2$ & $70.09 \%$ & $0.86 \%$ & $0.89 \%$ & & $19.63 \%$ & & & $3.39 \%$ & $5.14 \%$ & & $100.00 \%$ & 0.26184412 & $4.25 \%$ \\
\hline \multirow{4}{*}{ Gel-5 } & $\# 2$ & $68.62 \%$ & $0.55 \%$ & $0.53 \%$ & & $17.13 \%$ & & $0.43 \%$ & $4.41 \%$ & $8.33 \%$ & & $100.00 \%$ & 0.48628138 & $4.96 \%$ \\
\hline & \#2 & $70.51 \%$ & $0.41 \%$ & $0.49 \%$ & & $17.08 \%$ & & & $4.10 \%$ & $7.42 \%$ & & $100.01 \%$ & 0.43442623 & $4.51 \%$ \\
\hline & $\# 2$ & $70.10 \%$ & $0.51 \%$ & $0.36 \%$ & & $17.60 \%$ & & & $4.24 \%$ & $7.19 \%$ & & $100.00 \%$ & 0.40852273 & $4.75 \%$ \\
\hline & \#2 & $69.58 \%$ & $0.40 \%$ & $0.55 \%$ & & $17.92 \%$ & & $0.32 \%$ & $4.20 \%$ & $7.03 \%$ & & $100.00 \%$ & 0.39229911 & $4.60 \%$ \\
\hline \multirow{4}{*}{ Gel-6 } & $\# 2$ & $70.49 \%$ & $0.94 \%$ & $0.78 \%$ & & $18.86 \%$ & & $0.38 \%$ & $3.55 \%$ & $5.00 \%$ & & $100.00 \%$ & 0.26511135 & $4.49 \%$ \\
\hline & \#2 & $72.62 \%$ & $1.04 \%$ & $0.53 \%$ & & $17.49 \%$ & $0.41 \%$ & & $3.15 \%$ & $4.76 \%$ & & $100.00 \%$ & 0.27215552 & $4.19 \%$ \\
\hline & \#2 & $65.40 \%$ & $0.99 \%$ & $0.93 \%$ & & $22.10 \%$ & & & $4.16 \%$ & $6.14 \%$ & $0.29 \%$ & $100.01 \%$ & 0.27782805 & $5.15 \%$ \\
\hline & \#2 & $66.26 \%$ & $0.99 \%$ & $0.96 \%$ & & $21.40 \%$ & $0.61 \%$ & & $3.72 \%$ & $5.78 \%$ & $0.28 \%$ & $100.00 \%$ & 0.27009346 & $4.71 \%$ \\
\hline \multicolumn{2}{|c|}{ Average } & $68.20 \%$ & $0.83 \%$ & $0.56 \%$ & & $21.88 \%$ & $1.75 \%$ & $0.56 \%$ & $2.49 \%$ & $4.64 \%$ & $0.29 \%$ & $100.00 \%$ & 0.22726292 & $3.32 \%$ \\
\hline \multicolumn{2}{|r|}{ SD } & $2.22 \%$ & $0.39 \%$ & $0.30 \%$ & & $3.46 \%$ & $0.81 \%$ & $0.32 \%$ & $1.23 \%$ & $1.72 \%$ & $0.01 \%$ & $0.01 \%$ & 0.1152634 & $1.21 \%$ \\
\hline
\end{tabular}

RCA in solution 0.7 Molarity with Li: $\mathrm{Na}+\mathrm{K}$ of $1: 1$ for 4 weeks - SEM Samples 


\begin{tabular}{|c|c|c|c|c|c|c|c|c|c|c|c|c|c|c|}
\hline & & \multicolumn{10}{|c|}{ Atomic Concentrations } & \multirow[b]{2}{*}{ Total } & \multirow[b]{2}{*}{$\mathrm{Ca} / \mathrm{Si}$} & \multirow[b]{2}{*}{$\mathrm{Na}+\mathrm{K}$} \\
\hline & sample \# & $\mathrm{O}$ & $\mathrm{Na}$ & $\mathrm{Mg}$ & $\mathrm{AL}$ & $\mathrm{Si}$ & $\mathrm{P}$ & $S$ & $\mathrm{~K}$ & $\mathrm{Ca}$ & $\mathrm{Fe}$ & & & \\
\hline \multirow{4}{*}{ Gel-1 } & $\# 1$ & $68.77 \%$ & $0.32 \%$ & $0.51 \%$ & & $17.05 \%$ & & & $2.47 \%$ & $10.88 \%$ & & $100.00 \%$ & 0.63812317 & $2.79 \%$ \\
\hline & $\# 1$ & $69.90 \%$ & $0.45 \%$ & $0.29 \%$ & & $18.42 \%$ & & & $2.77 \%$ & $8.16 \%$ & & $99.99 \%$ & 0.44299674 & $3.22 \%$ \\
\hline & $\# 1$ & $69.54 \%$ & $0.38 \%$ & $0.26 \%$ & & $19.75 \%$ & & & $3.30 \%$ & $6.76 \%$ & & $99.99 \%$ & 0.34227848 & $3.68 \%$ \\
\hline & $\# 1$ & $69.52 \%$ & $0.32 \%$ & $0.45 \%$ & & $19.39 \%$ & & & $3.04 \%$ & $7.28 \%$ & & $100.00 \%$ & 0.37545126 & $3.36 \%$ \\
\hline & & & & & & & & & & & & & & \\
\hline \multirow{3}{*}{ Gel-2 } & $\# 1$ & $68.53 \%$ & $0.33 \%$ & $0.33 \%$ & & $20.21 \%$ & & & $3.41 \%$ & $7.19 \%$ & & $100.00 \%$ & 0.35576447 & $3.74 \%$ \\
\hline & $\# 1$ & $70.18 \%$ & $0.15 \%$ & $0.41 \%$ & & $18.50 \%$ & & & $3.12 \%$ & $7.66 \%$ & & $100.02 \%$ & 0.41405405 & $3.27 \%$ \\
\hline & $\# 1$ & $70.49 \%$ & $0.25 \%$ & $0.24 \%$ & $0.21 \%$ & $18.00 \%$ & & & $2.86 \%$ & $7.94 \%$ & & $99.99 \%$ & 0.44111111 & $3.11 \%$ \\
\hline \multirow{4}{*}{ Gel-3 } & \#1 & $69.50 \%$ & $0.50 \%$ & & & $21.24 \%$ & & & $3.27 \%$ & $5.50 \%$ & & $100.01 \%$ & 0.25894539 & $3.77 \%$ \\
\hline & $\# 1$ & $70.44 \%$ & $0.44 \%$ & & & $18.54 \%$ & & & $3.55 \%$ & $7.03 \%$ & & $100.00 \%$ & 0.37918015 & $3.99 \%$ \\
\hline & $\# 1$ & $72.24 \%$ & $0.39 \%$ & $0.44 \%$ & & $15.59 \%$ & & & $2.01 \%$ & $8.83 \%$ & & $99.50 \%$ & 0.56638871 & $2.40 \%$ \\
\hline & $\# 1$ & $67.81 \%$ & $0.16 \%$ & & & $21.81 \%$ & & & $3.34 \%$ & $6.88 \%$ & & $100.00 \%$ & 0.31545163 & $3.50 \%$ \\
\hline & & & & & & & & & & & & & & \\
\hline \multirow{2}{*}{ Gel-4 } & $\# 1$ & $69.50 \%$ & $0.21 \%$ & $0.65 \%$ & & $21.17 \%$ & & & $2.57 \%$ & $5.90 \%$ & & $100.00 \%$ & 0.27869627 & $2.78 \%$ \\
\hline & $\# 1$ & $69.55 \%$ & $0.05 \%$ & $0.37 \%$ & & $19.48 \%$ & & & $2.52 \%$ & $8.03 \%$ & & $100.00 \%$ & 0.41221766 & $2.57 \%$ \\
\hline & & & & & & & & & & & & & & \\
\hline \multicolumn{2}{|r|}{ Average } & $69.69 \%$ & $0.30 \%$ & $0.40 \%$ & $0.21 \%$ & $19.17 \%$ & & & $2.94 \%$ & $7.54 \%$ & & $99.96 \%$ & 0.40158916 & $3.24 \%$ \\
\hline \multicolumn{2}{|r|}{ SD } & $1.07 \%$ & $0.13 \%$ & $0.13 \%$ & & $1.75 \%$ & & & $0.45 \%$ & $1.35 \%$ & & $0.14 \%$ & 0.10658515 & $0.50 \%$ \\
\hline
\end{tabular}

RCA in solution 0.7 Molarity without Lithium for 4 weeks- SEM Samples 


\begin{tabular}{|c|c|c|c|c|c|c|c|c|c|c|}
\hline \multirow[b]{2}{*}{ Spectrum \# } & \multicolumn{9}{|c|}{ Atomic concentrations } & \multirow[b]{2}{*}{$\mathrm{Na}+\mathrm{K}$} \\
\hline & $\mathrm{O}$ & $\mathrm{Na}$ & $\mathrm{Mg}$ & $\mathrm{Al}$ & $\mathrm{Si}$ & $\mathrm{P}$ & $\mathrm{S}$ & $\mathrm{K}$ & $\mathrm{Ca}$ & \\
\hline Spec-1 & 70.13 & 0.52 & 2.14 & 1.2 & 13.73 & 0.34 & 0.94 & 0.34 & 10.65 & 0.86 \\
\hline Spec-2 & 70.81 & 0.69 & 1.88 & 0.65 & 13.99 & 0.42 & 0.71 & 0.44 & 10.41 & 1.13 \\
\hline Spec-3 & 70.26 & 0.34 & 1.61 & 1.38 & 13.01 & 0.58 & 1.27 & 0.28 & 11.27 & 0.62 \\
\hline Spec-4 & 72.1 & 0.47 & 1.64 & 1.41 & 12.66 & 0.26 & 1.15 & 0.32 & 9.99 & 0.79 \\
\hline Spec-1 & 70.58 & 0.48 & 1.24 & 1.47 & 11.14 & & 1.94 & 0.37 & 12.78 & 0.85 \\
\hline Spec-2 & 71.74 & 0.64 & 0.73 & 1.13 & 11.75 & & 1.55 & 0.38 & 12.08 & 1.02 \\
\hline Spec-3 & 71.76 & 0.6 & 2.52 & 2.01 & 10.35 & & 1.48 & 0.37 & 10.91 & 0.97 \\
\hline Spec-4 & 77.72 & 0.36 & 0.72 & 6.42 & 2.26 & & 0.4 & 0.15 & 11.98 & 0.51 \\
\hline Spec-1 & 70.29 & 0.52 & 2.15 & 1.2 & 13.85 & & 0.96 & 0.34 & 10.68 & 0.86 \\
\hline Spec-2 & 71.01 & 0.69 & 1.9 & 0.65 & 14.14 & & 0.73 & 0.44 & 10.44 & 1.13 \\
\hline Spec-4 & 72.22 & 0.48 & 1.65 & 1.41 & 12.74 & & 1.16 & 0.33 & 10.01 & 0.81 \\
\hline \multicolumn{2}{|c|}{ Average } & 0.53 & & & 11.78 & & & 0.34 & 11.02 & 0.87 \\
\hline \multicolumn{2}{|c|}{ SD } & 0.12 & & & 3.39 & & & 0.08 & 0.91 & 0.19 \\
\hline
\end{tabular}

Paste of RCA Stock - SEM Samples

\begin{tabular}{|c|c|c|c|c|c|c|c|c|c|c|}
\hline & \multicolumn{9}{|c|}{ Atomic concentrations } & \multicolumn{1}{c|}{} \\
\hline Spectrum \# & $\mathrm{O}$ & $\mathrm{Na}$ & $\mathrm{Mg}$ & $\mathrm{Al}$ & $\mathrm{Si}$ & $\mathrm{P}$ & $\mathrm{S}$ & $\mathrm{K}$ & $\mathrm{Ca}$ & $\mathrm{Na}+\mathrm{K}$ \\
\hline Spec-1 & 69.16 & 0.76 & 1.98 & 1.77 & 14.7 & 0.21 & 0.51 & 0.49 & 10.42 & 1.25 \\
\hline Spec-2 & 68.89 & 0.62 & 2.79 & 1.38 & 15.8 & 0.05 & 0.58 & 0.57 & 9.32 & 1.19 \\
\hline Spec-3 & 68.38 & 0.7 & 1.8 & 1.73 & 15.28 & 0.27 & 0.31 & 0.33 & 11.19 & 1.03 \\
\hline Spec-4 & 71.34 & 0.71 & 2.77 & 1.17 & 14.04 & 0.24 & 0.28 & 0.34 & 9.11 & 1.05 \\
\hline Spec-5 & 70.84 & 1.18 & 1.14 & 3.75 & 9.75 & 0.15 & 0.68 & 0.63 & 11.9 & 1.81 \\
\hline Spec-3 & 70.72 & 0.61 & 1.42 & 1.25 & 13.89 & 0.27 & 0.42 & 0.28 & 11.13 & 0.89 \\
\hline Spec-4 & 65.12 & 0.13 & 2.19 & 3.62 & 8.07 & 0.15 & 2.66 & 0.28 & 17.77 & 0.41 \\
\hline Spec-2 & 69.48 & 0.52 & 3.58 & 1.87 & 10.24 & 0.16 & 0.99 & 0.28 & 12.89 & 0.8 \\
\hline \multicolumn{2}{|c|}{ Average } & 0.65 & & & 12.72 & & & 0.40 & 11.72 & 1.05 \\
\hline \multicolumn{2}{|c|}{ SD } & 0.29 & & & 2.92 & & & 0.14 & 2.75 & 0.40 \\
\hline
\end{tabular}

Paste of RCA in concrete prism - SEM Samples 


\begin{tabular}{|c|c|c|c|c|c|c|c|c|c|c|c|}
\hline & \multicolumn{10}{|c}{ Atomic concentrations } & \multicolumn{1}{l|}{} \\
\hline Spectrum \# & $\mathrm{O}$ & $\mathrm{Na}$ & $\mathrm{Mg}$ & $\mathrm{Al}$ & $\mathrm{Si}$ & $\mathrm{P}$ & $\mathrm{S}$ & $\mathrm{K}$ & $\mathrm{Ca}$ & $\mathrm{Fe}$ & $\mathrm{Na}+\mathrm{K}$ \\
\hline Spec-1 & 72.62 & 0.03 & 2.43 & 1.24 & 7.93 & 0.67 & 0.8 & 0.13 & 13.82 & 0.33 & 0.16 \\
\hline Spec-2 & 71.43 & -0.02 & 0.9 & 1.27 & 7.84 & 0.89 & 1.09 & 0.1 & 16.24 & 0.24 & 0.08 \\
\hline Spec-3 & 70.54 & 0.02 & 1.02 & 3.15 & 3.4 & 1.55 & 0.63 & 0.03 & 19.39 & 0.26 & 0.05 \\
\hline Spec-4 & 72.66 & -0.03 & 1.14 & 2.23 & 5.82 & 1.74 & 1.09 & 0.14 & 14.95 & 0.24 & 0.11 \\
\hline Spec-1 & 70.51 & 0.03 & 0.63 & 1.76 & 7.46 & 1.51 & 1.46 & 0.02 & 16.24 & 0.39 & 0.05 \\
\hline Spec-2 & 64.07 & 0.37 & 0.92 & 1.57 & 16.09 & 1.79 & 2.1 & 0.27 & 12.43 & 0.38 & 0.64 \\
\hline Spec-3 & 64.74 & 0.21 & 2.04 & 2.25 & 17.89 & 0.84 & 2.39 & 0.06 & 9.01 & 0.57 & 0.27 \\
\hline Spec-4 & 69.36 & 0.09 & 1.01 & 2.04 & 10.84 & 0.85 & 3.44 & 0.11 & 11.87 & 0.39 & 0.2 \\
\hline \multicolumn{2}{|c|}{ Average } & 0.09 & & & 9.66 & & & 0.11 & 14.24 & 0.35 & 0.20 \\
\hline \multicolumn{2}{|c|}{ SD } & $13.70 \%$ & & & 5.01 & & & 0.08 & 3.19 & 0.11 & 0.20 \\
\hline
\end{tabular}

Paste of RCA in Solution 0.7 Molarity with Li: $\mathrm{Na}+\mathrm{K}$ of 1:1 for 4 weeks - SEM Samples

\begin{tabular}{|c|c|c|c|c|c|c|c|c|c|c|c|}
\hline \multirow[b]{2}{*}{ Spectrum \# } & \multicolumn{10}{|c|}{ Atomic Concentrations } & \multirow[b]{2}{*}{$\mathrm{Na}+\mathrm{K}$} \\
\hline & $\mathrm{O}$ & $\mathrm{Na}$ & $\mathrm{Mg}$ & $\mathrm{Al}$ & $\mathrm{Si}$ & $\mathrm{P}$ & $\mathrm{S}$ & $\mathrm{K}$ & $\mathrm{Ca}$ & $\mathrm{Fe}$ & \\
\hline Spec-1 & 75.99 & 0.34 & 1.48 & 0.92 & 3.23 & 0.23 & 0.3 & 0.37 & 16.21 & 0.94 & 0.71 \\
\hline Spec-2 & 72.34 & 0.13 & 2.04 & 2.15 & 5.95 & & 0.43 & 0.09 & 16.49 & 0.38 & 0.22 \\
\hline Spec-3 & 70.24 & 0.03 & 1.22 & 3.17 & 9.24 & 0.59 & 0.64 & 0.14 & 14.15 & 0.58 & 0.17 \\
\hline Spec-4 & 70.39 & 0.24 & 2.53 & 1.81 & 5.74 & & 0.37 & 0.15 & 18.19 & 0.58 & 0.39 \\
\hline Spec-1 & 69.14 & 0.04 & 2.66 & 2.66 & 7.33 & 0.44 & 0.7 & 0.14 & 15.32 & 1.57 & 0.18 \\
\hline Spec-2 & 68.74 & 0.18 & 2.17 & 1.04 & 11.45 & 0.46 & & 0.12 & 15.4 & 0.45 & 0.3 \\
\hline Spec-3 & 71.8 & 0.06 & 1.55 & 1.31 & 8.74 & & 0.63 & 0.12 & 15.33 & 0.46 & 0.18 \\
\hline Spec-4 & 63.98 & 0.18 & 0.5 & 0.4 & 2.83 & & 0.64 & 0.1 & 30.97 & 0.4 & 0.28 \\
\hline \multicolumn{2}{|c|}{ Average } & 0.15 & & & 6.81 & & & 0.15 & 17.76 & 0.67 & 0.30 \\
\hline \multicolumn{2}{|c|}{$s d$} & 0.11 & & & & & & 0.09 & 5.47 & 0.41 & 0.18 \\
\hline
\end{tabular}

Paste of RCA in Solution 0.7 Molarity without Lithium for 4 weeks - SEM Samples 
Appendix C: Backscattered Electron Images for RCA 
RCA aggregate stock

Gel-1

Spectrum processing

No peaks omitted

Processing option: All elements analyzed (Normalised)

Number of iterations $=5$

Standard:

O SiO2 1-Jun-1999 12:00 AM

$\mathrm{Na}$ Albite 1-Jun-1999 12:00 AM

$\mathrm{Mg} \mathrm{MgO}$ 1-Jun-1999 12:00 AM

$\mathrm{Si} \quad \mathrm{SiO} 2$ 1-Jun-1999 12:00 AM

K MAD-10 Feldspar 1-Jun-1999 12:00 AM

Ca Wollastonite 1-Jun-1999 12:00 AM

\begin{tabular}{l|ll}
\hline Element & Weight\% & Atomic\% \\
& & \\
O K & 54.37 & 70.43 \\
$\mathrm{Na} \mathrm{K}$ & 1.04 & 0.94 \\
$\mathrm{Mg} \mathrm{K}$ & 0.20 & 0.17 \\
$\mathrm{Si} \mathrm{K}$ & 24.61 & 18.16 \\
$\mathrm{~K} \mathrm{~K}$ & 5.39 & 2.86 \\
$\mathrm{Ca} \mathrm{K}$ & 14.39 & 7.44 \\
& & \\
Totals & 100.00 & \\
\hline
\end{tabular}
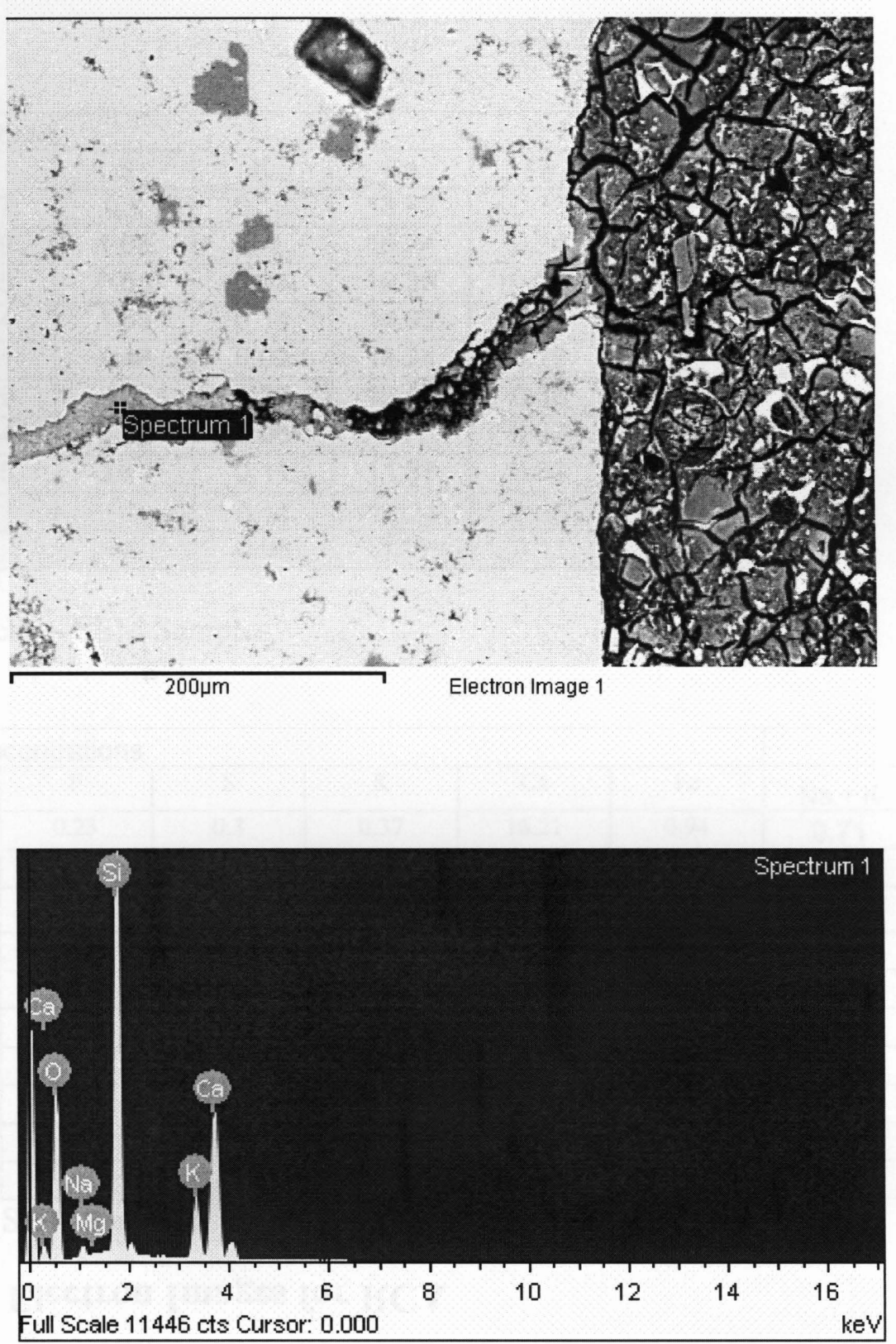
RCA aggregate stock

Gel-2

Spectrum processing:

Peak possibly omitted: $2.308 \mathrm{keV}$

Processing option: All elements analyzed (Normalised)

Number of iterations $=6$

\section{Standard:}

O SiO2 1-Jun-1999 12:00 AM

Na Albite 1-Jun-1999 12:00 AM

$\mathrm{Si} \quad \mathrm{SiO} 2$ 1-Jun-1999 12:00 AM

K MAD-10 Feldspar 1-Jun-1999 12:00 AM

Ca Wollastonite 1-Jun-1999 12:00 AM

\begin{tabular}{l|ll}
\hline Element & Weight\% & Atomic\% \\
& & \\
O K & 58.13 & 73.68 \\
Na K & 0.35 & 0.31 \\
Si K & 22.80 & 16.46 \\
K K & 6.33 & 3.28 \\
Ca K & 12.40 & 6.27 \\
& & \\
Totals & 100.00 & \\
\hline
\end{tabular}
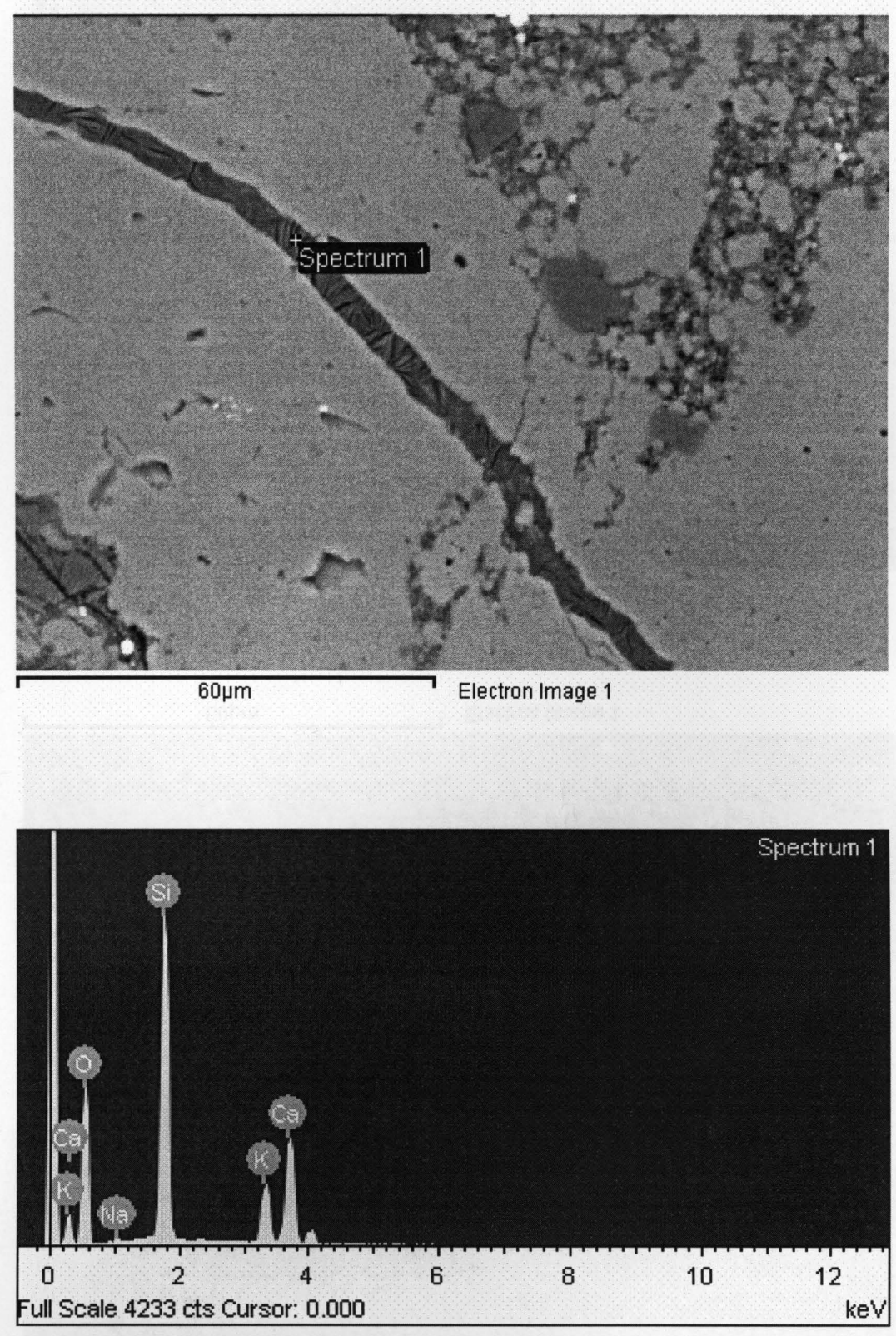
RCA aggregate stock

Gel-3

Spectrum processing:

No peaks omitted

Processing option: All elements analyzed (Normalised)

Number of iterations $=5$

\section{Standard:}

O SiO2 1-Jun-1999 12:00 AM

$\mathrm{Na}$ Albite 1-Jun-1999 12:00 AM

$\mathrm{Si} \quad \mathrm{SiO} 2$ 1-Jun-1999 12:00 AM

S FeS2 1-Jun-1999 12:00 AM

K MAD-10 Feldspar 1-Jun-1999 12:00 AM

Ca Wollastonite 1-Jun-1999 12:00 AM

\begin{tabular}{l|ll}
\hline Element & Weight\% & Atomic\% \\
& & \\
O K & 56.25 & 71.85 \\
Na K & 1.03 & 0.92 \\
Si K & 24.28 & 17.66 \\
S K & 0.65 & 0.41 \\
K K & 6.93 & 3.62 \\
Ca K & 10.86 & 5.54 \\
& & \\
Totals & 100.00 & \\
\hline
\end{tabular}

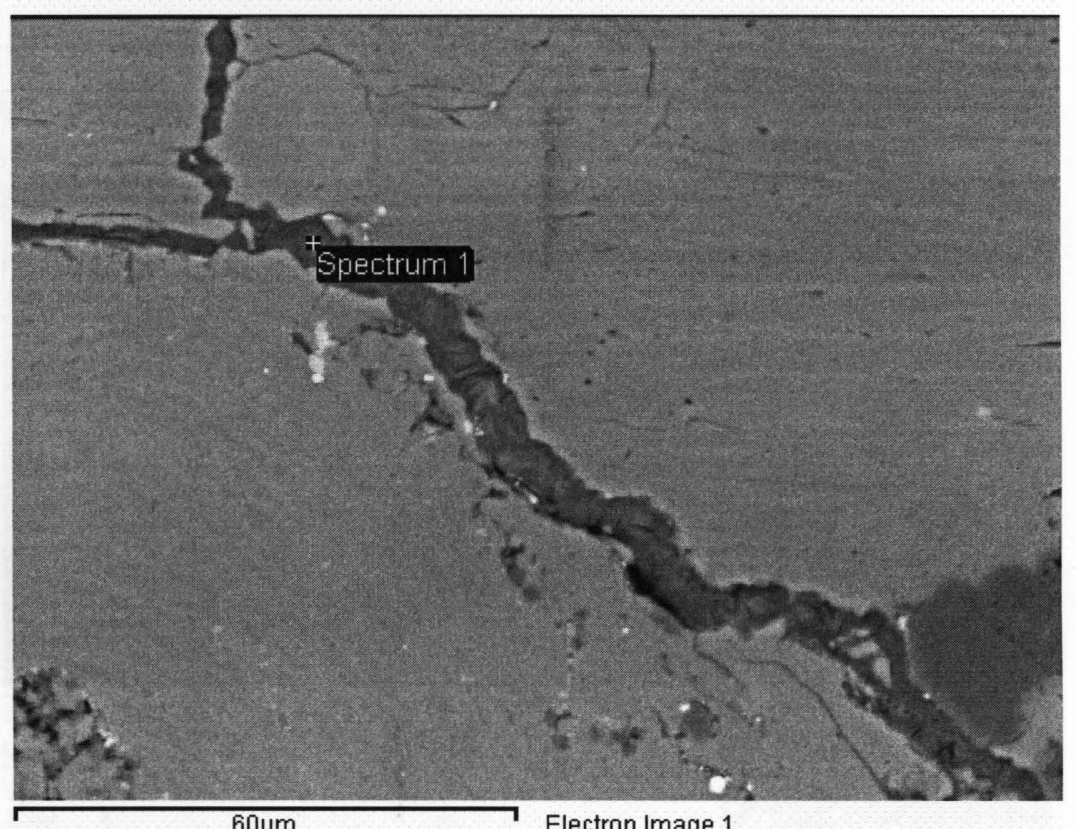

$60 \mu \mathrm{m}$

Electron Image

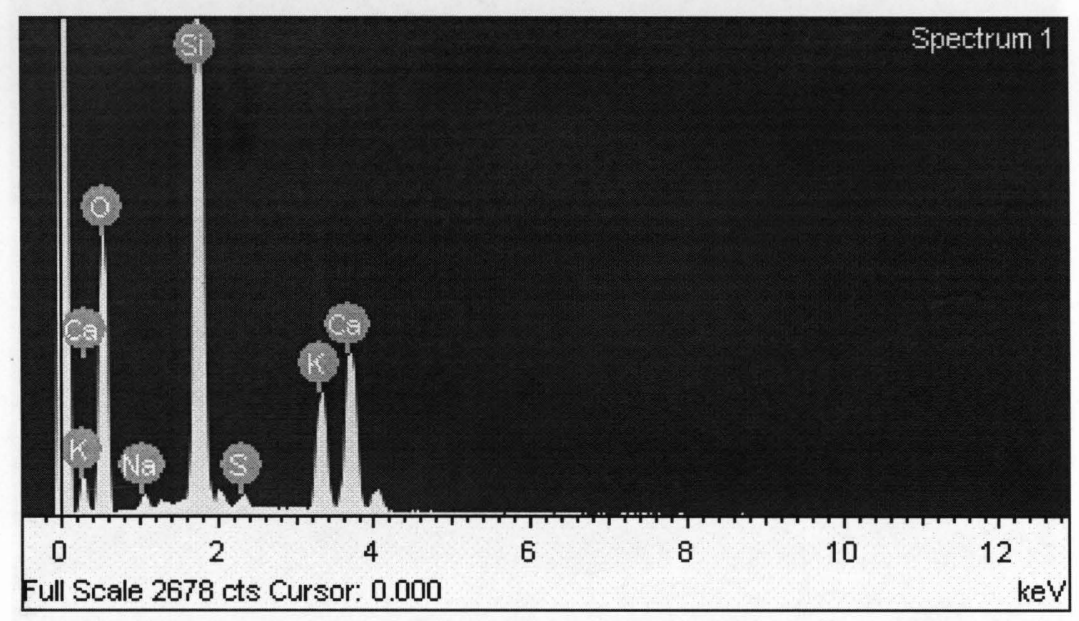


RCA aggregate in concrete prism

Gel-1

Spectrum processing:

Peak possibly omitted: $10.500 \mathrm{keV}$

Processing option: All elements analyzed (Normalised) Number of iterations $=$

\section{Standard:}

O $\mathrm{SiO} 2$ 1-Jun-1999 12:00 AM

$\mathrm{Na}$ Albite 1-Jun-1999 12:00 AM

Si SiO2 1-Jun-1999 12:00 AM

K MAD-10 Feldspar 1-Jun-1999 12:00 AM

Ca Wollastonite 1-Jun-1999 12:00 AM

\begin{tabular}{l|ll}
\hline Element & Weight\% & Atomic\% \\
& & \\
O K & 50.94 & 67.61 \\
Na K & 1.52 & 1.41 \\
Si K & 25.11 & 18.99 \\
K K & 8.76 & 4.76 \\
Ca K & 13.66 & 7.24 \\
& & \\
Totals & 100.00 & \\
\hline
\end{tabular}
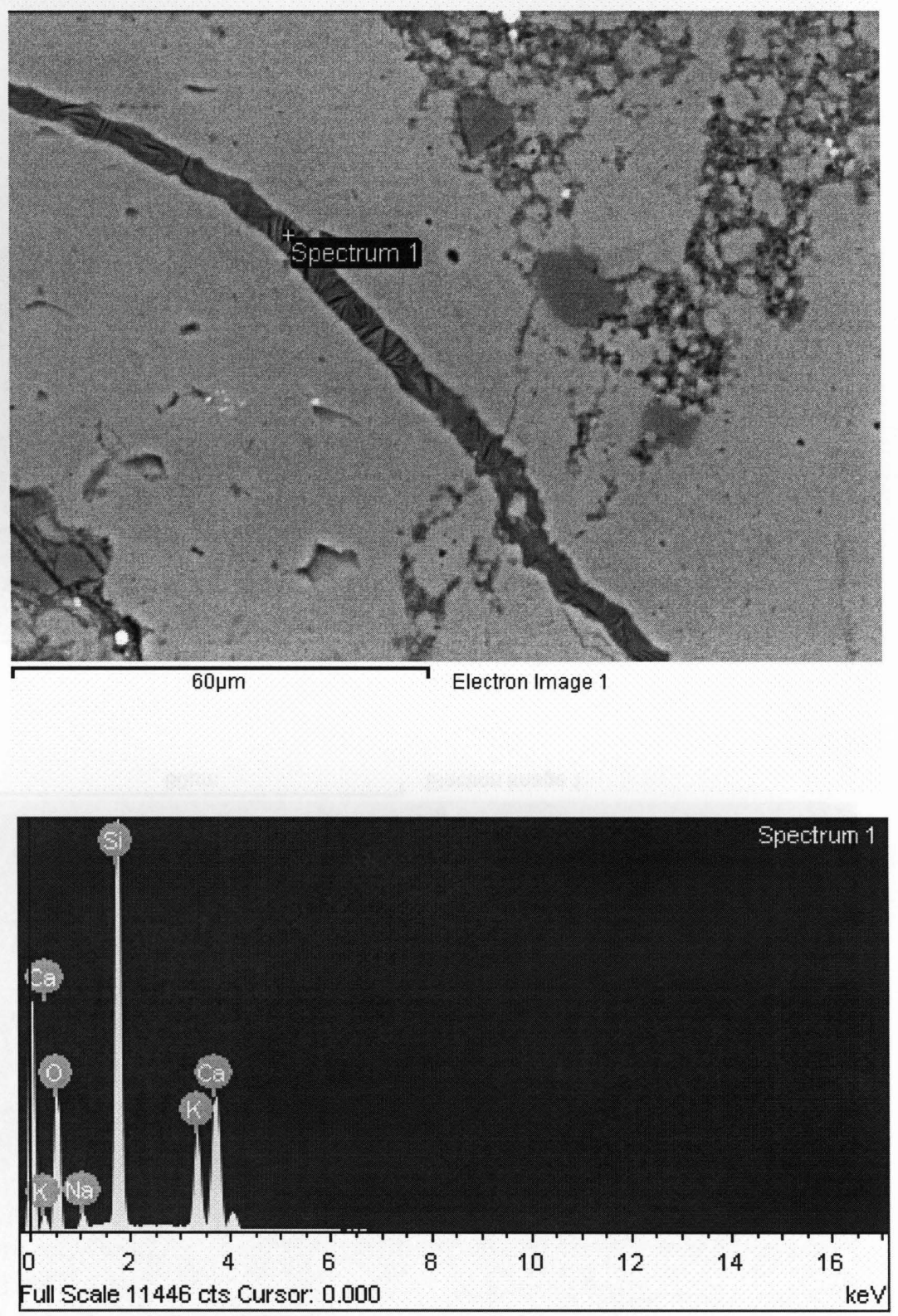
RCA aggregate in concrete prism

Gel-2

Spectrum processing:

No peaks omitted

Processing option: All elements analyzed (Normalised)

Number of iterations $=4$

Standard:

O SiO2 1-Jun-1999 12:00 AM

Na Albite 1-Jun-1999 12:00 AM

Mg MgO 1-Jun-1999 12:00 AM

Si SiO2 1-Jun-1999 12:00 AM

K MAD-10 Feldspar 1-Jun-1999 12:00 AM

Ca Wollastonite 1-Jun-1999 12:00 AM

\begin{tabular}{l|ll}
\hline Element & Weight\% & Atomic\% \\
& & \\
O K & 53.25 & 69.18 \\
$\mathrm{Na} \mathrm{K}$ & 1.01 & 0.92 \\
$\mathrm{Mg} \mathrm{K}$ & 0.11 & 0.09 \\
$\mathrm{Si} \mathrm{K}$ & 27.29 & 20.19 \\
$\mathrm{~K} \mathrm{~K}$ & 8.34 & 4.43 \\
$\mathrm{Ca} \mathrm{K}$ & 10.01 & 5.19 \\
& & \\
Totals & 100.00 & \\
\hline
\end{tabular}
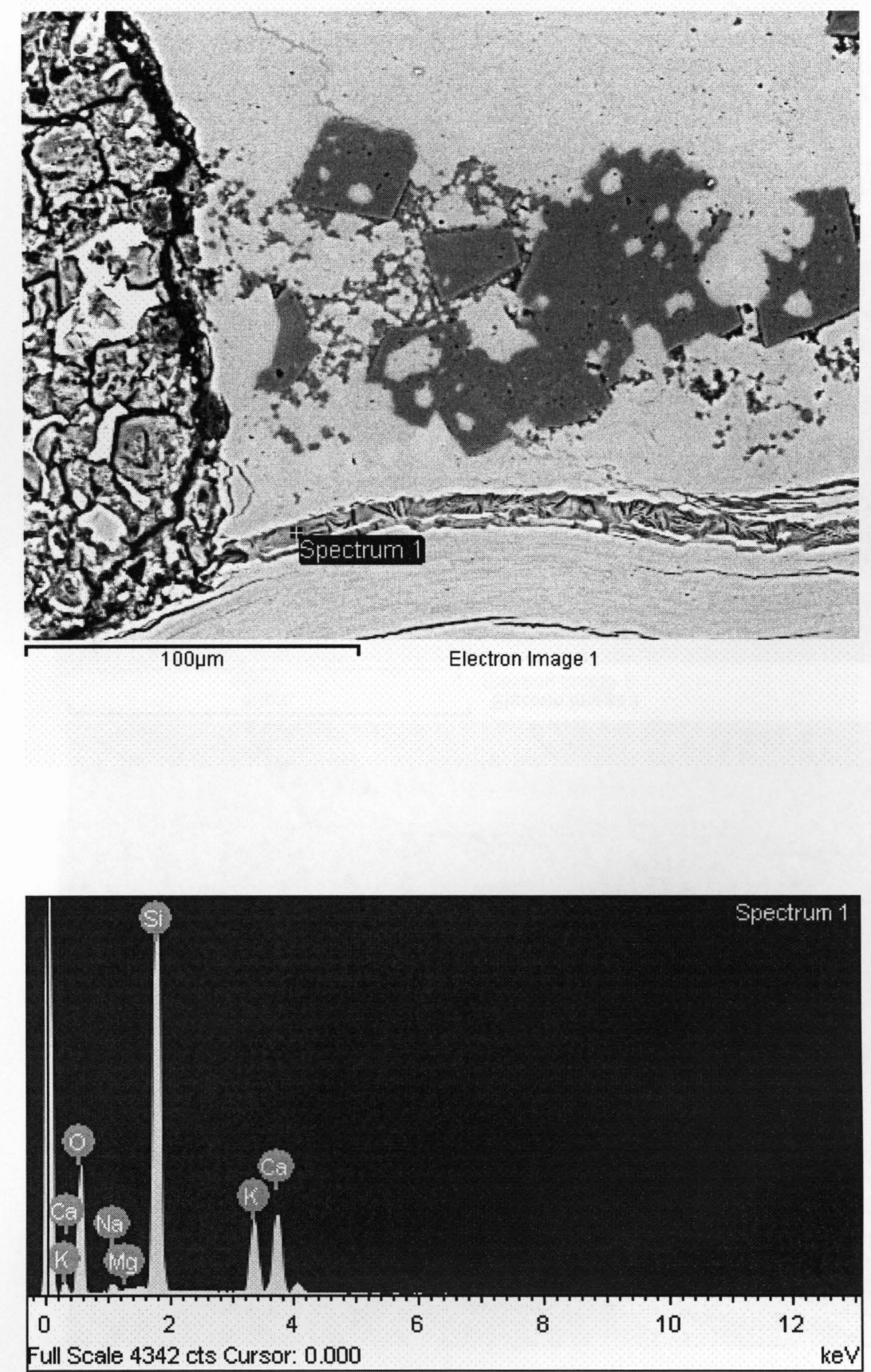
RCA aggregate in concrete prism

Gel-3

Spectrum processing:

No peaks omitted

Processing option: All elements analyzed (Normalised)

Number of iterations $=5$

Standard:

O $\mathrm{SiO} 2$ 1-Jun-1999 12:00 AM

$\mathrm{Na}$ Albite 1-Jun-1999 12:00 AM

Mg MgO 1-Jun-1999 12:00 AM

Si SiO2 1-Jun-1999 12:00 AM

K MAD-10 Feldspar 1-Jun-1999 12:00 AM

$\mathrm{Ca}$ Wollastonite 1-Jun-1999 12:00 AM

\begin{tabular}{l|ll}
\hline Element & Weight\% & Atomic\% \\
& & \\
$\mathrm{O} \mathrm{K}$ & 51.03 & 67.12 \\
$\mathrm{Na} \mathrm{K}$ & 1.21 & 1.10 \\
$\mathrm{Mg} \mathrm{K}$ & 0.30 & 0.26 \\
$\mathrm{Si} \mathrm{K}$ & 28.87 & 21.64 \\
$\mathrm{~K} \mathrm{~K}$ & 8.64 & 4.65 \\
$\mathrm{Ca} \mathrm{K}$ & 9.95 & 5.22 \\
& & \\
Totals & 100.00 & \\
\hline
\end{tabular}
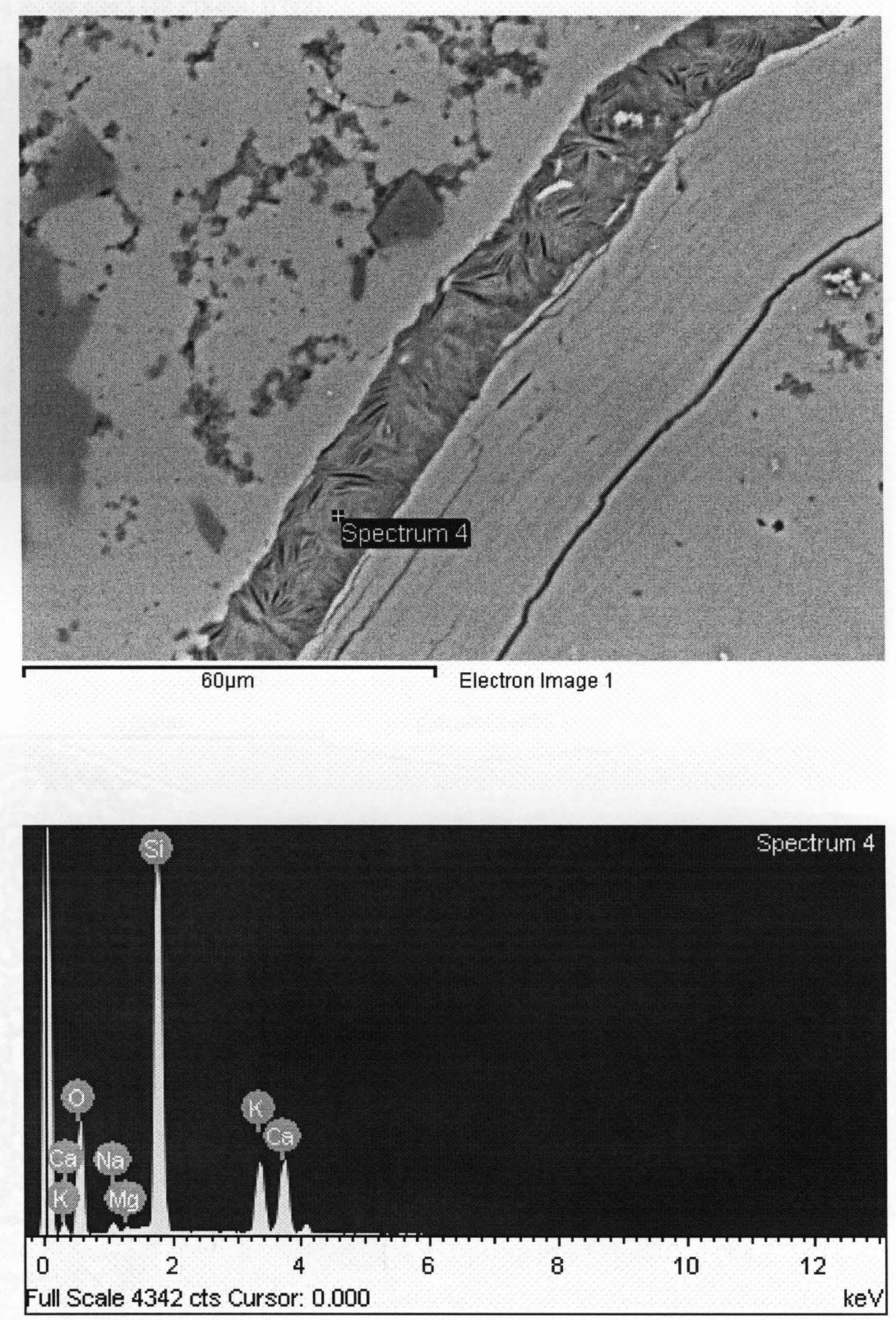
RCA aggregate in Solution 0.7 Molarity Li: $\mathrm{Na}+\mathrm{k}$ of $1: 1$

Gel-1

Spectrum processing:

No peaks omitted

Processing option: All elements analyzed (Normalised)

Number of iterations $=5$

\section{Standard:}

O SiO2 1-Jun-1999 12:00 AM

$\mathrm{Na}$ Albite 1-Jun-1999 12:00 AM

Si SiO2 1-Jun-1999 12:00 AM

P GaP 1-Jun-1999 12:00 AM

S FeS2 1-Jun-1999 12:00 AM

K MAD-10 Feldspar 1-Jun-1999 12:00 AM

Ca Wollastonite 1-Jun-1999 12:00 AM

\begin{tabular}{l|ll}
\hline Element & Weight\% & Atomic\% \\
& & \\
O K & 54.10 & 68.60 \\
Na K & 1.61 & 1.42 \\
Si K & 33.03 & 23.86 \\
P K & 1.40 & 0.92 \\
S K & 1.37 & 0.87 \\
K K & 2.70 & 1.40 \\
Ca K & 5.80 & 2.93 \\
& & \\
Totals & 100.00 & \\
\hline
\end{tabular}
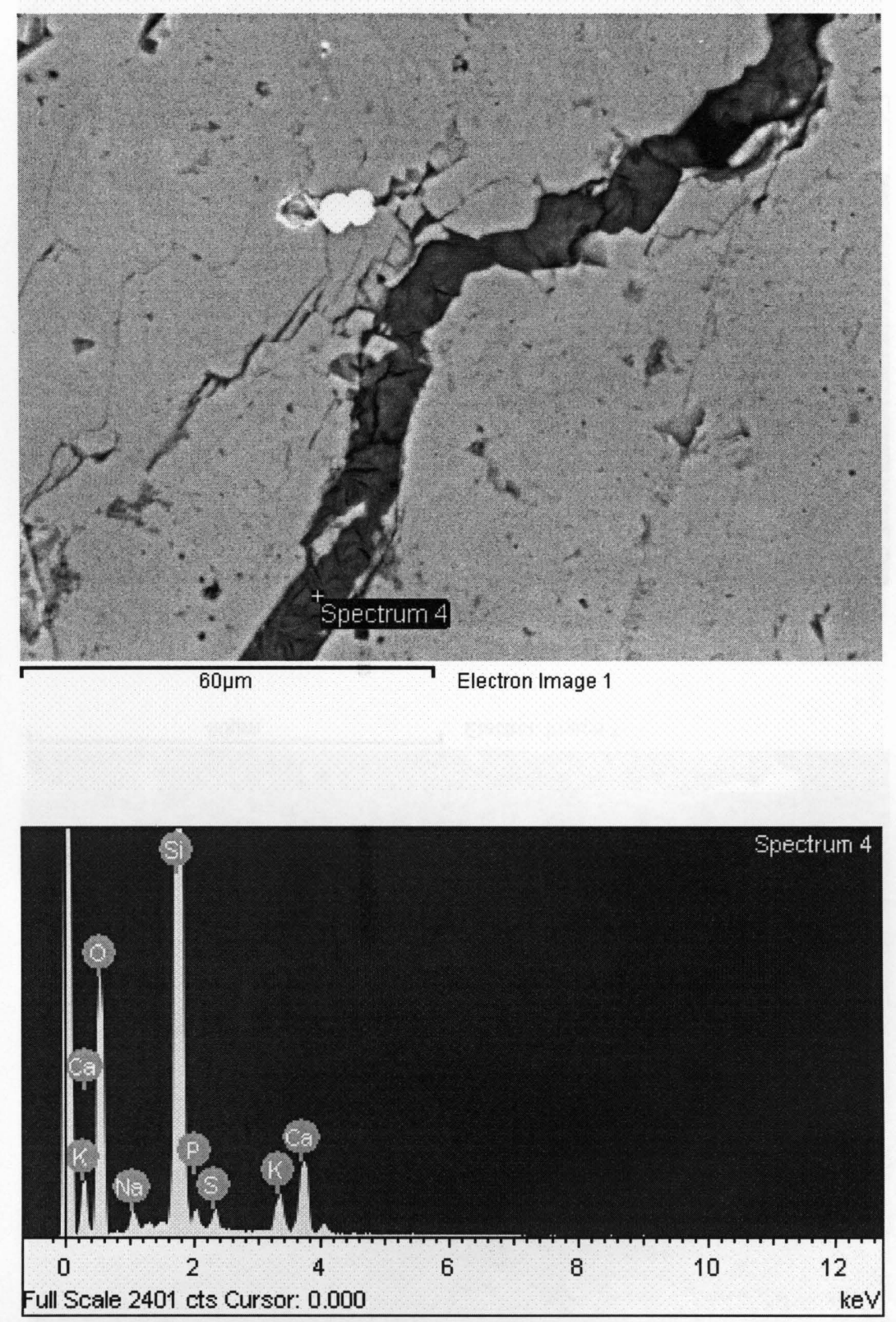
RCA aggregate in Solution 0.7 Molarity

Li: $\mathrm{Na}+\mathrm{k}$ of $1: 1$

Gel-2

Spectrum processing:

No peaks omitted

Processing option: All elements analyzed (Normalised) Number of iterations $=5$

Standard:

O $\mathrm{SiO} 2$ 1-Jun-1999 12:00 AM

Na Albite 1-Jun-1999 12:00 AM

$\mathrm{Mg} \mathrm{MgO}$ 1-Jun-1999 12:00 AM

Si $\quad \mathrm{SiO} 2$ 1-Jun-1999 12:00 AM

P GaP 1-Jun-1999 12:00 AM

S FeS2 1-Jun-1999 12:00 AM

K MAD-10 Feldspar 1-Jun-1999 12:00 AM

Ca Wollastonite 1-Jun-1999 12:00 AM

\begin{tabular}{l|ll}
\hline Element & Weight\% & Atomic\% \\
& & \\
O K & 52.33 & 67.19 \\
$\mathrm{Na} \mathrm{K}$ & 0.25 & 0.23 \\
$\mathrm{Mg} \mathrm{K}$ & 0.44 & 0.37 \\
$\mathrm{Si} \mathrm{K}$ & 34.48 & 25.22 \\
$\mathrm{P} \mathrm{K}$ & 3.29 & 2.18 \\
$\mathrm{~S} \mathrm{~K}$ & 0.38 & 0.24 \\
$\mathrm{~K} \mathrm{~K}$ & 3.34 & 1.75 \\
$\mathrm{Ca} \mathrm{K}$ & 5.49 & 2.81 \\
& & \\
Totals & 100.00 & \\
\hline
\end{tabular}
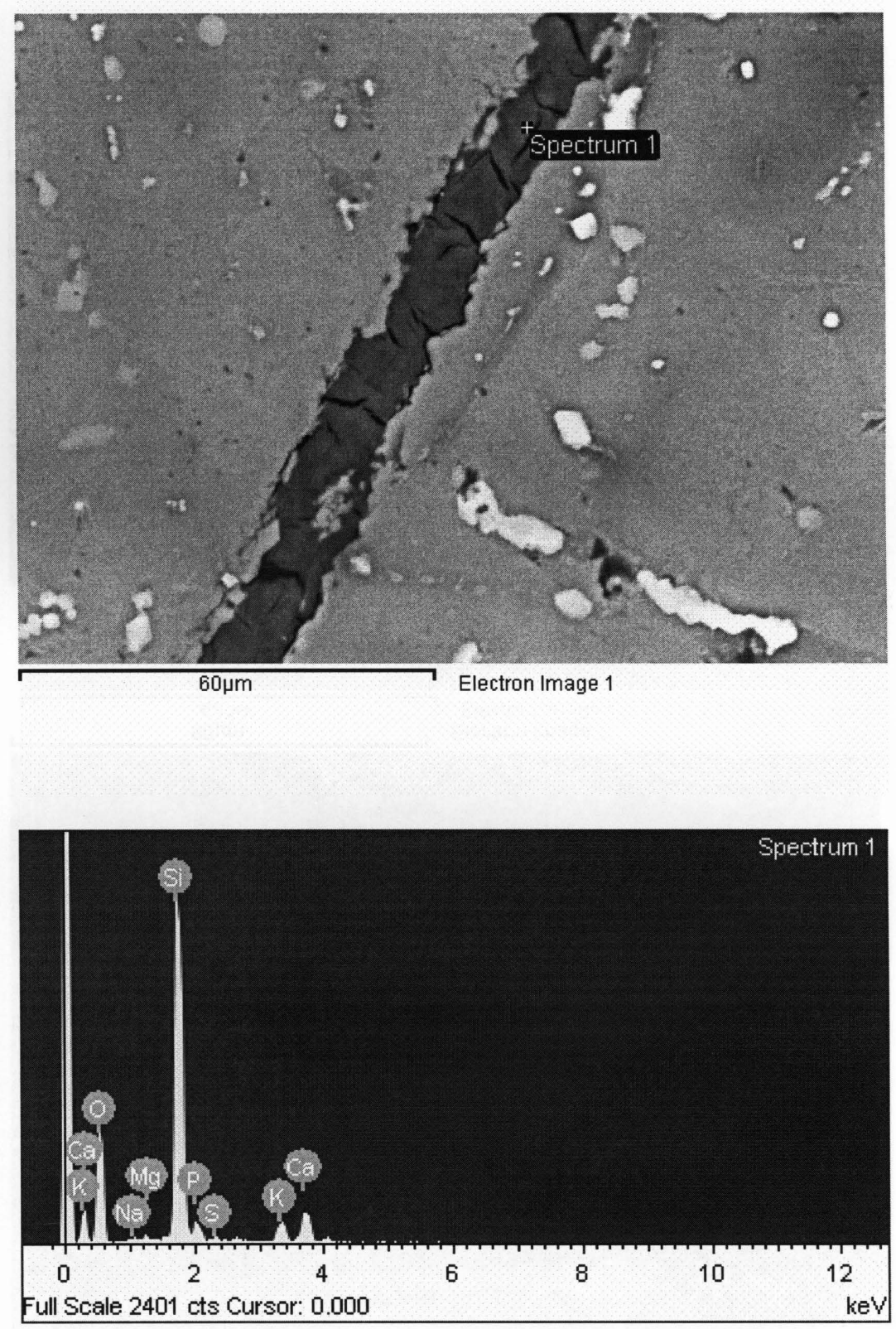
RCA aggregate in solution 0.7 Molarity $\mathrm{Li}: \mathrm{Na}+\mathrm{k}$ of $1: 1$

\section{Gel-3}

Spectrum processing:

No peaks omitted

Processing option: All elements analyzed (Normalised)

Number of iterations $=5$

\section{Standard:}

O SiO2 1-Jun-1999 12:00 AM

Na Albite 1-Jun-1999 12:00 AM

Mg MgO 1-Jun-1999 12:00 AM

$\mathrm{Si} \mathrm{SiO} 2$ 1-Jun-1999 12:00 AM

P GaP 1-Jun-1999 12:00 AM

S FeS2 1-Jun-1999 12:00 AM

K MAD-10 Feldspar 1-Jun-1999 12:00 AM

Ca Wollastonite 1-Jun-1999 12:00 AM

\begin{tabular}{l|ll}
\hline Element & Weight\% & Atomic\% \\
& & \\
O K & 54.74 & 69.00 \\
$\mathrm{Na} \mathrm{K}$ & 1.15 & 1.00 \\
$\mathrm{Mg} \mathrm{K}$ & 0.34 & 0.28 \\
$\mathrm{Si} \mathrm{K}$ & 33.08 & 23.75 \\
$\mathrm{P} \mathrm{K}$ & 2.32 & 1.51 \\
$\mathrm{~S} \mathrm{~K}$ & 1.66 & 1.04 \\
$\mathrm{~K} \mathrm{~K}$ & 1.78 & 0.92 \\
$\mathrm{Ca} \mathrm{K}$ & 4.93 & 2.48 \\
& & \\
Totals & 100.00 & \\
\hline
\end{tabular}
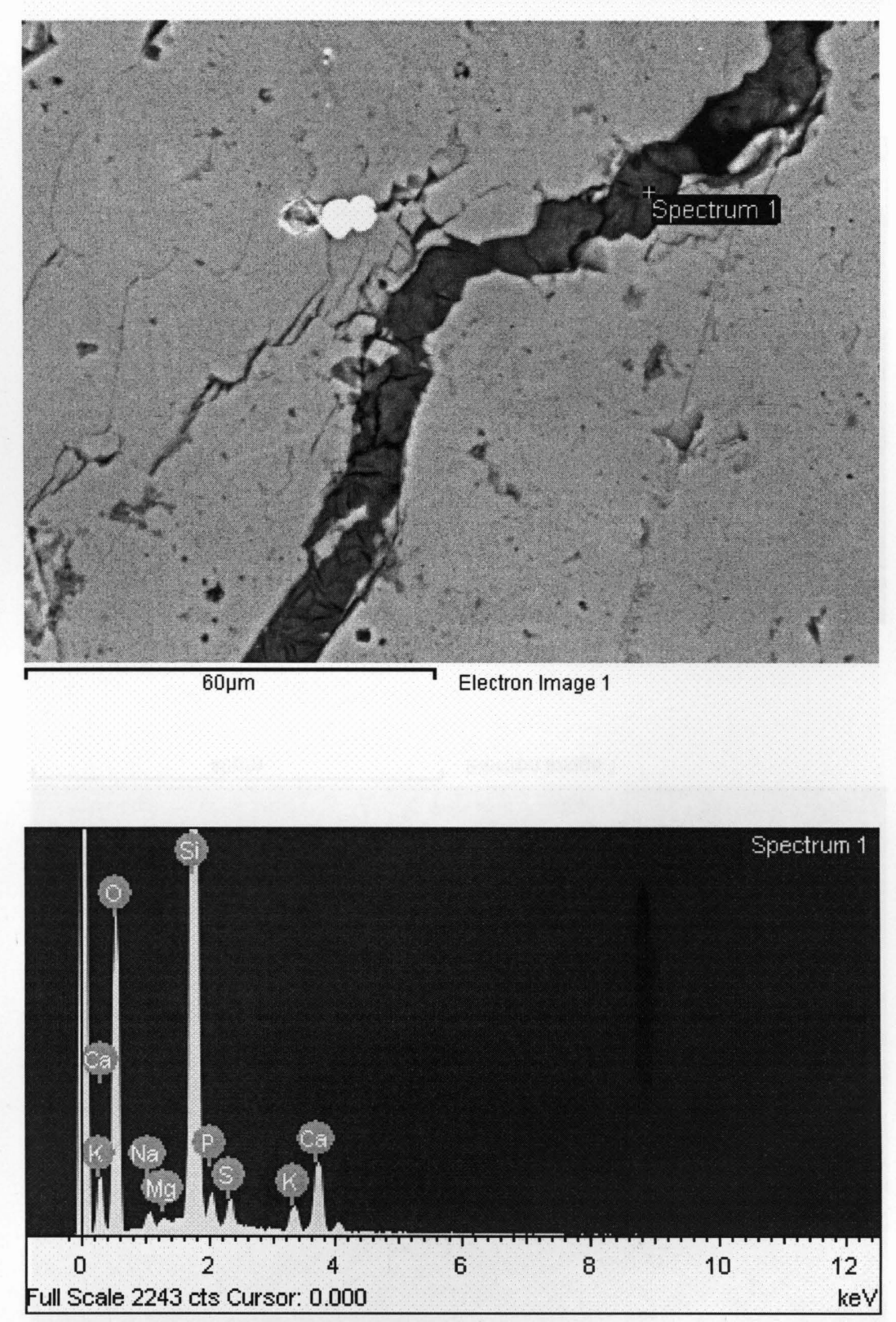
RCA aggregate in solution 0.7 Molarity

$\mathrm{Li}: \mathrm{Na}+\mathrm{K}$ of $1: 1$

Gel-4

Spectrum processing:

No peaks omitted

Processing option: All elements analyzed (Normalised)

Number of iterations $=5$

Standard :

O $\mathrm{SiO} 2$ 1-Jun-1999 12:00 AM

Na Albite 1-Jun-1999 12:00 AM

Mg MgO 1-Jun-1999 12:00 AM

$\mathrm{Si}$ SiO2 1-Jun-1999 12:00 AM

K MAD-10 Feldspar 1-Jun-1999 12:00 AM

Ca Wollastonite 1-Jun-1999 12:00 AM

\begin{tabular}{l|ll}
\hline Element & Weight\% & Atomic\% \\
& & \\
O K & 56.01 & 70.97 \\
$\mathrm{Na} \mathrm{K}$ & 1.62 & 1.43 \\
$\mathrm{Mg} \mathrm{K}$ & 1.40 & 1.17 \\
$\mathrm{Si} \mathrm{K}$ & 26.12 & 18.86 \\
$\mathrm{~K} \mathrm{~K}$ & 5.60 & 2.90 \\
$\mathrm{Ca} \mathrm{K}$ & 9.25 & 4.68 \\
& & \\
Totals & 100.00 & \\
\hline
\end{tabular}
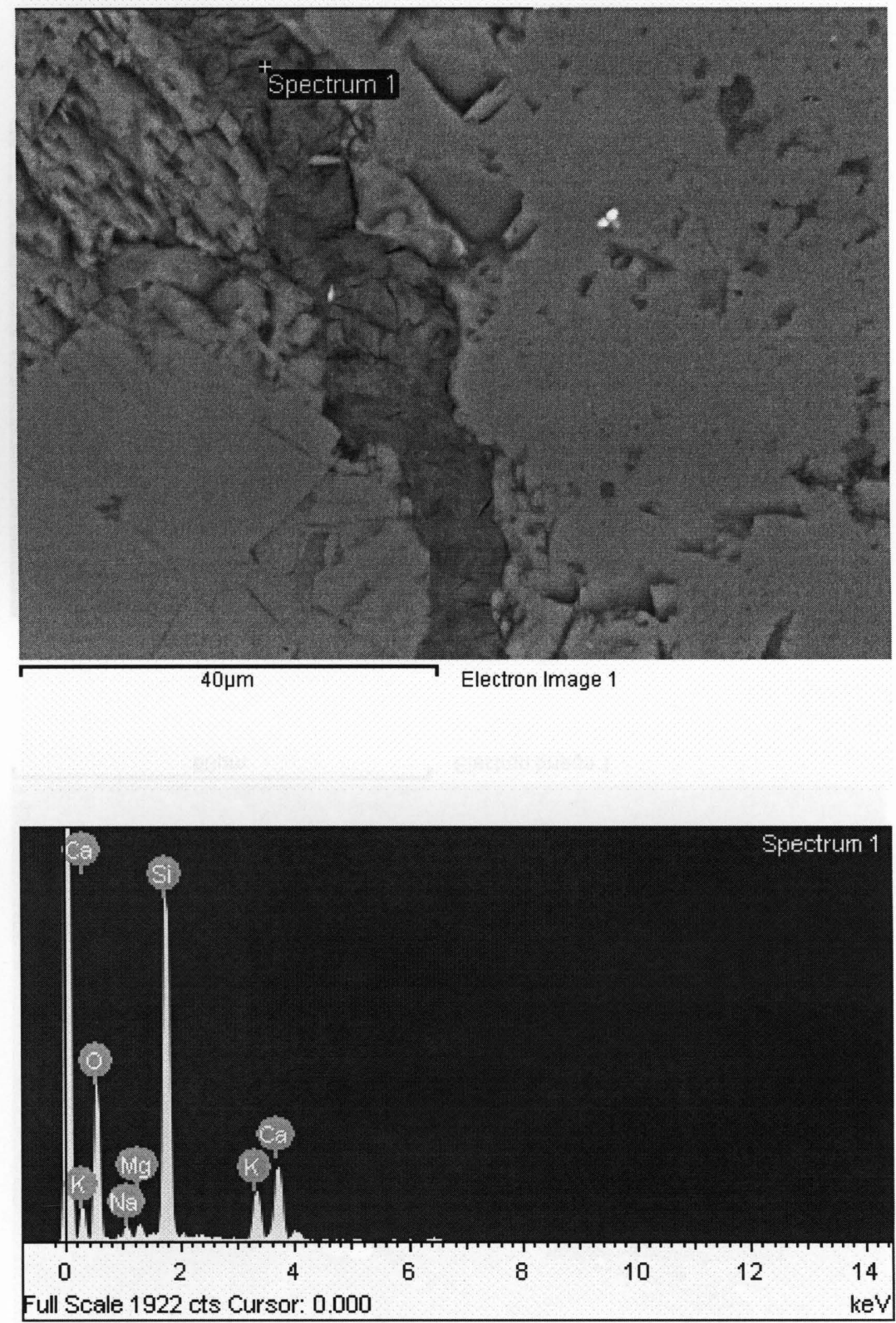
RCA aggregate in solution 0.7 Molarity

Li: $\mathrm{Na}+\mathrm{K}$ of $1: 1$

Gel-5

Spectrum processing:

No peaks omitted

Processing option: All elements analyzed (Normalised)

Number of iterations $=4$

\section{Standard:}

O $\mathrm{SiO} 2$ 1-Jun-1999 12:00 AM

Na Albite 1-Jun-1999 12:00 AM

$\mathrm{Mg} \mathrm{MgO} \mathrm{1-Jun-1999} \mathrm{12:00} \mathrm{AM}$

$\mathrm{Si} \quad \mathrm{SiO} 2$ 1-Jun-1999 12:00 AM

S FeS2 1-Jun-1999 12:00 AM

K MAD-10 Feldspar 1-Jun-1999 12:00 AM

Ca Wollastonite 1-Jun-1999 12:00 AM

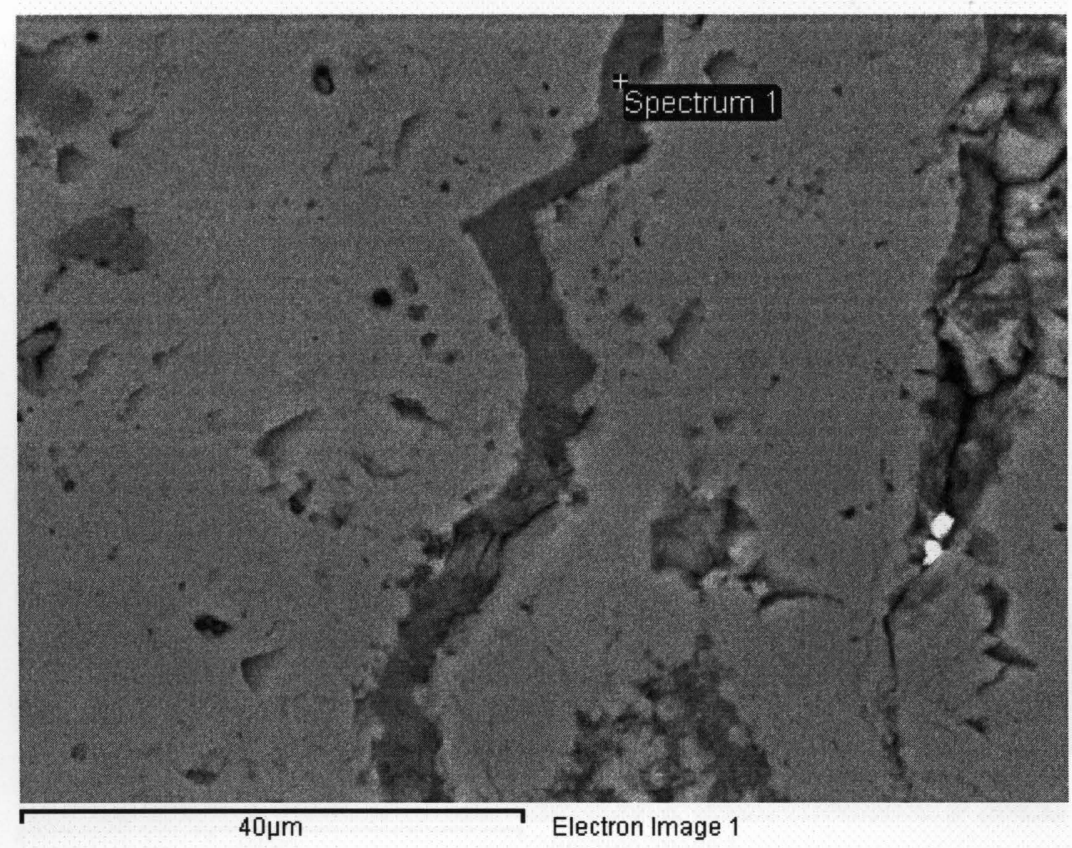

\begin{tabular}{l|ll}
\hline Element & Weight\% & Atomic\% \\
& & \\
O K & 51.68 & 68.62 \\
$\mathrm{Na} \mathrm{K}$ & 0.60 & 0.55 \\
$\mathrm{Mg} \mathrm{K}$ & 0.61 & 0.53 \\
$\mathrm{Si} \mathrm{K}$ & 22.64 & 17.13 \\
$\mathrm{~S} \mathrm{~K}$ & 0.65 & 0.43 \\
$\mathrm{~K} \mathrm{~K}$ & 8.12 & 4.41 \\
$\mathrm{Ca} \mathrm{K}$ & 15.71 & 8.33 \\
& & \\
Totals & 100.00 & \\
\hline
\end{tabular}

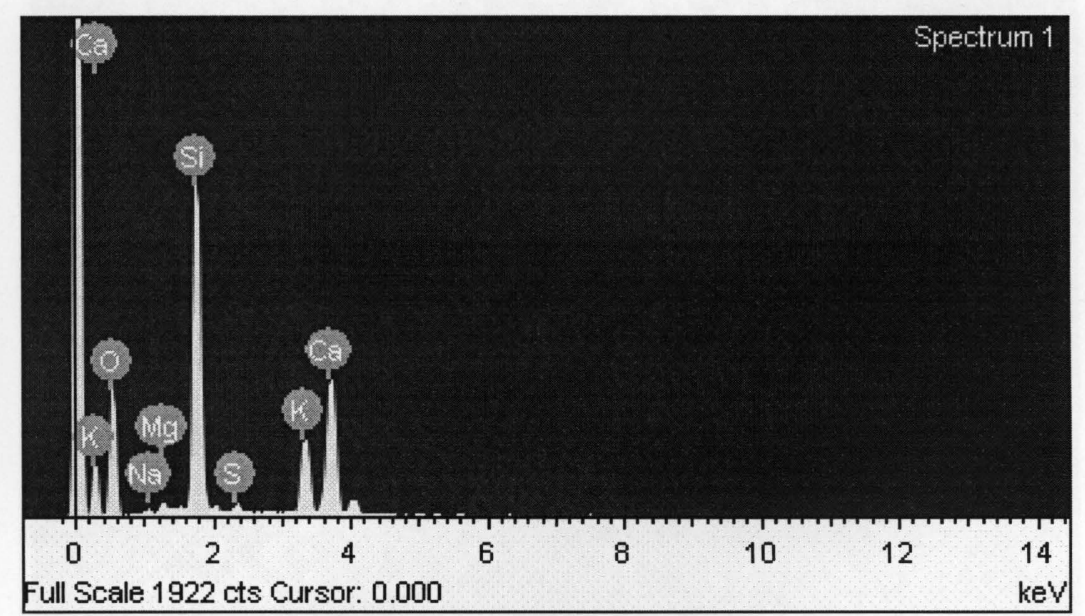


RCA aggregate in solution 0.7 Molarity $\mathrm{Li}: \mathrm{Na}+\mathrm{K}$ of $1: 1$

\section{Gel-6}

Spectrum processing:

Peak possibly omitted: $6.400 \mathrm{keV}$

Processing option: All elements analyzed (Normalised)

Number of iterations $=5$

\section{Standard:}
O SiO2 1-Jun-1999 12:00 AM
Na Albite 1-Jun-1999 12:00 AM
$\mathrm{Mg} \mathrm{MgO}$ 1-Jun-1999 12:00 AM
$\mathrm{Si} \quad \mathrm{SiO} 2$ 1-Jun-1999 12:00 AM
S FeS2 1-Jun-1999 12:00 AM
K MAD-10 Feldspar 1-Jun-1999 12:00 AM
Ca Wollastonite 1-Jun-1999 12:00 AM

\begin{tabular}{l|ll}
\hline Element & Weight\% & Atomic\% \\
& & \\
$\mathrm{O} \mathrm{K}$ & 55.02 & 70.49 \\
$\mathrm{Na} \mathrm{K}$ & 1.06 & 0.94 \\
$\mathrm{Mg} \mathrm{K}$ & 0.92 & 0.78 \\
$\mathrm{Si} \mathrm{K}$ & 25.85 & 18.86 \\
$\mathrm{~S} \mathrm{~K}$ & 0.59 & 0.38 \\
$\mathrm{~K} \mathrm{~K}$ & 6.78 & 3.55 \\
$\mathrm{Ca} \mathrm{K}$ & 9.77 & 5.00 \\
& & \\
Totals & 100.00 & \\
\hline
\end{tabular}
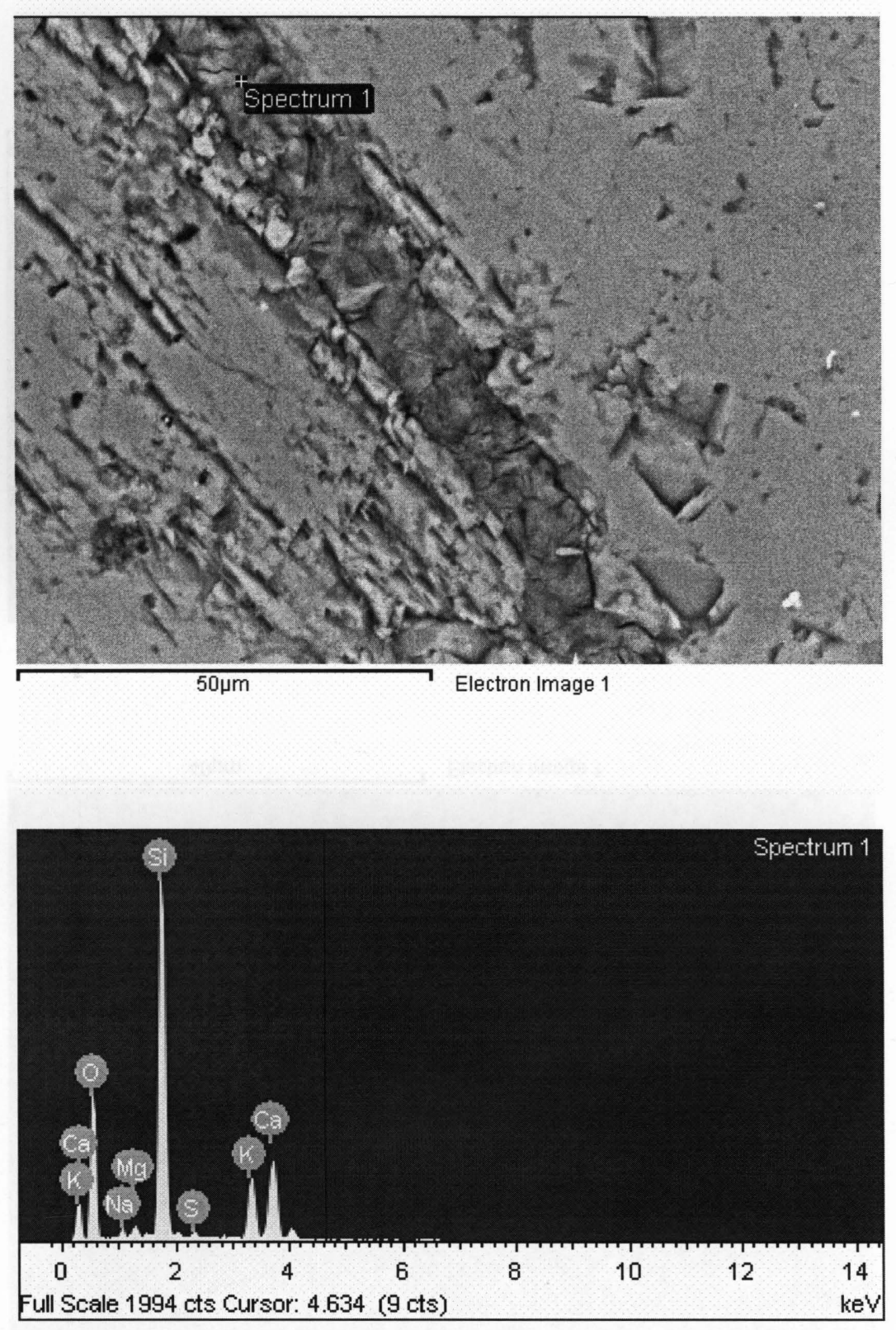
RCA aggregate in solution 0.7 Molarity without Lithium Gel-1

Spectrum processing:

Peak possibly omitted: $7.200 \mathrm{keV}$

Processing option: All elements analyzed (Normalised)

Number of iterations $=5$

Standard:

O $\mathrm{SiO} 2$ 1-Jun-1999 12:00 AM

$\mathrm{Na}$ Albite 1-Jun-1999 12:00 AM

Mg MgO 1-Jun-1999 12:00 AM

Si SiO2 1-Jun-1999 12:00 AM

K MAD-10 Feldspar 1-Jun-1999 12:00 AM

$\mathrm{Ca}$ Wollastonite 1-Jun-1999 12:00 AM

\begin{tabular}{l|ll}
\hline Element & Weight\% & Atomic\% \\
& & \\
O K & 51.61 & 68.77 \\
$\mathrm{Na} \mathrm{K}$ & 0.34 & 0.32 \\
$\mathrm{Mg} \mathrm{K}$ & 0.58 & 0.51 \\
$\mathrm{Si} \mathrm{K}$ & 22.47 & 17.05 \\
$\mathrm{~K} \mathrm{~K}$ & 4.53 & 2.47 \\
$\mathrm{Ca} \mathrm{K}$ & 20.46 & 10.88 \\
& & \\
Totals & 100.00 & \\
\hline
\end{tabular}
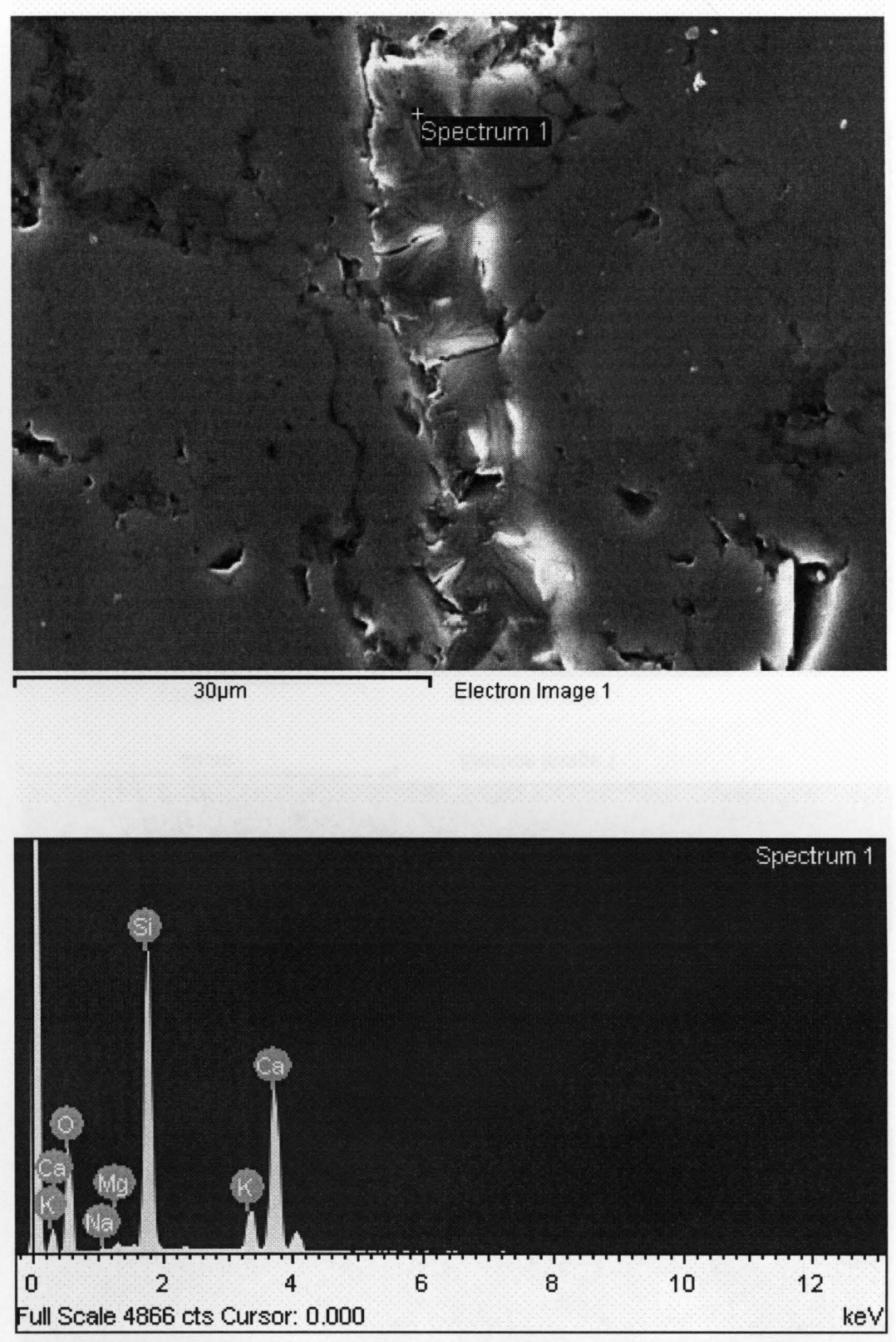
RCA aggregate in solution 0.7 Molarity without Lithium Gel-2

Spectrum processing:

No peaks omitted

Processing option: All elements analyzed (Normalised) Number of iterations $=4$

Standard:

O $\mathrm{SiO} 2$ 1-Jun-1999 12:00 AM

$\mathrm{Na}$ Albite 1-Jun-1999 12:00 AM

Mg MgO 1-Jun-1999 12:00 AM

$\mathrm{Si}$ SiO2 1-Jun-1999 12:00 AM

K MAD-10 Feldspar 1-Jun-1999 12:00 AM

Ca Wollastonite 1-Jun-1999 12:00 AM

\begin{tabular}{l|ll}
\hline Element & Weight\% & Atomic\% \\
& & \\
O K & 52.18 & 68.53 \\
$\mathrm{Na} \mathrm{K}$ & 0.36 & 0.33 \\
$\mathrm{Mg} \mathrm{K}$ & 0.38 & 0.33 \\
$\mathrm{Si} \mathrm{K}$ & 27.01 & 20.21 \\
$\mathrm{~K} \mathrm{~K}$ & 6.35 & 3.41 \\
$\mathrm{Ca} \mathrm{K}$ & 13.72 & 7.19 \\
& & \\
Totals & 100.00 & \\
\hline
\end{tabular}
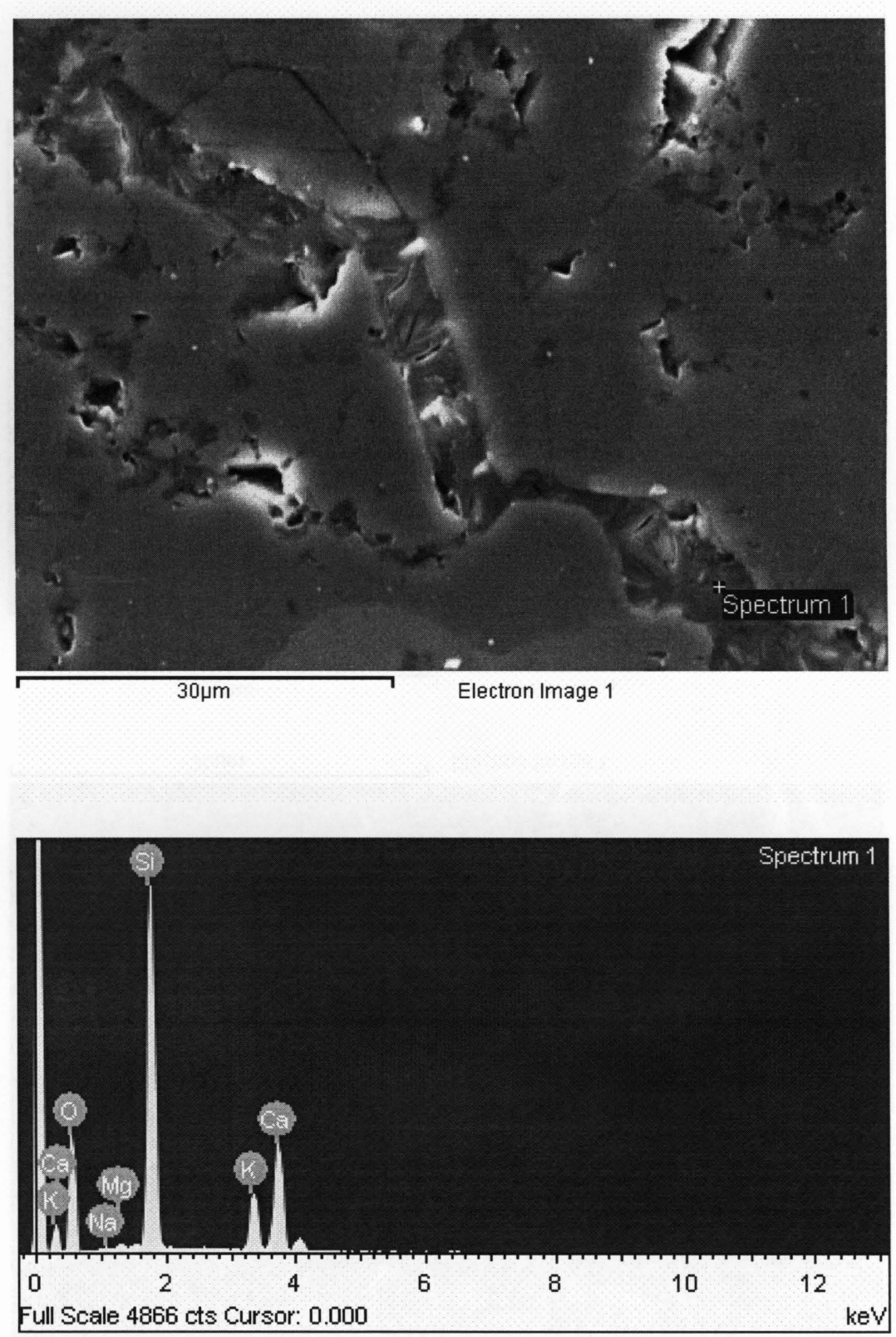
RCA aggregate in solution 0.7 Molarity without Lithium Gel-3

\section{Spectrum processing:}

No peaks omitted

Processing option: All elements analyzed (Normalised)

Number of iterations $=4$

\section{Standard:}

O $\mathrm{SiO} 2$ 1-Jun-1999 12:00 AM

$\mathrm{Na}$ Albite 1-Jun-1999 12:00 AM

Si SiO2 1-Jun-1999 12:00 AM

K MAD-10 Feldspar 1-Jun-1999 12:00 AM

Ca Wollastonite 1-Jun-1999 12:00 AM

\begin{tabular}{l|ll}
\hline Element & Weight\% & Atomic\% \\
& & \\
O K & 53.77 & 69.50 \\
$\mathrm{Na} \mathrm{K}$ & 0.55 & 0.50 \\
$\mathrm{Si} \mathrm{K}$ & 28.84 & 21.24 \\
$\mathrm{~K} \mathrm{~K}$ & 6.19 & 3.27 \\
$\mathrm{Ca} \mathrm{K}$ & 10.65 & 5.50 \\
& & \\
Totals & 100.00 & \\
\hline
\end{tabular}
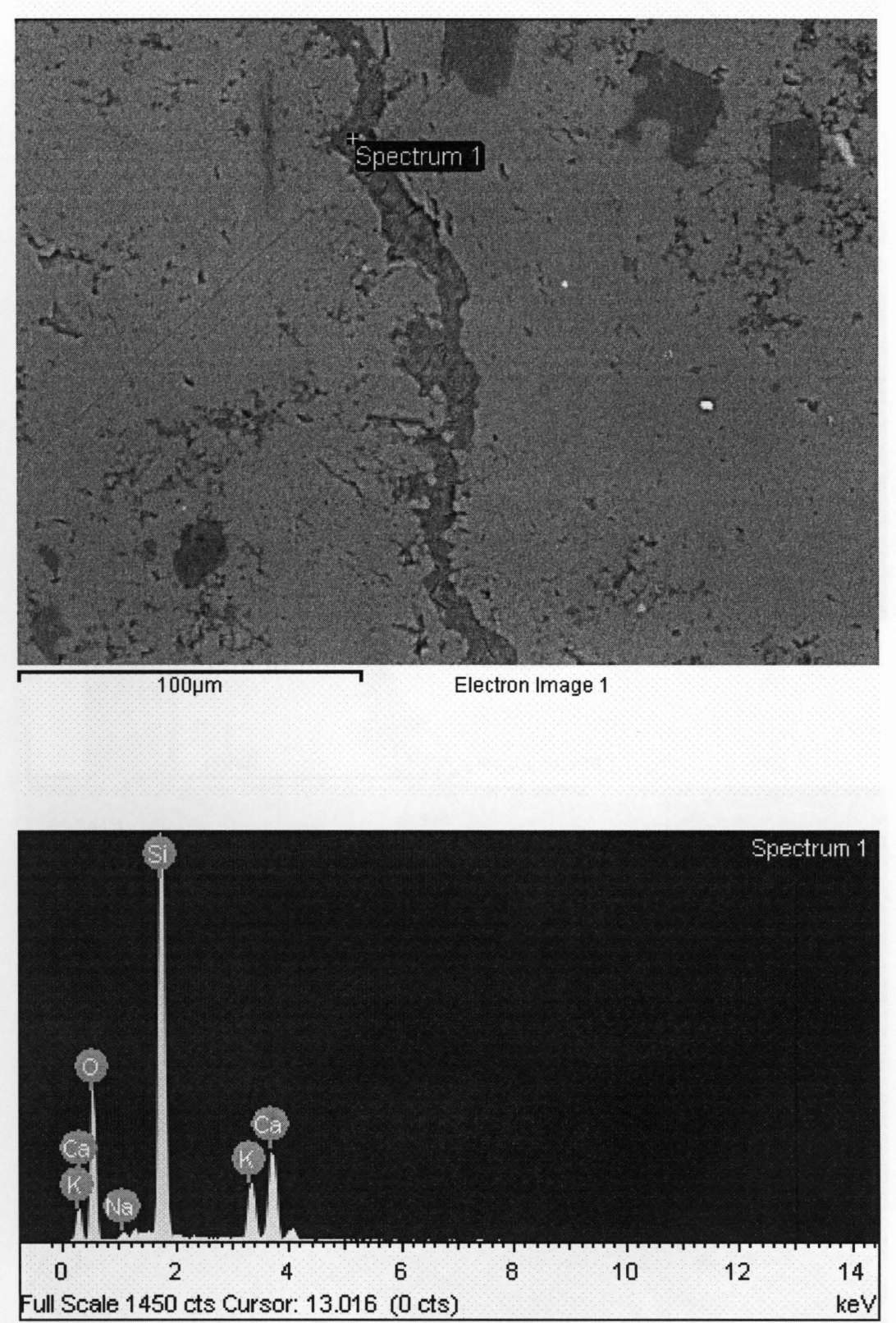
RCA aggregate in solution 0.7 Molarity without Lithium Gel-4

Spectrum processing:

No peaks omitted

Processing option: All elements analyzed (Normalised)

Number of iterations $=4$

Standard:

O $\mathrm{SiO} 2$ 1-Jun-1999 12:00 AM

$\mathrm{Na}$ Albite 1-Jun-1999 12:00 AM

$\mathrm{Mg} \mathrm{MgO}$ 1-Jun-1999 12:00 AM

$\mathrm{Si} \mathrm{SiO} 2$ 1-Jun-1999 12:00 AM

K MAD-10 Feldspar 1-Jun-1999 12:00 AM

Ca Wollastonite 1-Jun-1999 12:00 AM

\begin{tabular}{l|ll}
\hline Element & Weight\% & Atomic\% \\
& & \\
$\mathrm{O} \mathrm{K}$ & 53.87 & 69.50 \\
$\mathrm{Na} \mathrm{K}$ & 0.23 & 0.21 \\
$\mathrm{Mg} \mathrm{K}$ & 0.77 & 0.65 \\
$\mathrm{Si} \mathrm{K}$ & 28.80 & 21.17 \\
$\mathrm{~K} \mathrm{~K}$ & 4.88 & 2.57 \\
$\mathrm{Ca} \mathrm{K}$ & 11.45 & 5.90 \\
& & \\
Totals & 100.00 & \\
\hline
\end{tabular}
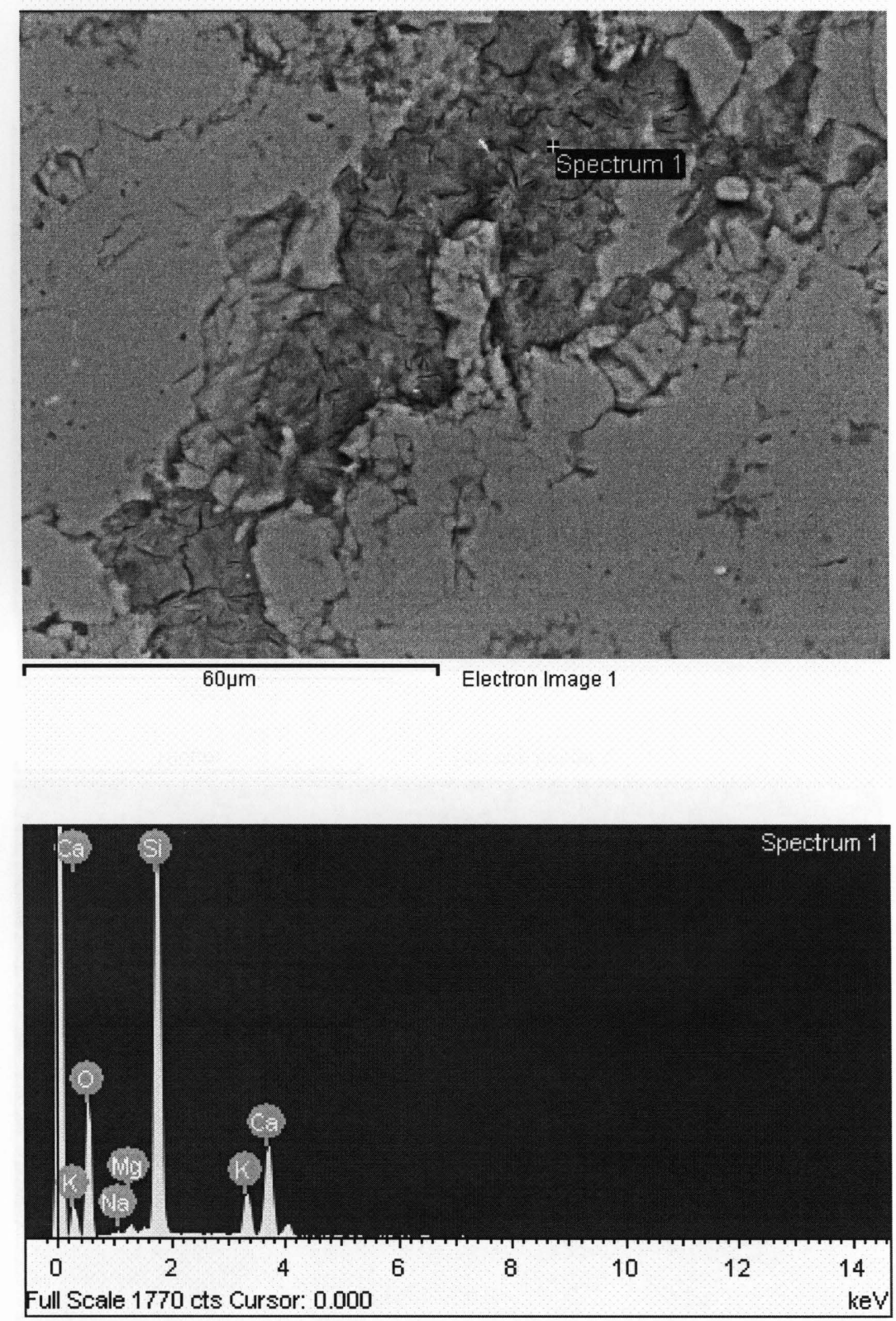


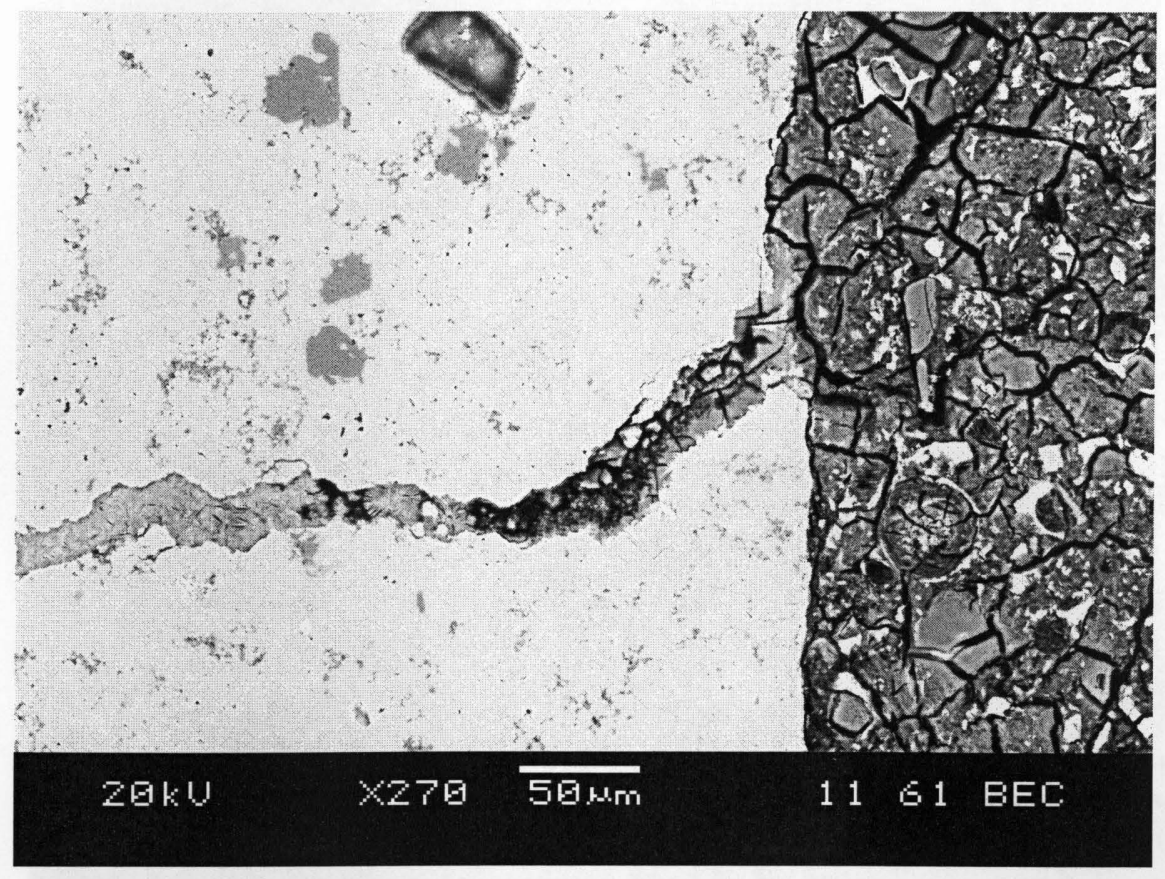

RCA aggregate stock

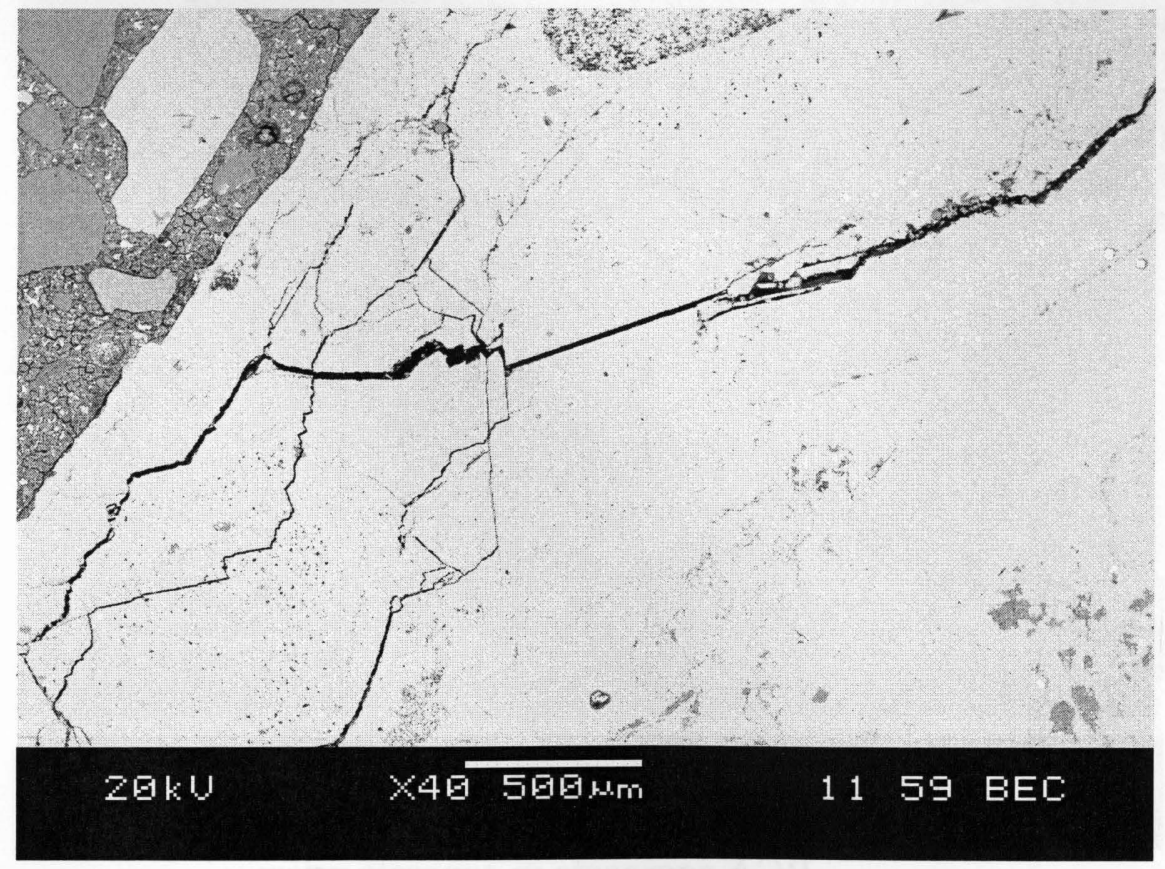

RCA aggregate stock 


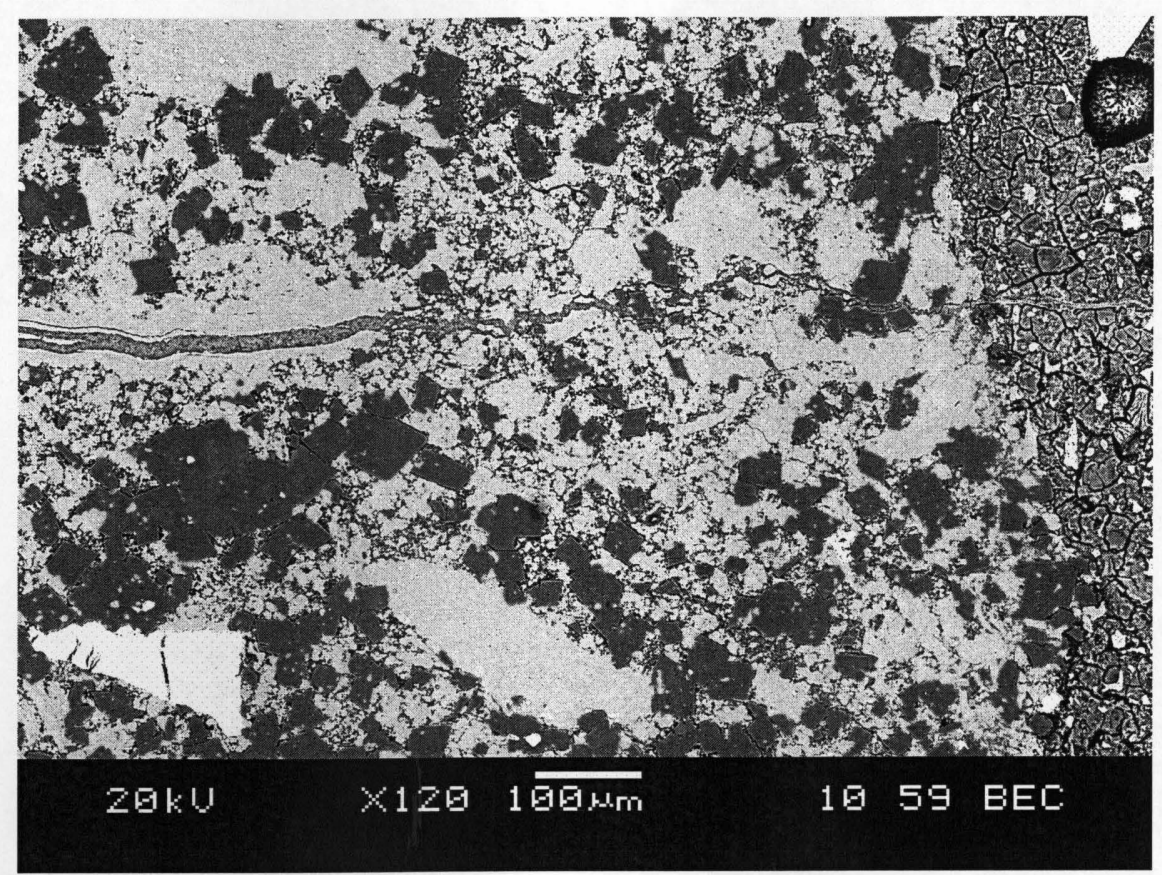

RCA aggregate in concrete prism

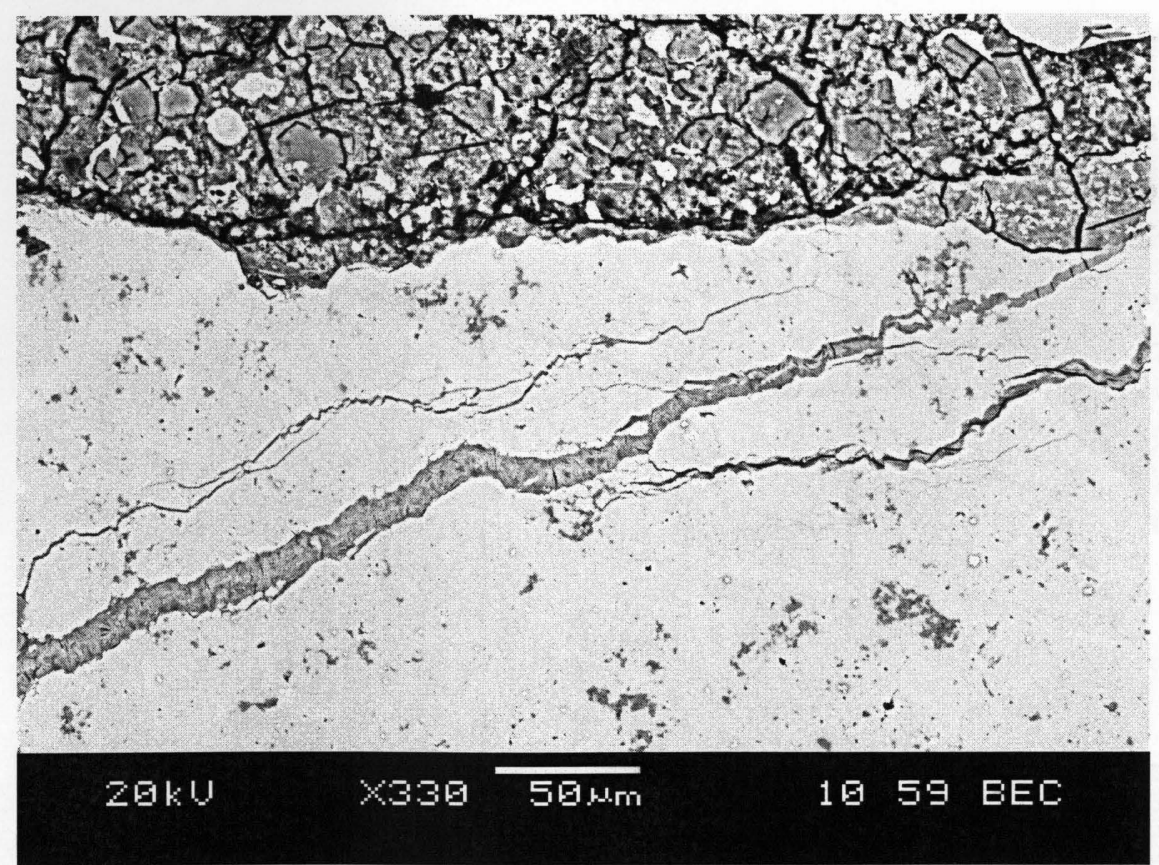

RCA aggregate in concrete prism 


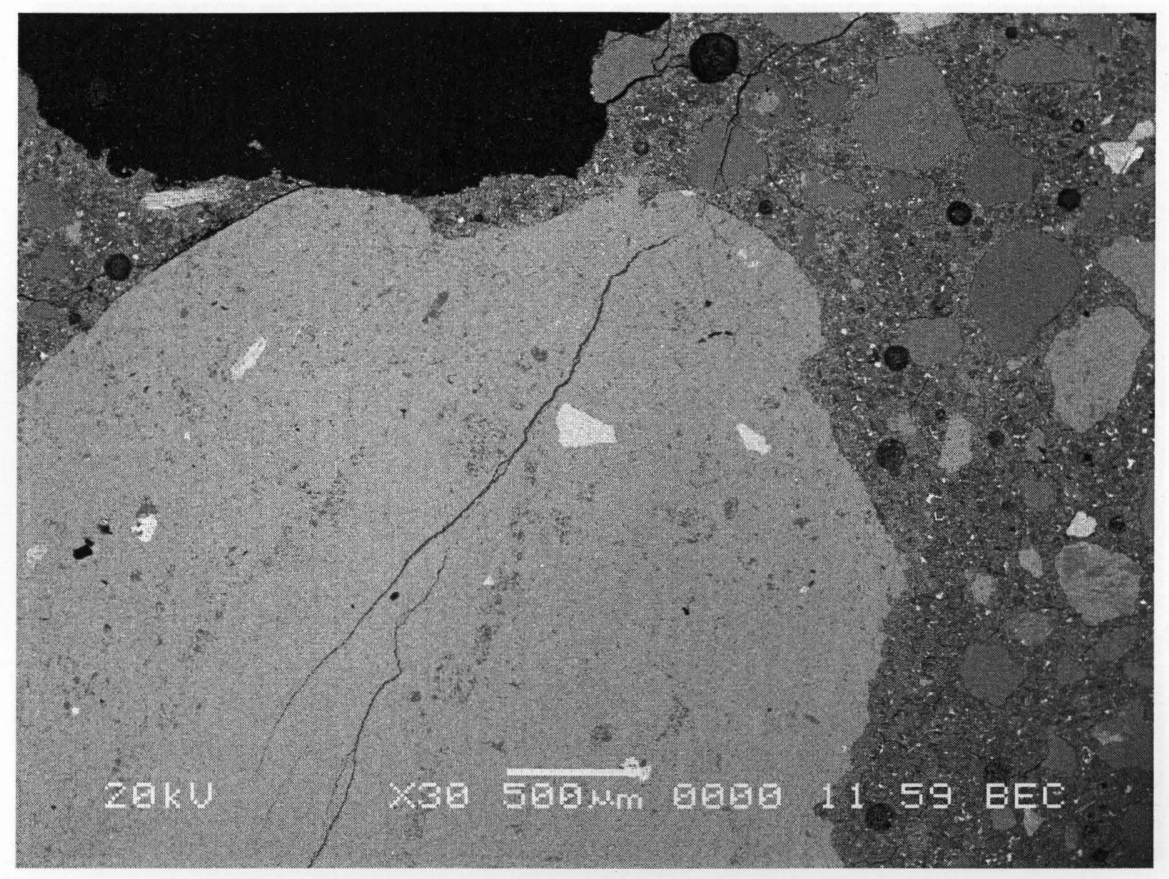

RCA aggregate in solution 0.7 Molarity with $\mathrm{Li}$ : $\mathrm{Na}+\mathrm{K}$ of $1: 1$

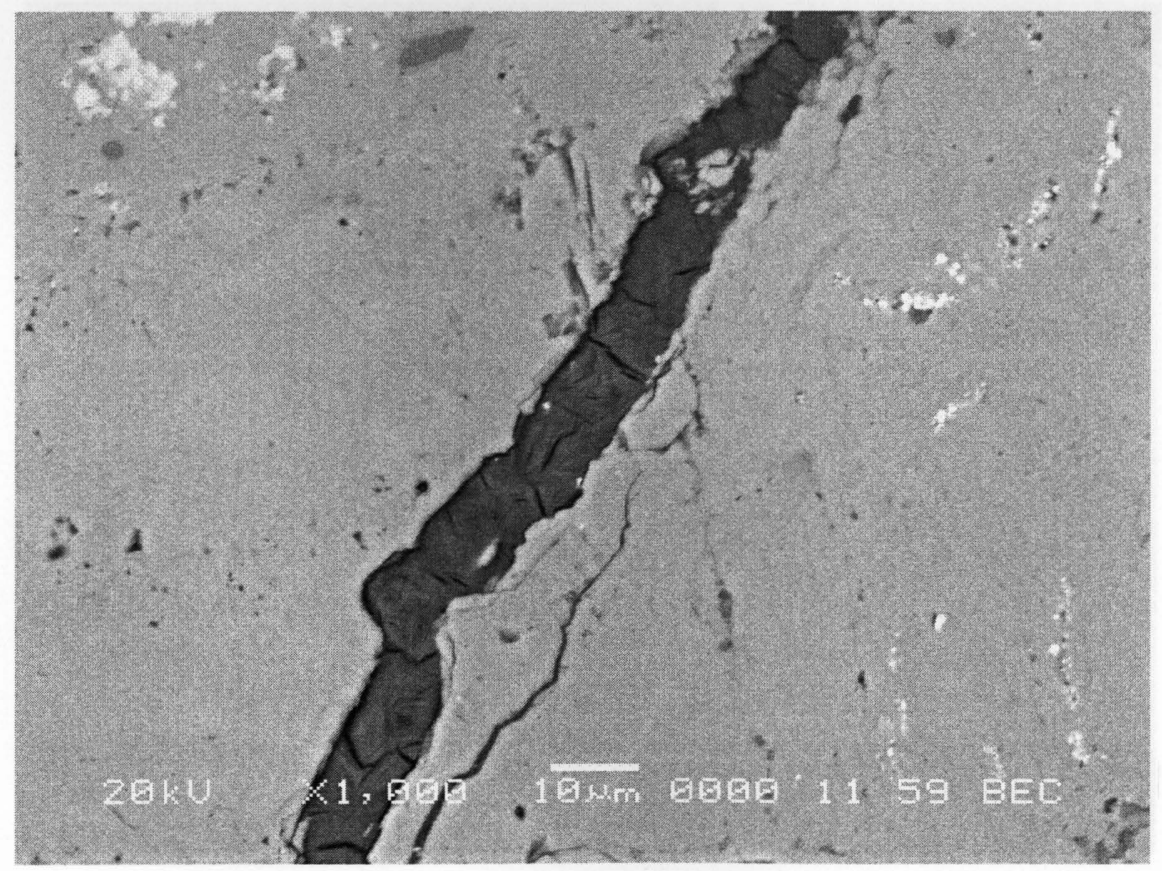

RCA aggregate in solution 0.7 Molarity with $\mathrm{Li}$ : $\mathrm{Na}+\mathrm{K}$ of $1: 1$ 


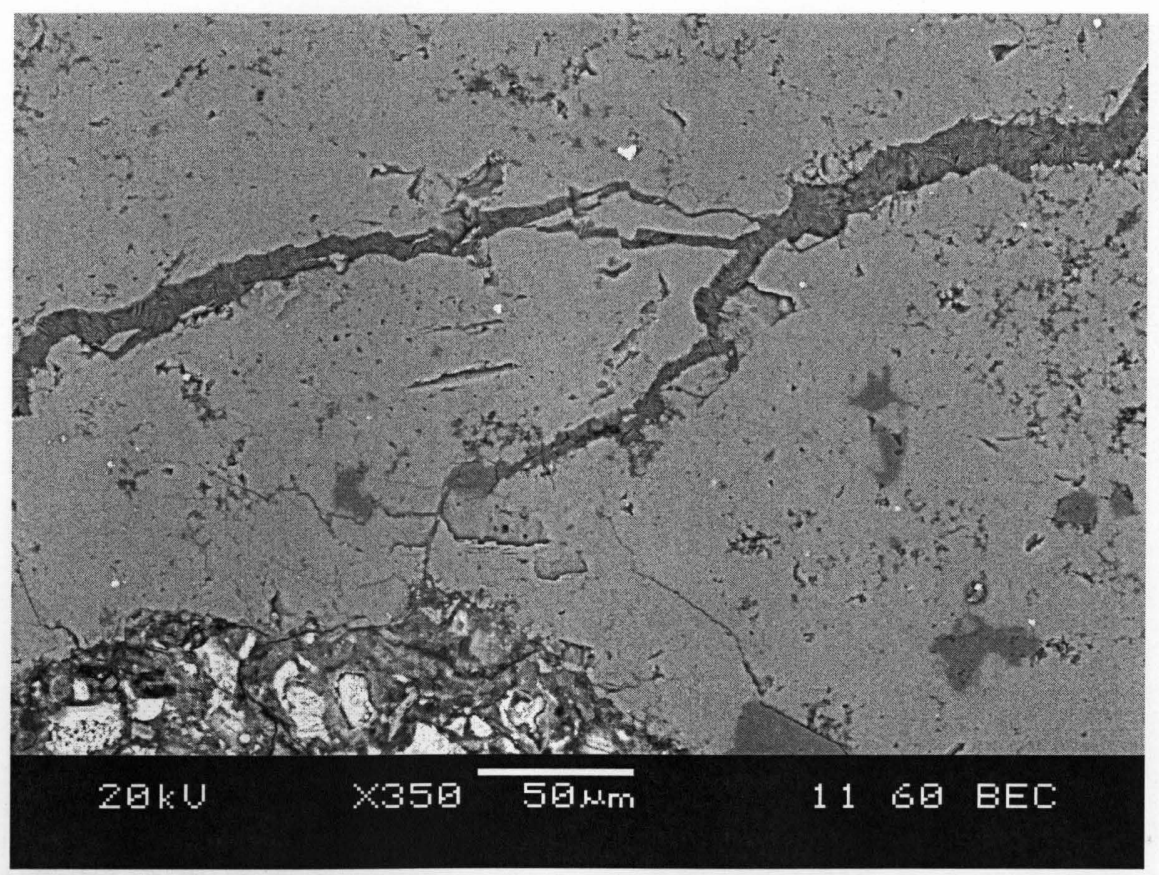

RCA aggregate in solution 0.7 Molarity without Lithium

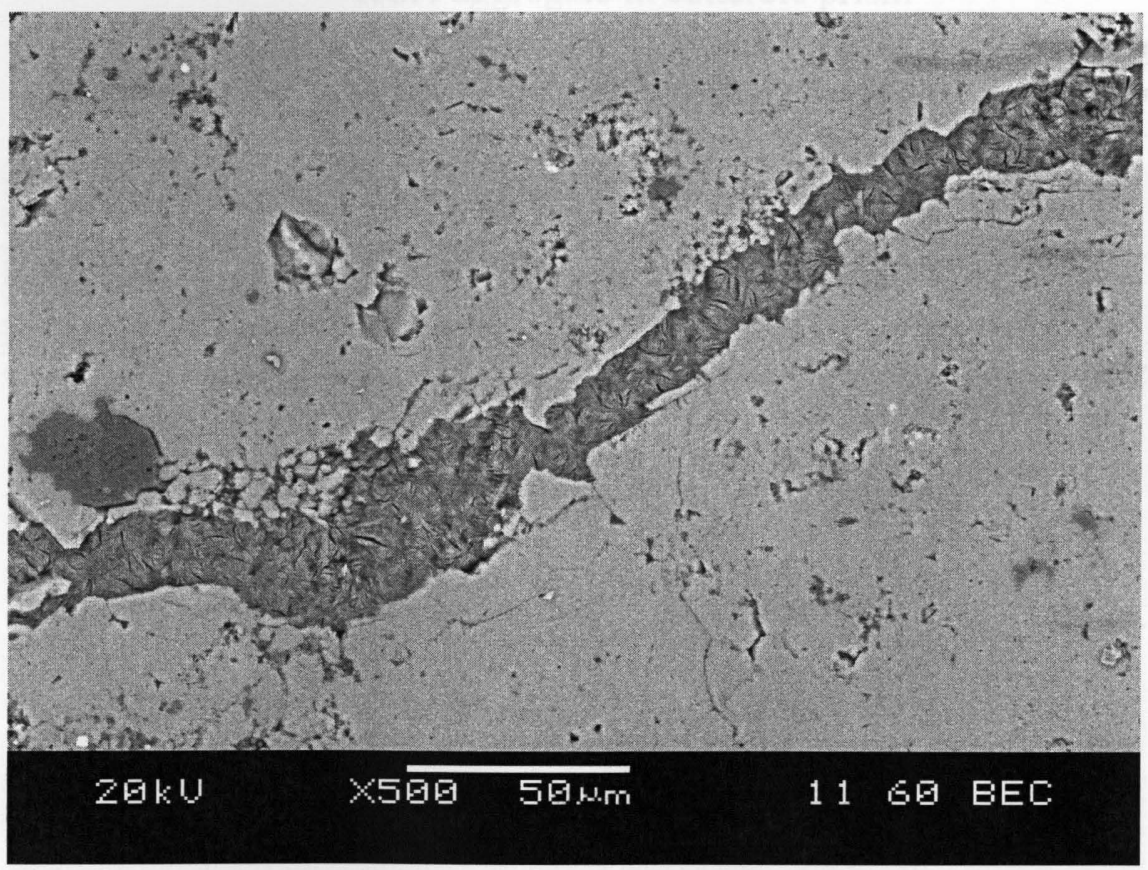

RCA aggregate in solution 0.7 Molarity without Lithium 